\title{
Indigenous peoples, civilization and the expansion of international society:
}

\section{An 'inter-societal' perspective}

\author{
by
}

\author{
Mark Pearcey
}

A thesis submitted to the Faculty of Graduate and Postdoctoral Affairs in the partial fulfillment of the requirements for the degree of

\section{Doctor of Philosophy}

in

Political Science

\author{
Carleton University \\ Ottawa, Ontario
}

(C)2013

Mark Pearcey 


\section{Abstract}

Until recently, the expansion of international society has been depicted as the linear projection of European norms and values into the non-European world; specifically, Westphalian norms and values. Increasingly however, critical English School scholars - amongst others - have begun to critique this perspective, noting that the evolution of international society has been constituted through the interaction between expanding European empires and the non-European peoples they came into contact with. Edward Keene (2002), for instance, argues that the norms and values that underpin international society are the product of imperialism. Problematically however, many of these accounts tend to overlook the long-term negative effects of these norms and values, focusing instead on how they established the foundations for a cosmopolitan society of states. This dissertation reflects critically on these types of arguments, through an historical analysis of Indigenousstate relations. Specifically, it asks: What role have state-Indigenous relations had in constructing the colonial legacies of the discourse on civilization? And, what are the implications of this for understanding the relationship between international and world society in International Relations theory? Through this analysis, this dissertation contribute to IR theory in three ways: 1) by supplementing the English School's focus on intra-societal relations with greater attention paid to intersocietal' relations; 2) by establishing a space for dialogue between the English School and Postcolonialism; and 3) by 'decolonizing' English School theory, challenging its Eurocentric and state-centric assumptions. 


\section{Acknowledgements}

I would like to express my deepest gratitude to my committee, Fiona Robinson, Hans-Martin Jaeger and David Long, without whom this dissertation would not be a reality. Their combined support, insight and constructive feedback are the backbone of this project, and I sincerely thank them for their dedication to it. I would like to thank my beautiful wife, Norah Pearcey, whose love and support encouraged me to see this project through; Norah, without you I would have never finished what I set out to accomplish. I would also like to thank my family, in particular my mother and father, who have dedicated their lives to the success of their children and to whom I am eternally indebted. Finally, I would like to thank the countless number of people that have influenced this project in their own way family, friends, colleagues and educators, thank you! 


\section{Table of Contents}

Chapter one: Introduction ....................................................................................... 1

Defining the term 'Indigenous' .................................................................................. 14

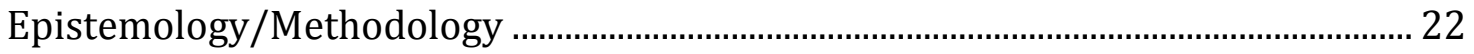

Theoretical background and methods ……………………………………………... 32

Chapter outlines....................................................................................................... 39

Chapter two: Literature revie: Indigenous peoples and disciplinary neglect .. 43

Anarchy \& the philosophic origins of IR theory …………………………………...... 49

State-centrism \& IR's disciplinary history ……………………………………….... 57

The international-domestic dichotomy \& disciplinary marginalization ................... 63

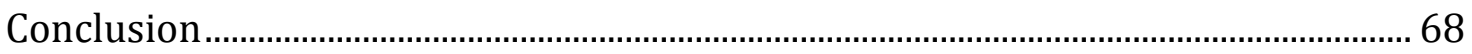

Chapter three: Theoretical framework: An inter-societal approach...................75

'Reintroducing' world society ..................................................................................... 83

Indigenous peoples and Buzan's framework ……………………………………….. 90

Power, Postcolonialism and English School analytics .................................................. 94

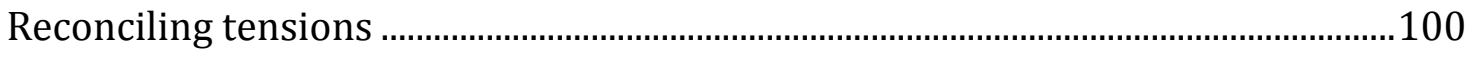

Conclusion.........................................................................................................104

Chapter four: Civilization and the inception of European international law 108

The Westphalian narrative and its critics.......................................................................114

Civilization, the self, and the other …………………................................................122

Vitorian jurisprudence and European colonialism .....................................................129

From Vitoria to the Doctrine of Discovery …………………………………………...135

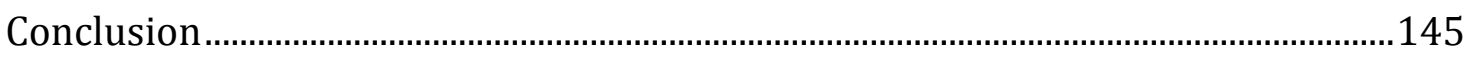

Chapter five: Civilization and the fermentation of European international law

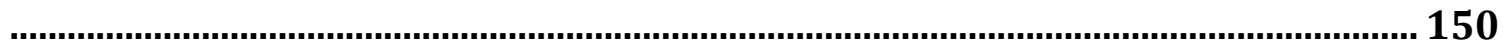

The Standard of Civilization .......................................................................................158

The Standard of Civilization and Indigenous peoples..................................................164

Chief Levi General and the League of Nations.............................................................169

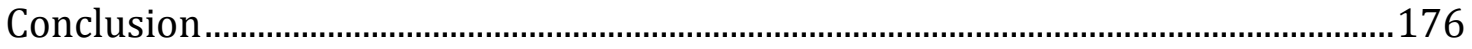




\section{Chapter six: Civilization and the 'post-colonial challenge' to European

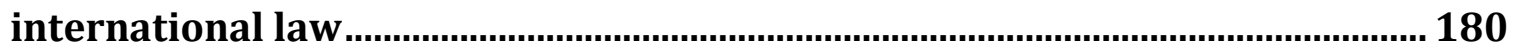

Minimalism, maximalism and the concept of self-determination ............................189

Decolonization and the minimalist stance ...................................................................196

An Indigenous right to self-determination ................................................................204

Conclusion...........................................................................................................218

Chapter seven: Case study: Civilization and Indigenous knowledge ................ 222

Indigenous knowledge and the global economy ………………………………….....230

Civilization and the governance of Indigenous knowledge ………............................238

Governing knowledge through a standard of modernity/human rights..................246

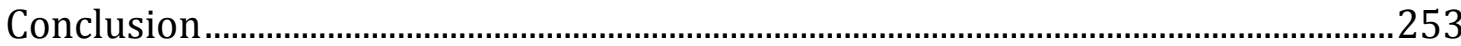

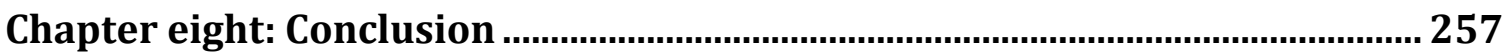

Towards an inter-societal approach .............................................................................263

Disciplinary implications of an inter-societal approach ............................................271

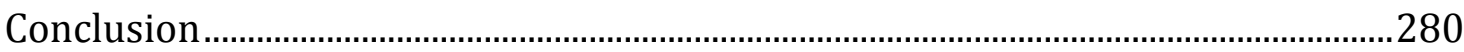

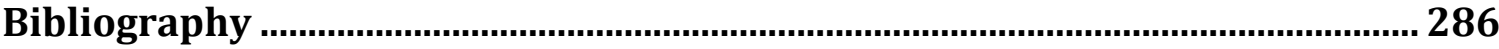




\section{List of tables}

Table I.1: Research questions, objectives and implications ............................... 12

Table III.1: socially 'thin' to 'thick' societies, by Buzan's (2004) analytical

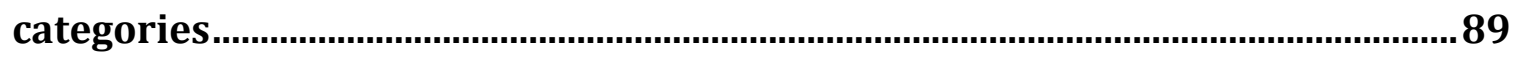

Table VI.1: Overview of key multilateral forums addressing the issue of traditional knowledge, as identified by Maina (2011) ..................................... 237

Table VI.2: Three key forms of intellectual property ........................................ 239 


\section{List of Illustrations}

Illustration III.1: Buzan's (2004) analytical reconstruction of the English

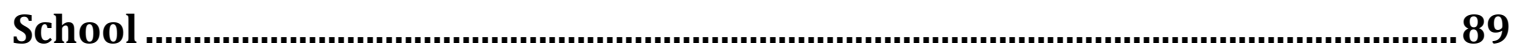




\section{Chapter one}

\section{Introduction}


Mainstream International Relations (IR) generally refers to 'civilization' broadly; Samuel Huntington (1993), for instance, refers to civilization as a "cultural entity." ${ }^{1}$ (23) According to him, a "civilization is [...] the highest cultural grouping of people and the broadest level of cultural identity people have short of that which distinguishes humans from other species." (24) In this sense of the term, neither the culture nor the territory of a civilization need be entirely fixed. In fact, a civilization's connection to culture and territory is often left purposefully ambiguous. When Huntington (1993) refers to a clash of civilizations, for instance, he refers to broad categories of people sharing only the most basic cultural identifiers within a general geographical location. In this sense, a civilization can be differentiated from a nation and a state: a nation need not be restricted to a particular geographical location but must retain a common culture, and a state need not be associated with a single homogenous culture but must be delimited by territorial borders. However, the concept of civilization - as used by Huntington (1993) - becomes much more complex when it is subjected to critical scrutiny. For example, Huntington's (1993) conception of civilization can be criticized for its failure to account for divisions within what appear to be similar cultures; how, for instance, can he account for cleavages/nuances within his eight categories of civilization: Western, Confucian, Japanese, Islamic, Hindu, Slavic-Orthodox, Latin American and African? And, how can Huntington draw a clear line between his

\footnotetext{
${ }^{1}$ A distinction is made between the discipline of International Relations (IR) and the practice of
} international relations. 
categories of civilization?2 ${ }^{2}$ These issues notwithstanding, the concept of civilization suffers from another flaw; it presumes socio-political hierarchies premised on selfother dichotomies. Understood in this way, the concept of civilization not only refers to a body of people, it assumes a normative dimension - one that implies a superior-inferior relationship between a civilized self and an uncivilized other. ${ }^{3}$ It was in this manner that the concept of civilization was applied by European powers in the non-European world - for instance, when the French justified their imperial expansion under the guise of a mission civilisatrice, the English according to a selfproclaimed white man's burden, and the Americans on the basis of manifest destiny. 4

The manner in which Western imperialists deployed the concept of civilization is thus significantly different from how the term is usually employed within mainstream IR. The meanings that the French, English and Americans amongst others - ascribed to civilization were intended to justify the imposition of Western forms of knowledge upon the 'primitive' non-European world. This was the assumption underpinning the Standard of Civilization (the Standard), an explicit legal principle that emerged in the late 19th century as a mechanism to help regulate the expansion of international society (Gong 1984). According to its terms, a non-European society could not enter the civilized society of states until it met the

${ }^{2}$ Huntington (1993) acknowledges that people have layers of identity. "The culture of a village in southern Italy may be different from that of a village in northern Italy, but both will share in a common Italian culture that distinguishes them from German villages." (Huntington 1993, 24)

${ }^{3}$ It may be argued that when 'civilization' is used to signify the more neutral meaning of a people sharing a common culture and/or territory, the term implies a normative dimension; specifically, that a group of people form a civilization once they have become 'civilized.'

${ }^{4}$ The fact that various European peoples conceptualized civilization differently speaks to the fact that the content of any definition of civilization is contingent on any number of social, cultural, historical and/or other factors. However, for the sake of parsimony, this thesis generalizes the concept of European civilization; specifically, a concept that predicates a self-other dichotomy on features associated with being 'civilized.' A more detailed analysis of the concept of civilization is provided in chapter four. 
most basic requirements of European socio-political organization; that is to say, demonstrable statehood. In what is perhaps the most comprehensive account of the Standard, Gerrit Gong's, The Standard of Civilization in International Society (1984), contends that it became the benchmark for membership within international society, and in so doing, smuggled into international relations a European definition of legitimate socio-political organization (i.e. the state). However, Gong's (1984) analysis suffers from the fact that it restricts itself to understanding the role of the Standard in facilitating inclusion within international society. For example, his case studies focus on the manner by which China, Siam and Japan gradually adopted the criteria of the Standard to gain entry into the once regional society of European states. This is not to say that Gong (1984) approaches the Standard uncritically. Indeed, his analysis highlights the debilitating effects of it on non-European cultures, (including its imposition of humiliating concessions) and the fact that it did not guarantee cultural equality between states. But, by focusing on the Standard's role in facilitating the inclusion of some non-European societies within the society of states, Gong (1984) overlooks the way it functioned to exclude others.

Amongst those most historically excluded from participation within international society are Indigenous peoples. By failing to meet the criteria of civilization, Indigenous peoples were, over the course of colonialism, subsumed within the territorial boundaries of states that rationalized this process through civilizing missions. In turn, calls for greater levels of Indigenous self-determination have since been perceived as a direct threat to the territorial integrity of the states in which Indigenous peoples have become ensconced. This has led to the 
problematic and commonly held perception that Indigenous peoples are best conceptualized as domestic populations rather than self-determining peoples - by being conceptualized as domestic populations, states have historically been able to marginalize the Indigenous voice in world affairs by denying them the status as independent peoples (see below). As will be discussed in the chapters that follow, this perception is directly attributable to two inter-related phenomena: 1) the evolution of international law; and 2) the expansion of international society from a once regional society of nascent European empires. ${ }^{5}$ Deployed as a concept used to delineate self from other, civilization established a normative basis - later codified into international law - for European powers to justify incursions into the nonEuropean world. In settler states like Canada and the United States, the concept of civilization bestowed upon Europeans a duty to spread civilization to the 'primitive' peoples they encountered - hence the mission civilisatrice and the white man's burden. In the United States, this viewpoint was expressed by Supreme Court Chief Justice John Marshall in 1831 (see chapter four), when he decided that the relationship between Indigenous peoples and the federal government was to be conducted as though it were the relationship between a ward and his guardian (Norgren 2004). With their claim to sovereignty impeded, on account of their failure to meet the criteria of civilization, ${ }^{6}$ Indigenous peoples residing in settler

\footnotetext{
${ }^{5}$ A distinction is made between a European and a global international society. European society refers to a society of European powers prior to the late $19^{\text {th }} /$ early $20^{\text {th }}$ century - at which point in time a global international society involving non-European members began to emerge.

${ }^{6}$ The use of the term 'sovereignty' in this sentence does not refer to territorial sovereignty, but to a more broadly cited conceptualization of sovereignty connected to the concept of self-determination. This account of sovereignty is discussed in chapter three and chapter six.
} 
states subsequently became the focus of state control and were denied the right later extended to other non-European peoples - to claim territorial sovereignty.

Despite the historical injustices Indigenous peoples have faced in asserting an international legal personality, they have become an increasingly influential group of actors at the international level. In terms of global demographics, recent estimates suggest a population of 370 million Indigenous people residing in some 90 countries (Permanent Forum on Indigenous Issues 2009, 1). Indigenous peoples have garnered significant political momentum at the international level in forums like the UN, with the creation of the Permanent Forum on Indigenous Issues (2000), two International decades of the World's Indigenous People (1995-2004; 2004-2014), and the Declaration on the Rights of Indigenous Peoples (the Declaration, 2007). Although Indigenous international activism can be traced to the late-19th century (and arguably earlier), these recent accomplishments have been the product of a sophisticated transnational movement connecting international Indigenous organizations, peoples and their representatives since the mid-20th century. Challenging the norms of international society, this network has achieved what Franke Wilmer (1993) considers an unprecedented degree of political success. As Wilmer (1993) notes, this level of success raises substantive questions about mainstream IR. Indeed, Indigenous transnationalism challenges mainstream theories like realism by highlighting the fact that significant achievements were made by non-state actors without a significant share of the resources or power that states maintain. Yet, despite raising these sorts of questions, Indigenous world politics have remained a peripheral concern to the discipline of IR, as Indigenous 
political activity rarely figures prominently in disciplinary debates about the balance of power, security, diplomacy or even global governance. ${ }^{7}$

Where IR research on Indigenous politics has occurred, it has usually focussed its attention on understanding Indigenous activism as a subset of civil society, or sometimes as an example of globalization in action - that is to say, as an example of the emergence of new global actors in an increasingly crowded international environment (see Wilmer 1993). However, these types of studies tend to pigeonhole Indigenous politics into a rather small niche, focusing more on the technical aspects of Indigenous transnationalism rather than drawing broader conclusions about what Indigenous politics tell us about international relations (Beier 2004; 2005; 2007 \& 2009). As has already been suggested, one such conclusion might involve the exclusionary aspects of international society and its association with Eurocentric definitions of civilization. In fact, this has become the topic of some recent English School research focusing on the expansion of international society in the non-European world. In a recent book, for example, Edward Keene (2002) critically evaluates the historical processes of international society's expansion; he argues that the advancement of European 'civilization' resulted in the marginalization of non-European peoples and the suppression of their socio-political systems. However, studies like Keene's (2002) tend to place a heavy emphasis on elucidating the theoretical consequences of their research for international society. This is particularly disappointing given the fact that most of these analyses take the relationship between international society and non-

\footnotetext{
7 Notable exceptions include the work of Marshall Beier (2004; 2005; 2007; 2009), David Bedford and Thom Workman (1997), Neta Crawford (1994), Karena Shaw (2008), and Franke Wilmer (1993).
} 
European societies as a basis for investigation; thus, it might be asked, what are the theoretical implications of this research for non-European societies beyond the scope of international society?

One way of addressing this question is to ask how the relationship between international society and non-European peoples - during the former's expansion constituted contemporary international relations. This is the approach adopted by this thesis, which focuses on the relationship between international society and the Indigenous members of world society. ${ }^{8}$ This analysis not only seeks to supplement the burgeoning literature on the expansion of international society and the imposition of European civilization, but to contribute to recent debates involving the analytics of the English School. ${ }^{9}$ In recent years, prominent English School scholars have suggested that the School's central concern for international society has prevented it from generating insights into societies composed of non-state actors; specifically, the concept of world society. Barry Buzan (2001) notes that this fixation has rendered the concept of world society an "analytical dustbin," and that "more work needs to be done to develop the [English] School's theoretical position, particularly in understanding the relationship between international and world society." (471) As will be detailed in the chapters that follow, this type of examination draws greater attention not only to the exclusionary aspects of

\footnotetext{
${ }^{8}$ Defined in a conventional way, international society refers to "the institutionalization of shared interest and identity amongst states, and puts the creation and maintenance of shared norms, rules and institutions at the centre of IR theory." (Buzan 2004, 7) By contrast,, world society "takes individuals, non-state organizations and ultimately the global populations as a whole as the focus of global societal identities and arrangements, and puts transcendence of the states-system at the centre of IR theory." (Buzan 2004, 7-8)

${ }^{9}$ See, for example: Barry Buzan's From International to World Society (2004); Hedley Bull and Adam Watson's The Expansion of International Society (1984); Paul Keal's European Conquest and the Rights of Indigenous Peoples (2003); Edward Keene's Beyond the Anarchical Society (2002).
} 
international society but also to the agency of Indigenous peoples in confronting the expansion of 'civilization' and their role in shaping the norms that underpin much of contemporary international relations (e.g. the concept of self-determination). In this way, my research highlights the fundamental role that the relationship between international society and Indigenous peoples has played in constituting the contemporary study and practice of international relations. To achieve this, my research proceeds by asking the following, central research questions: What role have state-Indigenous relations had in constructing the colonial legacies of the discourse on civilization? And, what are the implications of this for understanding the relationship between international and world society in International Relations theory?

This thesis answers the research question by focusing on how international society's evolution and expansion defined the primary institutions of international relations; in particular, international law. ${ }^{10}$ This is undertaken through what I term an inter-societal approach to the study of international relations. Borrowing from the English School, it conceptualizes international relations as occurring broadly between two types of societies: international and world society. ${ }^{11}$ Whereas the English School has principally focussed its attention on intra-societal relations occurring within the former, an inter-societal approach focuses on relations occurring between both - this framework is detailed in chapter three. Drawing on

10 While scholars disagree over which institutions form the primary institutions of international relations (see Buzan 2004), Bull (1977) identifies five; specifically, the balance of power, international law, diplomacy, war and the great powers.

11 Traditionally, the international system has featured prominently in English School research. As is explained in chapter three, this thesis chooses to focus explicitly on the relationship between international and world society. Borrowing from Barry Buzan (2004), this is justified by the argument that all systems are in inherently social; thus, they are better conceptualized as societies. 
insights from postcolonial scholarship, this thesis uses this framework to detail the role of a European discourse on civilization in constituting legal relations between international society and the Indigenous members of world society. Specifically, it argues that the evolution of international society was fueled by the concept of civilization and its implicit assumptions about 'Self' and 'Other' - as Europeans expanded their empires outward, they were confronted by the need to articulate a body of law that could both guide and justify their relations with peoples that they perceived to be fundamentally other to them. By invoking the concept of civilization, Europeans employed a discourse that assumed socio-political hierarchies between the civilized peoples of Europe and the uncivilized peoples of the non-European world. So ingrained was this discourse that despite variations in the type of legal frameworks employed - hierocratic, natural, positive or pragmatic law - one fundamental feature remained consistent: the assumption that civilization rationalized processes aimed at subsuming the uncivilized Other into the civilized Self. It was on this premise that members of international society assumed the right to erode the sovereignty of Indigenous peoples through imperial expansion - on the pretense of spreading civilization. ${ }^{12}$

Through this analysis, my thesis aims to move English School theory forward in three ways: 1) to supplement the English School's focus on intra-societal relations occurring within international society with a better understanding of inter-societal relations occurring between the society of states and types world society; 2) to build

\footnotetext{
${ }^{12}$ Chapter three details how this involved a transition in the meaning of civilization; specifically, a transition away from the assumption that sovereignty emanated from people, and towards the assumption that sovereignty emanated from territorial entities.
} 
a space for collaboration between the English School and Postcolonialism; and 3) to advance the process of decolonizing English School theory by paying critical attention to its Eurocentric and state-centric assumptions. Moreover, this analysis holds important implications for three core concepts/themes in the IR literature: power, order and anarchy. Where power is concerned, an historical analysis of Indigenous-state relations raises important questions about traditional narratives that depict the evolution of international society as the linear projection of European norms and values into the non-European world. Rather, it suggests that international society did not simply develop from inter-state relations, but rather evolved through a discourse on civilization that informed relations between states and non-state peoples/societies. This discourse also implied the view that international order was generated through the extension of civilization to uncivilized others; thus, it was assumed that European imperialism would generate international order. Yet, as scholars like Keene (2002) observe, European empires employed this account of order in a twofold way, as the discourse of civilization generated intra-societal order amongst the nascent members of international society while facilitating their expansion into the non-European world. In this sense, the disorder created by European imperialism in the non-European world became the constitutive 'outside' of European order. Finally, because of the association made between civilization and statehood, order was implicitly connected to territorial sovereignty; and, it was this institution that has historically impeded the Indigenous members of world society from having their voices heard on an equal footing at the international level. While it is true that Europeans first 
recognized Indigenous sovereignty through treaty relations, this would be eroded over time as: 1) the concept of sovereignty became increasingly connected to the concept of territory; and 2) Indigenous peoples increasingly became subsumed within the expanding borders of Europe's growing empires. This line of argumentation is detailed below in Table I.1:

\section{Table I.1: Research questions, objectives and implications}

\section{Research Question:}

- What role have state-Indigenous relations had in constructing the colonial legacies of the discourse on civilization? And, what are the implications of this for understanding the relationship between international and world society in International Relations theory?

\section{Objectives:}

To move the English School forward by:

- Supplementing the School's focus on intra-societal relations within international society, with attention paid to inter-societal relations between international and world society;

- Establishing a space for dialogue and collaboration between the English School and Postcolonialism;

- Advancing the decolonization of English School theory by challenging its Eurocentric and state-centric assumptions.

\section{Implications for IR theory:}

This thesis suggests that:

- Discursive forms of power can have profound socio-political effects on real people. For example, contemporary institutions like international law have been constituted through a European discourse on civilization, which distinguishes between self and other - subordinating the other to the self. As a consequence of being established through this discourse, contemporary institutions and other social structures reproduce the assumptions of civilization.

- The concept of order has been applied in a two-tiered way; within international society, institutions like international law have been used to generate order, while facilitating marginalization and exclusion of nonmembers.

- Sovereignty is a socially-constructed concept with shifting meanings. Because of a gradual association between sovereignty and territory, however, non-state and sub-state peoples have historically been ignored by the discipline and practice of international relations. 
With the aim of establishing the foundations for this analysis, this introductory chapter proceeds in four sections:

1. The first section examines the term 'Indigenous' by drawing attention to international, working definitions of it. In so doing, it highlights key tensions and debates surrounding the term, and adopts a working definition influenced by the work of José Martínez Cobo, Erica-Irene A. Daes and Rodolfo Stavenhagen, respectively.

2. The second section describes the epistemological and methodological commitments of the thesis. This is achieved by critically evaluating some of the problematic assumptions associated with positivism and post-positivism. In light of these problems, the thesis defends an epistemological/methodological approach that identifies the concept of 'honesty' as its core feature. As James Mayall (2009) describes it, this is an approach whereby the analyst must "be true to one's experience of the external world, and to the understanding one can arrive at through its study, combined with such intuitive insights that can be gained through introspection." (209)

3. The third section builds on the second section by describing some of the theoretical background that has informed the decision of this thesis to focus on international law - in particular, its relationship to English School debates about the concept of institutions. Finally, it highlights the methods of this study - specifically, the categorization of three historical periods, and the methods used to research them. 
4. The fourth section concludes this chapter by providing chapter outlines, with a focus on their line of argumentation.

\section{Defining the term 'Indigenous'}

The term 'Indigenous' occupies a precarious place in both the field and practice of international relations and has been the source of vigorous debate within the UN system. In 1997 Erica-Irene A. Daes, Chairperson of the Working Group on Indigenous Populations (WGIP) noted that "no single definition could capture the diversity of Indigenous peoples worldwide, and it was not desirable or possible to arrive at a universal definition at the present time." (quoted in Morgan 2011) This view both preceded and informed the Declaration (2007), which operates without an objective definition of the term. The decision to operate under these terms was directly fuelled by concern from the WGIP that a debate over an objective definition risked derailing the more important task of developing standards of protection for Indigenous peoples (Lâm 2000, 7). From the perspective of several UN member states, an expansive definition of the term could open the door to non-Indigenous peoples claiming special domestic rights. Conversely, Indigenous peoples feared that a narrow definition could provide states a basis to deny Indigenous peoples rights, by denying them Indigenous status. Nevertheless, in cases where a definition has been required, the most common has been the one proposed by former Special Rapporteur for the Sub-Commission on Prevention of Discrimination and Protection of Minorities, José Martínez Cobo. In his now famous Study of the problem of discrimination against Indigenous populations (1986), Cobo proposed that, 
Indigenous communities, peoples and nations [...] having a historical continuity with pre-invasion and pre-colonial societies that developed on their territories, consider themselves distinct from other sectors of the societies now prevailing on those territories, or parts of them. They form at present non-dominant sectors of society and are determined to preserve, develop and transmit to future generations their ancestral territories, and their ethnic identity, as the basis of their continued existence as peoples, in accordance with their own cultural patterns, social institutions and legal system. (E/CN.4/Sub.2/1986/7/Add4)

In effect, Cobo's (1986) definition premises itself on four inter-related factors, "subjection to colonial settlement; historical continuity with pre-invasion or pre-colonial societies; an identity that is distinct from the dominant society in which they are encased; and a concern with the preservation and replication of culture." (Keal 2003, 8-16) However, for the benefits of Cobo's definition in providing some analytical clarity, Paul Keal (2003) indicates that the criteria upon which it rests are subject to a number of controversies. Taking each in turn, Keal (2003) suggests a need to reflect critically upon each factor, paying particular attention to their relationship to the related concepts of self-determination and self-identification. On the first criterion, Keal (2003) draws attention to two controversial issues. First, he notes that some Asian states have used this criterion to deny the existence of Indigenous peoples within their borders. China, for instance, claims that the concept of Indigenous peoples is inherently connected to European colonialism and the establishment of settler states. From China's standpoint, Indigenous peoples can therefore not exist in non-settler states like those found in Asia. In this way, the concept of being Indigenous is restricted to a very particular historical and geographical context, limiting who can be counted as Indigenous to the four regions of the world subjected to European settler colonialism: North America, South 
America, Australia and New Zealand. Second, by linking the term Indigenous to colonialism a tendency emerged within UN deliberations on decolonization to associate the entire population of African states with being Indigenous. In so doing, UN member states failed to distinguish between different Indigenous peoples residing within shared territorial boundaries, thereby resulting in the perception that decolonization successfully resolved the question of Indigenous selfdetermination in Africa through the creation of new states (Keal 2003, 8).

On historical continuity, Keal (2003) notes that the decision to link the term Indigenous with the original occupants of a specific territory raises some potentially unhelpful questions; in particular, the question of 'who came first' and whether this status entitles a people to greater rights over others. In Canada, for instance, the term Aboriginal has been used to refer to Indigenous peoples with a relatively uncontroversial claim to being the first inhabitants. However, the term Aboriginal has been officially expanded to include the Métis, an Indigenous people whose identity stems from the mixing of Aboriginal peoples and French settlers. In this case, the question of whether the Métis 'were here first' becomes problematic on account of their bloodlines, and highlights tensions between a domestic interpretation of being Aboriginal and an international definition of being Indigenous. To deny the Métis their status as Indigenous/Aboriginal peoples, would thus risk protections guaranteed to them through international conventions. ${ }^{13}$

\footnotetext{
${ }^{13}$ In a recent court ruling of the Federal Court of Canada, Métis and other 'non-status Indians' should qualify as 'Indians' under the 1867 Constitution Act, which may force the Government of Canada to directly deal with 1 million people that were previously not defined as 'Indians' - if the ruling goes unchallenged. By being granted 'official status' status, these people(s) may be extended special rights to negotiate with the Crown directly, and to receive federal benefits. (Curry and Makin 2013, online)
} 
Interestingly, Benedict Kingsbury (1999) also notes that the issue of 'who came first' carries the risk of discrimination. According to Kingsbury (1999), "if some people are "Indigenous" to a place, others are vulnerable to being targeted as nonIndigenous, and groups deemed to be migrants or otherwise subject to social stigma may bear the brunt of a nativist 'indigenist' policy." (352; also quoted in Keal 2003, 10) It is on a similar basis that India and China have in the past claimed that no Indigenous peoples reside within their borders. According to India this is because after centuries of migration and absorption it is impossible to determine which peoples arrived first, while for China all nationalities have lived within its borders for eons (Keal 2003, 10). The position of both states has thus been that a distinction must be drawn between tribal and Indigenous peoples; without this clarification no international regime that protects Indigenous peoples can be enforced within their borders (Lâm 2000, 3).

Despite the controversies generated by the issue of 'who came first,' it is noteworthy that there is general consensus that being recognized as Indigenous is linked to some form of historical connection with a particular territory. Maivân Clech Lâm (2000) explains this in terms of the UN discourse around the definition of domestic minorities, from which the UN discussion about the definition of Indigenous peoples evolved. According to the 1979 UN Study on the Rights of Persons Belonging to Ethnic and Linguistic Minorities, Special Rapporteur Francesco Capotorti defined a minority group as a population dominated in number and in fact, exhibiting a distinct culture that this population wished to preserve. (Lâm 2000, 5). According to the study (1979), a minority referred to: 
A group numerically inferior to the rest of the population of a State, in a nondominant position, whose members - being nationals of the State - possesses ethnic, religious or linguistic characteristics differing from those of the rest of the population and show, if only implicitly, a sense of solidarity, directed towards preserving their culture, traditions, religion or language. (quoted in Lâm 2000, 5)

Given the similarity between this definition and the definition of Indigenous peoples proposed by Cobo (1986), Lâm (2000) argues that the inclusion of territory into a definition of Indigenous peoples helps distinguish it from the concept of minorities. Lâm (2000) emphasizes this point with reference to the Oglala Sioux. "Indigenous peoples [...] exhibit a singular connection to the territories that they occupy. The Oglala Sioux, for example, unlike Italian-Americans, look to the Black Hills in the West of the United States, and not some overseas country of origin, for the affirmation of their cultural identity." (Lâm 2000, 10) Lâm (2000) continues,

And the Black Hills, in contrast to ethnic neighbourhoods, bear all of the sacred sites, legendary landmarks, and specific material resources that sustain, for the Oglala Sioux, a meaningful culture and community. Withdraw that land, and sustenance and meaning, in Olglala Sioux terms, disappear. (Lâm 2000, 10)

Thus, it was for this reason that the Indigenous transnational movement at the UN emphasized retaining territory and resources in any definition of the term Indigenous (Lâm 2000, 11).

Indigenous arguments surrounding territory are linked to the right of selfdetermination. For example, Keal (2003) notes that "Indigenous peoples around the world are united by a common concern with control of land, preventing the exploitation of natural resources to the detriment of Indigenous rights and ways of life, and cultural survival or preservation; all of which cohere in the 'overarching theme of self-determination.'" (12) Although a more detailed conversation about the 
concept of self-determination is reserved for the sixth chapter of this thesis, it is important to note here the relationship between self-determination and the interpretation of Indigenous peoples as 'peoples,' rather than as 'populations.' Indeed, the basis upon which Indigenous representatives have made legal claims to a right to self-determination at the international level have hinged closely on their capacity to differentiate themselves from domestic populations like minorities. This distinction is important not only in theoretical terms, but also in its practical implications. For example, when understood as a domestic minority population, Indigenous peoples have little recourse to international bodies; this is problematic because it directs Indigenous rights claims to domestic courts that may themselves be inherently biased in ways favourable to the state. By contrast, when understood as distinct peoples, Indigenous peoples gain significant leverage in terms of claiming an international legal personality - it is from this basis that the legal claim to Indigenous self-determination subsequently derives (see chapter six).

Despite some resistance, the concept of Indigenous peoples, as peoples, has triumphed in international law and is evidenced by changes in the phraseology of UN bodies - consider the fact that initial work on Indigenous rights occurred through the Working Group on Indigenous Populations, while the Declaration (2007) now refers to Indigenous peoples. As will be discussed at length in the chapters to come, this transition is likely due to a minimalist account of selfdetermination that seeks to restrict the meaning of self-determination in such a way that does not threaten the state's territorial sovereignty (see chapter six). In any case, the decision to conceptualise Indigenous peoples as distinct and self- 
determining peoples has also implied the idea that they are culturally distinct from the dominant societies in which they reside. This has raised key points of tension in defining Indigenous peoples. On what objective basis does one determine a group as being Indigenous? Because of this question, most conceptualizations of Indigenous peoples hinge on granting peoples the right to self-identify. In fact, Article 33 (1) of the Declaration (2007) reads, "Indigenous peoples have the right to determine their own identity or membership in accordance with their customs and traditions. This does not impair the right of Indigenous individuals to obtain citizenship of the States in which they live." But, like most criteria of the term Indigenous, this has not gone without contestation. Some prominent Indigenous activists note that self-identification risks an overly-expansive definition of the term that dilutes the meaning of being Indigenous. For example, Taiaiake Alfred (1999) argues that being Indigenous,

[...] is a matter of blood and belonging determined through the institutions governing a community at a particular time. The collective right of Native communities to determine their own membership must be recognised as a fundamental right of self-determination, and respected as such. No individual has the right to usurp the identity of a nation simply by claiming it, much less when a collective decision has been made to the contrary. And no nation (or state or organisation) has the right to force an identity on another nation. (85-86; quoted in Keal 2003, 13)

In light of these concerns, some scholars have called for an approach that incorporates a number of objective and subjective criteria (see Kingsbury 1999). In addition to providing some analytical clarity, this approach retains a significant degree of flexibility. ${ }^{14}$ In her work on the WGIP, for instance, Chairperson Daes -

\footnotetext{
${ }^{14}$ The Métis have sought to guard against abuse of the principle of self-identification, by highlighting the reciprocal relationship between self-identification and its acceptance by the Métis Nation as a
} 
building on the work of the Cobo report, and working in consultation with Indigenous and legal experts, academics and international organizations - proposed four criteria for conceptualizing Indigenous peoples, which emphasized:

1) Priority in time, with respect to the occupation and use of specific territory; 2) the voluntary perpetuation of cultural distinctiveness, which may include the aspects of language, social organization, religion, and spiritual values, modes of production, laws and institutions; 3) selfidentification, as well as recognition by other groups, or by state authorities, as a distinct collectivity; and 4) an experience of subjugation, marginalization, dispossession, exclusion or discrimination, whether or not these conditions persist. (Henderson 2008, 45)

It is noteworthy that these factors echo very similar themes as the Cobo report, and built off of them. However, it can be argued that a difference exists between Cobo's working definition and Daes' four criteria, that rests not in their content, but in their ethos. Whereas the former represents an effort to establish some clear parameters around the concept, the latter proposes landmarks from which to contextualize it, and as James Youngblood Henderson (2008) notes, "these factors do provide general guidance to reasonable decision-making in practice." (45) For this reason, this thesis adopts the ethos adopted by former Chairperson Daes as a basis for conceptualizing Indigenous peoples. In addition to adding some flexibility, this ethos allows for the incorporation of criteria identified by the Cobo report. ${ }^{15}$

whole. In 2002, the Métis adopted the following definition of the term 'Métis;' "'Métis' means a person who self-identifies as Métis, is distinct from other Aboriginal peoples, is of historic Métis Nation Ancestry and who is accepted by the Métis Nation." (Métis National Council 2013, online) In addition, it might be noted that the concept of self-identification could be used to serve a secondary purpose; that is, it may conceivably be used to guard against the idea that to be Indigenous is to be intrinsically internal to states. While, contemporary definitions of the term Indigenous are underpinned by the assumption of geographical encasement within a state; self-identification provides flexibility in allowing individuals and people to make their own claim.

${ }^{15}$ Francesca Merlan (2009) offers a critique of this approach. According to Merlan (2009), "The term Indigenous, long used to distinguish between those who are "native" and their "others" in specific locales, has also become a term for a geocultural category, presupposing a world collectivity of "Indigenous peoples" in contrast to their various "others." Many observers have noted that the 
However, in conjunction with former Chairperson Daes' four criteria, this thesis also heeds the insights of famed sociologist and former UN Special Rapporteur on the situation of the human rights and fundamental freedoms of Indigenous people, Rodolfo Stavenhagen (1994). For Stavenhagen (1994), the culturally and biologically-based concept of Indigenous peoples must be supplemented with recognition of the social relationships that constitute Indigenous identity. As Stavenhagen (1994) argues,

Indigenousness, independently of biological or cultural continuity, frequently is the outcome of governmental policies imposed from above and from the outside. It also quite often is the product of a "constructed discourse" enunciated by the emerging intellectual elites of the Indigenous peoples and their sympathizers among other sectors of the population. In any case, the discourse of "Indigenousness" leads to a denunciation of injustice (and crimes) committed against the Indigenous peoples (genocide, plunder, servitude, discrimination) and to the formulation of specific rights that derived from the injustice suffered [...]. (quoted in Henderson 2008, 45)

\section{Epistemology/Methodology ${ }^{16}$}

Over the past three decades, IR has been polarized by epistemological and methodological debates centering on the dichotomy between positivist and postpositivist approaches. ${ }^{17}$ At the core of these debates have been questions about the

stimuli for internationalization of the Indigenous category originated principally from particular nation-states-Anglo-American settler colonies and Scandinavia. All, I argue, are relevantly political cultures of liberal democracy and weighty (in different ways) in international institutional affairs. However, international indigeneity has not been supported in any unqualified way by actions taken in the name of several nation-states that were among its main points of origin. [...] The apparently paradoxical rejection of the draft declaration by the establishing countries is consistent with the combination of enabling and constraining forces that liberal democratic political cultures offer." (303)

16 This section has been titled Epistemology/Methodology as opposed to Epistemology and Methodology because of the close relationship between epistemology and methodology, as scholars tend to conceptualize positivism and post-positivism differently - with some referring to them as methodologies and others referring to them as epistemologies.

${ }^{17}$ See, for example: Steve Smith's Positivism and Beyond (1996); and Robert Keohane's Neorealism and its Critics (1986). 
nature of knowledge. For their part, positivists contend that objective knowledge can be generated through empirical observation with an emphasis on causation. Post-positivists reject this claim. Instead, they argue that theory cannot be neutral or independent from practice - theories frame issues and problems, and thus construct the social world. Efforts to find a middle ground between these positions have led some scholars to embrace constructivism and/or the English School. Where the former is concerned, scholars note the benefits of its efforts to resolve the methodological divide through the institution of a social ontology, but warn that by retaining a positivist methodology it does little to incorporate the methodological criticisms of post-positivists. The English School, on the other hand, offers an intriguing alternative. Recognizing the important role of norms and values in shaping international society, English School scholars have put forth a methodology that deploys historical methods to interpret IR's normative content. Unlike Wendtian constructivism, which claims a capacity to generate causal inferences from social behaviour, the English School more modestly claims a capacity to deepen disciplinary understanding of social phenomena. In this way, it does not reject positivist methods, as much as it rejects the view that objective knowledge can be generated from these methods. This has led James Mayall (2009) to the position that "the most that one can aspire to is honesty, to be true to one's experience of the external world, and to the understanding one can arrive at through its study, combined with such intuitive insights that can be gained through introspection." (209) In other words, this approach acknowledges that 'reality' is socially constructed and contingent upon one's perspective. Thus, where research is 
concerned, the most one can aspire to is a sort of 'common sense' that seeks to provide as 'honest' an account of the evidence as possible, while acknowledging the limitations of objectivity in social research.

The benefits of this approach are twofold. First, by conceptualizing knowledge in terms of honesty, this approach prohibits research from making problematic truth claims. In this way, it responds to the concerns of post-positivists who recognize that truth claims are inherently connected to power, and that this connection to power can perpetuate the marginalization of other perspectives (Smith 1996). Second, this approach takes seriously the concern of positivists who rightly hold that theoretical arguments need to be supported by a comprehensive body of empirical evidence and research. Indeed, knowledge claims, though subject to interpretation, must be substantiated by empirical evidence, a point with which post-positivists would generally agree. ${ }^{18}$ With these benefits in mind, the English School's approach to knowledge is not immune to criticism; in fact, some scholars point out that the English School lacks a coherent set of methodological commitments. Cornelia Navari (2009) reminds us that "classical English School theorists generally disdained discussions of methodology. As for method, it is treated somewhat in the nature of underclothing - assumed to be there but scarcely discussed in polite society." (1) From the standpoint of method-driven scholars (both positivist and post-positivist alike), this methodological neglect opens the School to criticism. Amongst its critics, Robert Keohane (1992), has charged the

\footnotetext{
18 This is not to suggest that post-positivists do not share similar concerns about the relationship between theory and practice, but that positivists do tend to make this concern more explicit in their critiques of post-positivist approaches (ex. as a disjunction between theory and practice).
} 
English School with a lack of 'contingent generalizations,' while Roy Jones (1981) has cited the School's 'methodological sloppiness' as a reason for its closure (Navari 2009, 1). ${ }^{19}$ However, these criticisms often overlook the fact that the founders of the English School sought to move away from debates about methodology in a conscious effort to distinguish themselves from method-driven positivism, which characterized IR in the 1970s (Bull 1966). ${ }^{20}$

Recognizing these criticisms, Robert Jackson (2009) advances a defence of the English School's relative neglect of methodology. For him, a focus on methodology risks distancing the School from its primary theoretical concern with understanding the social practices of international relations. Jackson's (2009) argument advances in two stages. First, he defines the English School as a normative approach to world politics - an approach that seeks to discern, clarify and elucidate the norms that serve as standards of human behaviour within a given society at a given time and place. Second, Jackson (2009) juxtaposes this approach against method-driven positivism, arguing that method-driven approaches treat norms instrumentally, insofar as these norms are understood as sterile patterns of social behaviour, devoid of much content. By contrast, he suggests that a normative

19 Within the English School itself, Mayall (2009) has referred to himself as a 'reluctant methodologist,' (Mayall 2009, 209) and Peter Wilson has described the classical English School as the 'golden age of the amateur.' (Navari 2009, 1)

20 Christian Reus-Smit (2012) argues that IR has moved toward a more meta-theoretical orientation. This has led to calls from analytical eclecticists for IR to reengage with the practical dimensions of the discipline; specifically, by bracketing meta-theoretical debates of this nature. According to Reus-Smit (2012), "[m]ining the rich philosophical veins of American pragmatism, 'analytical eclecticists' are calling for a renewed emphasis on problem-driven research, in which the pursuit of understanding leads scholars to mix and match insights from contending research paradigms. It is important to note that analytical eclecticists are not anti-theoretical; they themselves pursue middle-range theoretical explanations of international political phenomena, and they insist that the hard theoretical work done within existing research paradigms is a necessary precursor to eclecticist mixing and matching." (529) 
approach allows for greater analysis of norms in terms of their value-laden content; that is to say, as "a [legal or moral] standard of conduct by which to judge the rightness and wrongness [...] of human conduct."21 (Jackson 2009, 22) Thus, the critical point Jackson (2009) makes about methodology is that positivism's focus on causal inference and explanatory power limits its capacity to comprehend the content of norms. Indeed,

There is a distinction in positivist social science between empirical theory and normative theory which indicates that norms could not be candidates for empirical inquiry. That clearly is a mistaken way of thinking. The human world is significantly composed of norms - that is, standards of conduct. (Jackson 2009, 22)

Jackson's (2009) critique is largely directed at positivist methodology, rather than post-positivist approaches. Moreover, for his important point about the role of methodology in defining the scope of research, he does leave a significant degree of ambiguity in terms of how we are to evaluate the value-base of norms. Surely, for its relative lack of concern with methodology, the English School must retain some basic premises about how to conduct research. Overarching methodological frameworks are difficult to find within the English School in large part due to the fact that its scholars employ differing methods; this has led some scholars to refer to the English School as being methodologically plural as opposed to methodologically monistic. For example, Richard Little (2000) argues that the school's identification of three core analytical categories - international system, international society and world society - invokes three methodological modes: explanation, interpretation

\footnotetext{
${ }^{21}$ In chapter four, it is argued that standards evolve from self-other dichotomies. In the specific context of this thesis, these self-other dichotomies pivot on the concept of civilization, which distinguishes the civilized self from the uncivilized other.
} 
and critique, respectively. Martin Wight (1992) similarly proposed that each of these analytical categories was best understood according to one of three philosophical traditions, each with their own methodological assumptions: international system understood through Realism, international society understood through Rationalism, and world society understood through Revolutionism (Little 2009, 89). Confusing matters further, Little (2009) notes that some scholars, following Wendt, have turned to hybrid methodologies involving a form of methodological pluralism that combines a social ontology with a positivist methodology, such as Buzan's From International to World Society (2004). Similar to the criticism levied at Wendtian constructivism, Timothy Dunne (2005a) argues that these efforts risk confusing reality (what there is) and truth (what we make of it), because such elaborate schemes often fail to first take account of historical contexts. $^{22}(163)$

From this critique, one can identify a common methodological commitment of the English School: to premise theory on historical inquiry and contextualization. Indeed, most English School research details a historical account of world politics to inform theoretical observations. For example, Adam Watson's The Evolution of International Systems (1992) adopted a comparative historical analysis to better understand the internal dynamics of international systems. Through this analysis, Watson (1992) justified a theoretical conceptualization of these dynamics as a balance between imperialism and independence. Similarly, Hedley Bull and Adam Watson's edited collection, The Expansion of International Society (1984), adopted

22 Conversely, critical scholars suggest that 'what there is' is constituted by 'what we make of it;' therefore, one cannot distinguish between reality and truth, given their social construction. 
historical analysis as a means of examining the colonial expansion of international society, from which a theoretically informed account of international society's evolution and its norms could be constructed. The significance of historical inquiry to the English School is nicely summed up by Jackson (2009), who notes that "[w]e cannot even attempt to answer these questions [questions about norms in world politics] with academic conviction unless we are informed about the historical context, and the historical context leads us to a different sort of treatment from that involved in purely philosophical inquiry." (27-28) If we return to the issue of how to study norms and institutions, one can respond by emphasising the role of historical contextualization. Thus, in this thesis, research proceeds by adopting a methodological approach that: 1) focuses attention on the socialization of norms through the constitution of self-other dichotomies between two of the English School's core analytical categories (international society and world society); and 2) critically evaluates the socio-political dimensions of these dichotomies through a historical contextualization of them..$^{23}$

In many respects, this historical approach builds on the one taken by Hedley Bull, who recognized that "[w]hat is important in an academic inquiry into politics is not to exclude value-laden premises, but to subject these premises to investigation and criticism, to treat the raising of moral and political issues as part of the inquiry." (quoted in Jackson 2009, 24) For Bull, this raised important questions about the relationship between the subject and object of study; in Bull's words, "I am no more capable than anyone else of being detached about a subject such as this. But I

${ }^{23}$ The theoretical framework of this thesis is detailed in chapter three. 
believe in the value of attempting to be detached or disinterested, and it is clear to me that some approaches to the study of world politics are more detached or disinterested than others." (quoted in Jackson 2009, 24) This question of detachment draws out the full implications of the debate between positivists and post-positivists, noted earlier. Like Bull (1977), my approach premises itself on the view that the subject of research can never truly be detached from value-based decisions, but that this does not imply a wholesale rejection of the 'impartial observer.' Rather, the aim is to moderate a rather difficult balancing act between the values of the researcher and the object of inquiry, by once again heeding the value of honesty in tempering truth claims. As it pertains to history, this approach is particularly important given the insights of historical methodologists who note that accounts of history are in fact representations of history. ${ }^{24}$ Hence, in his analysis of Indigenous peoples and international relations, Marshall Beier (2005) makes the important point that all history is current history; specifically, because 'history' is always contingent upon the way it is presently being conceptualized - for example the meaning of historical facts is contingent upon one's immediate perspective/interpretation of them, which may be conditioned by factors like social context, norms, values and power. In other words, Beier (2005) highlights the fact that the researcher can never objectively distance him/herself from the subject of study, and will instead embed subjective assumptions within analysis because of his/her time, place and perspective.

${ }^{24}$ Keene (2005) notes that in political theory, scholars have sought to represent the ideas of prominent theorists in a manner that feeds into contemporary debates; in this way, history is distorted to accommodate ideas in a new time or place, or for the sake of buttressing academic arguments. 
This approach to history likely moves farther away from what Bull (1977) had anticipated in his comments about the relationship between subject and object. However, in recent years, this more critical approach has been fuelling a new generation of English School scholars that have taken seriously post-positivist insights, allowing them to shed important new light on the content and evolution of contemporary international norms. Keene (2005), for instance, incorporates postpositivist insights by critically evaluating orthodox approaches to IR and their tendency to portray history in terms of consistent narratives. According to Keene (2005), these types of histories distort the historically contextual arguments of particular discourses to help make issues and events appear trans-historical. Applied in this thesis, I draw on this approach to demonstrate how IR's account of the Peace of Westphalia has distorted the principles behind the treaties that composed it, in a manner that depicts IR's association with Westphalian sovereignty in terms of an unbroken, trans-historical narrative (see chapter four). Thus, like Keene (2005), this thesis views historical analysis as a method for understanding political concepts on their own historical terms (both time and place). However, it also assumes that while discourses are historically contingent, they do nevertheless inform future discourses. As will be discussed in chapter four, for instance, the principles devised at Westphalia helped inform subsequent European relations with non-European peoples. Indeed, they helped facilitate the expansion of European society by delineating Europe from the rest of the world according to its own sociopolitical identity. ${ }^{25}$

${ }^{25}$ In this sense, my thesis may be subjected to the criticism that it too presents some 'facts' as trans- 
To summarize, my research proceeds by using a historical methodology premised on the insights of post-positivism; in particular, the inter-related insights that all history is contemporary history and that knowledge is contingent upon the subject-object relationship. Although this methodology is best characterized as post-positivist, it has been chosen because of its capacity to respond to both positivist and post-positivist criticisms. Specifically, it recognizes that a positivist, method-driven approach is limited in its capacity to evaluate the value-base of international norms and institutions, but that research must be grounded on a sound base of empirical evidence. Consequently, its overarching ethos is one of honesty: a view that tempers the ambitions of research by denying it the capacity to make truth claims, but which values - to the extent possible - an honest approach to research. In effect, this methodological approach premises itself on three elements: 1) a particular focus on the social content of international relations; 2) an emphasis on historical contextualization; and 3) a view to understanding how the social content of international relations can be understood through the core analytical categories of the English School, especially international and world society. These three elements are further conditioned by contemporary English School approaches that point to the historical contingency of political thought. This methodological approach provides a basis for thinking about how political concepts have informed

historical (ie. that the concept of civilization has performed a similar function over the course of centuries). But, my thesis does not make the claim that this is a trans-historical fact that will not change, nor that the meaning of civilization has not changed or been subjected to the influences of context. 
others and draws attention to the dangers of trans-historical narratives that remove concepts from their particular context. ${ }^{26}$

\section{Theoretical background and methods}

My thesis proceeds with a view to understanding the relationship between international and world society within the context of Indigenous-state relations. Taking the expansive history of Indigenous-state relations into account, research restricts itself to examining a core international institution used to govern these relations, international law. The concept of an institution is itself a topic of debate within the IR literature, since scholars apply the term in sporadic and sometimes incoherent ways. At one end of the spectrum, institutions can be conceptualized narrowly as formal organizations; at the other end, they can be conceptualized more broadly to include the norms, values and customs of international society. This terminological ambiguity has led Stephen Krasner (1983) to define institutions in terms of their relationship to rules and norms. According to Krasner (1983), norms represent customary/implicit forms of social regulation between states, whereas rules are a more specific/explicit form of these social regulations. It is on this basis that Krasner (1999) subsequently proposes that institutions are "formal or informal structures of norms and rules that are created by actors to increase their utility." (43; quoted in Buzan 2004, 165) However, this position only seems to repeat the problematic: on the one hand, institutions are 'formal structures' created by actors

\footnotetext{
${ }^{26}$ To quote Robert Cox (1981), "theory is always for someone and for some purpose. All theories have a perspective. Perspectives derive from a position in time and space, specifically social and political time and space [italics in the original]." (128)
} 
(eg. organizations); on the other hand they are also the 'informal structures' that seem to evolve organically to optimize social relations (eg. customs).

Buzan (2004) has sought to move the discussion on institutions forward by accepting Krasner's (1999) definition, but by categorizing institutions into one of two groups, secondary and primary institutions (each representing a formal and informal institution, respectively). ${ }^{27}$ Buzan (2004) makes this distinction clear through a comparison between the way regime theory and the English School approach the concept;

The institutions talked about in regime theory are the products of a certain type of international society [...], and are for the most part consciously designed by states [secondary institutions]. The institutions talked about by the English School are constitutive of both states and international society in that they define the basic character and purpose of any such society [primary institutions]. (Buzan 2004, 166)

Because of its commitment to an English School theoretical framework - detailed in chapter three - this thesis places its focus on primary institutions for two reasons. First, consistency with the concepts of previous English School studies is maintained, allowing research to proceed with a shared understanding of an institution. Second, and perhaps more importantly, primary institutions provide a better basis than secondary institutions for a long-term historical evaluation of Indigenous-state relations. Because secondary institutions are formally created at a given point in history, ${ }^{28}$ the norms and rules they convey are contingent upon the overriding norms and rules of the primary institution. This is not to say that

\footnotetext{
${ }^{27}$ It should also be noted that Buzan (2004) goes one step further, proposing to distinguish two types of primary institutions, master and derivative - this is the notion that some primary institutions generate others (Buzan 2004, 176-190).

28 Many secondary institutions that define contemporary international relations post-date 19th century history, and do not offer the long-term historical view this thesis takes in its analysis of stateIndigenous relations.
} 
secondary institutions do not figure into this thesis, but that when they are discussed they are understood as being historically contingent and derivative of primary institutions. Thus, in keeping with Buzan (2004), I define primary institutions according to two core elements, "that they are relatively fundamental and durable practices, that are evolved more than designed; and that they are constitutive of actors and their patterns of legitimate activity in relations to each other." (167)

In terms of which primary institution to study, this thesis places its focus on international law, in part because of its central role in the work of the English School. In The Anarchical Society (1977), for instance, Bull identified it as one of the core institutions of international society. Similarly, Wight (1992) implicitly accorded international law a central position within the English School when he traced the School's lineage to the Rationalist tradition, a philosophical tradition that premises itself on the work of Hugo Grotius, whom many consider the first international lawyer. ${ }^{29}$ More recently, Mayall (2000) has echoed the views of these orthodox English School scholars, when he referred to international law as "the bedrock institution on which the idea of international society stands or falls." (94; quoted in Buzan 2004, 143) International law's centrality within the English School is derivative of the fact that it is understood to play a fundamental role in maintaining order between states in an anarchical environment via the codification of rules and norms. However, as previously noted, Keene's (2002) research on the

\footnotetext{
${ }^{29}$ The view that Hugo Grotius was the first international lawyer is contested in chapter four, when the origins of contemporary international law are associated with the onset of colonialism and the legal relations between the Spanish and the Amerindians, and the work of Francisco de Vitoria.
} 
expansion of international society has helped contest this view, noting that international law may have provided a basis for the management of international order between European states, but also legitimated conquest and imperialism in the non-European world. On this basis, my research proceeds with the view that the normative content of international law played an important role in defining Indigenous-state relations.

In keeping with its historical methodology and its focus on primary institutions, research on the role of international law in defining Indigenous-state relations adopts a long-term historical perspective. Though the conventional account of international law holds that it began in the $17^{\text {th }}$ century, my research is influenced by the insights of post-colonial theory, which suggests that contemporary world politics were fundamentally shaped by the European discovery of the Americas and the subsequent processes of imperialism. As Geeta Chowdhry and Sheila Nair (2004) point out, Postcolonialism typically begins "with the premise that imperialism constitutes a critical historical juncture in which postcolonial national identities are constructed in opposition to European ones, and come to be understood as Europe's "others" [...]."(2) Incorporating this insight into the methods of this thesis, research on the normative content of international law begins in the early $16^{\text {th }}$ century and proceeds with an examination of three broad historical periods. Categorizing research into these three periods helps to further the objective of observing continuities and changes in the value base of international law in the context of Indigenous-state relations, and the broader issue of relations between international and world society. Each is detailed below: 
- Hierocratic and natural law of the early-16th century to the early-19th century: Research concentrates on the substantive basis of European international law governing relations between Christian and non-Christian peoples, as well as 'civilized' and 'uncivilized' peoples during this period. An emphasis is placed on the legal philosophy of Pope Innocent IV (hierocratic law) and the Spanish jurist Francisco de Vitoria (natural law) who devised a system of international law to define relations between the Spanish and the Amerindians.

- Positive law of the early-19th century to mid-20th century: Research concentrates on international law governing the relations between European and non-European peoples from the early-19th to mid-20th century - an emphasis is placed on positive law. To concentrate research, a particular focus is placed on the legal relations between 'civilized' and 'uncivilized' peoples, as defined by the Standard and its focus on European forms of sociopolitical organization.

- Legal pragmatism of the mid-20th century to the present: Research concentrates on the evolution of legal relations between Indigenous peoples and the state, from the mid-20th century onwards. A particular focus is placed on the formal UN process of decolonization - as defined by General Assembly Resolutions 1514 and 1541 - and its relationship to Indigenous calls for a right to self-determination. ${ }^{30}$

\footnotetext{
${ }^{30}$ It is important to recall that relations conducted between the expanding European powers and
} Indigenous peoples largely took place on the basis of treaty relations - the hallmark of sovereign-to- 
To undertake an analysis of these historical periods, this thesis performs a detailed literature review, covering both primary and secondary sources. ${ }^{31}$ Given the extensive history that this project covers, research for the first two historical periods (early-16th to early 19th century; early-19th to mid-20th century) relies principally on secondary sources, particularly those from the field of international law. For example, research on the early-16th to early-19th century draws especially from scholars like Brett Bowden (2002; 2004a) and Antony Anghie (2006; 2004; 1996) - contemporary scholars with an expertise in the relationship between the concept of European civilization and international law. Likewise, research on the early-19th to mid-20th century relies on scholars like Gong (1984), with an expertise in the evolution and impact of the Standard. In both cases however, this thesis corroborates these secondary sources with others, paying special attention to important tensions and continuities. For research on the period covering mid-20th century history to the present, secondary sources play an equally important role and help contextualize primary sources. In chapters six and seven, for instance, secondary sources help interpret primary sources like the Declaration (2007), and the Agreement on Trade-Related Aspects of Intellectual Property Rights. For these chapters, a variety of traditional and critical sources help provide a balanced account of these documents.

It should also be noted that this dissertation pays particular attention to universal international organizations and their associated documents - such as the

sovereign relations. In this way, there is a legal basis from which to interpret domestic Indigenousstate relations in terms of international relations.

31 These sources were primarily drawn from keyword searches using Google Scholar, and other online databases like JSTOR. 
UN and the Declaration. This selection is not intended to diminish the relevance of alternative sites in which Indigenous diplomacy has occurred. Indeed, Beier (2009) reminds us that some of the more significant diplomatic achievements made by Indigenous peoples have occurred in venues traditionally ignored by mainstream IR. For example, one might consider the role of Indigenous peoples on the Arctic Council, the realization of the Sami Parliament in Norway, or the creation of Nunavut that was negotiated between the Inuit and the Government of Canada. While each of these sites is significant in its own right, the focus on universal international organizations is largely a byproduct of research concerned with the historical evolution of international society and its discourse on civilization. As this thesis suggests, organizations like the UN, and its predecessor the League of Nations, evolved from the constitution of a state-based society. Moreover, it was through these organizations that Indigenous peoples made some of their first appeals to the collective members of international society, such as Chief Levi General's (Deskaheh) mission to the League of Nations (see chapter five). And, it was through the UN that representatives of the Indigenous transnational movement later engaged in substantive dialogue with the members of international society on the matter of Indigenous self-determination. As is discussed at length in the chapters that follow, these organizations have also been marked by the discourse of civilization, and thus offer an ideal site for a long-term historical analysis of Indigenous-state relations in the context of the discourse on civilization. 


\section{Chapter outlines}

As has been explained, this thesis is a theoretical inquiry into the relationship between international and world society in the context of Indigenous-state relations. Informed by primary and secondary sources alike, the thesis proceeds in seven chapters (not including this chapter). Below, an outline of each of chapter is provided:

\section{Chapter Two: Literature review: Indigenous peoples and disciplinary neglect}

In this chapter, a literature review is undertaken to help contextualize the theoretical framework that is tendered in chapter three. This chapter proceeds by performing a critical analysis of IR theories with the aim of highlighting: 1) how traditional IR has excluded Indigenous politics from analysis; and 2) how critical approaches have begun to introduce Indigenous politics to the discipline. This is achieved in four sections; the first three examine key concepts in the IR literature anarchy, civil-society, and the state - and the fourth concludes by focusing on an inter-disciplinary body of research that has begun to address the gap in IR's research on Indigenous peoples.

\section{Chapter Three: Theoretical framework: An inter-societal approach}

The third chapter establishes a theoretical framework that sets out to: 1) better incorporate the concept of world society into English School analysis; and 2) draw attention to the historical constitution of a self-other dichotomy and hierarchy through a discourse on civilization. To achieve this, the chapter draws attention to 
the scholarship of Barry Buzan (2004), who makes the case for 're-introducing' world society to the English School. Second, some theoretical content is added to Buzan's (2004) analytical framework by making the case for conceptualizing societies as 'moral communities'. Third, Postcolonialism is introduced as a basis for thinking critically about the concept of power. Fourth, the chapter addresses potential tensions in partnering English School analytics with the insights from Postcolonialism. Finally, it concludes by detailing what it terms an inter-societal approach to the study of international relations.

\section{Chapter Four: Civilization and the inception of European international law}

The fourth chapter sets out with two objectives: 1) to critically evaluate 'Westphalian' accounts of the expansion of international society; and 2) to introduce the concept of civilization as a basis for re-conceptualizing the expansion of international society. The chapter proceeds in four sections; first, it critically evaluates the evidence used to support orthodox accounts of the Peace of Westphalia. Second, it details an alternative account of the expansion by focusing on the concept of civilization. Third, it details the role of Vitoria in defining legal relations between the Spanish and Amerindians. Fourth, it concludes by examining the influence of Vitoria on future legal relations between the members of international society and the Indigenous members of world society. 


\section{Chapter Five: Civilization and the fermentation of European international law}

This chapter examines a transition in the meaning of civilization, from a concept closely associated with Christianity, to a concept closely associated with European socio-political organization. Influenced by the work of Gerrit Gong (1984), the first section of the chapter details the evolution of the Standard and its role in defining membership within the society of states. Second, the chapter turns to a more specific analysis of how the Standard was used to define relations between states and the Indigenous members of world society. Third, the chapter details how the jurisprudence of early-20th century legalists was deployed in practice - this is achieved through an analysis of a petition put forward by the Iroquois peoples to the League of Nations.

\section{Chapter Six: Civilization and the 'post-colonial challenge' to European international law}

This chapter focuses on the role of decolonization in facilitating a transition away from a discourse centered on the Standard to a discourse centered on a standard of modernity/human rights. First, the chapter details two competing perspectives of self-determination, the minimalist and maximalist perspective. Second, it turns to a critical analysis of how the minimalist account triumphed during the decolonization period and limited the capacity of Indigenous peoples to exercise sovereignty. Third, the chapter details the evolution of the Indigenous transnational movement and its efforts to achieve an Indigenous right to self-determination through the UN. 


\section{Chapter Seven: Case study: Civilization and Indigenous knowledge}

This chapter critically evaluates the use of a rights-based framework to advance self-determination in the context Indigenous knowledge. First, it sets out by defining the concept of Indigenous knowledge and highlighting controversies surrounding the term. Second, it highlights the role of Indigenous knowledge in the global economy, emphasizing its benefits to corporate and state actors. Third, it critiques the intellectual property system, highlighting its relationship to the discourse on civilization and tendency to: 1) benefit corporate and state actors; and 2) disadvantage Indigenous actors in practice.

\section{Chapter Eight: Conclusion}

Chapter eight concludes the thesis by describing how an inter-societal approach to the study of international relations moves the English School forward by: 1) supplementing the English School's focus on intra-societal relations within international society, with a better understanding of 'inter-societal' relations between international and world society; 2) building a space for collaboration between the English School and Postcolonialism; and 3) advancing the process of decolonizing English School theory. In addition, the chapter details the implications of the thesis' findings for IR conceptualizations of power, order and sovereignty. It concludes by connecting these findings to current issues associated with the implementation of the Declaration (2007). 


\section{Chapter two}

\section{Literature review: Indigenous peoples and disciplinary neglect}


It might be argued that Indigenous peoples have never constituted a subject matter appropriate to the focus of the field inasmuch as none has ever been possessed of the principal of its mainstream scholarship: the Westphalian state. But neither were the Ancient Greeks, so that one is left to wonder at the comparatively greater attention devoted to Thucydides' account of the Peloponnesian War and its alleged relevance to the study of contemporary international politics. We may also wonder what marks Indigenous American peoples statelessness as very much different from that of the Palestinians or the Kurds, both of which groups have been spared the same degree of neglect.

- Marshall Beier $(2004,83)$

Disciplinary International Relations (IR) has paid Indigenous peoples remarkably little attention; Marshall Beier (2004) puts it thusly, “[a]mong the more enduring oversights and omissions of international relations is its near total neglect of Indigenous peoples. In particular, the First nations of the Americas, ensconced within advanced colonial states, have been accorded almost no attention." (in Chowdhry and Nair 2004, 82). Karena Shaw (2008) echoes Beier's (2004) sentiment,

Other than the occasional text about the rise of Indigenous politics through international cooperation, or the increasing presence of conversations about the status of Indigenous peoples in international law, the literature of Indigenous politics within international relations comprises a rather slim file. (63)

Where research has occurred on Indigenous politics, it usually comes in the form of metatheoretical critiques - asking questions that generate introspection. For example, why have Indigenous peoples been marginalized by the discipline, and how might we account for this? According to Beier (2009), these introspective critiques have proved important because of their role in destabilizing orthodox accounts of international relations and putting Indigenous peoples on the IR agenda - much like feminist critiques have opened a space for conceptualizing gender. 
These critiques have been particularly effective in drawing attention to the role of state-centrism in marginalizing Indigenous politics. By highlighting Indigenous exclusion in this way, these critiques have implicitly made a case for incorporating Indigenous politics into the IR canon, especially with respect to Indigenous transnationalism and its role in challenging the state-centric norms of the international system.

For its accomplishments however, the small but growing IR literature on Indigenous politics has remained fundamentally concerned with traditional issues like state security and international conflict/cooperation. According to Beier (2005), this is rooted in a much broader tendency within Western society to cast foundational assumptions about political behaviour as both spatially and temporally universal. Specifically, Beier (2005) contends that IR is part of a western hegemonologue, "a knowing hegemonic Western voice that, owing to its universalist pretensions, speaks its knowledges to the exclusion of all others." ${ }^{32}$ (2) Working through the hegemonologue, IR casts Indigenous political histories in a way that makes them fit within the well-established narratives listed above (ex. security.). This is not only problematic because it casts political behaviour as trans-historical, but also because it de-contextualizes Indigenous political histories, and thereby fails to treat them on their own terms. For example, in her work on the Great Law of Peace (Gayanashagowa) - an oral constitution that bound the Iroquois Six Nations

32 For Beier (2005), the hegemonolgue is so engrained in society that it becomes almost unrecognizable, and resistant to critique. "That the hegemonologue so often goes as if unheard underscores that it bears our 'common senses,' those things we know so well about the world that it would be unthinkable to subject them to critical scrutiny; that we might do so seems not even to occur to us." (Beier 2005, 2-3) 
together beginning somewhere between 1090 and 1150 - Neta Crawford (1994) explains its significance to IR by situating it within an established discourse about security. For Crawford (1994), the Great Law of Peace is to be conceptualized as a collective security regime, an example of how Indigenous peoples confronted the problem of anarchy.

As David Bedford and Thom Workman (1997) point out, Crawford's (1994) work is a "praiseworthy effort to introduce Aboriginal experience to contemporary international relations scholarship, however, [one that] is marred by the forced application of Realist derived terms upon the Iroquoian document." (90) For its positive role in putting Indigenous politics on the IR map, Crawford's (1994) analysis subscribes to some traditional assumptions about anarchy and the state of nature; especially, realist ones. ${ }^{33}$ While realism is not the only IR theory influenced by the hegemonologue, it has certainly proved to be the most influential theoretical tradition in IR, and is for this reason the primary target of introspective critiques. According to Giorgio Shani (2008), realism's influence has been particularly important with respect to disciplinary accounts of anarchy, state-centrism and a methodological distinction between the domestic and international realm.

Three [realist] premises in particular continued (and arguably still continue) to set the research agenda for IR. First, conventional theories of IR unquestionably accepted the state's claim to legitimacy and sovereignty. Second, they followed neorealism in regarding a strict separation of domestic (intra-state) and international (inter-state) relations to be possible. Finally, the international system was assumed to be anarchic. (Shani 2008, 725)

\footnotetext{
33 Although Neta Crawford (1994) should not be conceptualized as a realist, likely more as a constructivist, her analysis conceptualizes the Great Law of Peace as a security regime, one that speaks to traditional realist concerns like the management of an international balance of power.
} 
Taking each of these influences in turn, this chapter provides a comprehensive literature review that examines how they have both marginalized and conditioned IR scholarship on Indigenous politics. Rather than fixate on realism however, it discusses how discourses around anarchy, the state and the international level have informed IR scholarship more generally. Doing so the literature review sets out to: 1) add to the growing body of critiques concerned with the marginalization of Indigenous politics; and 2) highlight the disciplinary significance of my thesis by drawing attention to gaps in the literature.

Unlike more conventional literature reviews however, this chapter proceeds by making an argument, rather than just providing a description of approaches. The reason for this is rooted in the fact that much of the IR literature on Indigenous politics is grounded in a critique of conventional approaches. Consequently, this literature review aims to bring this critique to life by highlighting key points of tension in the traditional literature, and how critical voices have both highlighted these tensions and demonstrated their problematic implications for the discipline of IR as a whole. In terms of the literature covered, this chapter draws especially on the critical literature on Indigenous peoples in IR to put more mainstream and traditional scholarship into perspective (ex. realism, liberalism, constructivism). ${ }^{34}$ However, it should be noted that while postcolonial literature has played an important role in the critique of mainstream literature, a more comprehensive account of Postcolonialism is reserved for the following chapter, which describes

\footnotetext{
${ }^{34}$ It should also be noted that this chapter largely brackets postcolonial scholarship that deals with the concept of Indigeneity; this is because the following chapter deals with this literature in a more explicit way.
} 
how its critical reflections are integrated into the thesis. In terms of structure, the chapter proceeds in four sections; whereas the first three examine how IR has marginalized/conditioned accounts of Indigenous politics, the fourth details an inter-disciplinary body of literature that is used by this thesis to overcome such gaps. A brief description of each of these sections is detailed below:

1. The first section examines IR conceptualizations of anarchy. In particular, it examines the philosophical origin of these conceptualizations by tracing them to social-contractarian philosophers who premised their arguments on ethnographic depictions of Indigenous peoples in the Americas. Juxtaposing Indigenous savageness against European civility, these philosophic accounts of human nature were incorporated into the IR canon, which then used them to justify a Euro-centric perspective of international relations.

2. The second section builds upon the first by examining how conceptualizations of civil-society have led to state-centrism. This is achieved by outlining a short disciplinary history that describes how and why IR has conceptualized the state as a vessel for order in international politics and how this has led to the marginalization of Indigenous politics from the discipline.

3. The third section examines how IR's state-centrism has led to a methodological distinction between domestic and international politics. Through this distinction, I show that Indigenous politics have been marginalized because they are cast as domestic populations rather than selfdetermining peoples. 
4. The fourth section concludes this chapter by drawing attention to an interdisciplinary body of research, from inside and outside IR, that can be used to address IR's limited scholarship on Indigenous politics. Specifically, it draws attention to critical literature from both the English School and the discipline of International Law (IL);35 both of which pay attention to the legacies of colonialism in contemporary international relations. It is on this basis, that the following chapter then turns to situating this project's theoretical approach within the IR canon; specifically, as an approach that merges English School analytics with Postcolonialism.

\section{Anarchy \& the philosophic origins of IR theory}

The assumption that anarchy is a defining principle of the international system remains dominant in the discipline of IR; indeed, relatively few scholars contest the claim that there is no overarching authority that exists with the coercive power necessary to submit states to the rule of law. However, what this implies for the behavior of states is much more open to debate; within IR, this debate has traditionally pivoted around the concept of human nature - philosophic accounts of human behavior unconstrained by secular authority. The importance of this debate was noted by Martin Wight (1991), who suggested that the fundamental question underlying international political theory is, what is the state of nature 14; in Keal 2003, 82)? For Wight (1991), the significance of the debate rested on the fact that accounts of human nature give content to the concept of anarchy, which then sets a

\footnotetext{
${ }^{35}$ Whereas international law refers to its practice, International Law (IL) refers to the discipline that studies it.
} 
foundation for the development of theory. For Wight (1991), this could be demonstrated through three traditions of international political theory - realism, revolutionism and rationalism. Despite sharing the same definition of anarchy, these traditions drew very different conclusions about international politics. Whereas realism describes international relations in terms of conflict and power, revolutionism focuses attention on universal morality and cooperation. For Wight (1991), these differences can be explained by their origin in competing accounts of human nature, such as realism's association with Hobbes, revolutionism's with Kant/Marx, and rationalism's with Grotius. In this section, I examine how accounts of human nature have conditioned two of IR's most influential theories - realism and liberalism - and how this has led to the marginalization of Indigenous politics.

By giving content to the concept of anarchy, accounts of human nature have structured how scholars have conceptualized civil society. This is achieved through a juxtaposition that contrasts anarchy with civil-society, savageness with civilization. As Paul Keal (2003) explains of Western political philosophy,

[...] the state of nature is contrasted with the situation of people living within a civil society, in which there is a regime of civil laws and a structure of political organization. European theorists regarded people they perceived as having no developed civil life or proper political organization as living in a state of nature and typically described them as 'savages.' (Keal 2003, 76)

It should be noted that the concept of savageness did not necessarily imply violent behaviour; rather, the term referred to an individual or peoples living outside a civil society or government recognizable to Europeans (Keal 2003, 72). This meant that the concept of a savage could be used to critique or support European forms of socio-political organization. For instance, the 'noble savage' was used to depict a 
desirable condition from which Europeans had fallen, while an 'ignoble savage' was used to depict a condition from which Europeans had progressed. In either case, the depiction of the savage was almost always attributable to misleading accounts of Indigenous peoples living in the Americas, premised upon the travelogues of early European colonists. In fact, it was upon these travelogues that Thomas Hobbes (1651) developed his argument for the creation of civil society, via the imposition of a Leviathan. Adopting the image of the ignoble savage, Hobbes (1651) writes that "the savage people in many places of America, except the government of small families, and concord whereof dependeth on natural lust, have no government at all; and live at this day in that brutish manner [of war against all]." (Chapter 13) As such, a Leviathan was necessary for constraining these destructive forces of human nature.

Hobbes' account of the ignoble savage is particularly important in the context of IR, because it informs much of the realist canon. In his first principle of political realism, for instance, Hans Morgenthau (1948) adopts Hobbes' account of human nature as the basis of his theory; "[p]olitical realism believes that politics, like society in general, is governed by objective laws that have their roots in [Hobbesian] human nature." (4) In fact, even where realist approaches have sought to distance themselves from accounts of human nature, they have implicitly called forth Hobbes' account of the ignoble savage. Despite its scientific credentials, for instance, neorealism invokes Hobbes to give content to its theory of anarchy. As Beier (2005) explains,

Neorealists fail to give sufficient content to their conception of international anarchy - that is to say, anarchy by itself is the cause of nothing. Structural 
anarchy might for example, allow wars to occur, but it does not tell us why they occur; for this, we must know something about those doing the warring. Failing this, we are left without an account of why conditions of anarchy should result in competition and not cooperation. In order to overcome this problem, the ontologized state must also be anthropomorphized through the ascription of self-interest, and this necessarily reintroduces the Hobbesianinspired commitments of Classical Realism. (161)

In this way, realist scholarship has tended to use an account of Hobbesian human nature, premised on a distinction between the ignoble savage and civil society. In terms of its theoretical implications, this has launched a realist perspective of international relations that depicts a self-help system composed of state actors, pursuing their self-interests.

For their part, realists note that Hobbes' account of human nature reveals important ethical implications for the conduct of international relations - human nature forces states to pursue their power/security relative to others. By failing to maximize their relative power, states run the risk of violent conflict with competing powers driven by the logic of human nature. ${ }^{36}$ For example, EH Carr (1939) suggested that the Second World War was attributable to the failure of status quo states (the Allies) to respond to changes in the balance of power being provoked by revisionist states (the Axis). By failing to meet this challenge, the status quo states allowed the revisionist powers to augment their military power and provoke violent conflict. As it pertains to civil society, realists suggest that power-seeking behaviour is thus critical to the peace and prosperity of one's domestic society. Morgenthau (1948) states this in the form of a warning; "[i]n order to improve society it is first

\footnotetext{
${ }^{36}$ For some, this denotes an 'ethic of responsibility.' As Tim Dunne and Brian Schmidt (2012) explain it, this involves "the careful weighing up of consequences; the realization that individual acts of an immoral kind might have to be performed for the greater good." (95)
} 
necessary to understand the laws [Hobbesian human nature] by which society lives. The operation of these laws being impervious to our preferences, men will challenge them only at the risk of failure." (Morgenthau 1948, 4) In this way, realism invokes Hobbes's dichotomy of anarchy/savageness with civil-society/civilization to rationalize the pursuit of power. By premising its argument on the work of Hobbes however, realism sets in motion a theoretical account of international relations that necessitates the exclusion of Indigenous peoples.

To summarize to this point, classical realism incorporates the work of Hobbes in the following way. First, it adopts an account of human nature premised on depictions of the ignoble savage; second, it uses these accounts of the ignoble savage to give content to the concept of anarchy; third, it uses this depiction of anarchy to portray civil society as a vessel for order; fourth, it defends the pursuit of power in international relations as a means of defending civil society. It is at this stage that realism can be identified as complicit in the erasure of Indigenous politics, and in the continued marginalization of Indigenous politics from IR. Where the former is concerned, realism can be considered complicit because of its uncritical acceptance of Hobbes' account of the ignoble savage, despite the fact that this imagery has been widely debunked by anthropologists. As Beier (2004) explains,

To the extent that the accounts and claims [of realism] are not sustainable in the face of challenges brought against them in critical anthropological literature [...] then, realist-inspired international relations theory becomes identifiable as an advanced colonial practice for perpetuating the erasures they effect. (82)

Where the latter is concerned, realism perpetuates the marginalization of Indigenous politics by building theory upon Hobbesian human nature. By accepting 
this frame of reference, realism elevates the state - as a form of civil society - to a place of ontological priority by treating it as a vessel for order in international anarchy. In this way, the state becomes the only logical solution to the problematic of anarchy, thereby marginalizing non-state alternatives - particularly Indigenous ones, which exemplify the very problem the state was designed to overcome.

Realism is not alone in effecting these erasures however. Often depicted as a counterpoint to realism, liberalism similarly premises itself on the work of European philosophers. Amongst them, John Locke has proven highly influential and is considered by Michael Doyle (1997) to be one of the founders of contemporary liberalism. Like Hobbes, Locke develops his concept of civil society through juxtaposition with anarchy. Also like Hobbes, Locke's account of civil society is premised upon a misleading account of Indigenous peoples. Paul Keal (2003) notes that Locke "made selective use of many books on the Americas in his possession, omitting aspects of Indian life not congenial to his theory." (99) Locke's purpose in doing this was to present an image of the Indigenous peoples of North America as living in a savage state of nature, which could then be used to justify British colonial expansion (Arneil 1996; Tully 1993; Keal 2003). As James Tully (1993) explains, this was achieved by connecting civil society to the creation of property. According to Tully (1993), Locke defined property in such a way that "Amerindian customary use is not a legitimate type of property. Rather it is construed as individual labour-based possession and assimilated to an earlier stage of European development in the state of nature, and thus not an equal footing with European property." (139; quoted in Keal 2003, 98) In this way, Locke could defend 
British colonialism in the Americas by claiming that its Indigenous peoples lived in a state of nature devoid of property, and thus had no property rights; without property rights, it followed for Locke that Indigenous peoples could then have no legitimate claim to territory. ${ }^{37}$

In addition to being a defence of British colonialism, Locke's argument is a valorization of European civil society. Part of Locke's purpose must have been to "legitimate and to celebrate the superiority of English colonial market agriculture over Amerindian hunting, gathering, and replacement agriculture that it forcefully displaced." (Tully 1993, 148; quoted in Keal 2003, 99) While contemporary liberals no longer set out to valorize European assumptions in the same way as Locke, it is significant to note that liberalism continues to promote a particular set of values rooted in Western thought. For example, liberal peace theorists like Bruce Russet and John O'Neal (2001) suggest that order can be generated at the international level through the promotion of Western-style democracy, greater economic interdependence, and the creation of International Organizations (IOs). In light of this, it is significant to note that Russet and O'Neal (2001) substantiate - in part - the promotion of these liberal values according to Locke's account of anarchy. Indeed, they suggest that the conditions of anarchy foster an unstable international

37 In addition to Locke, John Stuart Mill has recently been critiqued for advancing a political philosophy that premises itself on a distinction between civilized-European peoples and uncivilized non-Europeans, which intended to justify and propel British imperialism. As Beate Jahn (2005a) observes, "it is because Mill defines civilisation as a negation of barbarism that this civilisation cannot exist without barbarism. And for this reason, too, the rights of that civilisation - liberty, sovereignty, free speech - are not universally valid but continually reconstituted as particular rights. Millian liberalism is not only coeval with imperialism but also with nationalism; rather than constituting rights of the individual against the community - as the liberal-communitarian debate suggests - it actually constitutes the civilised community itself in opposition to internal and external 'barbarians'. The unfamiliar and backward represents a threat to this liberalism and the relationship between the two can therefore only be a struggle 'in which power and not understanding must be deployed'." (615) 
environment that can only be moderated through the creation of an international civil society, supposedly premised on liberal values. "Locke emphasized the need for a civil society to moderate the exercise of power. This need applies to international relations as well as to national governments." (Russett \& O’Neal 2000, 23)

For some, liberalism's association with accounts of human nature bear little on Indigenous issues. Speaking from a domestic perspective, Duncan Ivison (2002) suggests that the combined insights of Postcolonialism and liberalism reveal that "the values and practices appealed to by both Indigenous and non-Indigenous peoples are best realized in a particular kind of liberal political order." (2) However, these perspectives tend to overlook the criticisms levied at classical liberals by realists. Carr, for instance, noted in the Twenty Years Crisis (1939) a problematic tendency amongst liberals to view their values as universal. In effect, this tendency blinded liberalism to the fact that the 'universalization' of liberal values was premised upon the projection of power; specifically, the ability of the status quo states to project their values upon others. As it pertains to the marginalization of Indigenous peoples, this critique holds true. For example, Eric Wolf (1982) notes that the colonial expansion of European states into the non-European world was driven by capitalist motives that had their origin in liberal political philosophy, such as Locke's defence of British colonialism. Wilmer (1993) also reminds us that these economic values - premised upon a liberal account of civil society - are projected through the international development agenda, which links values like democracy and social progress to neoliberal economics. Problematically, these policies have 
not only promoted a distinctly liberal value-base, they have also been responsible for displacing Indigenous peoples from their traditional lands, and eroding their socio-political structures. ${ }^{38}$

\section{State-centrism \& IR's disciplinary history}

Dichotomies contrasting anarchy and order, savageness and civilization have helped promote the view that European forms of civil society are to be valorized. Since the Peace of Westphalia - discussed at length in chapter four - the sovereign state has come to represent the highest form of civil society, because of its capacity to promote order at both the domestic and international level through the exercise of internal and external sovereignty. Yet, despite coming under considerable scrutiny by scholars who note the emergence of non-state actors, the state remains a core unit of analysis for most of IR. This is typically justified by the fact that the state retains a preponderant amount of economic and military power; though some nonstate actors may exercise a high degree of economic power (ex. multinational corporations), seldom do they have the military capacities of states, or for that matter the same level of influence as great powers in diplomatic forums. However, there is another reason for IR's preoccupation with the state, one that emanates from its disciplinary history. Founded in the aftermath of World War I with the establishment of the first chair of international politics at the University of Aberystwyth, IR set out to understand international conflict and cooperation

\footnotetext{
${ }^{38}$ In a similar vein, Uma Narayan (1995) argues that a discourse of care plays an integral role in the liberal story of colonialism. Indeed, Narayan's (1995) article "point[s] to a colonial care discourse that enabled colonizers to define themselves in relationship to "inferior" colonized subjects. The colonized, however, had very different accounts of this relationship. While contemporary care discourse correctly insists on acknowledging human needs and relationships, it needs to worry about who defines these often contested terms." (133)
} 
between states. In this section, I examine the evolution of IR's state-centrism through a brief disciplinary history, and suggest that its state-centrism is connected to the discipline's preoccupation with order. Through this connection, I go on to show how IR has marginalized Indigenous politics.

IR's focus on the state came immediately after WWI, at which point in time Woodrow Wilson's Fourteen Points (1918) had been published, and had been widely accepted as a roadmap for international order. Premised on liberal assumptions, the document claimed that international peace could be established through the creation of IOs (ex. Article 14), economic integration (ex. Articles $1 \& 2$ ) and the promotion of Western political values (ex. Article 5). This argument did not sit well with classical realists, who cast inter-war liberalism as utopian, primarily because of its failure to focus on the 'facts' of international politics, power and the pursuit of it (Carr 1939). ${ }^{39}$ However, this did not suggest for classical realists that the state did not play a crucial role in the maintenance of order. As discussed above, classical realists claimed that order could only be achieved through the careful management of the balance of power, especially by the great powers. This proposition proved highly influential; with the end of the Second World War, classical realists like Morgenthau continued to advocate for a state-based system through which power relations could be managed. Even the onset of positivist methods in the post-WWII era adopted this ontology. Kenneth Waltz's Theory of International Politics (1979), for instance, proceeded on the assumption that international politics was about the

\footnotetext{
${ }^{39}$ For an excellent historiography of the inter-war debate between 'idealists' and 'realists,' see Brian Schmidt's The Political Discourse of Anarchy: A Disciplinary History of International Relations (1998).
} 
influence of anarchy upon states, and the role this influence had in shaping state behaviour.

This state-centrism forged a basis for the traditional theories of international politics to marginalize approaches that did not proceed with similar assumption. When asked in an interview with Fred Halliday and Justin Rosenberg (1998) about the meaning of theory, Waltz argued that the term theory - when applied to international politics - should be strictly applied to theories that explain causation. Specifically, Waltz drew a line between international political theory, and other types of more sociological approaches like feminism. ${ }^{40}$ For Waltz, feminism's perceived inability to account for systemic pressures on states rendered it more of a political philosophy. This perspective dominated mainstream scholarship throughout much of the Cold-War period, since neoliberal institutionalism neorealism's primary challenger - opted to accept most of neorealism's state-centric assumptions. Where differences did exist, they were primarily restricted to superficial debates about the role of international institutions in forging long-term cooperation and collaboration between states. In fact, this has led Ole Waever (2002) to refer to the neorealist/neoliberal debate of the 1980s as the 'neo-neo synthesis.' As Waever (2002) explains,

\footnotetext{
${ }^{40}$ In the interview, Justin Rosenberg (1998) points out, "Another book that came out in the same year as Man, the State and War, also a classic but in a different discipline, was C. Wright Mills' The Sociological Imagination. That elaborated a very different conception of theory. Mills says that the purpose of theory is to illuminate people's understanding of 'the present as history'. Now, that's very different." (Halliday \& Rosenberg 1998, 384) Kenneth Waltz (1998) replies, "Very different. There are all kinds of theory. There's the theory of literary criticism. And that obviously has to be a very different thing; I would not use the term theory for it. There's international political theory, there's feminist theory. Indeed there was a recent conference at USC held under the rubric 'Woman, the State, and War'. One can't legislate. People use 'theory' in all sorts of different ways. All I claim is that I do make clear how I use that term. And my usage has a good pedigree in the natural sciences, economics and much of the philosophy-of-science literature." (Halliday \& Rosenberg 1998, 384)
} 
A dominant neo-neo synthesis became the research progamme of the 1980s. No longer were realism and liberalism 'incommensurable' - on the contrary they shared a 'rationalist' research programme, a conception of science, a shared willingness to operate on the premise of anarchy (Waltz) and investigate the evolution of co-operation and whether institutions matter. (163)

Where efforts were made to challenge the neo-neo synthesis, they usually opted not to challenge it on the grounds of state-centrism; rather they sought to scrutinize the epistemological and methodological assumptions of positivism (see chapter one). Karena Shaw (2008) also points out that the challengers of the neoneo synthesis often elevated the status of the state, in such a way that marginalized Indigenous societies. Hedley Bull is particularly guilty of this in The Anarchical Society (1977), when he sets out to show that international order is sustained through the creation of a society of states that share common values and norms. Bull's (1977) particular focus on international society leads him to a state-centric account of international politics, despite the fact that it recognized the existence of alternative forms of socio-political organization (ex. the concept of world society). For Bull, (1977) "[t]he starting point of international relations is the existence of states, or independent political communities, each of which possesses a government and asserts sovereignty in relation to a particular portion of the earth's surface and a particular segment of the human population." (8; quoted in Shaw 2008, 61) On this basis, Bull (1977) goes on to dismiss other forms of socio-political organization as primitive. Indeed,

[...] primitive stateless societies rest not simply on a culture that is homogenous but also on one that includes the element of magical or religious belief [...] International society, by contrast, is part of the modern world, the secular world that emerged from the collapse of ecclesiastical and religious authority. (quoted in Shaw 2008, 62; Bull 1977, 64) 
In light of all this, Shaw (2008) draws the conclusion that "[w]ithout explicitly wishing to exclude Indigenous peoples from international relations, his [Bull's] argument clearly establishes the international arena as a particular - modern, secular - space in which their ontologies are inappropriate." (62)

It was not until the abrupt end of the Cold War that IR began to dispel some of its state-centrism, as the inability of mainstream IR to predict the stand-off's peaceful conclusion resulted in a considerable degree of disciplinary introspection (Beier 2005, 57) - a positive implication of which was greater attention to non-state actors. Indeed, IR's fixation on the military and economic power of states began to give way as constructivist analyses drew attention to the role of social construction in shaping phenomena in international relations. This focus not only provided a new avenue for explaining the end of the Cold War, but allowed for greater attention to be focused on non-state actors. Despite not having the same military or economic influence as states, non-state actors were recognized as having increased influenced in global politics and in shaping the social content of international relations (see Finnemore 1996; Keck \& Sikkink 1999; Risse-Kappen 1995).41 It was thus through the constructivist literature that IR began addressing Indigenous politics; specifically, Indigenous transnationalism and its influence upon norms of selfdetermination. ${ }^{42}$ Perhaps the best example of this scholarship is Franke Wilmer's,

\footnotetext{
41 This does not necessarily include Wendtian constructivism, which retained a primary focus on the role of states; in particular, their role in shaping the social contours of international relations.

42 Not all IR research on Indigenous peoples focussed on Indigenous transnationalism. As previously discussed, Neta Crawford's (1994) work adopted a more historical orientation, examining how Indigenous political structures inform IR. As also noted, however, her analysis has been criticized for situating Indigenous political histories within IR narratives, thus taking them out of context. Where the specific issue of state-centrism is concerned, this criticism seems to hold true, as Crawford (1994)
} 
The Indigenous Voice in World Politics (1993), which sought to understand how a movement lacking in relative economic and military power could have influence in the state-based organizations of international society. Working through liberal interdependence theory and constructivism, Wilmer (1993) contends that the success of Indigenous transnationalism rested on the capacity of Indigenous peoples/organizations to forge cooperative/collaborative action. Specifically, by identifying common interests from a shared colonial history, and then pursuing these interests through "persuasive, rhetorical, and symbolic power." (30)

Despite the important role of Wilmer's (1993) work in bringing disciplinary attention to Indigenous peoples, it is nevertheless premised on an implicit statecentrism. This is demonstrated by Shaw (2008), who indicates that Wilmer's (1993) work functions through two parallel histories. First, Wilmer (1993) details Indigenous political history, noting that it is only recently that their activism has achieved success despite centuries of resistance to colonial practices. Second, she parallels this with the history of the inter-state system, which she claims has become increasingly more progressive. According to Wilmer (1993),

[...] the overall progression of world order, as reflected in international legal norms developed among European nations but extended to the world system, has been in the direction of greater inclusiveness and a reduction in the arbitrariness with which force may be used by the state. (Wilmer 1993, 162; quoted in Shaw 2008, 63)

justifies her study by approximating Indigenous governance structures in a way that holds true with the function of state-governments. According to Crawford (1994), "The forms of Native American and European states certainly were different from each other, but their governments performed similar functions-functions that normally are associated with states: there were within Iroquois nations decision-making structures and ways to provide collective goods; there were elected and appointed representatives as well as hereditary leadership. Further similarities exist in the area of international relations: the nations of North America used diplomatic envoys, recognized the "sovereignty" of other nations, and negotiated binding treaties." (350) 
Thus, For Wilmer (1993), the success of Indigenous activism coincides with a more progressive inter-state system; for Shaw (2008), this has resulted in three implications. First, it depicts Indigenous peoples as being historically outside international relations, and their recent inclusion as a 'generous' expansion of the inter-state system. Second, this leads to the view that Indigenous peoples are objects of international relations rather than its subjects; specifically that agency rests primarily in the states that allow for Indigenous participation. Third, Wilmer's (1993) representation does little to empower Indigenous peoples, rather it empowers and legitimizes the inter-state system (Shaw 2008, 65-66).43 It is to this issue that the next section now turns.

\section{The international-domestic dichotomy \& disciplinary marginalization}

A logical extension of IR's state-centrism has been a focus on the international level, where inter-state relations take place. As suggested, neorealism and neoliberalism are particularly guilty of this charge because of their common decision to take the structure of the international system as a basis to develop explanatory theories about state behaviour. Specifically, it follows for both that the dependent variable of international relations (the state) is conditioned by the independent variable (the structure of the international system). In so doing, neorealism and neoliberalism bracket the domestic realm and exclude it from analysis. Like state-centrism, a

${ }^{43}$ It should be noted that IR scholarship on Indigenous peoples can be thought of as occurring in two waves. First, research from the early 1990s to early-2000s, characterized by works like Wilmer's (1993); and second, research from the 2000s, which has become more critical in orientation. The latter has not been discussed explicitly here, because it has been used extensively to inform critiques of the more mainstream scholarship; for example, this thesis' use of Beier $(2004,2005,2009)$ and Shaw's (2008) postcolonial critiques. 
focus on the international level is not unique to the neo-neo synthesis. Returning to the work of Bull (1977), Shaw (2008) notes that "[a]t the same time as he [Bull] insists on the state as the enabling assumption for the study of international relations, he also seeks to establish the analytical primacy of relations between states." (61) He "asserts the primacy of the society that these states form as the universal form of the international." (Shaw 2008, 61) Whether positivist or postpositivist in approach, traditional theories of IR thus focus much of their attention on the international system; as a result, this has acted as a considerable impediment to research on Indigenous politics, which are traditionally conceptualized as occurring in the domestic realm - we might recall the problematic view that Indigenous peoples are best conceptualized as Indigenous populations (see introduction). As Shaw (2008) explains, "[o]n this reading, Indigenous political movements lie outside the sphere of interest of international relations [because] they inhabit the realm of domestic politics, perhaps, or anthropology." (Shaw 2008, 60)

IR's fixation upon the international level has not only marginalized Indigenous politics, it has also blinded itself from making important revisions to traditional topics of concern, like security. Both these implications can be observed through the discipline's account of the decolonization period, which is traditionally associated with the official end of European colonialism. For much of the conventional literature, decolonization rectified many of the problems associated with colonialism through the creation of new states; specifically, by granting selfdetermination to subjugated peoples. Where Indigenous marginalization is 
concerned, this approach overlooked the fact that decolonization did little to resolve the sub-state claims of national groups ensconced within territorial boundaries not of their making. This was especially true of Indigenous peoples residing in settler states like Canada and the United States, who were entirely bypassed by the decolonization process. This was also true for many of the Indigenous peoples residing in the newly created states of Africa and Asia who were subsumed into states more representative of other nationalities. It is also worth remembering that in Africa, most of the territorial boundaries adopted by the new states were legacies of the Berlin Conference (1884-85), at which European powers divided the continent into territories unreflective of social, cultural and political histories (see chapter five). Thus, by focusing attention on the creation of states at the international level, conventional IR theory largely overlooked the sub-state claims of Indigenous peoples residing within them.

With the end of the Cold War, and the onset of many ethnic-based conflicts in the now 'decolonized' world, IR's fixation upon the international level became exposed to critique. By failing to look within these newly created states, IR had overlooked simmering sub-state tensions premised on national lines. Rooted in colonialism and left unresolved by decolonization, these tensions erupted into a number of violent conflicts that posed significant challenges to regional security, a traditional topic of IR's concern. It is perhaps unsurprising then that in the postCold War period, IR began to shift some of its attention to sub-state politics. Although this shift did not always address a direct concern with decolonization, attention paid to domestic issues did signal recognition on the part of the 
disciplinary mainstream that domestic politics mattered. For example, Scott Burchill (2005) notes that "in the 1990s Fukuyama revived a long-held view among liberals that the spread of legitimate domestic political orders would eventually bring an end to international conflict." (57) Likewise, some branches of realism began turning to domestic politics as a means of understanding why states behave the way they do internationally. Neoclassical realism, for instance, attempts to account for state behaviour by elaborating upon the role of domestic forces in shaping a state's foreign policy; as Stephen Walt (2002) puts it, neoclassical realism "places domestic politics as an intervening variable between the distribution of power and foreign policy behavior." (211; quoted in Dunne \& Schmidt 2012, 92)

IR's slow transition towards a research agenda concerned with the domestic level is especially important where Indigenous politics are concerned, as this transition broadens potential avenues for research. As previously discussed, IR research involving Indigenous politics has placed a heavy emphasis on the transnational movement. While important, Indigenous transnationalism is not the only way Indigenous politics inform IR. In an edited collection on Indigenous diplomacies, Beier (2008) - representing the contributors - notes that "Indigenous diplomacies [are] much more broadly sited, far more nuanced and complex, and more wholly sui generis than a focus on recent developments at the UN alone might reveal them to be." (Beier 2008, 2) For critical scholars like Beier (2008), the relevance of Indigenous politics to IR cannot simply be discussed in terms of the 'international,' since Indigenous politics occurring at the 'domestic' level speak to IR on a number of fronts. This is explained nicely by Beier (2005) who recounts 
anecdotal experience of his attendance at a 1997 McGill University conference on the release of Canada's Royal Commission on Aboriginal Peoples. ${ }^{44}$ He explains,

[...] the presentations and discussions suggested almost no end of senses in which the issues under consideration were issues of international relations: the legacies of conquest and enduring colonialism in the Americas were considered; different conceptions and competing claims of sovereignty were weighed; some participants reflected upon the history of Indigenous peoples' involvement at the United Nations and in other international fora; and, Kahnawake newspaper editor Kenneth Deer recounted the details of the Two Row Wampum [...].45 (Beier 2005, 2)

Beier's anecdote underscores the fact that Indigenous-state relations speak to IR on grounds previously obscured by a strict division between the domestic and international realms. This perspective need not be restricted to the Canadian context either; in the United States, for instance, Indigenous-state relations have been largely premised on centuries of treaty relations that initially recognized Indigenous peoples as sovereign entities. While many of these treaties were violated by the state, they have nevertheless retained some legal standing and have been used in cases against the state to claim reparations. ${ }^{46}$ Where legal arguments have been less persuasive - as in Australia and New Zealand - Indigenous peoples have drawn on persuasive moral arguments to emphasize their status as self-

\footnotetext{
44 The 3200 page report was the culmination of a five year process investigating the relationship between Canada and the Indigenous peoples that reside within it. The process was initiated by the Oka crisis in 1990, when Mohawk protesters confronted police over the expansion of a golf course encroaching on their territory. (Beier 2005, 1)

45 The two row wampum is a treaty between the Haudenosaunee and the Dutch. The treaty was recorded in a wampum belt marked by two rows of purple wampum beads, separated by three rows of white. The purple beads symbolize a Haudenosaunee canoe and a European ship travelling parallel together, and the three white strips represent the peaceful coexistence of the Haudenausonee and the Dutch settlers. The two row wampum is meant to symbolize the Haudenosaunee's commitment to maintaining peaceful relations with the Dutch in perpetuity. (Onandaga Nation 2007, online)

${ }^{46}$ From an English School perspective - in particular Barry Buzan's (2004) - it might be argued that the treaties are best conceptualized as derivative institutions of the master institution, international law.
} 
determining peoples that were denied this right by Europeans following colonization. In short, Indigenous-state relations in a number of countries establish a persuasive basis upon which to justify IR analyses of the domestic realm and a basis to erode the methodological distinction between two discrete spheres of political activity. This is not to diminish analyses singularly focussed on Indigenous transnationalism, but to broaden research in a way that responds to Beier's (2009) observation that Indigenous politics/diplomacies are broadly sited.

\section{Conclusion}

For the reasons highlighted in this chapter, IR scholarship on Indigenous peoples remains thin. Because of the limited availability of IR scholarship on Indigenous peoples, most research from within the field has turned to scholarship from outside of it to inform analysis. For example, Marshall Beier (2005) draws heavily on anthropology in an effort to show how the cosmology of the Lakota people informs international relations. In a similar vein, Karena Shaw (2008) looks to political philosophy as a method of understanding how and why IR has interpreted Indigenous politics the way it has - especially in terms of Thomas Hobbes' influence upon realism. Like the work of Beier (2005) and Shaw (2008), this thesis draws on an inter-disciplinary body of literature from inside and outside the discipline to inform analysis. Staying within the discipline, it draws on scholarship concerned with the role of colonialism in shaping contemporary international relations; especially, with respect to the evolution of international society. In general, this literature consists of critical scholarship from within the English School, which speaks to the insights of Postcolonialism. This includes scholars such as Edward 
Keene (2002) and Paul Keal (2003). From outside the discipline, the thesis makes use of research from IL, which has spent considerable time detailing the colonial evolution of international law, its role in marginalizing Indigenous peoples, and the legal responses Indigenous peoples have made to address this exclusion; this body of research consists of scholars like James Anaya (1996), Antony Anghie (2006; 2004; 1996), Robert Williams Jr. (1990) and Maivân Clech Lâm (2000).

Because of its historically-oriented approach, the English School has paid considerable attention to the evolution and expansion of international society. However, the approach the English School has taken to this issue has changed over time; shifting from a more 'orthodox' approach to a more 'critical' approach. In general, the orthodox account of the expansion is characterized by a high degree of Euro-centrism and state-centrism. A good example of this is Bull and Watson's edited collection, The Expansion of International Society (1984). In it, the editors portray the expansion of international society as a process beginning in Latin Christendom and slowly extending outward into the non-European world through centuries of European colonialism/imperialism. Watson (1984a) even goes so far as to distinguish Europe from other regions of the world by invoking celebratory tones. "[i]t [Latin Christendom] was far from being a closed world largely sealed off from other cultures and societies, as some Asian cultures have been. Innovative and expansionary, it filled out the uncultivated spaces within its boundaries and began to push back its geographic limits in many directions." (Watson 1984a, 13) By the late 19th century, this imperial expansion had resulted in the creation of a small society of European and other Western members, sharing common values and 
norms. Because of this society's origins in Europe, Bull and Watson (1984) conclude that "it was in fact Europe and not America, Asia, or Africa that first dominated and, in so doing, unified the world, it is not our perspective but the historical record itself that can be called Eurocentric." ${ }^{47}(2)$

Because of its Euro-centric outlook, the orthodox approach infuses its account of the expansion of international society with a good degree of statecentrism. This is largely on account of Europe's association with Westphalia (see chapter four), and the subsequent expansion of the state-system. As previously discussed, it is this state-centric approach that has helped to fuel the marginalization of Indigenous peoples from the IR literature; applied in the orthodox English School, however, it is also used to cast the expansion of international society in a positive light. Indeed, through the coalescence of a statebased society, order is said to be established at the international level through the creation of shared values and norms. This level of order is not only important in terms of regulating state relations, it is also said to be important for safeguarding the interests of humankind. As Bull (1977) explains,

If any value attaches to order in world politics, it is order among all mankind which we must treat as being of primary value, not order within the society of states. If international order does have value, this can only be because it is instrumental to the goal of order in human society as a whole. ${ }^{48}(21)$

\footnotetext{
${ }^{47}$ Bull and Watson (1984) recognize the role of non-European powers in shaping some of the norms of international society - especially in the decolonization period - but suggest that these are secondary to the linear projection of European norms and values into the non-European world. In subsequent chapters I argue against this perspective, suggesting that while Europe has heavily influenced the normative content of international relations, this has occurred through the constitution of European and non-European identities and relations.

${ }^{48}$ For Bull (1977), world order refers to a set of universal goals of all social life; namely: 1) limitation of violence resulting in bodily harm; 2) maintaining commitments; and 3) stabilization of possession through the mutual recognition of sovereignty. (18-19)
} 
In other words, the orthodox approach uses state-centrism in such a way that rationalizes its Euro-centrism, as it suggests that the ends of European expansion justified its means; specifically, that European colonialism in the non-European world provided a basis for international order, thereby advancing the interests of European and non-European peoples alike.

In recent years, the orthodox account of the expansion of international society has come under scrutiny by English School scholars influenced by postcolonial criticisms. These critical approaches are especially influenced by Gerrit Gong's, The Standard of Civilization in International Society (1984). Published in the same year as The Expansion of International Society (1984), Gong's work functioned as an early counterpoint to the orthodox approach. It should be noted however, that Gong's analysis left many orthodox assumptions in place; indeed, it continued to take the state as the primary subject of international relations and viewed contemporary international society as a vessel for order in world politics. Unlike the orthodox approach however, Gong (1984) sheds light on the negative consequences of international society's expansion; in particular, the Euro-centric assumptions of international law. Gong (1984) achieves this by drawing attention to the Standard of Civilization (the Standard), an express legal principle stipulating five criteria a society must meet before being deemed civilized (see chapter five). Developed by European states, these criteria were premised upon a distinction between the 'uncivilized' non-European world and the 'civilized' European world. Working through this dichotomy, the Standard sought to push non-European 
peoples towards accepting European forms of socio-political organization by promising equal legal standing within a society of civilized states. ${ }^{49}$

In effect, the civilized-uncivilized dichotomy of the Standard placed nonEuropean peoples in a double bind; either they could accept their culture to be 'inferior' and mimic the European model, or they could retain their traditional culture and lose any legal protection afforded by the Standard. Gong's (1984) research into this area has provoked contemporary scholars like Edward Keene (2002) and Paul Keal (2003) to further detail the role of this dichotomy in the historical evolution/expansion of international society. Keene (2002), for instance, has used the concept of civilization to explore the application of order during the expansionary period. According to him, the civilized-uncivilized dichotomy established a basis for European powers to divide the world into two spheres, the civilized (European) and uncivilized (non-European) world. Through this division, Europeans could then rationalize their application of international law in ways that facilitated expansion. Between Europeans, legal norms became a mechanism to minimize inter-state rivalry and to facilitate the 'orderly' expansion of their empires. Meanwhile, legal norms could be overlooked in dealings with uncivilized peoples, justifying incursions into non-European lands. A similar perspective is taken by Keal (2003) in his analysis of international society and Indigenous peoples. For him,

It [international law] defined and codified the terms for membership in the society of states. It marked the boundaries between those who belonged to the society and those that did not. Those that did formed a moral community

\footnotetext{
${ }^{49}$ Gong (1984) notes that being equal in law did not necessarily imply equality in practice. Despite being one of the first non-European members to comply with the Standard, Japan was regarded as socially and culturally inferior, leading to its gradual disassociation with the society of states and status as a revisionist power during World War II.
} 
bound by mutually agreed rules of conduct. And fundamental to this community was the idea that its members were not obligated to treat nonmembers according to the norms that applied to relations between themselves. (Keal 2003, 84)

Not surprisingly, the colonial evolution of international law has been a significant concern for scholars of international law, which has drawn similar conclusions as the critical English School. Critical legal scholarship has paid the civilized-uncivilized dichotomy considerable attention in structuring the foundations of modern international law. Perhaps the most comprehensive examination of this issue with respect to Indigenous peoples is The American Indian in Western Legal thought, by Robert A. Williams Jr. (1990). In it, Williams Jr. (1990) suggests that European colonialism functioned through Euro-centric representations of civility that cast non-European peoples as uncivilized. Not only did this facilitate the view that legal norms that governed inter-European relations could be ignored in the non-European world, it also provided an ethical foundation for European expansion - since it was through this dichotomy that European powers could justify colonialism/imperialism on the grounds of a civilizing mission. While the content of this civilizing mission changed according to the civilizer and the historical epoch, it generally proceeded on the assumption that European expansion was a morally noble endeavour, which would endow non-Europeans with the benefits of civilization. In his analysis of Spanish colonial law, Anghie (2004) draws a similar conclusion, noting that European colonialists conceptualized themselves as part of a civilizing mission that postulated "an essential difference [...] between the Europeans and non-Europeans, the Spanish and the Indians, the civilized and the uncivilized." (310) 
Recognizing the colonial origins of international law, IL scholars have focused considerable attention on the ways in which non-European and Indigenous peoples have confronted them. Anghie (2004), for instance notes that the developing world "must contend with the history of international law $[\ldots]$ a history in which international law continuously dis-empowers the non-European world [...]." (312) This leads him to an analysis of how developing world jurists have transformed colonial international law into a form of law responsive to the nonEuropean world. Similarly, a range of international legal scholars have turned their attention to Indigenous legal activism, focussing on the legal claims of Indigenous peoples and the strategies they have used to achieve them. Given recent successes at the United Nations, these analyses have focussed principally on Indigenous transnationalism and the process leading to the Declaration on the Rights of Indigenous peoples (2007). For example, James Youngblood Henderson (2008) has examined the way the Indigenous transnational movement seized upon the rightsbased discourse of international law to elevate an Indigenous legal norm to the right of self-determination. Casting Indigenous peoples as subjects of international law not simply its objects - this literature confronts longstanding tendencies in the orthodox literature to depict the expansion of international society/law as a unidirectional process emanating from Europe. In the next chapter, I begin to detail why this is important, particularly with respect to a theoretical framework intended to elaborate upon the relationship between international and world society. This is achieved by situating this thesis within English School and postcolonial literature, and by proposing a theoretical framework that sets out to partner these approaches. 


\section{Chapter three}

\section{Theoretical framework: An inter-societal approach}


Sovereignty is historically contingent. What it has meant and what it currently means belong to the political subjects who have deployed and are deploying it to do the work of defining their relationships with one another, their political agendas, and their strategies for decolonization and social justice. Therefore to understand how it matters and for whom, sovereignty must be situated with the historical and cultural relationships in which it is articulated. [...] Sovereignty carries the horrible stench of colonialism. It is incomplete, inaccurate, and troubled. But it has also been rearticulated to mean altogether different things by Indigenous peoples. In its link to concepts of self-determination and self-government, it insists on the recognition of inherent rights to the respect for political affiliations that are historical and located for the unique cultural identities that continue to find meaning in those histories and relations.

- Joanne Barker $(2005,26)$

Since its inception, the discipline of International Relations (IR) has focussed its analysis extensively on the concept of state sovereignty. In part, this focus is the result of a connection the discipline makes between sovereignty and the Peace of Westphalia (1648) - two peace treaties that ended the Thirty Years War by making the relationship between territory and sovereignty explicit. From the perspective of the English School, sovereignty has thus been conceptualized as the primary institution of world politics, because of its role in establishing order in an otherwise anarchical system. Indeed, the English School has spent considerable attention to the concept of international society for this reason; specifically, by making the claim that it projected sovereignty into the non-European world, and established a foundation with which to forge relatively peaceful relations between states - based on common norms and values. As Barry Buzan (2004) puts it, international society "is about the institutionalization of shared interest and identity amongst states, and puts the creation and maintenance of shared norms, rules and institutions at the centre of IR theory." (7) From a theoretical standpoint however, this has resulted in a state-centric bias that focuses on how sovereign states have forged order through 
the creation of these societies. In light of the state's centrality to the English School, Andrew Linklater (2005) has remarked that the "foundational claim of the English School is that sovereign states form a society, albeit an anarchic one in that they do not have to submit to the will of a higher power." (84)

Problematically, the English School's state-centrism and focus on territorial sovereignty has resulted in the under-development of its other core concepts: 1) the international system, and 2) world society. Taking each in turn, Buzan (2004) explains them as follows; the international system "is about power politics among states and puts the structure and process of international anarchy at the centre of IR theory." (7) By contrast, world society "takes individuals, non-state organizations and ultimately the global populations as a whole as the focus of global societal identities and arrangements, and puts transcendence of the states-system at the centre of IR theory." (Buzan 2004, 7-8) Where the relative neglect of the international system concept is concerned, Buzan (2004) observes that this has been of little consequence, since the concept has already garnered considerable attention from realism, which has focussed on the theoretical consequences of anarchy (see literature review). When applied in the English School, this has meant that the concept of an international system "is broadly parallel to mainstream realism and neorealism and is thus well developed and clearly understood."50 (Buzan 2004, 7) Unfortunately, the same cannot be said for the concept of world society, which remains poorly understood and seriously under-developed.

\footnotetext{
50 For an alternative perspective, see Tim Dunne's chapter in International Relations Theories:
} Discipline and diversity (2010). 
World society remains something of an analytical dustbin, uncomfortably containing revolutionism, cosmopolitanism and transnationalism. There is [however] a fairly strong agreement that international society and world society, at least for the present, rest on an ontological distinction between the state level on the one hand, and a rather complicated matrix of individuals and non-state groups and TNAs, on the other. (Buzan 2004, 44)

Despite this ambiguity, world society has paradoxically played an important role in English School theory. Bull's (1977) defence of international society rested on the assumption that the order it created was valuable only insofar as it advanced the interests of the morally prior society of humankind (see literature review). "The later Bull, and much more so [John] Vincent, saw it [world society] as the ideal to strive for." (Buzan 2004, 44) With the acceleration of globalization in the post-Cold War period, ambiguity surrounding the concept of world society has therefore become untenable - given that world society is the English School's principal concept for conceptualizing non-state actors, and that most scholars agree that the influence of non-state actors has increased over the past two decades. Indeed, the English School has, as a consequence of under-developing the concept of world society, impeded itself from launching more comprehensive examinations into the relationships and interdependencies between state and non-state societies. Furthermore, recent scholarship undertaken by Indigenous scholars has provided impetus to better incorporate the concept of world society. Indigenous scholars suggest that contemporary interpretations of sovereignty are conceptually narrow, evoking a very specific understanding that connects the concept rigidly to territory. In this way, they suggest that territorial accounts of sovereignty ignore the claims of non-state peoples. For this reason, they argue that the concept of sovereignty needs 
to be historically contextualized and understood within the social contexts in which it is deployed. ${ }^{51}$

In this vein, Joanne Barker (2005) notes that sovereignty has never been historically fixed. Citing the work of Vine Deloria Jr. (1999), she explains that sovereignty is an ancient concept that was once "used to describe both the power and the arbitrary nature of the deity in the Near East." (107; quoted in Barker 2005, 2) It was only later that "it was appropriated by European political thinkers in the centuries following the Reformation to characterize the person of the King as head of state." (Deloria Jr. 1999, 107; quoted in Barker 2005, 2) The appropriation of the concept was not seamless, while the secular and religious authorities in Europe agreed that the concept referred to the absolute power of an authority to govern, who this authority was remained contested. The Church, for instance, argued that the only true sovereign was God, while political authorities claimed that the right to govern on earthly/secular matters had been granted to them by God (Barker 2005, 2). In time, these debates would give way to a period of transition marked by "various political revolutions against the tyrannies of dogma and kingdoms to the ideologies and structures of the nation." (Barker 2005, 2) It was through this process that the "nation reorganized concepts of social status and responsibility from the obligations of subjects either of the church or of the kingdom to notions of citizenship, civil society, and democracy." (Barker 2005, 2) Accordingly, Barker

\footnotetext{
51 On this point, Taiaiake Alfred (2005) contends that, "Sovereignty, then, is a social construction. It is not an objective or natural phenomenon but the result of choices made by men and women, indicative of a mindset located in, rather than a natural force creative of, a social and political order. The reification of sovereignty in politics today is the result of the triumph of a particular set of ideas over others - no more natural to the world than any other man-made object." (46)
} 
(2005) explains that the concept of sovereignty took on a new meaning, one that understood it as emanating from the people. "Sovereignty seemed to belong to nations but was then understood to originate either from the people who made up those nations or as a character of the nation itself (nationhood)." (Barker 2005, 2)

Citing Anaya (1999b), Barker (2005) observes that this perspective was quickly replaced by a new account of sovereignty that began emphasizing territory, as the nation became characterized by rights to "exclusive jurisdiction, territorial integrity, and nonintervention in domestic affairs". (21; quoted in Barker 2005, 3) Indeed, "these rights would be correlated to concepts of sovereignty." (Barker 2005, 3) Critically, Barker (2005) notes that at the heart of this interpretation of sovereignty lay the concept of civilization; these rights "were modeled on concepts of individual personal freedom and linked to both secular and Christian ideologies about civilization." (3) Barker (2005) continues,,

Depending on the theorist, civility was evidenced by the existence of reason, social contract, agriculture, property, technology, Christianity, monogamy, and/or the structures and operations of statehood. [...] Nations possessed the full measure of civilization because they were the highest form of civilization; individuals roaming uncultivated lands did not possess either civilization or sovereignty. (3)

Three important and inter-related insights can be drawn from Barker's (2005) analysis; first, her analysis speaks to the fact that the concept of sovereignty has never been static; rather, it has assumed different meanings based on context. Second, her analysis connects territorial accounts of sovereignty to a Eurocentric discourse centered on civilization - a discourse that has marginalized non-state interpretations of sovereignty in favour of state-based ones. In this way, contemporary accounts of sovereignty are suggestive of a self-other relationship 
that distinguishes the civilized society of states from a collection of uncivilized nonstate peoples.

Barker's (2005) analysis supports the development of the world society concept by highlighting a self-other relationship that has historically privileged an account of sovereignty that has elevated the 'civilized' society of states over the 'uncivilized' members of world society. Recognizing this, some Indigenous scholars have called for a shift in the way that sovereignty is itself defined. Taiaiake Alfred (2005), for instance, contends that,

Discussion of the term sovereignty in relation to Indigenous peoples [...] must be framed differently within an intellectual framework of internal colonization. Internal colonization is the historical process and political reality defined in the structures and techniques of government that consolidate the domination of Indigenous peoples by a foreign yet sovereign settler state. ${ }^{22}(33)$

Challenging territorial definitions of sovereignty, the work of Indigenous scholars like Alfred (2005; 1999), Anaya (1999), Barker (2005) and Deloria Jr. (1999) is suggestive of the need for a more nuanced English School framework that incorporates non-state actors and their accounts of sovereignty into analysis. In light of this, this chapter sets out to establish such a framework by better incorporating world society into analysis, in a way that is attenuated to the concept

\footnotetext{
${ }^{52}$ Although the content of this definition is debatable, Barker (2005) suggests that it can be described as one which recognizes that "sovereignty emanates from the unique identity and culture of peoples and is therefore an inherent and inalienable right of peoples to the qualities customarily associated with nations [not states]." (3) It should be noted however that neither Alfred (2005) nor Barker (2005) can speak on behalf of Indigenous peoples more generally - indeed, this would be contrary to their very argument that sovereignty is a socially constructed concept. With this in mind, the point being made here is that sovereignty assumes different meanings based on those that employ it in different contexts, and is the product of a particular set of norms, values and assumptions. In this vein, it suggests that territorial definitions of sovereignty are themselves historically particular and open to critique when presented as both natural and universal.
} 
of civilization and the constitution of self-other dichotomies between state and nonstate societies. This is achieved in four sections:

1. In the first section, I draw on recent scholarship by Barry Buzan (2004) to further substantiate the case for 'reintroducing' world society to the English School. This achieved in two stages: 1) by highlighting arguments from within the English School for doing so; and 2) explaining the steps necessary for achieving this. Through this process, I tender Buzan's (2004) 'analytical reconstruction' of the English School as a foundation for structuring analysis.

2. In the second section, I begin to add some theoretical content to Buzan's (2004) analytical framework by proposing that societies be conceptualized as moral communities that define relations based on self-other dichotomies. On this basis, I propose conceptualizing relations between international and world society - in the context of state-Indigenous relations - as a relationship between self and other. I also situate Indigenous transnationalism within one of Buzan's (2004) core concepts; specifically, I conceptualize it as a likeminded coalition of transnational associations.

3. In the third section, I introduce Postcolonialism to the theoretical framework of this thesis, by arguing that its account of power helps respond to criticisms raised against Buzan (2004). Specifically, I suggest that Postcolonialism provides a historically-nuanced account of power that takes into account both its material and social forms. By adopting this account of power, the thesis is better able to detail the historical evolution and expansion of international society in relation to non-European and Indigenous peoples. 
4. In the fourth section, I address conceptual tensions in the process of partnering English School analytics with Postcolonialism.

5. Finally, in the fifth section, I detail what I refer to as an inter-societal approach to the study of international relations.

\section{'Reintroducing' world society}

By focussing almost exclusively on the concept of international society, the English School has not only neglected the role of non-state actors in world politics, it has done so to its own disadvantage, tendering an ambiguous concept that varies in meaning from one scholar to the next. In light of this, Buzan (2004) highlights three principal reasons to restructure the English School in a way that generates greater understanding of world society and improves the theoretical capacities of the English School as a whole.

First is that the English School needs to clarify the nature of its own claim to the idea in relation to the claims of others using the concept. Second is that English School theory itself cannot develop until the weak world society pillar is brought up to strength. Third, is that there is an opportunity to use English School theory to clarify the perennially unfocussed, but politically central, debate about globalisation. (11)

To achieve this, Buzan (2004) proposes a merger between English School analytics and constructivist theory. Constructivism has long been considered a natural ally of the English School because of its social ontology and attention to processes of norm socialization, which parallel the English School's attention to the concept of society and the construction/convergence of shared norms, values and institutions. ${ }^{53}$ In

\footnotetext{
53 Emanuel Adler (2005) casts some doubt over this perspective, arguing that constructivism's affinity with the English School is more apparent than real. "First, unlike the English School, whose roots lie mainly in international politics, constructivism began as interpretive ontology and post-
} 
fact, Timothy Dunne (1995), remarks that there "is an affinity between the international society tradition and the work of constructivists like Alexander Wendt. Both assume the centrality of states and both interrogate the meaning of international system/society according to the intersubjective practices through which it is constituted." (385)

For these reasons, synergies between constructivism and the English School have garnered higher levels of attention over the past two decades, with both constructivists and English School scholars interested in the potential for crossfertilization. In this vein, Buzan's From International to World Society? (FIWS 2004) stands as one the most comprehensive efforts to advance such efforts, with its aim "to create a synthesis between the structural elements of the Bull/Vincent side of English School theory about international and world society, and Wendt's social theory of international politics." (3) As a point of departure, Buzan (2004) begins by noting that the English School has traditionally suffered from two inter-related problems. First, its founders polarized the way in which the School has come to conceptualize international society, suggesting that it is depicted as either minimally or maximally social. As a consequence, international society is limited to being either a pluralistic society of states that share only the most basic norms and values needed to maintain world order, or a solidarist society of states that are highly integrated and knitted together by a variety of shared norms and values. ${ }^{54}$ Indeed,

positivist epistemology and only then moved to IR theory. Second, constructivism's mainstream emphasis on normative structures and 'the logic of appropriateness' [...] was analytical rather than normative; in other words, it purported to explain why and how norms and dialogue matter, rather than offer critical injunctions about social change." (172)

${ }^{54}$ These positions have fueled the pluralism-solidarism debate, a debate that hinges "on the question of the type and extent of norms, rules and institutions that an international society can form without 
pluralists hold that states espouse vastly different values and interests, which prevent them from forging deep social bonds. As a result, international society is limited to state-to-state arrangements that contribute to their mutual interests. ${ }^{55}$ By contrast, solidarists, view international society as a vessel for promoting the rights of humankind; for them, the task of international society is to translate humanity's latent but common values into reality (Mayall 2000, 47).56

Second, and inter-related, Buzan (2004) suggests that solidarism's ontology blurs the line between international and world society, by including both state and non-state actors in a definition of international society. As Buzan (2004) explains,

Because the pluralist position is entirely state-based, it is relatively straightforward and coherent. The solidarist position is more problematic. Because it ties together state and non-state actors, and draws on cosmopolitan notions of individual rights and a community of humankind, it cannot help but blur the boundary between international and world society. ${ }^{57}$ (Buzan 2004, 48)

In addition to fostering a relatively narrow debate about international society's level of social integration, solidarism has also inhibited comprehensive analysis of the world society concept by fusing state and non-state actors into a single ontology. Drawing on these ontological assumptions, for instance, Bull (1977) tenders an exceptionally broad and demanding definition of world society; for him, world

departing from the foundational rules of sovereignty and non-intervention that define it as a system of states." (Buzan 2004, 46)

55 This is the position of scholars like Bull (in his early work), who remained skeptical of the capacity of states to move beyond intuitions that promoted their common interests in international order.

${ }^{56}$ Amongst those who are identified with this position, John Vincent is likely the most prominent, who's Human Rights and International Relations (1986) sought to show how human rights could be viewed as compatible with the more conventional interests of states.

${ }^{57}$ Buzan (2004) suggests that the ontologies of pluralism and solidarism are underpinned by their respective affinities with realism and revolutionism, which result in two philosophic assumptions about world politics: 1) that world politics is conditioned by self-interested state actors operating in a self-help system (realism/pluralism); and 2) that world politics is about a cosmopolitan community of humankind - which includes but is not limited to states - that is willing to cooperate under conditions of international anarchy (revolutionism/solidarism). 
society refers "not merely [to] a degree of interaction linking all parts of the human community to one another, but a sense of common interest and common values, on the basis of which common rules and institutions may be built." (269) Invoking similarly broad definitions, most English School scholars have viewed the materialization of world society skeptically and have seen little reason to pay much attention to it.

In light of these issues, Buzan (2004) restructures the orthodox English School by invoking the social ontology of constructivism; this results in two substantive changes: 1) it amends the English School's analytics (what Buzan (2004) terms the 'what' dimension); and 2) it emphasizes degrees of social behaviour within societies (what Buzan (2004) terms the 'how/why' dimension). Where the 'what' dimension is concerned, Buzan (2004) notes that a social ontology forces revisions to English School analytics by assuming that all systems are inherently social, as he observes that even the most mechanistic systems require some set of social assumptions. In an economic system, for instance, in which buyers and sellers never meet, both sides must establish a common set of assumptions about value in order for trade to be facilitated. Recognizing that all systems are social, Buzan (2004) collapses the concept of an international system. Buzan (2004) explains,

Dissolving the distinction between physical and social systems, or at least downgrading it to what [Alexander] Wendt calls 'rump materialism' [...] turns the spotlight on to whether English School theory needs to retain the distinction between international system and international society. [...] What changes is that the physical aspect ceases to provide the principal basis for distinguishing one type of international system from another. (101-102) 
With the concept of international system collapsed, the 'what' dimension of the English School is subsequently reduced to two analytical categories, an international society of states, and a world society of non-state actors.

The distinction Buzan (2004) draws between state and non-state societies helps resolve ambiguity by clearly delineating between the actors that compose international and world society. To further clarify the concept of world society however, Buzan (2004) further subdivides it into two core categories, interhuman and transnational societies. ${ }^{58}$ (159) As Buzan (2004) explains, this distinction is premised on a differentiation between primary and second-order societies; whereas interhuman societies are based on relations between people, transnational societies are based on relations between collectives. ${ }^{59}$ Thus, the implication of this move is recognition that in most cases, relations that occur between and within societies at the international level are second-order.

Thinking about the individual level is very largely focused on questions of identity and community. This is reflected in debates within political theory about cosmopolitanism versus communitarianism. [...] it is actually quite difficult to think about a pure interhuman society because the dynamics of a society almost always jump to the transnational and/or state levels. By contrast, thinking about the transnational level is mostly focused on questions of society. While it is not impossible to think about community at the transnational level, the huge diversity of actor types among TNAs tends to impose pretty strict limits on how far shared identity can go. (Buzan 2004, 127)

\footnotetext{
${ }^{58}$ In terms of how these categories relate to one another, Buzan (2004) explains that, "If one accepts the trilogy of unit types, then it follows that there can be three types of pure basic 'international' social systems: 'interstate (state-to-state interaction), transnational (TNA-to-TNA interaction) and interhuman (individual-to-individual interaction). Nothing forbids these from coexisting, and indeed overlapping [...]. In theory and in practice all sorts of mixtures are possible." (120)

${ }^{59}$ Buzan (2004) acknowledges that interstate societies are themselves composed of collectives, but distinguishes these from transnational societies on the basis that their members are strictly states.
} 
With this in mind, the issue for Buzan (2004) in conceptualizing inter-societal relations becomes the question of how to conceptualize social integration within and between societies. ${ }^{60}$

To answer this, Buzan (2004) turns his attention to the 'how/why' dimension of his framework. Premised on constructivist insights, the 'how/why' dimension is intended to break from the 'either-or' posturing of the pluralism-solidarism debate by focussing attention on the degrees of social behaviour that characterize a society. In light of this, Buzan (2004) recasts pluralism and solidarism as two ends of a spectrum, in a way that "represent degrees of difference rather than contradictory positions." (49) Citing his decision to collapse the concept of international system through the incorporation of a social ontology, Buzan (2004) explains, "[i]f all human interaction is in some sense social and rule-bound, then what results is not a distinction between international systems and international societies, but a spectrum of international societies ranging from weak [...] to strong". ${ }^{61}(100)$ The idea that social integration occurs over a spectrum is also extended to interhuman and transnational societies, providing greater nuance in the way these societies are conceptualized - especially in terms of their social activity (ie. the degree to which these societies integrate shared values and norms). ${ }^{62}$ Accordingly, Buzan's (2004)

${ }^{60}$ Although Buzan (2004) drops the term world society, this thesis retains the term world society in cases where it refers to non-state societies broadly. Recognizing that world society is composed of first- (inter-human) and second-order societies (transnational), however, the thesis employs the terms 'interhuman' or 'transnational' society to make this distinction clear.

61 This statement also refers to Buzan's (2004) decision to collapse international system, and highlights the close connection between the 'what' dimension of research and the 'how/why' dimension.

${ }^{62}$ Minimal levels of social behavior are characterized by societies that require coercion to force social cohesion, maximal levels of social behavior are distinguished by societies that hinge on collective beliefs and shared identities. In between these positions are societies that are characterized by both 
analytical categories are distinguished by various degrees of social integration. Moving from 'thin' to 'thick,' these degrees of socialization are described for each type of society in Table III.1 and Illustration III.1, below:

\section{Table III.1: Socially 'thin' to 'thick' societies, by Buzan's (2004) analytical categories}

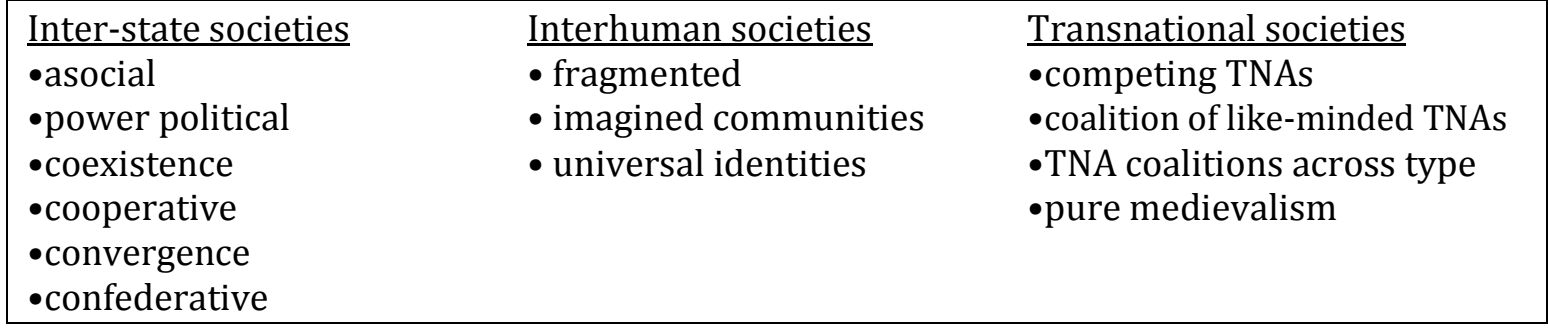

\section{Illustration III.1: Buzan's analytical reconstruction of the English School63}

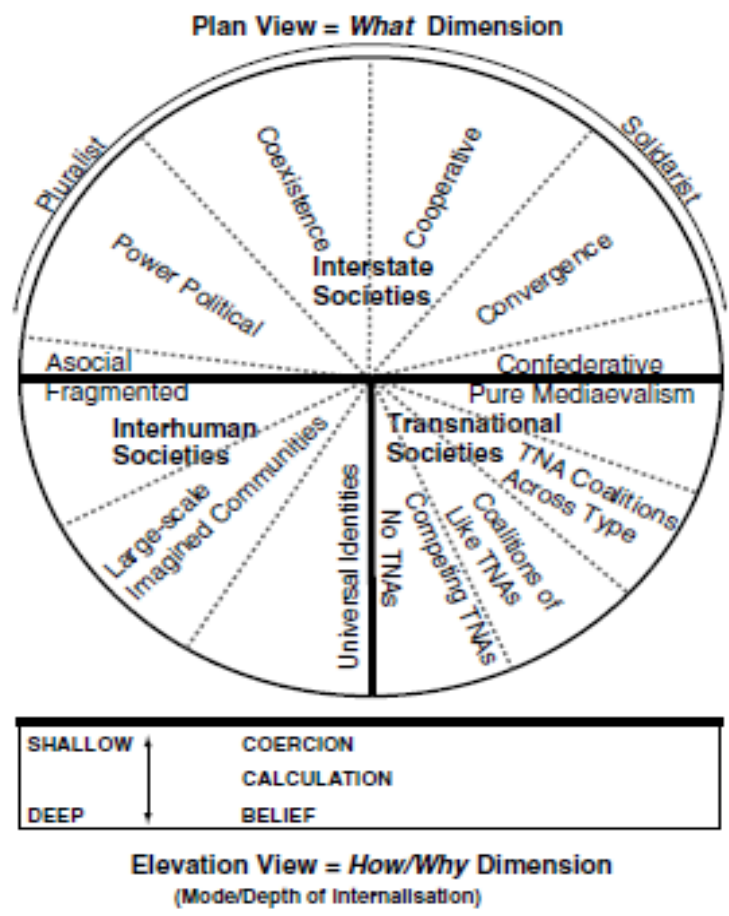

coercion and belief, and which form primarily on the basis of strategic calculation to advance common interests.

${ }^{63}$ This table appears in Buzan's From International to World Society (2004) on page 159. 


\section{Indigenous peoples and Buzan's framework}

While Buzan's (2004) analytical reconstruction of the English School helps disambiguate core concepts, his framework does not provide sufficient substance in the way of theory. Rather, Buzan's (2004) framework is analytical in nature and intended principally as a guide with which to pursue an analysis of relations between his societal archetypes, consequently it says little about how the norms and values that compose these archetypes are used to define relations between them. To help address this, this thesis makes the assumption that societies are moral communities; specifically, moral communities that,

[...] concede to each other rights and obligations with regard to being treated alike. [...] Implicit in this idea is that moral communities have boundaries that draw the line between who belongs and who does not. Or, to put this another way, between who gets included and who gets excluded. In essence, moral communities have rules; not only about the rights and duties members owe each other, but also rules determining rightful membership. (Keal 2003, 29)

While this does not mean that a society will never grant non-members the same rights as members, it does mean that there is no necessary obligation to do so. (Keal $2003,29)$ Indeed, it is through a society's collective identity around shared norms and values that it juxtaposes its Self against an Other, and defines relations accordingly. Although Gerrit Gong (1984) does not explicitly use the term moral community,' he implies it in his analysis of the Standard of Civilization (the Standard). According to Gong (1984), this express legal principle of the early 20th century evolved from a distinction between a civilized society of 'Western' states and an uncivilised body of non-state peoples - almost exclusively located in the nonEuropean world. Using the concept of civilization to distinguish Self from Other, 
international society codified a set of five criteria with which to judge membership in international society; 64 by failing to meet these criteria, non-state peoples were excluded from membership and the protections afforded by international law. Where Indigenous peoples are specifically concerned, their status as uncivilized/non-state peoples subsequently relegated them to a peripheral role in state-based politics for much of the $20^{\text {th }}$ century.

By conceptualizing societies as moral communities, it might be asked how Indigenous peoples fit within Buzan's (2004) framework. First, by being marginalized from the high politics of international society, Indigenous peoples have not traditionally been thought of as forging a society at the international level. Second, Indigenous peoples compose a great diversity of individual societies, each with their own unique set of traditions, cultures, and political and social systems; this highlights the potential risks of collectively referring to Indigenous peoples as a homogenous society. Thus, while it is relatively uncontroversial to assume that individual Indigenous societies can be conceptualized as members of world society - on account of being non-state actors - there is considerable ambiguity as to whether collective Indigenous action at the international level is best conceptualized as forming an interhuman or transnational society. Indeed, conceptualizing Indigenous peoples as an interhuman or transnational society raises important questions about Buzan's (2004) archetypes; this is because

64 These criteria are discussed at length in chapter five; according to Gong (1984), they include: 1) the capacity to guarantee basic rights to its citizens and to foreigners; 2) to exist as an organized political bureaucracy; 3) to adhere to international law; 4) to maintain adequate and permanent diplomatic channels with other states; and 5) to conform to the norms and practices of international society. 
Indigenous peoples can be conceptualized as occupying a middle ground between both categories - despite Buzan's (2004) insistence that these categories remain analytically distinct. On the one hand, it might be argued that Indigenous peoples operating at the international level form an imagined community by forging a shared identity that has coalesced around the concept of indigeneity - a collective identity premised on common experiences and histories, especially those associated with a shared history of colonialism. As Mathias Guenther (2006) explains of indigeneity, in the specific context of post-Apartheid South Africa,

'Indigenous' is a term applied to people - and by the people to themselves who are engaged in an often desperate struggle for political rights, for land, for a place and space within a modern nation's economy and society. Identity and self-representation are vital elements of the political platform of such peoples. (17)

On the other hand, collective Indigenous action at the international level can be conceptualized principally as a form of transnational society, due to the fact that Indigenous transnationalism is characterized by smaller societies operating in tandem, thereby forming a second-order society.

It is in these ways that Indigenous transnationalism provokes tensions in Buzan's (2004) societal archetypes; specifically, by suggesting a degree of overlap between interhuman and transnational society. With this in mind however, this thesis conceptualizes contemporary Indigenous transnationalism as a transnational society that defines its membership according to a common identity centred indigeneity. This conceptualization is not perfect; indeed, non-Indigenous organizations and individuals have involved themselves in the Indigenous transnational movement as key partners and allies. However, these non-Indigenous 
actors have principally functioned on the belief that the world's Indigenous peoples do share some common political interests and similar histories associated with the legacies of colonialism. As such, their efforts have focussed on objectives that advance the interests of peoples which self-identify as Indigenous; and, for this reason, they are widely perceived as partners in the transnational movement despite not self-identifying as Indigenous themselves. In light of this, there are two other benefits to conceptualizing the Indigenous transnational movement as a transnational society; one that closely resembles Buzan's (2004) concept of a 'coalition of like-minded transnational actors.'

1. It alludes to the fact - noted above - that the Indigenous transnational movement more closely resembles a second-order society than a primary one, by being composed of a number of collectives rather than individuals. Conceptualizing Indigenous transnationalism in this way, this thesis helps break away from the individualistic ontology of the interhuman archetype, an archetype that implicitly calls forth cosmopolitan assumptions. Indeed, the interhuman society archetype can only be extended so far before it implies a cosmopolitan community of humankind (i.e. once it has been extended globally, it assumes that all humans are bound by common norms and values, creating a cosmopolitan Self that can have no 'Other').

2. Second, and inter-related, it breaks from the problematic tendency - also noted above - of homogenizing the identities of individual Indigenous societies/peoples, without obfuscating the concept of indigeneity and its role in defining membership within the Indigenous transnational movement. 


\section{Power, Postcolonialism and English School analytics}

In conceptualizing societies as moral communities, this thesis draws attention to the constitution of self-other dichotomies, premised on collective identities that are made up of shared norms and values. In doing so, this thesis draws attention to the role of power in defining inclusion and exclusion in world politics; and, by doing this, it also helps respond to a criticism of Buzan's (2004) framework. In a critique of FIWS (2004), Emmanuel Adler (2005) argues that Buzan effaces power when he collapses the concept of an international system. According to Adler (2005), "[m]aterial power almost vanishes as a conceptualisation of structure, while social structure carries no alternative conceptualisation of power."(178) He continues, "The only traces of power in Buzan's theory are found in the mechanisms of coercion through which values and norms are internalised."65 (Adler 2005, 178) As a consequence, Adler (2005) argues that Buzan (2004) must go further down the constructivist path,

Power should enter a social theory of international politics [...] not only as material and institutional resources, but also as dominant normative understandings and discourses that help build subjectivity, institutionalise practices, and construct and transform social structures. (178)

In light of Adler's (2005) criticism, and given the subject matter of this thesis, I invoke the insights of Postcolonialism to help conceptualize the social and material dimensions of power, in a way that contributes to an understanding of the relationship between international and world society in the context of stateIndigenous relations.

\footnotetext{
65 It is important to reiterate that this move does not take the physical out of the analysis altogether. Physical elements such as the distribution of power, and the nature of interaction remain central to the analysis of all social systems.
} 
As Geeta Chowdhry and Sheil Nair (2004) explain, a postcolonial account of power is one that emphasizes "representation and cultural politics, resistance and agency and the intersections of race, gender, and class." 66 (Chowdhry \& Nair 2004, 10) Broadly speaking, 'postcolonial' accounts of power are influenced by two other accounts of power, one that focuses on representation, identity and discourse, and another that focuses on materiality. Where the former is concerned, postcolonial scholars have generally focused on how Europeans socially constructed the identities of non-Europeans as 'other,' constituting a Self-Other dichotomy with which to define their relations with them. ${ }^{67}$ Perhaps the most influential scholar in this regard has been the literary critic Edward Said (1978). Focusing on European scholarship concerned with the Middle East and East Asia, Said (1978) contends that Europeans have not only depicted non-Europeans as others, they have constructed an account of them entirely from the cultural perspective of Europe - an account that says nothing about the way non-Europeans actually live, but rather fetishizes non-European identities that support both European conceptualizations of the self and of imperialism. Indeed, Said (1978) argues that by depicting nonEuropean as inferior, Europeans could rationalize imperialist objectives that required the assertion of European power over non-European others. This argument has similarly been made by scholars like Frantz Fanon (1963), who

\footnotetext{
${ }^{66}$ It should be emphasized that this is Chowdhry and Nair's (2004) account of Postcolonialism; other postcolonial scholars do not necessarily foreground gender in the same way. Nevertheless, Chowdhry and Nair's (2004) account of Postcolonialism is broadly similar to the accounts of other postcolonoial scholars, and has thus been used here as point of departure for conceptualizing it.

67 This type of scholarship is heavily indebted to the work of postmodern and post-structural scholars, who challenge the idea that power is a concentrated act of force, directed by and against a distinct group of people. In the context of IR theory, this approach has become influential because of its capacity to shed light on the concept of 'othering' - the way that dominant societies exercise power through discourse to represent others as 'alien, subversive, dirty or sick.' (Campbell 2, 1992)
} 
concentrated his research on understanding mechanisms of colonial control through discourse. ${ }^{68}$ "Unlike the emphasis in IR on objective power relations (which would point out that France is more powerful than its colony Algeria in military, economic, and cultural terms), the stress in Fanon's work is on the power of colonial discourses to colonize the minds of all involved." (Sylvester 2012, 186) The implications of this are summarized by Christine Sylvester (2012), who explains,

This meant that European colonizers would see their exercise of dominating power as justified, and colonized societies would come to accept and internalize the diminished and subordinate statuses imposed on them. The vehicle of such status differentiation is not the force of the gun but the force of language - words, racial epithets, and daily insults thrown at people. (186)

Applied in this thesis, such an approach helps establish a basis for conceptualizing the exercise of social power, especially by international society. By focusing on the concept of civilization, chapters four through seven of my thesis detail how the most powerful members of international society - European and other Western states - articulated a self-other dichotomy with which to frame their relations with Indigenous peoples. Implicit in this analysis is recognition of the important role of material power; indeed, it was the military and economic might of European empires that furbished their expansion. However, the role of material power in facilitating the expansion of international society - not to mention its role in shaping international relations - is already well documented, both by the English School and other branches of IR theory (ex. realism). In light of this, a particular emphasis is placed on understanding the role of discursive power in delineating an

${ }^{68}$ It is acknowledged that Fanon is likely better known for his work on the violence involved in colonial relations. 
inside from an outside, which in turn 'justified' the exercise of material power in turn - be it military, economic or other - to 'civilize' the uncivilized. For example, Antony Anghie's (1996) post-colonial analysis of $15^{\text {th }}$ century Spanish colonialism, reveals that racially- and socially-motivated representations of Amerindians were used to legitimate Spanish colonialism through international law (see chapter four). This process seems to have continued well into the 20th century as positive-law jurists similarly framed non-state peoples as uncivilized, so as to justify the expansion of international society (see chapter five). ${ }^{69}$

Because of their indebtedness to post-modern and post-structural theory however, such accounts of power have come under critique from more conventional approaches, which cite their 'over-emphasis' on the social dimensions of power. Postcolonialism "has been accused of merely "deconstructing" knowledge, of failing to locate its critique and analysis in the material histories of the oppressed, and of being seduced by French "high theory" at the expense of Indigenous literature." (Chowdhry \& Nair 2004, 25) Although these critiques point to an important issue in the history of colonialism - the application of material power by colonizing states they do not take full account of the connection Postcolonialism makes between materiality and power. As most postcolonial scholars recognize, contemporary international relations is marked by the material legacies of European colonialism, such as its role in economic exploitation and the violent coercion of non-European peoples. Whereas more conventional approaches focus on the structural dynamics

\footnotetext{
${ }^{69}$ As an added benefit, this approach to power allows for an analysis of Indigenous-state relations to also keep an eye on the domestic level, whereas some more conventional accounts of power remain primarily fixated on the sovereign exercise of material power - both military and economic - at the international level.
} 
of the international system and the function of material power in facilitating these dynamics (see literature review), postcolonial scholars connect contemporary power structures to the colonial past. Identifying an association between social power and its material effects, for instance, Olufunmilayo Arewa (2006) argues that the constitution of self-other identities during the colonial period enabled Europeans to construct hierarchies of power that justified the exercise of their material power in the non-European world. Furthermore, Arewa (2006) observes that the long-term legacy of this exercise was the creation of a balance of power; specifically, one that has been historically tilted in the favour of Western states. To make such arguments, postcolonialists have been heavily influenced by Marxian accounts of power, which detail the evolution of contemporary power dynamics through an economic reading of political history - one that pays close attention to periphery-core relations in the context of Western hegemony. ${ }^{70}$ This is especially noticeable in the work of postcolonial scholars that attend to issues involving subaltern identities. Sylvester (2012) observes that much of this literature is indebted to Antonio Gramsci, whose concept of the subaltern - the most subordinated groups of any society - forms the very basis of study. Drawing on the subaltern concept, some postcolonial scholars argue that contemporary IR is itself a colonial construct that privileges Western knowledge over the voices of marginalized peoples,

The subaltern studies group endeavoured to turn around the position of the subaltern in knowledge, from being the lowest in a chain of influence starting with colonial powers and ending with the post-colonial state and its leaders

\footnotetext{
70 This is touched on in chapter seven, in the context of intellectual property rights and the negotiation of the Agreement on the Trade-Related Aspects of Intellectual Property Rights.
} 
to being the most relevant for building the kind of knowledge that could respond to tales of colonial power, glory and individual or national (European) heroism. ${ }^{71}$ (Sylvester 2012, 187)

Drawing attention to the social and material dimensions of power, postcolonial scholarship has thus sought to detail how contemporary international relations exhibit legacies rooted in the colonial exercise of power; especially by Europeans in the non-European world. Postcolonial scholarship,

[...] reveals how pseudo-scientific racist and gendered constructions of the other [...] inscribe the cultural authority and dominance of the West under colonial rule and in the postcolonial present. Dichotomous representations of the West and East, Self and Other, which essentialize identity and difference are critical to the maintenance of Western hegemony. ${ }^{72}$ (Chowdhry and Nair 2004, 17)

By focusing on the colonial exercise of power and its contemporary effects, however, postcolonial scholarship has also provided a basis with which to contest colonialism and its legacies. ${ }^{73}$ For instance, Sylvester (2012) observes that Homi Bhabha (1994) has specifically focused his critique on the inability of colonialism to exercise control over postcolonial subjects; his analysis reveals "that colonialism was never fully successful in defining and restricting the lives of colonial and post-colonial subjects." (191) According to Bhabha (1994), these 'subjects' were at once depicted as

\footnotetext{
${ }^{71}$ Sylvester (2012) notes that these scholars include Ranajit Guha, Dipesh Chakrabarty and Gayatari Spivak.

72 In a similar argument, Bart Moore-Gilbert (1997) argues that Postcolonialism makes important connections between discursive and material forms of power. According to Moore-Gilbert (1997), this connection is an important theme in the work of postcolonial scholars like Edward Said, Chandra Mohanty and Gaytari Spivak, who sought to highlight the "relationship between Western representation and knowledge on the one hand, and Western material and political power on the other." (34; quoted in Chowdhry \& Nair 2004, 15) From this perspective, postcolonial accounts of power do not intend to obfuscate its material sources, but to contextualize how these material sources function through social behaviour (ie. the representation of an other).

${ }^{73}$ Speaking directly to the material legacies of colonialism, Chowdhry and Nair (2004) argue that "Postcolonialism is attentive to these material histories, and in fact, relates these histories to the question of resistance and agency. [...] Hence, the significance of colonizing practices, counternarratives, and struggles, and the marginalized's recovery of self [...]." (Chowdhry \& Nair 2004, 25)
} 
incapable of living up to modern moral codes, and yet - in some cases - capable of being civilized (Sylvester 2012, 191). As Sylvester explains, colonialism "is [thus] accompanied by efforts to train some 'natives' to speak European languages and aspire to European values and culture." (Sylvester 2012,191) In so doing, Bhabha (1994) contended that colonialism breeds hybrid identities that threaten the colonial process. And, by breeding hybrid identities, colonialism is forced to confront tensions in its own rationale; specifically, the existence of others with a claim to membership in the Self. ${ }^{74}$

\section{Reconciling tensions}

Traditionally, the English School and Postcolonialism have tendered two very different accounts of the evolution and expansion of international society. On the one hand, the English School has valorized its evolution and expansion by associating state sovereignty with order. From the perspective of the English School, it was the expansion of international society into the non-European world that established international stability in an otherwise anarchic system, through the creation of new sovereign states. On the other hand, postcolonial scholars have argued that it was a consequence of this expansion that contemporary power imbalances that privilege Western states currently exist. Focussing on the constitution of a self-other dichotomy - between Europeans and non-Europeans these scholars highlight the role of social and material power in constituting

\footnotetext{
${ }^{74}$ And, in being confronted by these hybrid identities, colonialists are forced to intensify efforts to further subsume local peoples into the colony, exacerbating colonial tensions, fueling resistance to colonial rule, and opening a space for political change. (Sylvester 2012, 191)
} 
postcolonial legacies. ${ }^{75}$ From the perspective of postcolonial scholars, the evolution and expansion of international society is better conceptualized as a centuries-long process marked by the exercise of European power in the non-European world. In light of these very different accounts of the evolution and expansion of international society, it is acknowledged that partnering English School analytics with insights from Postcolonialism may appear at best unconventional, and at worst contradictory. However, it should be noted that recent scholarship has made inroads towards this objective.

Recent scholarship by English School scholars like Edward Keene (2002) and Paul Keal (2003) has sought to critically assess traditional accounts of the evolution and expansion of international society. While these accounts do not claim to use Postcolonialism, it is clear that both make an effort to incorporate non-European histories into analysis in a way that shares affinities with postcolonial research. In his work, for instance, Keene (2002) draws attention to the way that international law was used by Europeans to maintain intra-European order during the colonial period, while facilitating the appropriation of non-European lands. Meanwhile, Keal (2003) examines the role of international law in marginalizing Indigenous peoples from participation in international society. Drawing on an English School framework, these scholars have demonstrated how the constitution of self-other identities - contrasting 'civilized' from 'uncivilized' have influenced the evolution of

\footnotetext{
75 Scholars suggest that the hyphen in 'Post-colonialism' implies that international relations has moved beyond the colonial period; arguing that it is better to remove the hyphen to show how we remain in a colonial system highlighted by its legacies - hence 'Postcolonialism.' In a similar vein, Chowdhry and Nair (2004) "agree with [Raka] Shome and others that the postcolonial does not signify the end of colonialism, but rather that it accurately reflects both the continuity and persistence of colonizing practices, as well as the critical limits and possibilities it has engendered in the present historical moment." (11)
} 
intra-societal relations within international society between European and nonEuropean societies. Accordingly, scholars like Keal (2003) and Keene (2002) have opened a conceptual space for 'partnering' English School analytics with the insights of Postcolonialism in a way that conceptualizes their core concepts, themes and interests as constitutive elements of connected and relational histories. ${ }^{76}$

It is acknowledged that for some scholars, such an approach remains problematic; not least because the concept of international society - as it has been traditionally deployed - is steeped in problematic assumptions about its role in establishing global order through Western imperialism. For example, Siba Grovugui (2001) argues that,

Underneath the radicalism of today's theorists of international society, civil society, and human rights lie disturbing silences, banalizations, and erasures. These lacunas related to non-European groups can be explained partly by the rejection of social theory in favor of analyses of international politics. This distinction is compounded by the canonization of particular historical trajectories and parochial texts as foundations of international reflections. (437)

With this in mind however, it might be argued that Gorvugui's (2001) concern underlines the need to partner English School analytics with postcolonial insights, rather than conceptualizing them as mutually exclusive alternatives. If traditional accounts of international society are in fact marked by 'silences, banalizations, and

\footnotetext{
${ }^{76}$ While the English School and Postcolonialism hold different opinions on the interpretation of history, it is interesting that both concern themselves with similar historical periods, issues, and concepts. Roger Epp (1998) for instance observes that the "The [Expansion of International Society's (1984)] multifarious chapters trace, for example, the reciprocal diplomatic relations between African and European polities dating back to the first stirrings of the modern states-system; the European application of a 19th-century 'standard of civilization' and the imposition of unequal treaties in relations with Asia; the significance of race; and the reassertion of non-Western cultures over against colonialist presumption, but within the paradox of the postcolonial state that insists on the Westphalian norms of non-interference and sovereign equality." (57) Indeed, while the English School and Postcolonialism may draw very different conclusions about international relations, they are both engaged in a dialogue centred on similar historical events and their legacies.
} 
erasures' then there would seem to be a dire need for addressing these problems through the incorporation of insights from other perspectives. And, because Postcolonialism places a central focus on understanding the legacies of colonialism and the expansion of European empires - the very side of international society's history that the English School overlooks - then Postcolonialism seems especially suited for this task. In fact, it is noteworthy that for some English School theorists, postcolonial accounts of international society are not necessarily at odds with English School thinking (Epp 1998; Dunne 1997). While Roger Epp (1998), for instance, does not specifically address the relationship between Postcolonialism and the English School, he alludes to the way in which Postcolonialism and the English School might speak to each other in the context of international society. According to Epp (1998) "[i]n an important sense, the English School like the history of international society it excavates is founded on the problem of relations with the outsider." (57) He continues, "[a]s the progression of [Martin] Wight's organizing questions makes clear, it is impossible to think about international society without also thinking about its limits, whether geographic, ideological, or cultural." (57) As Epp (1998) suggests, the question of relations between self and other are thus at the heart of English School thinking, even if these questions have not yet been fully addressed.

In a similar vein as Epp (1998), Timothy Dunne (1997) identifies some points of convergence between the English School and Postcolonialism. Acknowledging that IR accounts of culture have been principally motivated by postcolonial scholars, Dunne (1997) suggests that questions of culture and the 
articulation of self-other relations are not foreign to English School theory itself; as he explains,

[...] certain thinkers in academic International Relations-associated with the 'English School'- have not neglected questions of culture and identity. In particular, Martin Wight's lectures on international theory, given at the London School of Economics (LSE) from the early 1950s to the early 1960s, included a key lecture on the 'theory of mankind' and its relations with the 'other'. (310)

Admittedly, English School inquiries of these sorts have been relatively few; nevertheless, the combined insights of Epp (1998) and Dunne (1997) indicate a conceptual space for partnering English School analytics with Postcolonialism. And, as noted, the works of Keene (2002) and Keal (2003) are indicative of recent efforts to address the concerns of Grovugui (2001); specifically, by revising the concept of international society through the incorporation of Postcolonialism.

\section{Conclusion}

Adopting the analytics proposed by Buzan (2004), this chapter has proposed an inter-societal approach; specifically, an approach that seeks to understand the constitution of relations between second-order societies. ${ }^{77}$ Partnered with Postcolonialism, this approach - as applied in this thesis - is used to detail relations between the society of states and the Indigenous members of world society. Significantly however, such an approach is confronted with a considerable challenge in the context of this thesis: from an historical perspective, Indigenous peoples have principally engaged with the members of international society on a bilateral basis.

\footnotetext{
77 The term 'society,' in the term 'inter-societal' refers to the transnational and inter-state societies that Buzan (2004) categorizes as ideal types; I am not employing the more common usage of the term to denote a society composed of individuals (ex. Canadian society).
} 
This is not to suggest that Indigenous peoples have not acted cooperatively in the past by forging military and diplomatic alliances to leverage their relations with states, but that global scale cooperation did not occur on a systematic basis until the mid-20th century. It was during this period that Indigenous peoples forged a coalition of like-minded transnational actors (see chapter six). In light of this, it is difficult to term the relations between international society and Indigenous peoples, prior to the mid-20th century, inter-societal. To reflect this challenge, subsequent chapters adopt an inter-societal approach that: 1) details the formation of the Indigenous transnational movement by examining its historical precedents, and 2) examines subsequent inter-societal relations between the Indigenous transnational movement and international society.

Where the former is concerned, chapters four and five detail the foundations of the Indigenous transnational movement by focussing on colonial relations between Indigenous peoples and European powers. Like the Indigenous peoples with whom they came in contact, European imperial powers principally engaged in bilateral relations with Indigenous peoples prior to the 20th century. In this sense, this period cannot be said to have been characterized by inter-societal relations, but rather by relations between the members of a nascent international society and Indigenous peoples. However, these colonial interactions did nevertheless facilitate the material and discursive foundations that have shaped contemporary relations between the Indigenous transnational movement and the society of states. As discussed in chapter four, for instance, Spanish relations with the Amerindians established important precedents for subsequent colonial relations between 
European powers and Indigenous peoples. Moreover, it was through the evolution of these relations that the European discourse on civilization evolved and was codified into international law; subsequently becoming a source of debate between the Indigenous transnational movement and the society of states - as is discussed later, the legacies of this discourse are at the heart of Indigenous efforts to redefine their relationship with states.

With these foundations established, chapter six and seven attend to an analysis of inter-societal relations between the Indigenous transnational movement and international society. While a detailed analysis of Indigenous transnationalism is reserved for these chapters, it should be noted that the term transnationalism has been specifically used to emphasize the point that Indigenous transnationalism is conceptualized by this thesis as a type of transnational society. It might be argued, for instance, that Indigenous transnationalism is better conceptualized as a type of 'subaltern internationalism,' given the fact that much of what is being demanded by the movement is principally a re-articulation of norms and values derivative of the Westphalian system. For example, the Declaration on the Rights of Indigenous Peoples builds on existing human rights standards to ensure the "survival, dignity and well-being" of Indigenous peoples, rather than transcending the human rights framework altogether (Amnesty International, online). However, there is good reason to conceptualize Indigenous transnationalism as a transnational society. Specifically, the activities of the movement have transcended traditional state-based interaction. Rather, they reflect Portes' (1999) definition of transnationalism that is, activities " $[\ldots]$ that take place on a recurrent basis across national borders and that 
require a regular and significant commitment of time by participants. [...] These activities are not limited to economic enterprises, but include political, cultural and religious initiatives as well." 78

Through these chapters, the inter-societal approach details how a discourse on civilization fashioned colonial relations between Indigenous peoples and imperial powers, and later influenced future relations between the society of states and a transnational society of Indigenous actors. Informed by a postcolonial account of power, this approach pays special attention to the discursive dimensions of power; in particular, the constitution of a self-other dichotomy that juxtaposed a civilized self against an uncivilized other. Indeed, I contend that it was through this discourse that the expanding society of states rationalized the gradual encasement of Indigenous peoples within their borders. Put differently, what this approach does is examine how Indigenous peoples were 'othered' by the outward process of international society's evolution and expansion

\footnotetext{
${ }^{78}$ A similar definition was put forward by Keohane and Nye (1981), who as Patricia Clavin (2005) explains, "used the term to describe 'contracts, coalitions and interactions across state boundaries' that were not directly controlled by the central policy organs of government." (425)
} 


\section{Chapter four}

\section{Civilization and the inception of European international law}


Since the Sixteenth Century, [European and non-European] temporalities and histories have been irrevocably and violently yoked together... Their grossly unequal trajectories, which formed the very ground of political antagonism and cultural resistance, have nevertheless been impossible to disentangle, conceptualise or narrate as discrete entities: though that is precisely what the dominant western historiographical tradition has often tried to do. No site, either 'here' or 'there', in its fantasied autonomy and in-difference, could develop without taking into account its significant and/or abjected others. The very notion of an autonomous, self-produced and self-identical cultural identity, like that of a self-sufficient economy or absolutely sovereign polity, had in fact to be discursively constructed in and through 'the Other'... The Other ceased to be a term fixed in place and time external to the system of identification and became, instead, a symbolically marked 'constitutive outside'

- Hall 1996, 252

Due to the important role international society plays in the theoretical framework of the English School, it is of little surprise that a large number of scholars make some connection between the English School and the work of Hugo Grotius. Martin Wight (1992), for instance, connects international society to the Rationalist tradition and the legal philosophy of Grotius. In Wight's (1992) view, the work of Grotius demonstrates how international law and discourse facilitate international order through the establishment of common rules, values and norms (see chapter three). Similarly, Hedley Bull (1990) argues,

The work of Grotius is cardinal because it states one of the classic paradigms that have since determined both our understanding of the facts of inter-state relations and our idea as to what constitutes right conduct therein. This is the idea of international society: the notion that states and rulers of states are bound by rules and form a society or community with one another, of however rudimentary a kind. ${ }^{79}(71)$

\footnotetext{
${ }^{79}$ Echoing Hedley Bull (1990), Adam Watson (1992) argues that Westphalia was the culmination of a process that saw the collapse of Latin Christendom and the emergence of a state system premised on the Italian stato. The states of Europe "[...] recognized that, since the medieval restraints had disappeared or become irrelevant, new rules and procedures were needed to guide their relations. In Hedley Bull's terms they needed to constitute a new international society. The decisive feature of this process was the general settlement negotiated in Westphalia at the middle of the century after the exhausting Thirty Years War." (Watson 1992, 182)
} 
Because of his association with international society, Grotius has subsequently been linked to the Peace of Westphalia (the Peace, 1648), a moment traditionally conceptualized by the English School as the inception of international society though one initially contained within the territorial borders of Europe. Bull (1990) argues that the "idea of international society which Grotius propounded was given concrete expression in the Peace of Westphalia, and Grotius may be considered the intellectual father of this first general peace settlement of modern times [...]." (75)

Over the past two decades however, linkages between Grotius and the Peace (1648) have been subjected to considerable scrutiny. Increasingly, critical English School scholars are asking whether Grotius' political philosophy does in fact resonate with conventional interpretations of the Peace (1648); in particular, whether Westphalia originated the values and norms of contemporary international society as said to be propounded by Grotius. In an influential critique of orthodox accounts, for instance, Edward Keene (2002) notes that two central elements of Grotius' political philosophy have been overlooked by orthodox scholars as 'nostalgic medievalism' or 'idealistic utopianism.' First, "that the sovereign prerogatives held by public authorities are divisible from one another; and secondly, that private individuals can acquire property rights in the law of nations under certain specific circumstances." (Keene 2002, 145) According to Keene (2002), the failure of the orthodox English School to pay much attention to these Grotian principles has led to an impoverished account of the evolution and expansion of 
international society. ${ }^{80}$ Indeed, orthodox accounts of the expansion of international society focus almost exclusively on the role of Westphalian institutions in promoting inter-European order, rather than detail how these institutions shaped - and evolved through - relations between European society and the non-European world.

Keene's (2002) criticisms are not restricted to the English School however, since the discipline of International Relations (IR) has, as a whole, largely subscribed to this orthodox interpretation of the inception and expansion of international society. For example, Hans Morgenthau (1948) argues that Westphalia was a pivotal moment in the creation of an international system premised on the institution of sovereignty. For him, "the Treaty of Westphalia [...] made the territorial state the cornerstone of the modern state system." (294; quoted in Osiander 2001, 261) And, Seyom Brown (1992) argues that "to this day two principles of interstate relations codified in 1648 constitute the normative core of international law: 1) the government of each country is unequivocally sovereign within its territorial jurisdiction, and 2) countries shall not interfere in each other's domestic affairs." (74; in Osiander 2001, 261) For Benno Teschke (2003), these orthodox accounts of the Peace (1648) have thus formed a 'Westphalian narrative;' a narrative that gives the discipline a "sense of theoretical direction, thematic unity,

80 I adopt Jürgen Osterhamel's (1995) definitions of colonialism and imperialism. "Colonialism is a relationship of domination between an Indigenous (or forcibly imported) majority and a minority of foreign invaders. The fundamental decisions affecting the lives of the colonized people are made and implemented by the colonial rulers in pursuit of interests that are often defined in a distant metropolis. Rejecting cultural compromises with the colonized population, the colonizers are convinced of their own superiority and of their ordained mandate to rule." (Osterhamel 1995, 17) By contrast, "Imperialism' is the concept that comprises all forces and activities contributing to the construction and the maintenance of transcolonial empires. Imperialism presupposes the will and the ability of an imperial centre to define as imperial its own national interests and enforce them worldwide in the anarchy of the international system. Imperialism thus implies not only colonial politics, but international politics for which colonies are not just ends in themselves, but also pawns in global power games [italics in the original]." (Osterhamel 1995, 21) 
and historical legitimacy."81 (2) In this way, the Westphalian narrative offers a disciplinary structuring device that allows IR to treat the evolution and expansion of international society as an encapsulated and linear process - 'encapsulated' in the sense that it almost exclusively focuses on intra-European norms and values, and 'linear' in the sense that it depicts these norms and values as being projected into the non-European world over time. It is this narrative that has subsequently obscured insights like those of Grotius pertaining to the acquisition of property and the divisibility of sovereignty under the Law of Nations.

As the work of scholars like Keene (2002) and Teschke (2003) shows, the Westphalian narrative has thus naturalized assumptions about international relations in ways that obscure the role of non-European and non-state societies in its constitution. ${ }^{82}$ As a consequence, this has inhibited critical inquiry into the historical evolution and expansion of international society, which as Keene (2002) suggests, rests at the heart of Grotius' political philosophy. Grotius' attention to property rights and the sub-division of sovereignty reveals,

[...] a remarkably prescient analysis of how Europeans would conduct themselves over the next three centuries in the world beyond Europe, appropriating vast swaths of land and artfully manipulating treaties with Indigenous rulers, not even noticeably 'unequal' ones, so as to give themselves a share in the latter's public authority. (58-59)

\footnotetext{
${ }^{81}$ Andreas Osiander (2001) similarly notes, "[a] typical founding myth, [Westphalia] offers a neat account of how the 'classical' European system, the prototype of the present international system, came about. Conveniently and comparatively, it explains the origin of what are considered the main characteristics of that system, such as territoriality, sovereignty, equality, and nonintervention. It fits perfectly with the accepted view of what international relations is about, or at least has "traditionally been about: relations of a specific kind (with the problem of war occupying a central position) among actors of a specific kind (territorial, sovereign legally equal)." (266)

82 The naturalized assumptions of the Westphalian narrative speak to the concerns of Steve Smith (2002), who warns, "Once established as common sense, theories become incredibly powerful since they delineate not simply what can be known but also what it is sensible to talk about or suggest. [...] Defining the common sense is therefore the ultimate act of political power." (13)
} 
In this chapter, I set out to build on Keene's (2002) argument by detailing the historical evolution and expansion of international society, paying special attention to the constitution of international law through the interaction between European and non-European peoples; this focus draws attention to the function of property rights and the sub-division of sovereignty in facilitating European expansion during the colonial period. To achieve this, this chapter proceeds in four sections:

1. The first section critically evaluates the Westphalian narrative in two stages. First, it casts doubt over the historical evidence used to support it, and second it details the disciplinary implications of its Euro-centric and statecentric biases. In particular, it highlights the narrative's role in marginalizing non-European political history and in producing what Sanjay Seth (2010) refers to as a 'sanitized' account of the expansion of European/international society.

2. The second section details an alternative account of the inception and expansion of international society, by paying attention to the concept of civilization. Drawing on the work of Prasenjit Duara (2004), it argues that the concept of civilization helped structure contemporary relations between international society and Indigenous peoples by delineating self from other, while justifying a process that sought to subsume the other into the self. With this as a basis, the section then turns to an analysis of the concept of civilization, as used by Pope Innocent IV to structure relations between Christian Europe and the non-Christian world - a moment Brett Bowden 
(2004) contends was seminal in the evolution of European relations with the 'uncivilized' world.

3. The third section examines the work of Francisco de Vitoria. Writing at a critical juncture in world history (i.e. the colonial encounter), Vitoria both collapses and reasserts a self-other dichotomy that juxtaposes civilized European society against uncivilized Amerindian society. This section then details how this dichotomy informed Vitoria's legal opinion of SpanishAmerindian relations; in particular, the latter's sovereign rights under the Law of Nations.

4. The fourth section details the role of international law in advancing the expansion of European society through settler colonialism. This is achieved in two sections. First, it highlights continuity between Vitoria's jurisprudence and subsequent generations of international law - i.e. the Doctrine of Discovery (the Doctrine). Second, it details the application of the Doctrine in the United States (US), paying special attention to its role in subsuming Indigenous peoples within the state, through a process that aimed to sub-divide Indigenous sovereignty.

\section{The Westphalian narrative and its critics}

The orthodox account of the Peace (1648) is both pervasive and influential, establishing a basis with which to trace the evolution of a once regional society of European nations into an international society of states. In addition to being criticized for its role in promoting a Eurocentric account of international relations, the Westphalian narrative has also been critiqued for its role in distorting the 
historical evidence that supports it. Andreas Osiander (2001), for instance, argues that contemporary articulations of the Westphalian narrative can be traced to the work of Leo Gross, who in 1948 depicted the settlement as 'the majestic portal' that led to the creation of an inter-state system premised on the foundational institution of sovereignty. As Osiander (2001) notes however, Gross's claims are not sufficiently supported by the textual evidence. In a primary source analysis of the treaties that composed the Peace (1648) - the Treaty of Münster and the Treaty of Osnabrück - Osiander (2001) makes three revelations. First, he notes that the Peace (1648) actually limited the independence of the German states that were seeking independence from the Habsburg Empire (272). Second, he points out that neither of the treaties was in fact a pan-European charter with implications for the whole of Europe. ${ }^{83}$ And third, Osiander (2001) notes that neither of the treaties raised the issue of sovereignty explicitly; in fact, Osiander (2001) suggests that the concept of sovereignty was already well established in Europe and assumed implicitly by the settlements' signatories (267).

It is noteworthy that even Gross (1948) acknowledged that there was limited textual evidence to support his claims. Instead, Gross (1948) argued that "In order to find a more adequate explanation [for the significance of the Peace (1648)] it would seem appropriate to search not so much in the text of the treaties themselves as in their implications, in the broad conceptions on which they rest and the developments to which they provided impetus." (quoted in Osiander 2001, 265)

\footnotetext{
83 The conditions of the Peace of Westphalia specifically addressed: 1) the Holy Roman Empire and the King of France (the Treaty of Münster); and 2) the Holy Roman Empire and the Queen of Sweden (the Treaty of Osnabrück).
} 
However, Gross' (1948) 'contextual' approach is equally problematic, as it is likely that it was informed by the misrepresentation of the Peace (1648) by early $19^{\text {th }}$ century counter-revolutionaries of the then independent states of Germany. Indeed, Keene (2002) notes that these counter-revolutionaries were keen to use the Peace (1648) in a manner that buttressed claims against revolutionaries inspired by Napoleonic France. Amongst the most influential of these counter-revolutionaries, C.W. Koch, described the Peace (1648) as a turning point in modern politics, as it confirmed the sovereignty of the German states and their important role in maintaining the balance of power in Europe.

At a stroke, Koch had provided exactly what the counter-revolutionaries needed: an account of the traditional pattern of public order in the European political system that highlighted the importance of the balance of power between mutually independent sovereigns, but derived the legitimacy of that system from agreements between dynastic rulers rather than abstract principles of natural law [emphasized by the ideology of revolutionary France]. (Keene 2002, 21)

In this way, Keene (2002) suggests that contemporary scholarship on the Peace (1648), like Gross' (1948), has been conditioned by political spin. Moreover, it is through this contorted view of the Peace (1648) that IR has subsequently justified its Euro- and state-centric assumptions about the evolution and expansion of international society. ${ }^{84}$

\footnotetext{
${ }^{84}$ Turan Kayaoglu (2010) offers a similar argument, stating that "the Westphalian narrative was first developed by German historians and usurped by international jurists in the nineteenth century. According to its earliest formulation by German historians, the Peace of Westphalia allowed European states to establish an international order based on mutual independence, political tolerance, and the balance of power. This alleged Westphalian sovereign vision stood in stark contrast to the menacing Napoleonic imperial vision. Nineteenth-century jurists added an external dimension to the Westphalian narrative: lacking a Westphalia-like arrangement, non-European societies remained in political disorder and religious intolerance." (3)
} 
To claim that contemporary international society originated in Europe, with the Peace of Westphalia, the orthodox English School emphasizes historical 'facts' to substantiate its Eurocentric account. In The Expansion of International Society, for instance, Hedley Bull and Adam Watson (1984) cite the 'historical record.' According to them,

The present international political structure of the world - founded upon the division of mankind and of the earth into separate states, their acceptance of one another's sovereignty, of principles of law regulating their coexistence and co-operation, and of diplomatic conventions facilitating their intercourse - is, at least in its most basic features, the legacy of Europe's now vanished ascendancy. Because it was in fact Europe and not America, Asia, or Africa that first dominated and, in so doing, unified the world, it is not our perspective but the historical record itself that can be called Eurocentric. (2)

In light of the suspect historical foundations that support the Westphalian narrative, however, Bull and Watson's (1984) reliance on the 'historical record' should be treated with caution. Moreover, it is by recognizing their account to be tenuous that a space opens with which to expose the Westphalian narrative to critical scrutiny; specifically its claim that international society established a basis for inter-state order, and that this order has led to the conditions necessary for the betterment of humankind.

This sense of triumphalism can only be justified by a rigid historical focus on the intra-European order created by the Peace (1648); and, it uncritically assumes that the colonial expansion of European society was in the long-term a beneficial development for international relations because it universalized Westphalian norms that regulated state-behaviour. Turan Kayaoglu (2010) highlights some of the issues with this point of view, when he observes that "[t]his [Eurocentric] bias maintains that Westphalia created an international society, consolidating a 
normative divergence between European international relations and the rest of the international system." (193) He continues,

This dualism is predicated on the assumption that with Westphalia European states had solved the anarchy problem either through cultural or contractual evolution. Non-European states, lacking this European culture and social contract, remained in anarchy until the European states allowed them to join the international society-upon their achievement of the "standards of civilization." (Kayaoglu 2010, 193)

In turn, Kayaoglu (2010) observes that "[t]he Westphalian narrative distorts the emergence of the modern international system and leads to misdiagnoses of major problems of contemporary international relations." (193) In addition, a "commitment to the Westphalian narrative prevents international relations scholars from adequately theorizing about international interdependencies and accommodating global pluralism." (Kayaoglu 2010, 193)

Kayaoglu's (2010) analysis points not only to deficiencies in the Westphalian narrative, but also to its negative implications for IR scholarship: 1) distorting the historical evolution/expansion of international society; and 2) impeding the theorization of international interdependencies. Significantly, both these issues have been addressed in more detail by recent scholarship. Where the former is concerned, Sanjay Seth (2011) details how orthodox interpretations of the expansion of international society articulate a 'sanitized' account. As Seth (2011) explains, the orthodox account of the expansion is one "of a period that includes the bloody conquest of the Americas, the transatlantic slave trade, the expropriation and sometimes genocide of Indigenous peoples, wars of conquest, land grabs, exploitation and oppression, [which] somehow manages to elide much of this history." (Seth 2010, 171) In fact, the orthodox account does not introduce non- 
European peoples into its narrative until the mid-20th century, at which point they are said to have been granted independence from colonial rule by meeting the standards of statehood. ${ }^{85}$ This is problematic on at least two grounds. First it depicts the integration of non-European peoples into international society established at Westphalia - as an inclusionary process, which "has only one powerful actor, the white man, who eventually comes to see that the very principles of his club mandate inclusion rather than exclusion." (Seth 2010, 171)

Second, Seth (2011) points out that this account depicts non-European peoples as passive recipients of European 'civilization.' In The Expansion of International Society (1984), for instance, Bull and Watson imply that the appearance of non-European states was something of a historical inevitability, as non-European peoples became aware of the benefits that statehood and membership in European society offered; specifically, a degree of order in an otherwise anarchic system. As Bull and Watson (1984) explain,

[...] the most striking feature of the global international society of today is the extent to which the states of Asia and Africa have embraced such basic elements of European international society as the sovereign state, the rules of international law, the procedures and conventions of diplomacy and international organization. (433)

For Seth (2011), these problems are connected to a failure on the part of orthodox accounts of the expansion of international society to critically evaluate the Euroand state-centric assumptions they make, resulting in an inadequate account of how non-European peoples were involved in the constitution of contemporary

\footnotetext{
${ }^{85}$ It is acknowledged that Bull and Watson (1984) do to some degree reference the role of European imperialism in the non-European world in facilitating the evolution of international society; however, they tend to downplay the gross abuses of power that this implied and their impact on non-European peoples.
} 
international relations. In this respect, Seth (2011) quotes Sheldon Pollock (2006), who in his reflection on the Western bias of the social sciences, argues that orthodox narratives of the Western tradition are "historically very peculiar, temporally very thin, and spatially a very narrow slice of human history." (quoted in Seth 2011, 180; Pollock 2006, 564) The "theory developed from that history fails to help us understand [...] what did happen elsewhere and how this might differ from what eventually produced the peculiar combination of culture and power in the modern world called the nation-state." (quoted in Seth 2011, 180; Pollock 2006, 564)

In addition to Seth (2011), Sebastian Schmidt (2011) observes that the Westphalian narrative has not only conditioned the history of disciplinary IR, but has also conditioned the way scholars interpret the contemporary dynamics of globalization. Speaking to Kayaoglu's (2010) insights into the role of the Westphalian narrative in shaping IR interpretations of international interdependencies, Schmidt (2011) observes that Westphalia oversimplifies interpretations of international order by serving as a 'conceptual foil.' According to Schmidt (2011),

[Westphalia] has helped scholars concerned with the study of globalization and growing international interdependence to orient their analyses of the state system and to define their arguments more clearly by serving as a conceptual foil: various incarnations of the Westphalia concept are essentially what interdependence is not, what transnationalism is not, and what integration is not. (615)

Indeed, "the vast majority of works that make use of the Westphalia concept do so in a cursory, uncritical fashion, in which it serves as a simple foil or analytical assumption." (Schmidt 2011, 615) In turn, Schmidt (2011) suggests that this can lead to two problems; first, "because the Westphalian system itself is often 
acknowledged as one that might never have actually existed in the world, its use as a starting point for investigations of change may lead scholars to exaggerate the magnitude of recent developments in international politics." (Schmidt 2011, 617) Second, it implies the "linear progression from some Westphalian configuration toward some "post-Westphalian" state of affairs: a movement from high levels of state autonomy in political, economic, and social affairs to lower levels of autonomy." (Schmidt 2011, 618)

In addition to these problems, a third might be added; specifically, by focusing on the evolution and expansion of the state, the Westphalian narrative overlooks relations between the members of international and world society. Instead, the Westphalian narrative places a heavy emphasis on inter-state relations, and the norms and values that sustain them. In light of all this, the combined insights of Kayaoglu (2010), Seth (2011) and Schmidt (2011) are suggestive of the need to jettison the traditional account of the Peace (1648). As Schmidt (2011) explains,

Given subsequent scholarship on the nature of globalization and the actual impact of the Peace on the development of the international system, it should be acknowledged that the Westphalia concept has outlived its usefulness. [...] Continued references to a Westphalian system and the like are far more likely to obscure than illuminate. (619)

As subsequent chapters of my thesis reveal, the constitution of contemporary international relations hinged closely on the construction of a self-other relationship between European and non-European, civilized and uncivilized. This dichotomy has not only played a fundamental role in shaping international relations, but has also persisted in one of its primary institutions, international law. From this standpoint, 
globalization has not necessarily implied a departure from foundational assumptions about self and other, so much as it has tried to accommodate them in a world marked by structural changes and shifting power dynamics. This is highlighted by the persistence of a discourse premised on the European account of civilization, which continues to influence relations between states and Indigenous peoples. In the next section, I begin to trace this discourse.

\section{Civilization, the self, and the other}

In concluding his critical analysis of the expansion of international society, Seth (2011) remarks that what makes 'the international' interesting is that it sheds light, "on questions which are of broad political, theoretical and epistemological importance." (183) But, he also finds that "a great deal of IR theory is an obstacle to a recognition and exploration of this, rather than a guide to it, for it seems content to naturalise what it could problematize, and to assume that which it should deconstruct: whence the need for its critique." (Seth 2011,183) This critique can be levied against the Westphalian narrative, which naturalizes both Eurocentric and state-centric assumptions about the evolution and expansion of international society, thereby failing to account for non-European peoples and/or for the relational construction of (European) international society. This is not to diminish the prominent role European society played during the colonial period however; as Jürgen Osterhammel (2005) reminds us, between 1500 and 1920, "most of the world's places and peoples came under at least nominal control of Europeans: all of the Americas, all of Africa, nearly all of Oceania, and [...] the better part of the Asian continent." (3-4) Rather, it is to suggest that an account of the evolution and 
expansion of international society must take account of its constitution by European and non-European peoples alike. As Seth (2011) puts it,

[...] any satisfactory account of the emergence of the modern international system cannot simply chart how an international society that developed in the West radiated outwards, but rather needs to explore the ways in which international society was shaped by the interactions between Europe and those it colonised. (183)

One avenue for conceptualizing the evolution and expansion of international society is through the concept of civilization. As a number of scholars suggest, the concept of civilization has played a formative role in the constitution of self-other relations over the course of history. The ancient Greeks, for instance, drew on the concept of civilization to distinguish themselves from barbarians, whom they conceptualized as "people who did not speak Greek and were consequently by definition 'uncivilized'." (Keal 2003, 69) The implications of this perspective are highlighted in Aristotle's ideas about 'natural slaves,' whom he perceived as lacking in reason. Aristotle, in Book I of the Politics, proposed that reason could only be imparted to slaves by their natural masters; and since it was only the Greeks that were endowed with reason, it followed that a natural hierarchy existed between Greeks and barbarians - the former being natural masters, and the latter being the natural slaves of the former. This was premised on an organic description of the state; specifically, one that conceptualized it as being composed of a number of organic parts. Through this description, Aristotle argues that a natural hierarchy exists between elements of the body, with some controlling others. In the context of ancient Greek civilization, it subsequently followed that it was the civilized Greeks that controlled the uncivilized barbarians - as Aristotle states in the Politics, "among 
barbarians no distinction is made between women and slaves, because there is no natural ruler among them: they are a community of slaves, male and female." (Book 1) Moreover, it was on this basis that Aristotle could justify Greek slavery; specifically, as a type of benevolent enterprise that spread civilization to the uncivilized.

In this way, the ancient Greeks played an important role in articulating an account of civilization that at once distinguished between self and other, while justifying the self's role in asserting its power over the other. This was also picked up by the Romans, "who distinguished barbarians as those who did not live under Roman law; but by submitting to Roman law 'barbarians' could gain citizenship and admission to civilisation." (Keal 2003, 69) Significantly, similar accounts of civilization have also been employed by a number of non-European peoples. Muslims, for instance, characterized Europeans as infidels over the course of the Middle Ages, while imperial China maintained that it was the height of civilization. In both cases, it became the mission of civilized peoples to spread civilization to uncivilized peoples. In the case of imperial China, for instance, Prasenjit Duara (2004) notes that, "[i]n the older imperial formations, such as Chinese, it is certainly true that civilization or wenming could be seen mainly as a process: the spread of virtue from the moral center to barbarians and people with "depraved" customs." (2) And, in the case of India, Duara (2004) observes that "it took the form of what M. 
N. Srinivas has called Sanskritization, or the process of lower castes rising in the hierarchy by imitating upper castes." ${ }^{86}(2)$

Summarizing the meaning ascribed to civilization by various peoples, Duara (2004) explains that most accounts of civilization "have shared an understanding of "civilization" as a way of identifying and ordering value in the world." (1) Duara (2004) continues, "[t]he identification of value, however, sometimes implies the identification of a community of value, and civilization can also become the means of marking the Self from the Other." (1) Indeed, "civilization may resemble other identity forms like nationalism, with which it often becomes conflated. However, what distinguishes the civilizational idea from nationalism is its appeal to a higher, transcendent source of value and authority, capable of encompassing the Other." (Duara 2004, 1-2) It is in this way that the concept of civilization is applied in this thesis. Moreover, while it is acknowledged that nuances exist in the way that civilization has been applied by different peoples, Duara's (2004) insight into the role of civilization in encompassing the other into the self is of particular importance to understanding international society's evolution from a once regional society of nascent European empires to an international society of states. Indeed, with the overseas expansion of European society in the $16^{\text {th }}$ century, European conceptualizations of civilization proved important because of their role in defining legal relations with non-European peoples. As Robert Tignor (2005) observes of European colonialism, much of it premised itself on a civilizing mission. European colonialism "bespoke an overt sense of European superiority toward the rest of the

${ }^{86}$ Duara (2004) notes that "in both cases [Chinese and Indian], this process also met with groups that it could not or did not seek to civilize-they remained Other." (2) 
world and a powerful mission to bring civilization, whether it be Christianity or modernity, to the less fortunate." ${ }^{87}$ (Osterhammel 2005, viii)

It is difficult to identify a precise moment at which to begin an analysis of European conceptualizations of civilization, and their role in shaping contemporary international society. However, Brett Bowden (2005) suggests that a foundational moment in the articulation of self-other relations, premised on a European conceptualization of civilization, can be traced to the Middle Ages with the articulation of papal-infidel relations by Pope Innocent IV in 1245.88 Bowden (2005) contends that this moment marked one of the first authoritative legal opinions on Christian Europe's relations with non-Christian peoples. "Instigated by issues of dominium raised by the Crusades, Innocent IV sought to address the question: 'Is it licit to invade a land that infidels possess or which belongs to them?'” (Bowden 2005, 4) However, this moment is also significant because it marks a critical moment in history that witnessed the blending of classical scholarship and Christian theology, as one of the purposes of Innocent IV's legal opinion was to use humanist assumptions to advance the hierocratic purposes of the Church;

[...] the naturalistically inspired ideas later synthesized by Thomas and subsequent Christian Humanists were literally in the air. No one with as able and supple a legal mind as Innocent's could have afforded to ignore them. The task, in fact, was to tame them and make them "useful" for the Church. [...] Innocent's pontificate was literally caught between two ages, and an unceasing intellectual effort was required in order to maintain bridges between the theoretical onslaught of the approaching Renaissance and

\footnotetext{
87 This is echoed by Duara (2004), who observes that "while the concept of Western civilization was an important means of justifying imperialist domination of the rest of the world in the late nineteenth century, it was accompanied by the ideal of the "civilizing mission," a mission that exemplified the desire not (simply) to conquer the Other, but to be desired by the Other." (2)

${ }^{88}$ Pope Innocent IV's analysis of papal-infidel relations came in the form of a commentary on Pope Innocent III's Quod super his.
} 
receding glacial style of legal thought fossilized in papal hierocratic discourse. (Williams Jr. 1990, 43-44)

In this way, Innocent IV's articulation of papal-infidel relations can be viewed as an attempt to modify the approaches of ancient Greek philosophy - and its layered assumptions about civilization - with those of Church views about nonChristians. This can be observed in the way Pope Innocent IV answers the question of papal-infidel relations, as he tenders two key points; first, he articulates the legal right of the Church to exert influence over foreign peoples; and second, he achieves this by dividing the world into two categories of people: civilized Christians and uncivilized infidels. Specifically, Pope Innocent IV argued that the rights of infidels fall under two categories. On secular matters, "[m]en can select rulers for themselves [...] Sovereignty, possessions, and jurisdiction can exist licitly, without sin, among infidels, as well as the faithful." (Bowden 2005, 4) Where religious matters are concerned, Innocent IV argued that the Church could exert its authority over infidels because of their repudiation of the Christian religion; when infidels failed to heed the religious authority of the church, ${ }^{89}$ the pope was vested with the legal power to summon Christian armies and dispossess infidels from their lands. According to Innocent IV, infidels "[...] ought to be compelled by the secular arm and war may be declared upon them by the pope and not by anyone else." (quoted in Bowden 2005, 4-5)

By making this argument, Innocent IV connects European identity with a sense of 'civilizational' superiority; specifically, by making the claim that its religion

\footnotetext{
${ }^{89}$ Foreshadowing the work of Francisco de Vitoria (discussed below), Innocent IV identifies two actions that warrant the Church invading non-Christian lands: 1) when infidels prohibit proselytizing; and 2) when they occupy lands 'illegally.'
} 
entitled it to influence over non-Christians. In fact, both Bowden (2005) and Robert Williams Jr. (1990) note that Innocent IV was so convinced of this superiority that in the same year as his commentary was published, he sent two diplomatic missions to the Great Khan Guyak of the Mongol empire. Convinced of Latin Christendom's superiority, these missions brought letters instructing Guyak "in the rudiments of Christian doctrine" and the role of the Pope in guiding those to follow the faith or face punishment (Williams Jr. 1990, 4-5). Reception of the letters was not met with a passive reply..$^{90}$ Rather, the Great Khan responded by noting a number of flaws in the logic of the Pope, citing the fact that the Mongols had already conquered a vast amount of land that could seemingly not be done without the will of God. On this basis, Guyak called on Innocent IV to submit before him instead. In a letter sent to Innocent IV, Guyak writes, "come at once to serve and wait upon us. At that time, I shall recognize your submission." (quoted in Williams Jr. 1990, 5) As Williams Jr. (1990) notes of this interaction between Innocent IV and Guyak, Innocent IV's letters are significant because: 1) they demonstrate Europe's conviction of its own civilizational superiority; and 2) they foreshadow the basic assumptions that underpinned European expansion in the years to come. Williams Jr. (1990) explains,

As Pope Innocent's letters to the Great Khan of the Mongols signify, the 'West' has sought to impose its version of the truth on non-Western peoples since the Middle Ages. In seeking the conquest of the earth, the Western colonizing nations of Europe and the derivative settler-colonized states produced by their colonial expansion have been sustained by a central idea: the West's

\footnotetext{
${ }^{90}$ It might be added that in addition to foreshadowing the assumptions of European colonialism, the interaction between Innocent IV and Guyak also foreshadowed the fact that non-European peoples would not simply comply with European pressure.
} 
religion, civilization, and knowledge are superior to the religious, civilization, and knowledge of non-Western peoples. ${ }^{91}$ (Williams Jr. 1990, 6)

\section{Vitorian jurisprudence and European colonialism}

In his critical analysis of the concept of European civilization, Brett Bowden (2005)

identifies the important influence of Innocent IV on subsequent generations of European legal scholars. Innocent IV is "significant because of the influence he would have on jurisprudential successors like Franciscus de Vitoria and Hugo Grotius, the widely acclaimed founding fathers of international law." (Bowden 2005, 4) Influenced by the jurisprudence of Innocent IV, Vitoria stands out as a particularly important figure in the evolution of international law for at least two reasons. First, Vitoria's jurisprudence is specifically concerned with colonial relations between the Spanish and the Amerindians. And, in this sense, his legal opinions on Spanish colonialism speak to a foundational moment in the development of international law. As Anghie (1996) explains,

The problem confronting Vitoria [...] was not the problem of order among sovereign states, but the problem of creating a system of law which could be used to account for relations between societies which he understood to belong to two very different cultural orders [...]. The essential point is that international law, such as it existed in Vitoria's time, did not precede and thereby effortlessly resolve the problem of Spanish-Indian relations; rather, international law was created out of the unique issues generated by the encounter between the Spanish and the Indians. (322)

Second, and related, Vitoria's jurisprudence fundamentally concerned itself with the concept of civilization; especially, as it applies to societal distinctions between self and other. In his Reflectiones, for instance, Vitoria explains that his jurisprudence

\footnotetext{
${ }^{91}$ Martin Wight (1977) echoes this, stating that these papal claims represent "the earliest version of the European assertion of superiority" (quoted in Bowden 2005, 8)
} 
focuses on Spain's relations with an "altogether barbarous [society], composed of Indians without law, without King, and without any certain place of abode, but go in troupes like savage beasts." 92 (quoted in Bowden 2005, 9)

Unlike Innocent IV's jurisprudence, Vitoria departs in one important respect. Rather than use hierocratic law as a basis for defining legal relations between the Spanish and the Amerindians, Vitoria opts to work through a natural law framework. As Nicolás Lewkowicz (2007) explains, this leads to a four-point legal framework for the conduct of relations between the Spanish and the Amerindians. First, Vitoria argues that all humans share basic rights grounded in nature; as such, it followed for him that Amerindians shared the same rights as the Spanish, regardless of their faith (Lewkowicz 2007, 87). Second, Spain could therefore not claim any right of ownership over non-Christian lands, despite this being codified into papal bulls of the $15^{\text {th }}$ century. ${ }^{93}$ According to Vitoria, "[u]nbelief does not destroy either natural law or human law; but ownership and dominion are based

\footnotetext{
92 Vitoria's jurisprudence was part of a wider dialogue concerning Spanish-Amerindian relations. Around the same time as Vitoria was articulating his views, Ginés Sepúlveda and Bartolomé de las Casas engaged in The Valladolid Debate (1550-1551). Nicolás Lewkowicz (2007) summarizes the positions of this debate accordingly; "Sepúlveda contributed to the debate with a tractate entitled Demócrates Alter, maintaining that the natives, as inferior human beings, had to be subjected to Spanish rule on the grounds that they were incapable of governing themselves. In addition to this, Spanish rule over the natives would prevent the practise of cannibalism, human sacrifices and idolatry as well as facilitate the evangelical role of the Church. Las Casas replied with his Apología, using the example of Aztec architecture in an attempt to 'prove' that the natives were indeed rational human beings [italics in the original]." (86)

${ }^{93}$ At roughly the same time as Spain was consolidating its power, the Portuguese had similarly begun to consolidate their own - with an eye to buttressing defences against their Spanish rival. It was in this context of heightened competition that the discovery of the Americas unleashed a political dilemma; specifically, the validity of Spanish title to newfound lands. The resolution was the institution of a territorial boundary demarcating Spanish and Portuguese title. Predating the Peace of Westphalia (1648) by over 150 years, the papal bull Inter Caetera (1493), granted Spain all lands south and west of a pole to pole line 100 leagues west and south of the Azores and Cape Verde Islands. The following year, this line was renegotiated by the two powers, resulting in the Treaty of Tordesillas (1494). According to its terms, the crowns of Portugal and Spain would observe a new pole to pole line more favourable to Portuguese interests along a meridian 370 leagues west of the Cape Verde Islands.
} 
either on natural law or human law; therefore they are not destroyed by want of faith." (quoted in Anghie 1996, 324) Third, Vitoria argued that the discovery of new lands could not in itself confer upon European powers an inherent right of possession to non-European lands (Lewkovicz 2007, 87). And fourth, he argued that by virtue of natural law's universality, both the Spanish and the Amerindians were required to respect it and its postulates; in particular, the natural right of a people to travel, trade and proselytize in foreign lands - in practice this right could only be exercised by the Spanish, since the Amerindians lacked the technology to travel overseas (Lewkowicz 2007, 87).

While this four-point framework has been conventionally interpreted as a defence of Amerindian property rights and sovereignty under the Law of Nations, ${ }^{94}$ scholars such as Anghie (1996 \& 2004), Bowden (2005) and Williams Jr. (1990) (and Carl Schmitt in Nomos of the Earth (1950) before them) have argued that Vitoria's jurisprudence was in fact intended to furnish Spain's colonial expansion. As Anghie (1996 \& 2004) explains, this occurs through an argument composed of two related parts: 1) a complex characterization of Amerindian identity; and 2) an elaboration of natural law (325). Where the former is concerned, it is noteworthy that Vitoria collapses the medieval distinction between Christian and infidel in the context of Spanish-Amerindian relations; specifically, he highlights the latter's capacity for reason and draws a parallel between Amerindians and Europeans. According to Vitoria, "[t]his is clear, because there is a certain method in their

\footnotetext{
94 This is the position of Lewkowicz (2007), who in discussing the fourth postulate argues that "any refusal [to secure this right] on their [the Amerindians] part ought not to give rise to a right of [Spanish] conquest." (87)
} 
[Amerindians'] affairs, for they have polities which are orderly arranged and they have definite marriage and magistrates, overlords, laws, and workshops, and a system of exchange, all of which call for the use of reason [..]." (quoted in Anghie 1996, 325) It is on this basis, that Vitoria can then justify his decision to situate the Amerindians within his natural law framework, and hold them accountable to the same laws governing intra-European relations. On account of their demonstration of reason, the Amerindians were entitled to the same legal rights and responsibilities as Europeans under a natural Law of Nations. However, it was also by situating Amerindians within this legal framework that Vitoria exposes them to a form of law fundamentally premised on Spanish norms and values.

The consequences of situating Amerindians within this natural Law of Nations were such that Amerindians became expected to abide by Spanish mores and customs; and in these respects, had to behave in accordance with Spanish culture. "Spanish identity is projected as universal in two different but connected dimensions of Vitoria's system; Spanish identity is both externalized, in that it acts as the basis for the norms of jus gentium, and internalized in that it represents the authentic identity of the Indian." (Anghie 2004, 37) Problematically, this inferred that failure on the part of the Amerindians to do so would be indicative of their savageness; specifically, because it would be indicative of a breach in reason and a failure to comply with natural law. Thus, when Vitoria introduces the fourth point of his natural law framework (see above), the Amerindians are presented with a dilemma; either they must comply with the colonial endeavours of the Spanish, or they can resist them and be branded as uncivilized savages. In other words, 
Vitoria's decision to incorporate Amerindians within a natural Law of Nations actually functions as a trapping device that reasserts Innocent IV's distinction between a self and other, by forcing Amerindians to adopt European civilization. In fact, it is this distinction between civilized Europe and the uncivilized Amerindians that would come to characterize Spanish society in the Americas. As Eric Wolf (1982) explains, "[t]he new society [...] came to be divided from the outset into "the natives of the land" [...] and Spaniards. [...] Above the native stood the Spaniards [...] who came to define themselves as "men of reason."” (131)

Making matters worse for the Amerindians, Vitoria's re-assertion of Innocent IV's self-other dichotomy served as the foundation upon which to validate Spain's violent appropriation of Amerindian lands and resources. By failing to abide by the natural Law of Nations, the Amerindians were liable to punitive actions by the Spanish in the form of just war. According to Vitoria, the Spanish "may enforce against them [the Amerindians] all the rights of war, despoiling them of their goods, reducing them to captivity, deposing their former lords and setting up new ones." (quoted in Williams 1990, 103) It is noteworthy however that this right is not extended to the Amerindians even when they are in compliance with natural law, since Vitoria assumed that a just war could only be undertaken by a Christian sovereign. Thus, Anghie (1996 \& 2004) concludes that by denying Amerindians a right to wage just war, Vitoria is denying Amerindians full sovereignty under the Law of Nations; "in the final analysis, the most unequivocal proposition Vitoria advances as to the character of the sovereign is that the sovereign, the entity empowered to wage just war, cannot, by definition, be an Indian." (Anghie 2004, 26) 
Moreover, it is this position that leads Vitoria to the view that just war not only serves a punitive function, it serves as the vessel with which to bring civilization to the Amerindians - Vitoria contends that "brotherly correction is required by the law of nature [when it is broken], just as brotherly love is. Since, then, the Indians are all not only in sin, but outside the pale of salvation, therefore, it concerns Christians to correct and direct them; nay, it seems that they are bound to do so [...]."(quoted in Williams Jr. 1990, 104)

Foreshadowing the League of Nations' mandates system by roughly 400 years (see chapter five) Vitoria articulates a basis for the imposition of European civilization upon non-Europeans. Specifically, Vitoria contends that the division of Amerindian sovereignty is in fact a beneficial action, as "[i]t might, therefore, be maintained that in their [Amerindian] interests the sovereigns of Spain might undertake the administration of their [Amerindian] country, providing them with prefects and governors for their own towns, and might even give them new lords" (quoted in Bowden 2005, 11) In this respect, Vitoria's jurisprudence is paradoxical as it lambastes hierocratic papal discourse for its role in marginalizing the Amerindians, while supporting the exclusive right of Christian peoples to wage just war by denying Amerindians sovereignty on account of their savageness. As Williams Jr. (1990) explains,

Hierarchical subjugation of the Indian, so repugnant to Victoria and other Humanist theorists when presented in hierocratic papal discourse, was regarded as eminently acceptable when explained as necessitated by the totalizing vision of reason contained in a natural Law of Nations. (103)

In the next section, I detail continuity between Vitoria's jurisprudence and subsequent generations of international law. In particular, I pay special attention to 
the role of the self-other dichotomy, as constituted through the concept of civilization, in defining European relations with non-European others.

\section{From Vitoria to the Doctrine of Discovery}

In his analysis of settler colonialism, ${ }^{95}$ Cole Harris (2004) inadvertently makes an important connection between the processes of colonial dispossession and the jurisprudence of Vitoria; specifically, Harris (2004) identifies three core features of settler colonialism that share striking similarities with Vitoria's jurisprudence. First, Harris (2004) notes that the motivation behind settler colonialism stemmed from European commercial interests and the acquisition of property rights in the new world; the same interests that inspired Vitoria to articulate a natural right to travel, trade and proselytize. Second, Harris (2004) indicates that the pursuit of these economic interests was premised on the material power of states and "a cultural discourse that located civilization and savagery and extolled the advantages for all concerned of replacing the latter with the former [italics removed]." ${ }^{\prime 6}$ (179) Grounded in the medieval distinction between Christian and infidel, these sources of power echo the relationship that Vitoria built between the 'civilizational' superiority of the Spanish and their exclusive right to wage just war and exert sovereignty over non-Christians. Finally, Harris (2004) notes that these colonial activities were undertaken through a set of disciplinary technologies that included the articulation and application of international law. Combined, "[a]ll these powers facilitated the

\footnotetext{
95 Settler colonialism refers to a process whereby "immigrants seize land from the Indigenous population and become the dominant population." (Spiegel et al 2012, 186)

${ }_{96}$ Harris (2004) distinguishes material power from a cultural discourse; here, I have combined them because of the theoretical approach taken by this thesis; specifically, its view that power comes in both material and discursive/social forms (see chapter three).
} 
emergence of a new, immigrant human geography, which became native peoples' most pervasive confinement [italics removed]." (Harris 2004, 179)

Harris' (2004) analysis reveals the influence of Vitoria's jurisprudence on the development and application of international law over the course of the colonial period, a view that is supported by Robert Miller (2006). Miller (2006) contends that Vitorian jurisprudence became part of a wider legal discourse that evolved into what he terms the Doctrine of Discovery (the Doctrine), a legal framework "developed by European, Christian countries to control their own actions and conflicts regarding exploration, trade, and colonization in non-European countries and was used as a justification for the domination of non-Christian, non-European peoples." (12) Shaped through the interaction of the expanding European powers, the Doctrine sought to establish legal grounds with which to dispossess Indigenous peoples by minimizing inter-European conflict. This was achieved through the creation of ten legal principles that denied Indigenous peoples external sovereignty, while granting Europeans exclusive property rights over newly 'discovered' lands. According to Miller (2006), these principles were:

1. First discovery entitled the first European power to discover new lands to hold property and sovereign rights over them;

2. Actual occupancy insisted that a discovering power must occupy discovered lands in reasonable time in order to claim full property and sovereign rights over them;

3. Preemption/European title granted a discovering power the exclusive right to buy land from Indigenous peoples residing on the land in question; 
4. Indian title implied the erosion of Indigenous property rights, who were now only allowed to sell their land to the discovering power;

5. Tribal limited sovereign and commercial rights referred to the restriction of Indigenous diplomacy and trade with the discovering European power;

6. Contiguity refers to the assumption "that Europeans had a Discovery claim to a reasonable and significant amount of land contiguous to and surrounding their settlements and the lands that they actually possess in the New World;"

7. Terra nullius literally means vacant lands, and refers to the argument that "if lands were not possessed or occupied by any person or nation, or were occupied by non-Europeans but not being used in a fashion that European legal systems approved, the lands were considered to be empty and waste and available for Discovery claims;"

8. Christianity entitled Christian peoples to superior rights over non-Christian peoples with respect to land, sovereignty and self-determination - allowing Christians to trump the rights of non-Christians following discovery;

9. Civilization was a concept used by Euro-Americans to justify their expansion as a means of bringing uncivilized peoples civil society, authorizing paternalism and guardianship powers;

10. Conquest refers to both military conquest - i.e. just war - and to the effect that military conquest has on the property rights of the conquered peoples (3-4).

Although individual principles of the Doctrine were applied instrumentally by colonizing powers in different colonial endeavours, the Doctrine's application as 
a unified body of law was largely restricted to settler states like Australia, Canada, New Zealand and the United States (US). In these states, the Doctrine not only served to dispossess Indigenous peoples of their lands, but also to consolidate the territorial sovereignty of the colonizing power. As Williams Jr. (1990) observes,

The history of the American Indian in Western legal thought reveals that a will to empire proceeds most effectively under a rule of law. In the United States, and in other Western colonized states, that rule begins with the Doctrine of Discovery and its discourse of conquest, which denies fundamental human rights and self-determination to Indigenous tribal peoples (325)

Recognizing this, a number of scholars have pointed to a series of US Supreme Court cases heard in the early $19^{\text {th }}$ century by former diplomat Chief Justice John Marshall, as being indicative of how the Doctrine served this purpose. Two of these cases stand out in particular: 1) Johnson versus M'Intosh (1823); and 2) Cherokee Nation versus Georgia (1831). To give context to both cases however, it should be noted that the early $19^{\text {th }}$ century was a pivotal moment in the political history of the US; having recently defeated the English in the War of Independence (1776), the US was eager to consolidate its power on the North American continent through westward expansion and the assertion of its territorial sovereignty.

It was in this context that Chief Justice Marshall (1823) heard the Johnson case, a case between two white property owners contesting their rightful title to large plots of land on what was Piankeshaw territory. Johnson (the plaintiff) claimed the land based on his private purchase of it from the Piankeshaw tribe, while M'Intosh (the defendant) claimed it based on his purchase of a federal land 
patent acquired through the US federal government. ${ }^{97}$ For the court, the fundamental question was thus whether the Piankeshaw had a right to sell their property. To answer this question, Marshall's (1823) opinion advanced in two stages. First, Marshall (1823) turned to a historical analysis of European expansion and its relationship to international law; referring to the Doctrine, Marshall (1823) explains that "all the nations of Europe, who have acquired territory on this continent, have asserted in themselves, and have recognized in others, the exclusive right of the discoverer to appropriate the lands occupied by the Indians" (quoted in Miller 2006, 52). It was on this basis that Marshall (1823) upheld the argument that Indigenous peoples 'discovered' by Europeans had their right to sell private property limited. Second, Marshall (1823) explains that by virtue of the US's victory in the War of Independence (1776), all rights acquired by England through discovery had been devolved to the US' federal government, which now retained the exclusive right to buy and sell Indigenous lands.

Working through this logic, Marshall (1823) used existing principles of international law to confirm that M'Intosh was indeed the true owner of the contested land; specifically, because his purchase of it had occurred through the only body with the right to sell it. By using the Doctrine in this way, Marshall (1823) limited Indigenous property rights by forcing Indigenous peoples into transactions with the US government; and, by implication, denied Indigenous peoples a right to

\footnotetext{
${ }^{97}$ In reality, the two plots of land did not actually overlap one another. In fact, there is some evidence that the Plaintiff knew this, but chose to ignore it in order to obtain a ruling on the broader issue of private land purchases. "Mapping the United Companies' claims alongside McIntosh's purchases as enumerated in the district court records shows that the litigants' land claims do not overlap." (Kades 2001, 99)
} 
exercise external sovereignty (i.e. by limiting the capacity of Indigenous peoples to enter into legal relations with private and/or public entities, Marshall reduced their capacity to engage in international relations). Accordingly, Williams Jr. (1990) observes that "Johnson, a case involving two white litigants, effectively denied American Indian tribes recognizable full legal title to their ancestral homelands under the Doctrine of Discovery, which had been adopted by Marshall and the Court as the domestic law of the United States." (313) In addition to denying Indigenous peoples these rights however, it is important to remember that Marshall's ruling in the Johnson case (1823) was also an implicit defence of Western expansion on two grounds. First, it assumed that the Doctrine was a legitimate body of international law that could validate the appropriation of Indigenous lands; second, it assumed that the Doctrine could be used as a basis for domestic law and to facilitate the appropriation and redistribution of Indigenous lands by the government and to westward settlers.

Ensconced within the territorial boundaries of the US, and now formally denied full property and external sovereignty by the Supreme Court, Indigenous peoples residing within the US were faced by the additional challenge of US westward expansion in the years following the Johnson case (1823). By the early 1830s, tensions provoked by US imperial ambitions were becoming increasingly more evident in relations between the state of Georgia and the Cherokee Nation. With an interest in consolidating and expanding its territorial sovereignty, the state of Georgia began looking for ways to motivate the relocation of the Cherokee Nation, whose territory was ensconced within the borders of the state. In an effort to 
achieve this goal, Georgia's legislature began passing laws in the late 1820s with the purpose of extending the state's legal powers over the Cherokee, thereby hoping to entice the Cherokee Nation into signing a treaty that would see them relocate west of the Mississippi. In 1827, for instance, Georgia "attempted to extend the jurisdiction of [its] courts in counties near the Cherokee Nation over crimes by or against Georgia citizens committed in the Cherokee Nation." (Norgren 2004, 46) Emboldened with the election of President Andrew Jackson in 1828 - a proponent of 'Indian removal' and a major advocate of US westward expansion - Georgia passed legislation that sought to erode the internal sovereignty of the Cherokee Nation. As Jill Norgren (2004) explains, Georgia,

[...] enacted another jurisdiction law [...] through which the state intended immediately to make all white people living in the Cherokee Nation in 1830 subject to the laws of Georgia. More threatening still, the legislation stated that Georgia would consider all Cherokee laws and customs null and void as of June 1, 1830. If successful, the laws would have made all Indians living under the jurisdiction of the Cherokee Nation in 1830 subject to the laws of Georgia as second-class citizens of color lacking the political and legal rights of whites, including the right to testify against whites in a Georgia court. (47)

Because of the hostile measures taken by the state of Georgia, the Cherokee Nation - led by principal Chief John Ross - turned to the Supreme Court in the hopes of obtaining an injunction against the state of Georgia. ${ }^{98}$ In the bill sent to the Supreme Court requesting a hearing before it, Cherokee Nation - represented by attorney general William Wirt - made its appeal by emphasizing the Cherokee Nation's existence as a distinct political society entitled to sovereignty. "That, from

\footnotetext{
98 Prior to this, John Ross of the Cherokee Nation embarked on a diplomatic mission to Washington, DC, to garner Congressional support against Georgia. Despite his best efforts, Ross' delegation was informed on his visit that President Jackson would support the state of Georgia and its legislation. In Jackson's view, the states that comprised the United States were independently sovereign, and federal involvement within them would constitute a breach of their sovereignty.
} 
time immemorial, the Cherokee Nation have composed a sovereign and independent State, and in this character have been repeatedly recognized, and still stand recognized by the United States, in the various treaties subsisting between their nation and the United States." (Cherokee Nation versus Georgia, 30 US 1, 1831) In fact, it is noteworthy that this bill substantiates this claim by situating it in a discourse centered on the concept of civilization. ${ }^{99}$ In what was perhaps an attempt to pre-empt the Supreme Court from dismissing the Cherokee as uncivilized, Ross highlights the fact that the Cherokee had taken measure to meet the principles of European civilization as required by treaties between themselves and the US; "the bill asserts that great progress has been made by the Cherokees in civilization and in agriculture."100 (Cherokee Nation versus Georgia, 30 US 1, 1831) With this argument being made, the central question confronting the Supreme Court was whether the Cherokee Nation could rightly be considered a distinct political society with sovereign rights.

\footnotetext{
${ }^{99}$ Complicating the Supreme Court decision was the fact that the Cherokee were amongst what were considered the 'five civilized tribes' of the United States, in large part due to the fact that the Cherokee had successfully integrated European customs with their own cultural heritage - this included formation of a European-style government that governed a defined territory.

100 According to the syllabus of the Cherokee Nation versus Georgia ruling, 30 US 1 (1831) ,"The [Cherokee] bill alleges, from the earliest intercourse between the United States and the Cherokee Nation, an ardent desire has been evinced by the United States to lead the Cherokees to a greater degree of civilization. This is shown by the fourteenth article of the treaty of Holston, and by the course pursued by the United States in 1808, when a treaty was made giving to a portion of the nation which preferred the hunter state a territory on the west of the Mississippi in exchange for a part of the lower country of the Cherokees; and assurances were given by the president that those who chose to remain for the purpose of engaging in the pursuits of agricultural and civilized life in the country they occupied might rely "on the patronage, aid, and good neighbourhood of the United States." The treaty of 8th July, 1817, was made to carry those promises into effect, and, in reliance on them, a large cession of lands was thereby made; and in 1819, on the 27th February, another treaty was made, the preamble of which recites that a greater part of the Cherokee Nation had expressed an earnest desire to remain on this side of the Mississippi, and were desirous to commence those measures which they deem necessary to the civilization and preservation of their nation, to give effect to which object without delay, that treaty was declared to be made, and another large cession of their lands was thereby made by them to the United States."
} 
Despite Ross' efforts to defend the sovereign rights of the Cherokee - and the decidedly mixed opinions of the Justices on the question of Cherokee statehood Chief Justice Marshall (1831) ruled that the case could not be heard by the Supreme Court because of a distinction between a state and a foreign state. In fact, it is noteworthy that Marshall (1831) begins his legal opinion by recognizing the Cherokee as a distinct political society. Referencing sovereign-to-sovereign treaties made between the US government and the Cherokee Nation, Marshall (1831) concludes that "[t]he acts of our government plainly recognize the Cherokee nation as a state, and the courts are bound by those acts." (Cherokee Nation versus Georgia, 30 US 1 [5 Peters], 1831) Despite his apparent acknowledgement of Cherokee sovereignty however, Marshall (1831) continues by arguing that the case could not be heard by the Supreme Court because the Cherokee - despite their advances in civilization - remained dependent upon the benevolence of the United States. In terms strikingly similar to those of Vitoria, Marshall (1831) concludes that Indigenous tribes "may, more correctly, perhaps, be denominated domestic dependent nations." (Cherokee Nation v. Georgia 30 US 1 [5 Peters], 1831) He continued, "[...] they are in a state of pupilage. Their relation to the United States resembles that of a ward to his guardian." (Cherokee Nation versus Georgia, 30 US 1 [5 Peters], 1831) Speaking in paternalistic tones that emphasize the civilizational superiority of the US, Marshall (1831) explains,

They [the Cherokee] look to our government for protection; rely upon its kindness and its power; appeal to it for relief to their wants; and address the president as their great father. They and their country are considered by foreign nations, as well as by ourselves, as being so completely under the sovereignty and dominion of the United States, that any attempt to acquire their lands, or to form a political connexion with them, would be considered 
by all as an invasion of our territory, and an act of hostility. (Cherokee Nation versus Georgia, 30 US 1 [5 peters], 1831)

In just a few short years following this ruling, the Cherokee Nation would be forcibly removed from their ancestral lands within the state of Georgia and relocated to land west of the Mississippi, in what is today referred to as the Trail of Tears. Perhaps anticipating the violence of this forcible dislocation, it is significant to note that in 1832, Chief Justice John Marshall ruled favourably in a case that once again pitted the Cherokee Nation against the state of Georgia. ${ }^{101}$ Despite finding precedents for Cherokee sovereignty, Marshall's ruling was largely unenforced by President Jackson, who had passed the Indian Removal Act in 1830 and was keen on seeing the westward expansion of the United States through to its completion. In effect, the decisions reached by the Marshall court in M'Intosh versus Johnson (1823) and Cherokee Nation versus Georgia (1831) reveal three interrelated insights about the early $19^{\text {th }}$ century and the values/norms of the Doctrine: 1) they reveal the function of international law as a tool of conquest, used by states to facilitate the expansion and consolidation of territorial sovereignty; 2) they reveal the underlying assumption of European civilizational superiority within international law and the role of this assumption in justifying the denial of Indigenous property rights and the sub-division of Indigenous sovereignty; 3) they

\footnotetext{
101 This case was titled Worcester versus Georgia, in which two white clergymen did not follow the laws of Georgia in obtaining a permit to live on the territory of the Cherokee Nation. Sent to jail, these men were supported by the Cherokee Nation which once again turned to the Supreme Court. In what seems a surprising about face, Chief Justice Marshall in this instance argued that Georgia had violated the sovereignty of the Cherokee Nation by imposing the requirement of a permit to reside on the territory of the Cherokee Nation. On this basis, it ordered that the clergymen be freed on the assumption that the Cherokee exercised internal sovereignty, which could not be violated. Powerless to enforce the order without Presidential support, little was done to uphold the ruling and prevent the fate of the Cherokee Nation.
} 
demonstrate how international laws pertaining to Indigenous sovereignty were used over the course of several centuries to subsume and ensconce Indigenous peoples within the territorial boundaries of settler states.

\section{Conclusion}

As a disciplinary narrative, Westphalia has provided IR with a "sense of theoretical direction, thematic unity, and historical legitimacy." (Teschke 2003, 2) Despite its disciplinary functions however, critical scholars like Turan Kayaoglu (2010), Edward Keene (2002), Sanjay Seth (2011) and Sebastian Schmidt (2011) have revealed that the Westphalian narrative distorts the historical evolution and expansion of international society. As these scholars point out, the Westphalian narrative premises itself on Eurocentric assumptions that lead to a valorization of the state; specifically, as a vessel for order in international relations. In turn, the Westphalian narrative - or as Teschke (2003) calls it, the Westphalian myth - has led to a triumphant account of the expansion of international society. It suggests that the values and norms generated by states brought order to much of the world as Europeans expanded their society outward, and into the non-European world. It is in this way that the Westphalian narrative has implicitly informed disciplinary understandings about the relationship between international and world society. Recalling that world society has been traditionally conceptualized as a vast assembly of non-state actors, it follows for those that ascribe to the Westphalian narrative that non-state actors played a secondary role in the early evolution of modern international relations. Indeed, if one treats the evolution and expansion of international society as a linear process emanating out of Europe and into the non- 
European world, it follows that the most important actors were not the nonEuropean, non-state people, but rather the nascent states of Europe.

How then does a shift in the way that the evolution and expansion of international society evolved affect our conceptualization of relations between international and world society? To begin, we may recall the critiques levied at Westphalia by Kayaoglu (2010), Keene (2002), Seth (2011) and Schmidt (2011).102 First, Kayaoglu (2010) and Schmidt (2011) noted that the Westphalian narrative has greatly oversimplified interdependencies between state and non-state actors; especially, in the context of contemporary globalization. Second, Kayaoglu (2010) and Seth (2011) explain that the Westphalian narrative also fails to account for the non-European world. Moreover, both these points lend credence to Keene's (2001) observation that the European society of states, which evolved out of Westphalia, constructed norms and values that helped it maintain intra-European order, while facilitating aggressive expansion and disorder in the non-European world. Taking these criticisms into account, it has been proposed that a preferable way to conceptualize the evolution and expansion of international society is through the concept of civilization. The concept of civilization sheds light on relations between international and world society; specifically, as those between self and other, and in the context of international society's expansion, as those between European and non-European.

\footnotetext{
102 Although Seth (2011) aims his critique at the orthodox account of international society's expansion, I include him in this group of 'critical Westphalian authors' because his critique speaks directly to the assumptions that the Westphalian narrative makes about expansion.
} 
In addition, the concept of civilization also highlights an underappreciated point about self-other relations. As Prasenjit Duara (2004) reminds us, the concept of civilization is value-laden; it is not simply about delineating self from other, but also about rationalizing the incorporation of the other into the self. As noted above, this was evidenced by a persistent effort on the part of legal thinkers to justify European expansion as a process of inclusion. Working through a blend of humanist and hierocratic law, Pope Innocent IV justified European expansion in cases where Europeans were impeded from spreading the word of God. Working through a natural law framework, Vitoria similarly argued that Spanish colonialism could be justified in cases where the Amerindians violated Spanish norms and customs by breaching the Law of Nations - while Pope Innocent IV and Vitoria both viewed violent expansion as serving a punitive function, they also conceptualized it as a vessel with which to bring civilization to the uncivilized world. Recognizing this, two further insights can be drawn; first, it highlights the fact that despite changes to the meaning of civilization, the basic purpose of the concept has remained twofold: 1) to delineate self from other; and 2) to justify subsuming the other into the self. Second, the capacity of Vitoria to impose his concept of civilization on others is suggestive of the remarkable amount of power Europeans exercised during the colonial period. ${ }^{103}$ It was with this power that Europeans would subsequently define the norms and values of international society on Eurocentric assumptions about civilized-Europe's relationship with uncivilized non-Europeans.

\footnotetext{
103 I specifically refer to Vitoria here, and not Pope Innocent IV, because Pope Innocent IV ruled during a time when Europe was under threat by powerful empires, such as the Mongolian empire (see above).
} 
An expression of these norms and values coalesced around the Doctrine of Discovery, which established ten principles for the 'orderly' expansion of European empires. Indeed, the Doctrine helped ensure intra-European order by defining a legal basis for colonial activities. In his work, Keene (2002) has shed considerable light on this, explaining how European norms and values served the dual purpose of maintaining intra-European order, while facilitating colonial expansion in the nonEuropean world. What has often been missed by IR scholarship, however, is how these norms and values - centered on the concept of civilization - have been incorporated by states at the domestic level to define their relations with non-state and sub-state peoples. As suggested above, for instance, the US applied the Doctrine in such a way so as to advance its state-building enterprise - in the context of the Cherokee cases, the US subdivided Indigenous sovereignty so as to assert exclusive property rights and advance Western expansion. And, this was fundamentally premised on the articulation of a self-other relationship that characterized Indigenous peoples as uncivilized and/or lacking in socio-political development. Indeed, it was on this basis that the US Supreme Court could justify the subdivision of Cherokee sovereignty; specifically, on the basis that it was to their benefit (i.e. as a process that brought them civilization). As Chief Justice John Marshall put it, Cherokee-US government relations were like 'those of a ward to his guardian.' (Cherokee Nation versus Georgia, 30 US 1 [5 Peters], 1831).

Significantly, the application of the Doctrine in the domestic context of the US also foreshadowed a transition in the way civilization was conceptualized by the early Western members of international society. Moving from hierocratic, humanist 
and natural law frameworks, $19^{\text {th }}$ century positive-law jurists finally began to associate civilization more closely with sovereign statehood. Just as Chief Justice John Marshall denied the Cherokee sovereignty on account of their failure to demonstrate key features of European statehood, so too would positive-law jurists deny non-European countries standing in international society on account of their failure to meet the hallmarks of European socio-political organization - as defined by an explicit legal principle which would come to be known as the Standard of Civilization (the Standard).104 In effect, the Standard's state-centric assumptions about civilization would establish a clear hierarchy of relations between state-based and non-state societies. In the next chapter, I turn to a more detailed analysis of these relations through the concept of civilization; paying special attention to how this concept's association with sovereignty helped justify the exclusion/marginalization of Indigenous peoples from sharing legal equality with the members of international society. Moreover, I describe how this exclusion was in fact perpetrated by a process of 'inclusion;' specifically, a process that sought to subsume Indigenous peoples within the 'civilized' state.

\footnotetext{
104 As discussed in the following chapter, the hallmarks of European socio-political organization, as defined by the Standard were: 1) the capacity to guarantee basic rights to its citizens and to foreigners; 2) to exist as an organized political bureaucracy; 3 ) to adhere to international law; 4) to maintain adequate and permanent diplomatic channels with other states; and 5) to conform to the norms and practices of international society. (Gong 1984)
} 


\section{Chapter five \\ Civilization and the fermentation of European international law}


By the late 19th century, there was a very clear division in the world between two different patterns of political and legal order. Within Europe, international order was supposed to provide for peaceful coexistence in an anarchic and plural world by encouraging toleration: the fundamental norm governing relations between European states was therefore the reciprocal recognition of each state's equality and independence with regard to its territorial sovereignty. Beyond Europe, international order was intended to promote civilization: the fundamental norm governing relations between European states and non-European peoples was that the latter were backward and that some of the sovereign prerogatives of Indigenous rulers ought to be held by more advanced Europeans in order to introduce the economic, political and judicial benefits of civilized life.

- Keene 2002, 147

Between 1884 and 1885, representatives of Europe's leading powers met in Berlin to discuss the partition of Africa into exclusive economic trading zones. The purpose of the Berlin Conference was to create a negotiated agreement that could facilitate order amongst the members of European society during a period of rapid imperial expansion into Africa; in this way, it bears striking similarities to the Doctrine of Discovery (the Doctrine). The General Act of the Berlin Conference (The General Act, 1885) granted European powers exclusive property rights over predefined territories in Africa as a means of avoiding inter-European rivalry over competing claims. To ensure that these rights were maintained, European powers were forced to demonstrate their 'occupancy' of the territory under the principle of effectivity. ${ }^{105}$ To achieve this, members of European society entered into protectorate and capitulation agreements with local peoples designed to usurp some of the latter's sovereign authority. As Charles Alexandrowicz (1973) explains, "[t]he Protectorate means a split of sovereignty and its purpose is to vest in the Protector rights of external sovereignty while leaving rights of internal sovereignty

105 The principle of effectivity stated that colonial powers could only hold colonies if they possessed them in practice, such as maintaining treaties with local leaders or administering the territory. 
in the protected entity." (62) With a protectorate established, the European power could then go about consolidating its influence over the territory by weakening local resistance. $^{106}$ In this way, the agreement reached at the Berlin Conference reasserted what had become common practice in preceding centuries - the creation of a legal framework that ensured Europeans property rights in the non-European world by dividing, and partially usurping, the sovereignty of non-European peoples.

The appropriation of non-European property and sovereign rights would not have been possible without a normative basis to justify their acquisition. For this, the General Act (1885) was underpinned by the concept of civilization, which not only justified European expansion into Africa, but also compelled it. For example, Article Six of the General Act (1885) asserts an explicit tone of European paternalism when it depicts the expansion of European civilization as a benefit to African 'natives;' specifically, by highlighting the role of European civilization in helping support the suppression of slavery, the promotion of religious freedom and the improvement of moral and material well-being in Africa. In this way, Article Six highlights an important transition in the way Europeans began to conceptualize civilization in the $19^{\text {th }}$ century. Whereas Pope Innocent IV, Vitoria and the Doctrine of Discovery (to some extent), had emphasized an association between civilization and Christianity, Article Six began to break from this association and to move in an

\footnotetext{
106 Working through a strategy of 'divide and conquer', European powers would compose their forces with ethnic minorities in the hopes of exacerbating local tensions. "For example, in India, Britain used Muslim mercenary troops against Hindus and vice versa, thus contributing to the maintenance of Indigenous ethnic conflict that eventually resulted in the bloody partition of the subcontinent at independence in 1947 [...]."(Spiegel 2012, 195)
} 
increasingly secular direction. ${ }^{107}$ Though it continued to privilege Christian civilization, the emphasis of Article Six was focussed mainly upon the promotion of basic political freedoms. According to Article Six of the General Act (1885),

All the Powers exercising sovereign rights or influence in the aforesaid territories bind themselves to watch over the preservation of the native tribes, and to care for the improvement of the conditions of their moral and material well-being, and to help in suppressing slavery, and especially the slave trade. They shall, without distinction of creed or nation, protect and favour all religious, scientific or charitable institutions and undertakings created and organized for the above ends, or which aim at instructing the natives and bringing home to them the blessings of civilization. ${ }^{108}$

Adopting the same paternalistic assumptions that had characterized international law during the colonial period, the Berlin Conference similarly justified European expansion on the basis of its superior civilization. In fact, Charles Alexandrowicz (1973) suggests that the Berlin Conference introduced a new legal principle to the field of international law, the Sacred Trust of Civilization (the Sacred Trust). What is particularly important about this principle is its association with European forms of socio-political organization, as the Sacred Trust conceptualized sovereign states as the vessels with which to bring civilization to 'uncivilized' peoples. In fact, for some late-19th century statesmen, Europe maintained a moral obligation to expand the norms and values of Europe through the expansion of the inter-state system/society. In Africa, for instance, the Sacred Trust was seen as "a

\footnotetext{
${ }^{107}$ As discussed below, this too is true of the Standard of Civilization, which "reflected the norms and practices of the liberal European civilization which arose to replace, though it remained firmly rooted in, the mores of Christendom." (Gong 1984, 15)

108 Privileging Christian mores, Article Six of the General Act (1885) continues, "[...] Christian missionaries, scientists and explorers, with their followers, property and collections, shall likewise be the objects of especial protection. Freedom of conscience and religious toleration are expressly guaranteed to the natives, no less than to subjects and to foreigners. The free and public exercise of all forms of divine worship, and the right to build edifices for religious purposes, and to organize religious missions belonging to all creeds, shall not be limited or fettered in any way whatsoever."
} 
'mission' [...] for preparing the way to their [Africans'] reversion to independence and for effecting their entry into the Family of Nations on a footing of equality." (Alexandrwiocz 1973, 112) Hence, by the early-20th century, this mission was formally codified into international law with the Covenant of the League of Nations, which, under Article 22, instituted the mandate system by citing the Sacred Trust. Noting the collapse of Germany and the Ottoman Empire, Article 22 sought to extend the reach of civilization to their former colonies; this was to be achieved by placing these colonies under the tutelage of international society's members, named Mandatories. Article 22 reads,

To those colonies and territories which as a consequence of the late war have ceased to be under the sovereignty of the States which formerly governed them and which are inhabited by peoples not yet able to stand by themselves under the strenuous conditions of the modern world, there should be applied the principle that the well-being and development of such peoples form a sacred trust of civilisation and that securities for the performance of this trust should be embodied in this Covenant.

Speaking to more secular interpretations of civilization, the mandates system assumed that civilization was derivative of sovereign statehood, and that the members of international society maintained an obligation to expand it. In this way, the Mandates system, premised upon the Sacred Trust, "reinforced the idea that a single process of development - that which was followed by the European states was to be imitated and reproduced in non-European societies, which had to strive to conform to this model." (Anghie 2004, 145) The assumption that statehood represented the height of socio-political organization "justified and lent even further reinforcement to the continuing presence of the colonial powers - now mandatory powers - in these territories, as the task of these powers was not to exploit, but 
rather to civilize the 'natives.'” (Anghie 2004, 145) In fact, this basic assumption led to the notion that European colonies could be distinguished according to their level of civilization. As Article 22 of the Covenant argues, "[t]he character of the mandate must differ according to the stage of the development of the people, the geographical situation of the territory, its economic conditions and other similar circumstances." Leading to a tiered system, the Covenant subsequently identified the administrative duties of mandatory powers in three types of mandates, each classified according to their level of semblance with European civilization. 'A' mandates, for instance, were defined as the former colonies of the Turkish Empire that "have reached a stage of development where their existence as independent nations can be provisionally recognized subject to the rendering of administrative advice and assistance by a Mandatory until such time as they are able to stand alone." (League of Nations 1919, Article 22)

While the 'A' mandates were granted provisional independence at the cost of limited foreign influence, the Covenant denied this to ' $\mathrm{B}$ ' and ' $\mathrm{C}$ ' mandates. Both these categories were largely viewed as lacking in the most basic features of European civilization, therefore warranting direct foreign influence by a mandatory power. Where the 'B' mandates are concerned, for instance, Article 22 of the Covenant contends that mandatory powers must be responsible for ensuring conditions that guarantee basic political freedoms and opportunities for commerce and trade. The underlying assumptions of this were of course threefold: 1) that these political freedoms are premised upon European social mores and customs; 2) that mandatory powers stood to benefit from open markets in these territories; and 
3) that the peoples residing in B mandates, barring European guidance, were incapable of developing in such a way. ${ }^{109}$ Moreover, these assumptions were made all the more explicit in the case of ' $C$ ' mandates. Citing ' $C$ ' mandates' remoteness from 'civilization,' Article 22 allows for a mandatory to assert its sovereignty over such territories; according to the Covenant, 'C' mandates,

[...] such as South-West Africa and certain South Pacific Islands, which owing to the sparseness of their population, or their small size, or their remoteness from the centres of civilisation, or their geographical contiguity to the territory of the Mandatory, and other circumstances, can be best administered under the laws of the Mandatory as integral portions of its territory, subject to the safeguards above mentioned in the interests of the Indigenous population. (League of Nations 1919, Article 22)

In these ways, Article 6 of the General Act and Article 22 of the Covenant are suggestive of a shift in the way European society conceptualized civilization during the $19^{\text {th }}$ and early $20^{\text {th }}$ century. Indeed, both texts are suggestive of a move toward an increasingly secular account of civilization that made sovereign statehood a central feature of civilization. Moreover, both texts speak to Prasenjit Duara's (2004) critical point about the concept of civilization - specifically, its role in distinguishing self from other, while using the value-base of civilization to justify subsuming the other into the self (see chapter four). In this chapter, I examine this issue in depth, paying particular attention to the association between the concept of civilization and sovereign statehood at the turn of the 20th century. This is achieved

\footnotetext{
${ }^{109}$ According to Article 22 of the Covenant (1919), 'B' mandates were composed of "Other peoples, especially those of Central Africa, [that] are at such a stage that the Mandatory must be responsible for the administration of the territory under conditions which will guarantee freedom of conscience and religion, subject only to the maintenance of public order and morals, the prohibition of abuses such as the slave trade, the arms traffic and the liquor traffic, and the prevention of the establishment of fortifications or military and naval bases and of military training of the natives for other than police purposes and the defence of territory, and will also secure equal opportunities for the trade and commerce of other Members of the League."
} 
through a focus on the role of international law in: 1) forging a benchmark with which to define inclusion/exclusion within/from international society; and 2) how this benchmark could then be used to subsume the other into 'civilized' society, in such a way that excluded the other from meaningful participation within the state. This chapter subsequently proceeds in three sections:

1. In the first section, I detail how the concept of civilization was used to define inclusion and exclusion within/from international society. Influenced by the work of Gerrit Gong (1984), this section details this with reference to the Standard of Civilization (the Standard), an explicit legal principle that defined a country's level of civilization based on its form of socio-political organization.

2. In the second section, I specifically examine the role of the Standard in defining relations between members of international society and Indigenous peoples. Drawing on the work of Paul Keal (2003), this is achieved through an examination of legal scholarship by the key proponents of the Standard.

3. In the third section, I detail how jurisprudence of the early 20th century was deployed in practice to deny Indigenous participation in international society. This is achieved through an examination of a petition put forward by the Iroquois peoples to the League of Nations, seeking that their rights as sovereign peoples be defended against the encroachment of the Canadian state. 


\section{The Standard of Civilization}

For the orthodox English School, the consolidation of a truly international society did not occur until the late-19th century, at which point non-European countries began to emulate the European model of socio-political organization with greater frequency. As an increasing number of non-European countries began to enter the state system, the traditional members of European society were faced with a dilemma; specifically, to determine which non-European countries they considered civilized and thus members of the burgeoning society of states. Working through positive law - an approach which dictates that law is derivative of man-made agreements - the answer to this dilemma came in the form of the Standard, an explicit legal principle that extended the protections of international law to a society that demonstrated five core features of European civilization: 1) the capacity to guarantee basic rights to its citizens and to foreigners; ${ }^{110}$ 2) to exist as an organized political bureaucracy; 3) to adhere to international law; 4) to maintain adequate and permanent diplomatic channels with other states; and 5) to conform to the norms and practices of international society (Gong 1984, 14-15). ${ }^{111}$ In short, the test of civilization rested upon the capacity of a non-European country to demonstrate its

\footnotetext{
110 Gong (1984) notes that the Standard resembled Vitorian jurisprudence in four ways. First, its first criterion resonated with Vitoria's first postulate regarding the right of the Spanish to travel, trade and proselytize unhindered. Second, the Standard assumed that international relations were to be conducted through a legal framework. Third, the Standard adopted a sense of moral responsibility; specifically, a sense of noblesse oblige that "required that Europeans involved outside Europe deal justly with weaker nations, or at least justify their behaviour according to some standard of what was right or fair." (39) Fourth, the Standard was premised on a hierarchy that conceptualized European society as the height of civilization (40).

111 George Schwarzenberger (1976) adopts a more moderate view, arguing that "The test whether a State was civilised and, thus, entitled to full recognition as an international personality was, as a rule, merely whether its government was sufficiently stable to undertake binding commitments under international law and whether it was able and willing to protect adequately the life, liberty and property of foreigners." (114)
} 
successful mastery of European forms of socio-political organization.112 Indeed, non-Europeans were expected to adopt distinctly European norms, values and assumptions associated with European civilization. For instance, Gong (1984) notes that it was not uncommon for non-European states to find themselves a part of the state system before they became members of civilized society;

It is not surprising that non-European countries previously unfamiliar with the European states-system found themselves part of the international system long before they were considered as candidates for the 'civilized' international society. Countries seeking to enter the 'civilized' international society were first expected to learn its [European] customs and norms, and to embrace its institutions. (11)

Gong continues, "[f]ew in the West ever fully appreciated the deep-seated humiliation which resulted when individuals and societies, highly cultured according to their own standards of 'civilization,' were ridiculed as uncivilized."113 (Gong 1984, 12)

Defining inclusion and exclusion in this way, the Standard continued to function like preceding generations of international law through a distinction between self and other; "those who fulfill the requirements of a particular society's

112 Foreshadowing the Standard, Beate Jahn (2005) notes that John Stuart Mill conceptualized modern, representative government as something that was only available to civilized peoples, such as Europeans. As Jahn (2005) explains, "Mill sets out his philosophy of history in each of his major writings to some extent. The most detailed and systematic exposition, however, we find in Considerations on Representative Government. Here Mill argues that representative government is the best form of government - but only for civilised nations. He begins by stating that political machinery does not act of itself. As it is first made, so it has to be worked, by men, and even by ordinary men. It needs, not their simple acquiescence, but their active participation; and must be adjusted to the capacities and qualities of such men as are available.' Some nations, Mill goes on to argue, will never accept the restraints of a regular and civilised government - such as North American Indians or the barbarians who overran the Roman Empire." (601)

113 Reflecting on the challenge this posed to non-Europeans political structure, Gong (1984) observes that "to threaten the traditional standards of 'civilization' of these non-European counties, and the larger cultural systems with which they associated themselves, was to undermine the traditional cultural and political foundations on which they were based. Further, because the governing elites in many of these non-European countries were mandated to defend and promulgate their own standard of 'civilization', confrontation with the seemingly superior European standard of 'civilization challenged the legitimacy of their regimes, both domestically and internationally." (7) 
standard of civilization are brought inside its circle of 'civilized' members, while those that do not so conform are left outside as 'not civilized' or possibly 'uncivilized."' (Gong 1984, 3) Combined with the military strength of European states, this resulted in the gradual adoption of the Standard by non-European countries, which had long-maintained their own socio-political cultures and orders. Indeed, non-European elites,

[...] soon realized that Europe's military strength was an integral outgrowth of European civilization. [...] The perceived need for strengthened selfdefence appeared to necessitate adherence to the European standard of 'civilization' and thereby, at least to a certain degree, to the standard of European civilization. (Gong 1984, 99)

Unlike preceding generations however, the Standard's distinction between self and other assumed particular potency because of its supposed claim to objectivity. Whereas international law had previously distinguished civilization on abstract criteria like religion and culture, proponents of the Standard claimed that its criteria were discernible through empirical observation. This was emblematic of a more general shift in international law from natural law to legal positivism; whereas Vitoria premised jurisprudence on reason and the presumed existence of truths/values grounded in nature, positive law jurists began to search for legal principles in existing customs and treaties. Where the Standard is concerned, Gong (1984) notes that its codification occurred in two stages; the first stage involved an analysis of stipulations inserted into European treaties with non-European countries - such as ensuring the security/safety of foreign nationals. The second stage involved synthesizing these stipulations into an explicit legal framework by international legalists, such as Lassa Oppenheim (1905) and Henry Wheaton 
(1929).114 However, this process was deeply flawed, as its positivist methods overlooked the context and power dynamics within which treaties between Europeans and non-Europeans were signed.

Indeed, the body of empirical evidence used to define the Standard rested in large part upon a body of unequal treaties, signed by non-Europeans under duress from European pressure. Much like many of the treaties entered into between Indigenous peoples and European powers during the colonial period, these treaties were marked by two or more of the following features: 1) imposition of unequal obligations; 2) imposition of treaty through violence or threat of it; and 3) impairment of a country's sovereignty (Gong 1984, 67). In fact, Turan Kayaoglu (2007) points out that these treaties also ensured imperial powers a certain degree of extraterritorial influence in the non-European world by subdividing the latter's sovereign authority. For example, in ways strikingly similar to the usurpation of the Cherokee Nation's right to try American nationals - from the state of Georgia - in their lands (see chapter four), these treaties guaranteed Europeans the capacity to try their foreign nationals according to European norms and customs. Underpinning these courts was thus the assumption that European civilization and its legal traditions were superior to those of non-European countries, warranting

\footnotetext{
114 Lassa Oppenhein (1905) and Henry Wheaton (1929) demonstrate some consensus around the basic criteria of the Standard. For Oppenheim (1905), "A state to be admitted must, first, be a civilized State which is in constant intercourse with members of the Family of Nations; Such a State must expressly or tacitly consent to be bound for its future international conduct by the rule of International law." (quoted in Gong 1984, 30) And Oppenheim (1905) argues that "Those States which have hitherto formed the Family of Nations must expressly or tacitly consent to the reception of the new member." (quoted in Gong 1984, 30) Similarly, Wheaton (1929) suggests that, "The State to which international law is to be extended must have a form of civilization which renders it able to apply the rules of that law and it must be in communication with the States already enjoying it; It must further be prepared to accept the rule of that law as binding upon it; and The other states must agree to accept the new members of the Family of Nations." (quoted in Gong 1984, 30)
} 
the sub-division of these countries' internal sovereignty through the appropriation of legal power (Anghie 2004, 84-85). "Hence, when signing treaties with nonEuropean countries, the European countries deliberately inserted explicit provisions to make the non-European countries responsible for protecting European nationals according to what emerged as 'civilized' standards." (Gong 1984, 25)

Some non-European countries came to view the Standard's relationship to unequal treaties as a mechanism with which to assert an international legal personality; despite the Standard's deeply paternalistic assumptions, Gong (1984) suggests that it was - somewhat ironically - the vessel through which non-European countries could escape the stipulations that had impeded their sovereignty in the past. For instance, both China and Japan recognized that by adopting the basic requirements of the Standard, they would force the members of European society to recognize them as civilized and entitled to full sovereignty - both internal and external. By achieving complete sovereignty, countries like China and Japan would be in a much better position to reject the imperial influence of Europe and the stipulations that it had sought to impose through unequal treaties, like extraterritorial courts. Both Brett Bowden (2005) and Antony Anghie (1999) cast doubt over this perspective however - while Gong (1984) recognizes that once a "universal standard of 'civilization' was decreed, the tolerance for cultural pluralism in international law narrowed" (69), he largely overlooks the fact that this 'universalism' resulted in the homogenization and near elimination of nonEuropean forms of socio-political organization. Specifically, the Standard strictly 
associated civilization with statehood and thus denied non-state peoples recourse to international law. In this way non-European countries were forced to adopt the European model of socio-political organization, leading Anghie (1999) to conclude that the Standard "is mired in [a] history of subordinating and extinguishing alien cultures." (104; quoted in Bowden 2005, 23).

Even if one accepts the argument that the Standard offered non-European countries a practical tool with which to escape the stipulations of unequal treaties, it should be remembered that any practical benefits provided by the Standard to nonEuropean countries largely bypassed Indigenous peoples. For Indigenous peoples especially those residing in settler states - recognition as being sovereign was considerably impeded by the fact that most Indigenous societies had, by the early$20^{\text {th }}$ century, been ensconced within the territorial boundaries of states - the very same states which had been founded upon colonial international law, which denied Indigenous peoples external sovereignty and property rights. Moreover, by the early 20th century, many of these states were becoming recognized as full-fledged members of international society, or at the very least in the process of becoming members. In fact, by the mid-1800s, many of Europe's colonies in the Americas had declared independence and were being invited to participate in world forums. ${ }^{115}$ Thus, for Indigenous peoples seeking membership within international society through compliance with the Standard - claims of statehood would necessarily bring them into conflict with (aspiring) members of international society. In this

\footnotetext{
${ }^{115}$ At the International Sanitary Conferences, for instance, states from the Americas were invited to participate. These Conferences were a series of meetings held over the course of decades which aimed at reducing the risk posed to trade by various communicable diseases, such as cholera (Huber 2006).
} 
way, the colonial drive to subsume the other into the Self effectively shut out the other from participating in international society as independent peoples; put differently, civilization had become a tool of exclusion through inclusion. In the next section, I begin to detail how the Standard helped to achieve this in the context of Indigenous peoples and their relationship to international society during the late $19^{\text {th }}$ and early $20^{\text {th }}$ century.

\section{The Standard of Civilization and Indigenous peoples}

During the late- $19^{\text {th }}$ and early-20 th century, members of international society did little to address the concerns of Indigenous peoples at the international level. Where any such action did occur, it was primarily undertaken through inter-state agreements that did little to incorporate the views of Indigenous peoples. Within the League, for instance, Indigenous issues could conceivably be addressed through the creation of minority treaties. However, these treaties were strictly negotiated between states, purposefully excluding minorities from participation to help avoid conflict (Lâm 2000, 93). "The denial of locus standi to affected minorities in these treaties was conscious and undertaken to reduce the incidence of controversial public debates between minority and host state."' (Lâm 2000, 94) Beyond the League, inter-state agreements responding to Indigenous issues were similarly rare; though, in the late- $19^{\text {th }}$ and early-20 $0^{\text {th }}$ century, Western states increasingly sought to regulate the sale of alcohol and addictive substances to Indigenous peoples. Couched in the language of the Standard, these agreements were not only statecentric, but deeply paternalistic. As Fidler (2001) observes, 
In 1901 the US Senate proposed that "the principle ... that native races should be protected against the destructive traffic in intoxicants should be extended to all uncivilized peoples by enactment of such laws and the making of such treaties as will effectually prohibit the sale by the signatory powers to Aboriginal tribes and uncivilized races of opium and intoxicating beverages." Using this resolution, in 1902 the USA proposed a universal treaty on limiting liquor sales "in the western Pacific, or in any other uncivilized quarter where the salutary principle of liquor restriction could be practically applied." (843)

The exclusion of Indigenous peoples from international affairs during the late-19th and early-20th century was closely associated with the role of the Standard in denying non-state peoples legal standing at the international level. By associating civilization with statehood, the Standard asserted that the only credible international actors were countries that emulated the European model of sociopolitical organization. In fact, proponents of the Standard used this assumption in a way that further justified the expansion of international society and the encasement of Indigenous peoples. Drawing a distinction between civilized states and uncivilized peoples, legal scholars from the period like William Edward Hall, TJ Lawrence, and John Westlake argued that a lack of civilization rendered uncivilized parts of the world territorium nullius and thus open for possession - a claim that could ultimately be traced back, at least, to Locke's chapter on property in the Second Treatise of Government. "The problem with all of this was, as Lindley recognized in 1926, how the term 'state' should be understood and what it was that distinguished 'savage from civilised peoples."' (Keal 2003, 104) Reflecting on this question, Lindley (1926) turned to the Standard, arguing that the deciding test of civilization was the existence of a sovereign state that could ensure European settlers the same degree of safety and security that they enjoyed in Europe (Gong 
1984, 17; Keal 2003, 104).116 Consequently, any non-state peoples unwilling to afford European settlers security could be considered uncivilized, and have their territory dispossessed on the basis of territorium nullius.

Lindley (1926) was not alone in this position, however. Representative of his time, John Westlake (1914) similarly held that the test of civilization rested upon a state's capacity to "carry on the complex life to which they [Europeans] have been accustomed in their homes [...] and which may protect the natives enjoyment of a security and well-being at least not less than that they enjoyed before the arrival of strangers." (137; quoted in Keal 2003, 104) Like Lindley (1926), the implication of Westlake's jurisprudence was subsequently that a foreign government unable to provide Europeans safety and security through a state government was socially and politically backwards; consequently, a civilized member of international society had the right to dispossess uncivilized peoples of their lands on this basis, provided they ensured the security and well-being of the natives. "Territory that did have political society was not open to occupation, but tracts of land 'inhabited only by isolated individuals who were not united for political action' could be considered territorium nullius and open to occupation." (Keal 2003, 104) With this established, the question for Westlake (1914) became the issue of native title and the right of an uncivilized peoples to practice some degree of internal sovereignty following their dispossession; specifically, "whether, once a 'civilised' state turns a country into a

\footnotetext{
116 Arguing that the test of civilization rested upon the capacity of a foreign government to ensure the safety and security of European settlers in the non-European world, proponents of the Standard ensured the expansion of Western legal norms and customs. Proponents of the Standard forced nonstate peoples to either ensure the security and safety of European settlers by complying with European norms, or be branded uncivilized and allow for their land to be legally dispossessed.
} 
colony, the title to the land continues according to customs of the inhabitants before civilised government was established." (Keal 2003, 104)

For Westlake (1914), the answer to this question rested with the colonizing state. Westlake argued that the degree to which Indigenous peoples could exert some degree of internal sovereignty was up to the colonizing power, which by virtue of being civilized exercised full sovereignty over the lands that it claimed. "In his view it was up to the coloniser to either accept or reject native custom and law. The title to land was regarded as issuing from a grant by the colonising state, the authority of which derived from territorial sovereignty." (Keal 2003, 105) From this perspective, "property was viewed as issuing from sovereignty but that raised the question of the origin of sovereignty itself." (Keal 2003,105) To this end, Westlake (1914) argued that sovereignty was derivative of its recognition by the members of civilized society. In making this case, Westlake's (1914) jurisprudence results in two major implications for Indigenous peoples; first, Westlake uses the concept of civilization to deny Indigenous peoples both property and sovereign rights rendering them the responsibility of the colonizing state which is to bestow upon them civilization. In this way, Westlake (1914) rationalizes colonial processes that subsume Indigenous peoples within the borders of states; "[...] the establishment of a colony meant the inhabitants prior to colonisation were now contained within a state. They henceforth had [...] no international personality and no sovereign rights other than as citizens of the states which now exercised sovereignty over them." (Keal 2003,105) To this end, the colonizing state now assumed a guardian-like role, 
insofar as it maintained the responsibility of civilizing the 'natives' (Bowden 2005, 21).

Second, and inter-related, this meant that Indigenous peoples had virtually no recourse to international law; their status as both non-state and sub-state peoples negated any claim to sovereignty, Indigenous peoples were left without any recourse to address abuses imposed upon them by colonizing states. As Keal (2003) explains, "states might do dreadful things to 'uncivilized' people, such as take away their land, but as long as it did not transgress the norms of behaviour with fellow members of international society, it was of no concern to international law." (105) In this respect, the jurisprudence of Westlake, and that of his contemporaries, carried forward many of the legal assumptions that had justified the colonial expansion of European society in preceding generations; specifically, it facilitated the expansion of international society by assuming that international law remained a mechanism for the promotion of intra-state order and for the projection of civilization into the uncivilized world. Thus, while Vitoria had articulated this through a natural law framework, proponents of the Standard were now simply recasting many of Vitoria's assumptions about self-other relations through a positive law framework, which saw the state as the vessel for civilization. As Gong (1984) observes, "[w]hile positive international law sanctioned the selective use of force against the uncivilized [...] the effect of such doctrines did not depart that radically from what Vitoria's natural law philosophies had countenanced in the past." (Gong 1984, 43) 
As has been suggested, positive law jurists and proponents of the Standard recast colonial assumptions about European civilization in the late-19th and early$20^{\text {th }}$ century by transitioning its association with religion to statehood. Yet, much like the jurisprudence of earlier legal philosophers, this did little to change the basic assumption behind the concept of civilization: that the world was composed of civilized and uncivilized peoples, and that relations between the two were to be defined by the imperative of extending civilization to the uncivilized. Where Indigenous peoples are concerned, this resulted in a process that sought to subsume them within 'civilized' states; it was through this process of 'inclusion' that Indigenous peoples were subsequently denied a voice at the international level. By being subsumed within the state, Indigenous peoples were now regarded as domestic minorities, or at best, quasi-independent nations that fell under the jurisdiction and/or supervision of the state. In this way, the Standard justified the imperial expansion of a nascent international society in the late-19th and early-20th century, while silencing the voices of the Indigenous peoples it subsumed. In the next section, I examine how the extension of European civilization to Indigenous peoples - via international law - marginalized them from participation in world affairs. This is achieved through a case study of Chief Levi General's diplomatic mission to the League of Nations on behalf of the Haudenosaunee.

\section{Chief Levi General and the League of Nations}

The Standard worked to further marginalize Indigenous peoples from international society by defining membership within it upon statehood. Indeed, the legitimacy of a peoples' claim to an international legal personality rested upon its capacity to 
demonstrate internal and external sovereignty over a prescribed territory. Ensconced within the territorial boundaries of settler states, Indigenous peoples were increasingly relegated to the status of 'domestic populations' over the course of the 19th and early-20th century. As Ronald Niezen (2003) explains,

[...] in one form or another, Indigenous peoples came to be seen as minority groups inevitably to be assimilated in the dominant society or marginalized by colonial migration and "improvement" in the use of Indigenous territories. This view of Indigenous peoples was a major impediment to their ability to find redress of grievances against states that had failed to honor treaties, and were intent on acquiring land and resources even in violation of their own laws [...]. (23)

As a consequence, Indigenous activism was largely confined to national court systems during the 19th century - as highlighted by the Cherokee cases brought before the US Supreme Court in the early 19th century (see chapter four). In fact, Maivân Clech Lâm (2003) suggests that it was not until the establishment of the League of Nations in 1920 that Indigenous peoples saw the venues of international society as potential spaces through which to pursue their interests; the League's concern for 'minority' peoples could conceivably be seized upon by Indigenous peoples to bring their concerns to the international level, despite the fact that these treaties were initially meant to apply only to minorities in Europe. ${ }^{117}$ Until that point, "Maoris, Aboriginals, and Indians from Canada could do little more than reach over the heads of local officialdom to submit their stories of injustice to metropolitan authorities that, in the final analysis, enabled that injustice." (Lâm 2000, 33)

\footnotetext{
117 Niezen (2000) notes that there was some recourse for Indigenous peoples living within the British Empire to pursue a hearing before the Commonwealth; however, these hearings were usually in the form of a 'polite' meeting with little capacity to address the complaint (123).
} 
Despite its role in perpetuating European paternalism in the form of the Mandates System (see above), the League was singled out by several Indigenous leaders as a vessel for drawing international attention to their issues. While it is true that these sorts of diplomatic efforts were quite rare, efforts undertaken by Chief Levi General Deskaheh of the Cayuga (Iroquois), ${ }^{118}$ and Tahupōtiki Wiremu Rotana of the Maori, represent explicit efforts to address concerns pertaining to Indigenous-state relations at the international level (Wilmer 1992, 135).119 Although each of these diplomatic endeavours is significant in its own right, perhaps the most influential in terms of its long-term legacy was the diplomatic mission of Deskaheh, $^{120}$ which arrived in Geneva, Switzerland, in September 1923 on a passport authorized by the Six Nations (Simpson 2006, 108). As Niezen (2003) observes, the "grievance [Deskaheh] sought to resolve was common to Aboriginal peoples in Canada: the political turmoil and loss of sovereignty resulting from tribal governance under the Indian Act." (31) Passed in 1876, the Indian Act sought to define relations between the Government of Canada and the Aboriginal peoples residing within it. Reflective of colonial international law, the Act proceeded by dividing Indigenous sovereignty on the basis of civilization. The Act had "long [been] guided by the notion, common among legislators and Indian agents, that

\footnotetext{
118 Although the name Deskaheh is used in this thesis, "[t]he name Deskaheh actually refers to a chiefly title, but in press coverage during the 1920s was misapplied and popularized as a given name." (Niezen 2000, 123)

119 Tahupōtiki Wiremu Rātana sought support from the League of Nations on behalf of the Maori in 1922 (Lâm 2000, 33).

${ }^{120}$ Laurence M Hauptman (2008) explains that "Deskaheh's crusade still inspires the Iroquois efforts to win international recognition to protect their autonomy and that of other Indigenous peoples around the globe. [...] From the early 1970s onward, delegates from Onondaga, such as the late John Mohawk, journeyed to Geneva, Switzerland [...] Carrying forth the tradition of Deskaheh [...] they helped draft the United Nations Declaration on the Rights of Indigenous peoples that has recently been adopted." (120)
} 
Indian government, functioning within carefully defined limits, could have the benefit of 'civilizing' the Indians while protecting them from the encroachment of settlers." (Niezen 2003, 31)

In an effort to 'improve' Indigenous-state relations, the Indian Act (1876) was marked by a tension: on the one hand, it sought to grant Indigenous peoples some degree of self-determination; on the other hand it sought to ensure that this self-determination leads toward a particular form of Western civilization. As Lawrence Hauptman (2008) explains, "Canadian government officials pushed their policy of 'Indian Advancement,' one that included the replacement of the traditional government with an elected system and the extension of Canadian citizenship to the Indians on the [Six Nations] reserve." (126) Reflective of the increasing association between civilization and Western forms of socio-political organization, the Indian Act and the related policy of Indian Advancement led to increased efforts on the part of the Canadian Government to impose its vision of Western norms and values upon Indigenous peoples. In pursuit of seeing this policy through, the Government of Canada encroached on Six Nations territory with the Royal Canadian Mounted Police (RCMP), which rationalized their presence of the basis of: 1) suppressing the illicit distilling of alcohol, and 2) maintaining law and order generally. (Canada 1923, 14) While the Canadian Government justified these actions by claiming them to protect law-abiding 'Indians,' they were nevertheless a clear violation of the Haldimand Proclamation (1784); a decree through which King George III compensated the Iroquois that fought on the side of the British during the American 
Revolution, with land and rights to internal sovereignty in what is present day Canada.

From Deskaheh's perspective - and from much of the Six Nations'121 Canada's actions represented "an act of war" that required redress at the international level. In a petition later circulated to League members, titled The Red Man's Appeal to Justice, Deskaheh (1923) argued that the Government of Canada's actions sought to "destroy all de jure government of the Six Nations [...], and to fasten Canadian authority over all the Six Nations domain and to subjugate the Six Nations peoples, and these wrongful acts have resulted in a situation now constituting a menace to international peace." (quoted in Niezen 2003, 33) The diplomatic hurdle confronting Deskaheh was demonstrating to League members the legitimacy of his peoples' claim to participate in the state-based organization, despite the Six Nations' territory being ensconced within the borders of a League member, Canada. ${ }^{122}$ To achieve this, Deskaheh describes the Six Nations in terms consistent with the Standard. Recognizing that membership within the League was

\footnotetext{
121 The term 'much' has been used to signify the fact that the Iroquois were divided on the mission and their perception of Deskaheh as their leader. "There were also real Indian concerns about the Confederacy Council. To some, the chiefs were seen as out of touch with the realities of the postwar period and the daily economic needs of the community. Others saw Deskaheh's activities as a waste of time and money; they viewed the Six Nations' bond issue as a nefarious scheme to enrich the chiefs, whose council already faced allegations of corruption." (Hauptman 2008,132)

${ }^{122}$ Although Canada was a League member, it was not yet fully sovereign in the constitutional sense of the term. Canada had begun to take steps in this direction with the passage of British North America Act in 1867, but it did not technically gain full independence until 1982 with the passage of the Canada Act. With this in mind, Canadian membership within the League represented one of the first instance in which Canada could assert itself on legally equal terms with the other members of international society, within an international organization. In this respect, Canada was very much a part of the civilized society of states (at least within the League of Nations), though complete sovereignty from Britain remained a work-in-progress. Nevertheless, it is recognized that this raises a number of questions concerning the concept of sovereignty itself; indeed, it might be argued that Canada's role in the League of Nations underlines the notion that sovereignty - to borrow the term from Judith Butler (2010) - is a 'performance', more so than an objective condition.
} 
restricted to states, Deskaheh argued that the Six Nations could be accepted as a member through Article 17 of the League's Covenant (Hauptman 2008, 132), which states,

In the event of a dispute between a Member of the League and a State which is not a Member of the League, or between States not Members of the League, the State or States not Members of the League shall be invited to accept the obligations of membership in the League for the purposes of such dispute, upon such conditions as the Council may deem just. If such invitation is accepted, the provisions of Articles 12 to 16 inclusive shall be applied with such modifications as may be deemed necessary by the Council. Upon such invitation being given the Council shall immediately institute an inquiry into the circumstances of the dispute and recommend such action as may seem best and most effectual in the circumstances.

Alluding to Article 17 in an earlier petition to the Queen of the Netherlands in 1922, Deskaheh indicates that "the Six Nations are ready to accept for the purpose of this dispute, if invited, the obligation of membership in the League of Nations upon such conditions as the Council may prescribe, having due regard to our slender resources." (quoted in Niezen 2003, 33) As Niezen (2000) explains however, Deskaheh's reference to membership within the League is something of a concession to League members, intended to defend tribal self-determination from the encroachment of government forces. "Although the Six Nations did not expressly seek membership in the League of Nations, this was seen as a potential obligation necessary for the international recognition of their claims." (Niezen 2000, 124) To demonstrate the legitimacy of the Six Nations' recourse to international law, Deskaheh was forced to describe his petition in a manner consistent with secular interpretations of civilization. He achieved this by demonstrating the Six Nations' capacity to assume the responsibilities of full statehood. In fact, it was also through a discourse pertaining to statehood that the Canadian Government sought 
to rebuff Deskaheh's petition to the League - specifically, when it cast doubt over the capacity of the Six Nations to fulfill this role. In disparaging tones, the Canadian Government argued that the Six Nations were best conceptualized as a domestic population which had lost their sovereignty over the course of the colonial period through conquest and dispossession. According to the Government of Canada, "The Six Nations are not now, and have not been for 'many centuries' a recognized or selfgoverning people but are [...] subjects of the British Crown residing within the Dominion of Canada." ${ }^{123}$ (quoted in Niezen 2000, 124)

Supporting the Canadian position, the United Kingdom similarly argued for the removal of Deskaheh's petition from the League's agenda by arguing that the confrontation between the Government of Canada and the Six Nations was a domestic matter, and was thus an issue internal to the British Commonwealth. Exercising a significant amount of power in the League, support from the United Kingdom subsequently quashed Deskaheh's diplomatic endeavours and even denied his mission observer status in the League (Hauptman 2008). However, it is noteworthy that the British and Canadian governments did not go unchallenged. Despite not winning an audience before the League, Deskaheh was successful in garnering the support of other League members. In a letter signed and submitted to the president of the Council of the League, Estonia, The Netherlands, Ireland, Panama, Japan, and Persia, voiced their support in having Deskaheh's delegation heard; and, both Japan and the Netherlands sponsored Deskaheh's petition to

${ }^{123}$ Going further, Canadian Undersecretary of State for external affairs, Joseph Pope (1923) describes the Six Nations Council of Chiefs as an "antiquated" and "primitive matriarchal form of Government." (quoted in Hauptman 2008, 134) 
address the League (Simpson 2006, 108). Although unsuccessful in persuading the League to hear the Six Nations Chief, the views of these governments are a testament to Deskaheh's diplomacy and also foreshadow future developments in the latter half of the 20th century. Specifically, they foreshadow the role of the Indigenous transnational movement in negotiating new international norms pertaining to Indigenous self-determination. In this sense, they echo Deskaheh's view that,

The constituent members of the State of the Six Nations of the Iroquois, that is to say, the Mohawk, the Oneida, the Onondaga, the Cayuga, the Seneca and the Tuscarora, now are, and have been for many centuries, organized and self-governing peoples, respectively, within domains of their own, and united in the oldest League of Nations, the League of the Iroquois, for the maintenance of mutual peace. ${ }^{124}$ (quoted in Niezen 2000,124)

\section{Conclusion}

It is commonplace in disciplinary IR to associate the inception of a global international society with the late- $19^{\text {th }}$ and early- $20^{\text {th }}$ century. For much of the discipline, this period witnessed the consolidation of a truly global international society, as the United States and Japan entered the ranks of a once regional society of empires located in Europe. As suggested in the preceding chapter, however, a shift in the way IR conceptualizes the evolution and expansion of international society significantly changes the story of international relations. By moving away from the linear model presented by the Westphalian narrative, and toward a specific focus on the evolution of self-other relations constituted through the concept of civilization, the evolution and expansion of international society during the late-19th

\footnotetext{
${ }^{124}$ For greater context and detail on Deskahaeh's mission to the League of Nations, see Niezen (2000
} \& 2003). 
and early-20 $20^{\text {th }}$ century appears much different; specifically, as a Eurocentric enterprise that defined the terms of membership in international society on secular assumptions about sovereign statehood. From this perspective, what is unique about the late-19th and early- $20^{\text {th }}$ century is not so much the appearance of nonEuropean states, but rather the evolution of a civilizational discourse that sought to exclude peoples that did not live up to this standard of socio-political organization. In other words, it became a discourse that explicitly marginalized the members of world society from participating in international relations.

In this chapter, this has been described in terms of the transition from a natural law to positive law framework, and the fact that despite changes in the way these frameworks defined civilization, its basic purpose has remained consistent: to distinguish self from other, and to justify the self in subsuming the other. By the early $20^{\text {th }}$ century, these purposes were being motivated by an explicit legal principle, the Standard, which defined civilization on five basic principles: 1) the capacity to guarantee basic rights to its citizens and to foreigners; 2) to exist as an organized political bureaucracy; 3) to adhere to international law; 4) to maintain adequate and permanent diplomatic channels with other states; and 5) to conform to the norms and practices of international society. Where peoples failed to meet these criteria, members of international society assumed the right to exert extraterritorial influence over them, through an extension in their sovereign authority. As noted in the introduction of this chapter, this took place through a hierarchy of cultures, as suggested by the League's Mandates system, which classified peoples into A, B and C mandates according to their 'level' of socio- 
political development - i.e. their likeness to the Standard. Thus, it was for this reason that the level of European influence in non-European societies varied, with state-like societies being granted limited independence and non-state societies being forced to submit to European power.

This was particularly true for Indigenous peoples ensconced within the boundaries of existing states. Despite the fact that treaty-relations implied the existence of sovereign-to-sovereign relations throughout the colonial period, the $19^{\text {th }}$ century marked a shift in the way Indigenous peoples were perceived by the members of international society. As foreshadowed by early Supreme Court decisions in the United States (see chapter four), international society increasingly sought to subsume Indigenous peoples within the fabric of the state during the late$19^{\text {th }}$ and early-20th century - on account of their limited claim to external sovereignty. As was highlighted in the case of Deskaheh's diplomatic mission to the League of Nations, members of international society - though some were sympathetic to his cause - ultimately had to yield to the perspective of the British Commonwealth. By failing to meet the criteria of the Standard, and by being ensconced within the territory of a sovereign state, the Six Nations were not entitled to an audience at the League of Nations. Far from it, it was the perspective of Canada that relations with the Six Nations were to be conducted with the domestic government of Canada, on account of the fact that the Six Nations 'could not rightly' be called a sovereign state. In fact, it was also the position of the Government of Canada, that it maintained the right to exert power over the Six Nations, as this was a vessel for civilization and was to their benefit. 
In this way, this chapter has sought to show that despite changes in the definition of European civilization, its basic role as a tool for defining self-other relations continued through to the early $20^{\text {th }}$ century. With this in mind however, the shift to a socio-political definition of civilization did result in the explicit marginalization of non-state peoples. In this vein, conceptualizations of civilization during the late-19th and early $20^{\text {th }}$ century helped justify a process that sought to subsume Indigenous peoples within the state, and thereby to exclude them from international affairs. By being subsumed, Indigenous peoples were to be conceptualized as domestic populations and not sovereign peoples. Thus, positive law approaches to the concept of civilization helped propel a process of 'inclusion' one aimed at subsuming Indigenous peoples into the state - which ultimately resulted in the exclusion of Indigenous peoples from international relations. In the next chapter, I continue with this theme, detailing the role of states in defining an international system predicated on the European model of socio-political organization. Specifically, it explores this process through an examination of decolonization and a more detailed analysis of how states subsumed Indigenous peoples during the mid- to late-20 $20^{\text {th }}$ century. In addition, it examines how Indigenous peoples responded to these processes at the international level, with a focus on their claim to a right of self-determination. 


\section{Chapter six}

\section{Civilization and the 'post-colonial challenge' to European international law}


From the start of our international work, Indigenous peoples sought recognition of our right to self-determination. This right has been key from the beginning. The Declaration affirms in article 3 that "Indigenous peoples have the right to selfdetermination. By virtue of that right they freely determine their political status and freely pursue their economic, social and cultural development."

- $\quad$ Kenneth Deer 2010, 27

Gerrit Gong (1984) notes that by the end of the Second World War the Western members of international society were confronted with a problem: whereas previous centuries of European imperialism had been supported by a sense of cultural superiority, the Second World War and the looming threat of nuclear war cast doubt over the purported distinction between Europeans and non-Europeans civilized and uncivilized. According to Gong (1984), the "horrors perpetrated in Europe itself during the two World Wars did much to discredit Western claims of cultural superiority and to undermine the self-confidence from which such attitudes had originated." (87) James Youngblood Henderson (2008) concurs, noting that the "events of the first half of the [20th] century raised profound questions about the validity of the belief that Western Europe represented the highest point of human achievement." (25) With the cultural superiority of Western civilization in doubt, it became increasingly difficult for the Western members of international society to sustain the old Standard of Civilization (the Standard). Moreover, with the Standard falling into disrepute, Western states could no longer substantiate their purported right/obligation to exercise authority over their colonies in the non-European world (at least not on the basis of civilization). Indeed, the long held assumption that European civility endowed Western states with the right to exert extraterritorial 
influence over others had finally begun to erode, as these members of international society began to acknowledge the 'barbarian within.' 125

However, the erosion of the Standard and the onset of decolonization did not mark the end of standards with which to differentiate between peoples that belonged within international society from those that belonged outside of it. As Brett Bowden (2004) observes, "while it might be that the legal standard of civilization was superseded in the annals of international law, that is not to say that something similar did not continue to serve the same purpose in the conduct of international politics." (52) In fact, both Bowden (2004) and Gong (1984) argue that the erosion of the Standard was followed by the appearance of two new standards with which to judge the legitimacy of a state's membership within international society: 1) a standard of human rights; and 2) a standard of modernity. Where the former is concerned, Gong (1984) suggests that its origins can be traced to the Charter of the United Nations (UN) and the Universal Declaration of Human Rights (UDHR). Similar to the Standard, the standard of human rights "share[s] a common concern for fundamental rights of life, liberty, property, and individual dignity [...]." (Gong 1984, 91) In this way, "[t]here is an easy and natural transition from concern for 'civilized' rights to concern for 'human rights' [...]."126 (91) Where

\footnotetext{
125 Decolonization and the erosion of European extraterritorial influence was similarly influenced by other factors, such as changes in the post-WWII balance of power, independence movements in former colonies, and changes in world opinion. Thus, the disintegration of the old Standard of Civilization should be understood in the context of these forces and other forces, not simply European humility.

${ }^{126}$ In a similar vein, Christian Reus-Smit (2001) argues that human rights fuel the legitimacy of international society and the principle of state sovereignty. According to him "Sovereignty and human rights are generally considered separate, mutually contradictory regimes in international society." (519) By contrast, Reus-Smit (2001) "takes issue with this conventional assumption, and argues that only by treating sovereignty and human rights as two normative elements of a single,
} 
the latter is concerned, Gong (1984) suggests that it appeared in two inter-related forms. First, it appeared as a standard that "vindicates the nineteenth-century assumption that the laws of science, being universal, undergirded a rational cosmology which would bring the blessings of 'civilization' to all. [...] In another form, [it] raises the possibility of a contemporary cosmopolitan culture." (Gong 1984, 92)

In Bowden's (2004) view, neither of these 'new' standards exercised the same legal force as did the Standard. For him, this was in large part due to the Cold War which divided East and West along ideological lines and prohibited consensus around the specific content of these standards. For Bowden (2004) it was not until the end of the Cold War and the consolidation of Western power that these standards assumed some degree of universality. Referencing Mehdi Mozaffari (2001), Bowden (2004) explains that in the post-Cold War period "a variation of the "might equals right," or realist, brand of logic prevails; since it is the West that dominates, it is the West that sets the standard." (54) And, because it was the West that prevailed, contemporary standards have subsequently been characterized by a commitment to Western style democracy, integration within the capitalist system and adherence to basic human rights - "there is a belief in some quarters that in the march of progress, human rights, democracy, and Western-style modernity (or development) are so interdependent that they cannot be separated."127 (Bowden 2004, 59) In short, Bowden (2004) suggests that the post-Cold War period has been

inherently contradictory modern discourse about legitimate statehood and rightful state action can we explain key moments in the expansion of the international system during the twentieth century." (519)

127 Bowden (2004) cites Francis Fukuyama as an example of a scholar who adopts this perspective. 
characterized by a new standard that combines the content of both the standard of human rights and the standard of modernity. ${ }^{128}$ While Bowden (2004) is apt to identify this standard in the late $20^{\text {th }}$ century however, there is reason to believe that a variation of it was already in operation during the mid-20th century as well.

While it may be true that the Cold War impeded the creation of universal standards at the inter-state level, it is noteworthy that both the East and West were committed to an international system founded on the primary institution of territorial sovereignty. In this respect, both the US and the Soviet Union generally accepted the view that the state was the highest form of political organization and that its territorial integrity was not to be challenged. However, with the erosion of the Standard, and growing calls for independence in former European colonies, international society was being challenged by an emerging legal principle; specifically, the concept of self-determination. ${ }^{129}$ In fact, the concept appears in the Charter of the United Nations itself, under Article 1, paragraph 2, which states that UN members are "[t]o develop friendly relations among nations based on respect for the principle of equal rights and self-determination of peoples and to take other appropriate measures to strengthen universal peace."130 As Henderson (2008) observes, sub-state peoples greeted this evolving discourse with considerable

\footnotetext{
${ }^{128}$ For example, this standard has underpinned influential Western security discourses that justify action against states perceived as 'backwards,' both in terms of their human rights record and because of their political systems (i.e. 'the axis of evil').

129 While the concept of self-determination has been voiced at the international level for centuries, its codification as an explicit legal principle did not occur until the mid-20 $0^{\text {th }}$ century. As Xanthaki (2005) notes, "[a]lthough proclaimed previously, self-determination did not emerge as a principle of international law until the Second World War." (15)

130 There are two direct references to self-determination in the UN Charter; the second is found in Chapter IX, Article 55, which states, "[w]ith a view to the creation of conditions of stability and wellbeing which are necessary for peaceful and friendly relations among nations based on respect for the principle of equal rights and self-determination of peoples, the United Nations shall promote [...]."
} 
optimism as its reference to 'peoples' implied a legal basis with which to exercise a greater degree of independence and/or control over one's cultural and/or material resources. As Henderson (2008) explains, the "category of 'peoples' evidences a shift to a new legal category in international law. The change infers the application of the principle of self-determination to Indigenous peoples within the boundaries of independent or decolonizing states." (26)

But, as Xanthaki (2005) notes, this interpretation of self-determination proved highly problematic for the members of international society. "Selfdetermination has been the basis for numerous successful movements for secession, [and] it has also been the reason for the rise of many ethnic conflicts." (15) Moreover, "[i]ts potential implications for the stability of the international community has meant that there is no consensus about its meaning." (Xanthaki $2005,15)$ For these reasons, self-determination's “importance is well-accepted and recorded, yet its precise meaning has not yet been agreed. States accept and proclaim that 'peoples' should decide on their future; nevertheless, who is a 'people' is still to a large degree decided by states themselves." (Xanthaki 2005, 15) In practice, this meant that the concept of self-determination was applied in a twofold way during the mid-20 th century. At the international level, the members of international society conceded this right to the former colonies of Europe, granting them a right to seek independence (see below). At the sub-state level however, both Eastern and Western states were quick to narrowly define who constituted a people, and who was entitled to exercise this right. For the most part, this meant that substate peoples were conceptualized as domestic populations and thus not entitled to 
an external right to self-determination; instead, minorities and other sub-state 'populations' were to be protected through the evolving human rights regime.

Amongst those conceptualized as sub-state populations were Indigenous peoples who, despite lobbying the international community for recognition as selfdetermining peoples, were consistently addressed through the minority rights regime, well into the $20^{\text {th }}$ century. In this context, the human rights regime, developed to address Indigenous peoples during the mid-20th century, adopted a dual function. While rights were extended to Indigenous peoples to safeguard them against discriminatory practices, they were also extended with the intention of assimilating Indigenous peoples into the dominant society of the state. For example, this was the objective of International Labour Organization (ILO) Convention no. 107 - the Indigenous and Tribal Populations Convention (ITPC; 1957) - which rationalized its extension of human rights to Indigenous peoples on the basis that Indigenous peoples were less developed; their cultures were regarded as not being as advanced as those of the states in which they were ensconced.131 In ways

131 Despite its flaws, ILO Convention 107 was in many respects an important watershed in Indigenous-state relations; indeed, "ILO Convention 107 was a pioneering document in that it was the first international instrument to specifically address the human rights of Indigenous peoples." (UBC online) In addition, it laid the groundwork for Convention no. 169, which superseded it in 1989 by seeking to better incorporate the views and interests of Indigenous peoples. "Convention No. 169 takes the approach that the cultures and institutions of Indigenous and tribal peoples must be respected, and presumes their right to continued existence within their national societies, to establish their own institutions and to determine the path of their own development. ILO Convention No. 169 also calls for governments to consult with the peoples concerned." (Office of the High Commissioner of Human Rights, 2) Significantly Convention no. 169 did not manage to fully absolve itself from problematic language. "Many of the provisions in the Convention are qualified by terms such as 'as appropriate', 'as necessary', 'wherever practicable' or 'to the extent possible'. These terms give the Convention flexibility, although some critics say that they may also have the effect of limiting or making vague the obligations of ratifying governments." (Office of the High Commissioner of Human Rights, 3) 
reminiscent of the Standard, the ITPC (1957) alludes to the 'social backwardness' of Indigenous peoples when it defines them under Article 1 of the document as,

[...] populations in independent countries whose social and economic conditions are at a less advanced stage than the stage reached by the other sections of the national community, and whose status is regulated wholly or partially by their own customs or traditions or by special laws or regulations [italics added]." (ITPC 1957, Article 1)

On this basis, the ITPC (1957) substituted the principle of self-determination for a variety of cultural, religious, civil and social rights which sought to prevent discriminatory practices through the better integration of Indigenous peoples into the state. According to Article 2 of the ITPC (1957), "[g]overnments shall have the primary responsibility for developing coordinated and systematic action for the protection of the populations concerned and their progressive integration into the life of their respective countries."

As is being suggested, the ITPC's (1957) description of Indigenous peoples as societally less advanced - and its subsequent use of minority rights - evidences the existence of a standard; specifically, one that denied sub-state peoples the right to self-determination by subsuming them within the state. As James Anaya (1996) explains, the ITPC (1957) was "overshadowed by a persistent deference and even preference for national programs of integration and noncoercive assimilation." (44) Speaking to this issue at a more general level, Karen Engle (2010) similarly observes that "human rights constituted a modernizing move that would threaten the culture of Indigenous groups by imposing apparently universal values on their ways of life." (45) In this chapter I examine the evolution of the concept of civilization in the $20^{\text {th }}$ century, focussing especially on its relationship to a right to self-determination, and 
the ways in which members of international society defined self-determination to the detriment of Indigenous peoples. To achieve this, the chapter proceeds in three sections,

1. In the first section I detail two competing perspectives of self-determination, the minimalist and maximalist perspective; paying particular attention to the concepts of internal and external self-determination. Doing so, I establish a foundation on which the following two sections, which detail the struggle for an Indigenous right to self-determination from the mid-20th century to the early $21^{\text {st }}$ century, are based.

2. In the second section, I assess critically the formal UN processes and debates surrounding decolonization - a period traditionally associated with the erosion of the Standard and the emergence of a new normative environment within international relations. Specifically, I show that despite this view, decolonization did little to challenge the foundational assumptions used by members of international society in their relations with non-state and substate peoples.

3. In the third section I detail the evolution of the Indigenous transnational movement and its efforts to achieve an Indigenous right to selfdetermination. Through this section, I focus on the processes leading to the adoption of the United Nations Declaration on the Rights of Indigenous peoples (the Declaration, 2007) for two reasons. First, I focus on these processes as a means of highlighting tensions between international society and the Indigenous transnational movement, with respect to the concept of 
self-determination. Second, by focussing on these processes, I establish a foundation from which to examine the application of the right to national self-determination in the following chapter.

\section{Minimalism, maximalism and the concept of self-determination}

As noted above, the concept of self-determination remains ill-defined; "inclusion of self-determination in the Charter of the United Nations was a major advance; unfortunately, no clarifications were given about its content or its beneficiaries." (Xanthaki 2005, 16) Problematically, this has led to: 1) competing accounts of selfdetermination; 2) debates as to who constitutes a 'people' under international law; and 3) who is thus entitled to exercise this right. Moreover, with power concentrated in the hands of international society, these debates have traditionally been influenced by state interests. For example, it might be asked why the former colonies of Europe were granted a right to pursue their full independence in the post-war period, while the internally colonized peoples of settler states were not. Similar to the arguments of orthodox English School scholars, the most common answer to this question has rested on assumptions about international order. Indeed, members of international society have traditionally restricted the full exercise of self-determination to whole populations of established territories, on the basis that the extension of this right to sub-state peoples would risk the radical fragmentation of states and the state-system. This view was captured in the late 20th century by then-UN Secretary General Boutros Boutros-Ghali, who stated that "if every ethnic, religious or linguistic group claimed state-hood, there would be no 
limit to fragmentation, and peace, security and economic well-being for all would become ever more difficult to achieve." (quoted in Mayall 2007, 40)

Underpinning this interpretation of self-determination is a territorial dimension, one which assumes that a right to self-determination implies a right to secession. In fact, Aurelia Cristescu (1981) suggests that anxieties over secession were at the heart of debates involving the UN Charter. As Cristescu (1981) explains,

At the 6th meeting of Committee 1 of Commission I of the San Francisco Conference [...] the following remarks were made concerning the mention of the right to self-determination in Chapter I of the Charter: [...] on the one side that this principle corresponded closely to the will and desires of peoples everywhere and should be clearly enunciated in the Charter; on the other side [...] that the principle conformed to the purposes of the Charter only insofar as it implied the right of self-government of peoples and not the right of secession. ${ }^{132}$ (Cristescu 1981, 2)

For this reason, 'minimalists' who recognize a right to self-determination tend to divide it into two categories. Externally, self-determination is conceptualized as a right that entitles peoples to exert some form of sovereignty in their relations with foreign states, though this need not strictly mean statehood. Rather, "[a]pplications for the external aspect of the right [to self-determination] include independence, association, or integration with another state." (Xanthaki 2005, 205) Internally, selfdetermination is characterized by increasing a peoples' level of participation in the decision-making structures of the state. "Applications of the internal aspect of self-

132 Audrey Roy (2001) observes that similar tensions plagued the drafters of the Universal Declaration of Human Rights (UDHR), who explicitly refrained from including any reference to selfdetermination out of fear that its association with secession would inhibit state-support for the final draft. (7) Indeed, the creation of a full right to national self-determination may be in conflict with the principle of sovereignty. Since territorial integrity is considered a central feature of sovereignty, the exercise of national self-determination - by a sub-state people - could lead to territorial fragmentation of the state. 
determination include democratic governance, participation and autonomy." (Xanthaki 2005, 205)

Dividing self-determination in this way, minimalists articulate an inherent right of peoples to self-determination, while limiting sub-state peoples from exercising its external dimensions. Specifically, minimalists ensure that the exercise of self-determination by sub-state peoples remains limited to its internal dimension; that is, that Indigenous peoples are entitled to rights that: 1) ensure their democratic participation within the states that they are ensconced; and 2) protect them from discrimination. As Xanthaki (2005) observes however, the assumption upon which this external/internal dichotomy rests is deeply problematic. In addition to denying Indigenous peoples a right to exercise external selfdetermination - one arguably rooted in their treaty relations with Europeans states have traditionally used the internal/external dichotomy to justify subsuming Indigenous rights within a minority rights framework. While Indigenous calls for self-determination have focussed on a desire for greater control over their social, cultural and economic affairs, states have instead - at least traditionally - extended legal rights aimed at the further integration and participation of Indigenous peoples within the states that they are ensconced in. ${ }^{133}$ And, as Karen Engle (2010) observes, the extension of these rights has not been able to satisfy the collective interests of Indigenous peoples. In fact, Engle (2010) notes that,

\footnotetext{
133 Xanthaki (2005) notes that the minimalist position - in its most extreme form - outright denies a right to self-determination, "because of [self-determination's] vague and inconsistent application." (21) This despite the fact that "[n]otions like sovereignty, freedom, participation, and the right to expression all have certain degrees of generality which can be interpreted as vagueness. [Allowing] them to evolve according to international realities and needs." (Xanthaki 2005, 21)
} 
[...] we might think [...] that human rights would have provided some protection for Indigenous peoples and minority groups. Yet the human rights model was seen as limited in its applicability to these groups from its inception, in large part because of its focus on what were considered individual and universal rights. (42)

For these reasons, the minimalist position adopts a status quo bias that limits the evolution of an Indigenous right to external self-determination. Xanthaki (2007) observes that "for Indigenous peoples and many commentators, the obvious way to protect the group is through collective rights. In the Indigenous debate, this translates into recognizing that Indigenous peoples have the right to control matters that affect them and to manage, as a group, aspects of their lives, such as their education, language and lands." (29) Xanthaki (2007) continues, "providing Indigenous peoples with a system of individual rights [the preferred tool of minimialists] fails to protect them from the main violations of their human rights, because these include violations of a collective nature, towards Indigenous communities as a group." (31) Nevertheless, many Western states have persistently argued that collective rights are in some ways incompatible with individual rights.134 Within the working group on the Draft Declaration on the Rights of Indigenous Peoples, for instance, the United States explained its rejection of collective rights on the basis that these rights could be used to trump the individual rights of persons within the group (Xanthaki 2007, 32). Yet, by resisting a move towards collective rights, the US inhibited the creation of a rights-based framework

\footnotetext{
${ }^{134}$ In a way that demonstrates the status quo bias of minimalists, the Japanese representative to the working group on the Draft Declaration on the Rights of Indigenous Peoples, explained his government's hesitancy in adopting the phraseology of self-determination by noting its traditional relationship to decolonization. The representative of Japan, argued that the "concept of selfdetermination was set forth in the context of decolonization, mainly for colonized people who requested independence from states." (Xanthaki 2005, 22)
} 
that could go some way toward augmenting the exercise of internal selfdetermination by Indigenous peoples.

Taking a similar position, James Anaya (1990) critiques the minimalist perspective on its own terms, by citing its static and state-centric approach to selfdetermination. Anaya (1990) argues that "[u]nder a human rights approach, the concept of self-determination is capable of embracing much more nuanced interpretations and applications, particularly in an increasingly interdependent world in which the formal attributes of statehood mean less and less." (842; quoted in Xanthaki 2005, 25) In a later contribution, he argued that "it is distorting to attempt to organize self-determination precepts into discrete internal vs. external spheres defined by reference to presumptively mutually exclusive peoples." (Anaya 1996, 81) Instead, Anaya (1996) tenders an alternative approach to the concept of self-determination that seeks to de-link it from territorial premises and focus it instead on its substantive and remedial forms. ${ }^{135}$ Specifically, Anaya (1996) argues that on the substantive level, self-determination is marked by two elements,

First, in what may be called its constitutive aspect, self-determination requires that the governing institutional order be substantially the creation of processes guided by the will of the people, or peoples, governed. Second, in what may be called its ongoing aspect, self-determination requires that the governing institutional order, independently of the processes leading to its creation or alteration, be one under which people may live and develop freely on a continuous basis. (Anaya 1996, 81)

When either of these aspects is breached, self-determination assumes a remedial form, at which point it seeks to undo "any existing institutional impediment to the

\footnotetext{
135 It is important to note here, that in keeping with Anaya's argument, Indigenous peoples generally - have sought a greater degree of accommodation for their right to exercise greater levels of self-determination within the state. From this perspective, a maximalist account need not to be viewed as a threat to the territorial integrity of the state.
} 
continuous realization of self-determination values and to undo any current inequalities resulting from past deprivations of self-determination." (Anaya 1993, 163) In these ways, a maximalist approach concurs with a minimalist perspective; insofar as rights should be used to advance the participation of peoples within the state. But, it takes the minimalist approach further by suggesting that these rights not only entitle sub-state peoples to participation and freedom from discrimination, but also that sub-state peoples be granted rights that allow for the practical exercise of self-determination in areas like community governance, education, health, and culture - within Anaya's (1996) framework, the extent of these rights would be conditioned by their substantive and remedial dimensions.

Embodying a maximalist perspective, Anaya's (1996) interpretation of selfdetermination is thus one that is heavily premised on both historical context and contemporary realities; "remedies to redress historical violations of selfdetermination do not necessarily entail a reversion to the status quo ante, but rather are to be developed in accordance with the present-day aspirations of the aggrieved groups [...]." (Anaya 1996, 83) In light of this, Anaya (1996) is quick to note that selfdetermination does not necessarily imply a specific list of political solutions to grievances, but rather a range of measures used to address the claims of selfdetermining peoples to their social, cultural and economic affairs. And, while critics like Will Kymlicka (1999) have argued that Anaya's specific account of selfdetermination is principally founded in political theory rather than practice, maximalist accounts of self-determination are being voiced with increasing frequency by the Indigenous transnational movement and in international 
documents pertaining to Indigenous peoples. Xanthaki (2005) highlights two in particular, both of which focus on the cultural and economic dimension of selfdetermination: 1) the Indigenous peoples Earth Charter (IPEC; 1992); and 2) the Mataatu Declaration on Cultural and Intellectual Property Rights of Indigenous peoples (1993). ${ }^{136}$ Like minimalism however, the maximalist position does not come without its flaws. In particular, its broad interpretation of self-determination has been critiqued by minimalists for impeding action on Indigenous issues. Specifically, it is argued that by adopting a broad perspective of what selfdetermination means, the maximalist position can only vaguely be used to advance specific claims; indeed, "very often, other human rights can serve as a legitimate basis for claims, but the use of self-determination conceals them". (Xanthaki 2005, 28) Going even further, Rodolfo Stavenhagen (1996) argues that a maximalist approach "[...] may not only lead to chaos and anarchy [...] More than this, a 'maximalist' position will end up demeaning and devaluing the idea of selfdetermination itself, and will thereby only harm those collectivities who require it most." (quoted in Xanthaki 2005, 28) Nevertheless, momentum behind an Indigenous right to self-determination grew over the course of the decolonization period and in the next two sections, I begin to highlight this transition by analyzing critically international society's approach to self-determination; in particular, the processes leading to the Declaration (2007).

\footnotetext{
136 The preamble to the IPEC (1992) reads, "We Indigenous peoples maintain our inherent right to self-determination. We have always had the right to decide our own forms of government, to use our own ways to raise and educate our children, to our own identity without interference." Meanwhile the Mataatu Declaration (1993) states, "We declare that Indigenous peoples of the world have the right to self-determination, and in exercising that right must be recognized as the exclusive owners of their cultural and intellectual property."
} 


\section{Decolonization and the minimalist stance}

With the erosion of the Standard in the mid-20 $0^{\text {th }}$ century, Western members of international society found it increasingly difficult to sustain the distinction between the civilized self and the uncivilized other. Consequently, calls for independence in the former colonies of Europe were gathering momentum, and "[b]y the 1960s, the burgeoning [non-European] membership of the United Nations had closed the frontier of international society. The 'barbarian option', at least based on the old standard of 'civilization', disappeared." (Gong 1984, 85) The decolonization period has subsequently garnered considerable academic attention by both orthodox and critical English School scholars alike. For the orthodox English School, decolonization has been traditionally conceptualized as a period of disorder, since it marked the collapse of European empires and a radical transformation in the norms and values of international society. In fact, Hedley Bull (1984) suggested that the period was deeply implicated in the decline of Western prominence, a process he refers to as 'the revolt against the West.'137 By contrast, critical English School scholars have reflected on the period with more optimism, citing its role in challenging the discriminatory assumptions of international law. "The pivotal development here was the gradual erosion of the discriminatory distinction between European peoples as civilized and non-European peoples as backward." (Keene 2002, 147)

\footnotetext{
137 Bull (1984) argued that the revolt against the west began in the early 1900s with the normative bedrock of international society being shaken by WWI. In his view, the revolt encompasses five phases/themes: 1) the struggle for equal sovereignty; 2) the anti-colonial revolution; the struggle for racial equality; 4) the struggle for economic justice; and 5) the struggle for cultural liberation.
} 
Thus, despite differences in the way orthodox and critical English School scholars perceive the effects decolonization - as either negative or positive - they both agree that decolonization marked a period of radical change in the norms and values of international society. To what extent these norms and values actually challenged the foundational institutions of international society, however, is debateable. While it may be true that the more expansive membership of international society allowed for greater non-European participation in international affairs, and a platform to challenge Western assumptions of cultural superiority, ${ }^{138}$ the foundational institutions of international society - such as the sanctity of state sovereignty and the primacy of European forms of socio-political organization - remained largely untouched. Reminiscent of the Standard, some of the foundational documents outlining the decolonization process even borrowed from the civilizational discourse of preceding centuries. For example, Chapter XI of the UN Charter states that UN members with an administrative responsibility in non-self-governing territories "accept as a sacred trust the obligation to promote to the utmost, within the system of international peace and security established by the present Charter, the well-being of the inhabitants of these territories [...]." Going further, Article 73b indicates that these UN member states must take account of the fact that the peoples of these territories are of "varying stages of advancement;" despite not defining the concept of advancement itself.

\footnotetext{
138 For example, decolonization enabled the necessary preconditions for non-European states to forge political alliances to lobby for their interests, such as the non-aligned movement and the group of 77 .
} 
Significantly, it appears that the reason 'advancement' was left undefined by the Charter was because 'advancement,' at least in socio-political terms, was relatively uncontroversial. Specifically, socio-political advancement implied for most UN member states a recognizable form of self-government over a given territory. Article 73b of the Charter begins by noting that UN members with an administrative responsibility in non-self-governing territories are "to develop selfgovernment, to take due account of the political aspirations of the peoples, and to assist them in the progressive development of their free political institutions [...]."139 Working through this assumption, the UN approach to decolonization sought to promote the further expansion of the state system by granting colonial territories a right to pursue external self-determination, in such a way that realized their sociopolitical 'advancement' as self-governing and/or independent states. This was given further expression in UN General Assembly Resolution 1541, 'Principles Which Should Guide Members In Determining Whether Or Not An Obligation Exists To Transmit The Information Called For Under Article 73e Of The Charter.' With the purpose of defining the responsibilities of UN member states under Article 73e of the Charter, ${ }^{140}$ Resolution 1541 defines the moment at which a non-self-governing territory achieves self-government in distinctly state-centric terms. According to

\footnotetext{
139 This is expressed in Chapter XII, Article 76b of the UN Charter, which indicates that member states with an administrative responsibility in non-self-governing territories are "to promote the political, economic, social, and educational advancement of the inhabitants of the trust territories, and their progressive development towards self-government or independence as may be appropriate to the particular circumstances of each territory and its peoples and the freely expressed wishes of the peoples concerned, and as may be provided by the terms of each trusteeship agreement [...]."

${ }^{140}$ Article 73e of the UN Charter states that member of the UN with an administrative responsibility to a territory whose peoples have not yet achieved self-government, are "to transmit regularly to the Secretary-General for information purposes, subject to such limitation as security and constitutional considerations may require, statistical and other information of a technical nature relating to economic, social, and educational conditions in the territories for which they are respectively responsible other than those territories to which Chapters XII and XIII apply."
} 
Principle VI of Resolution 1541 (1960), “[a] Non-Self-Governing Territory can be said to have reached a full measure of self- government by: a) emergence as a sovereign independent state, b) free association with an independent state, or c) integration with an independent state."

While the UN approach to decolonization sought to guide territories towards European forms of socio-political organization - and by extension expand the state system - it is significant that this approach also restricted the exercise of external self-determination to territories, rather than to peoples. For example, in 1952, the General Assembly passed Resolution 637 on The right of peoples and nations to selfdetermination (1952). While the resolution acknowledged that peoples maintained a right to self-determination, it sought to restrict the exercise of this right to preestablished territories. According to Resolution 637,

The States Members of the United Nations shall recognize and promote the realization of the right of self-determination of the peoples of Non-Self Governing and Trust Territories who are under their administration and shall facilitate the exercise of this right by the peoples of such Territories according to the principles and spirit of the Charter of the United Nations in regard to each Territory and to the freely expressed wishes of the peoples concerned [...].

However, as Audrey Jane Roy (2001) observes, the failure of Resolution 637 to define a non-self-governing territory left the door open to broad conceptualizations of the term; including those that equated it with sub-state peoples. "When resolution 637 linked self-determination with non-self-governing territories, defining those territories and in essence defining who would be recognized as possessing the right to self-determination became vitally important." (Roy 2001) 
In light of the potential ramifications an expansive definition of non-selfgoverning territories had for states - such as the secession of sub-state peoples members of international society had to devise a philosophical premise upon which to restrict decolonization. For this reason, UN member states relied on what has come to be termed the blue-water thesis, ${ }^{141}$ which assumes that external selfdetermination is to be reserved for the overseas colonies of European empires. Citing its implications for sub-state and Indigenous peoples, Anaya (1999) aptly notes that the blue water thesis was "developed to preclude from decolonization procedures consideration of enclaves of Indigenous or tribal peoples living within the external boundaries of states." (43) Consequently,

The regime of decolonization prescription that were developed and promoted through the international system [...] largely bypassed Indigenous patterns of association and political ordering that originated prior to European colonization. Instead, the population of a colonial territory as an integral whole, irrespective of pre-colonial political and cultural patterns, was deemed the beneficiary unit of decolonization prescription. (Anaya 1996, 43)

Samuel Makinda (1998) concurs, noting that when "phrases like the selfdetermination of peoples were employed, they often referred to territorial entities." ${ }^{142}(106)$

It was not only the traditional members of international society that supported the blue-water thesis however, as recently 'decolonized' African and Asian states similarly opted to support it. In fact, some of these states proved to be

\footnotetext{
141 The blue-water thesis is also referred to as the salt-water thesis.

${ }^{142}$ It is acknowledged that the 'self-determination of peoples' may be perceived as a logical extension of 'individual self-determination,' embodied by the post-WWII human rights regime. However, it is argued that the self-determination of peoples implies a body of positive rights intended to facilitate national self-determination through action, whereas individual self-determination implies a negative conception of liberty that supports civil and political rights designed to ensure individual freedom from the interference of others.
} 
its staunchest supporters, when Belgium and France proposed that the concept of a non-self-governing territory be extended to "disenfranchised Indigenous peoples living within the borders of independent states, especially if the race, language, and culture of these peoples differed from those of the dominant population."143 (Pomerdance quoted in Roy 2001, 14) Support for the blue-water thesis by newly decolonized states was subsequently vocalized on two grounds. First, recently 'decolonized' states recognized that the Belgian thesis challenged their recently won sovereignty, just as much as it did settler states like Canada and the United States. In Africa, for instance, many of the territorial boundaries that had been established at the Berlin Conference (1884/85) remained intact following decolonization - as a consequence of the formal UN process restricting the beneficiaries of decolonization to pre-existing territories. Because the borders established at the Berlin Conference paid little attention to local politics - reflecting instead the commercial interests of Europe - newly decolonized African states were typically composed of many substate peoples with some form of a legitimate claim to external self-determination (see chapter five).

Second, 'decolonized' states noted that the Belgian and French proposal was couched in paternalistic assumptions that equated colonies with "primitive" peoples. Adopting the language of civilization "[France and Belgium] argued that the 'primitive' communities living within the frontiers of many states were in relevant respects indistinguishable from the peoples living in colonial territories

\footnotetext{
143 Anaya (1996) suggests that the Belgian thesis was advanced with self-interested motivations, rather than a concern for Indigenous peoples; according to him (1996), the thesis was advanced to "diffuse the political momentum coalescing around colonialism." (60)
} 
[...]." (Anaya 1996, 60) Having struggled to assert their own sovereignty for decades, by failing to meet the criteria of the Standard, African and Asian states thus rejected any association between themselves and the concept of 'primitiveness.' However, it is significant to note that these states did not necessarily reject the discourse as a whole. Indeed, while 'decolonized' states rejected their association with 'primitiveness' they did not necessarily reject the idea of their own superiority over certain sub-state/'domestic' peoples. Citing Hurst Hannum and Micha Pomerance, Roy (2001) notes,

Hurst Hannum, a noted international scholar, remarked that the same African nations who were so instrumental in pushing for a right to selfdetermination took a very narrow view of self-determination outside of the colonial context; territorial integrity and 'national' unity would take priority. Micha Pomerance has also noted that self-determination is almost exclusively applied when colonialism takes the form of [a] white colonizer oppressing a black population and almost never when one black population oppresses another. (17)

In other words, the very states which had endured centuries of European colonialism now found themselves accepting a discourse that granted them a right over others to exercise an exclusive right to external self-determination.

The legacy of the blue water thesis is present in subsequent resolutions pertaining to decolonization, including Resolution 1514, Declaration on the granting of independence to colonial countries and peoples (1960), and Resolution 1541. Where the former is concerned, Resolution 1514 seeks to limit the capacity of substate peoples from exercising external self-determination; according to Article VI, "[a]ny attempt aimed at the partial or total disruption of the national unity and the territorial integrity of a country is incompatible with the purposes and principles of 
the Charter of the United Nations [italics added]." In addition, Article VII of Resolution 1514 (1960) reads,

All States shall observe faithfully and strictly the provisions of the Charter of the United Nations, the Universal Declaration of Human Rights and the present Declaration on the basis of equality, non-interference in the internal affairs of all States, and respect for the sovereign rights of all peoples and their territorial integrity.

And, where Resolution 1541 is concerned, it draws heavily on the concept of territorial/geographic distinctiveness in defining a non-self-governing territory, so as to ensure that self-determination is limited to former colonial territories (Roy 2001, 18). Again, in clarifying the terms of Article 73b of the UN Charter, Resolution 1541 (1960) notes under Principle IV that member states with an administrative responsibility in non-self-governing territories have "an obligation to transmit information in respect of a territory which is geographically separate and is distinct ethnically and/or culturally from the country administering it [italics added]." Similarly, Principle V of Resolution 1541 (1960) begins, "Once it has been established that such a prima facie of geographical and ethnical or cultural distinctness of territory exists, other elements may then be brought into consideration [italics added].”

Viewed in this light, the 'erosion' of the Standard - proclaimed by orthodox and critical English School scholars alike - can be conceptualized as a beneficial, but limited outcome of decolonization. At the inter-state level, it opened a space for new voices to be heard in the form of newly independent states from the nonEuropean world - as these states joined the ranks of international society. However, while this space was generated by decolonization, the appearance of these non- 
European states did little to challenge the basic assumptions of international society; specifically, the primacy of the state and its near exclusive right to external self-determination and sovereignty. By upholding this assumption, newly independent states chose to limit the capacity of sub-state peoples to exercise external self-determination through the blue water thesis. Reflecting on the formal processes of decolonization, Paul Keal (2003) thus paraphrases Anaya (1996) in noting "that decolonization should be seen as rectification of a departure from the norm of self-determination and not as something that defines it." (Keal 2003, 133) The "universe of values that promoted the emancipation of colonial territories during the middle part of this [20th] century simultaneously promoted the assimilation of members of culturally distinctive Indigenous groups into dominant political and social orders that engulfed them." (Anaya 1996, 44)

\section{An Indigenous right to self-determination}

Since the formation of international society in the late-19th century, Indigenous peoples have faced considerable barriers to having their voices heard at the international level. The rebuffed delegations of Chief Levi General (Deskaheh) and Tahupotiki Wiremu Ratana to the League of Nations, for instance, symbolize the traditional resistance that members of international society have felt towards the grievances of sub-state peoples with a specific claim to self-determination (see chapter five). And, as observed above, this resistance persisted well into the 20th century as the state members of the UN restricted the beneficiaries of decolonization to territories rather than to peoples. In fact, Maivân Clech Lâm (2000) observes that as early as 1945, the "Iroquois again sought out international 
assistance. This time they attempted to address, again without success, the founding conference of the United Nations in San Francisco."(33-34) Indeed, "Further attempts to invoke UN intervention were made over the next decade, but generally floundered on the UN response that it could not deal with private, as opposed to state, sub-missions." (Lâm 2000, 34) Despite this resistance, however, Indigenous diplomatic endeavours persisted, and by the 1960s and 1970s an Indigenous transnational movement had begun to coalesce around common issues and interests. As the State of the World's Indigenous peoples (SWIP; 2010) report observes,

A great number of Indigenous peoples' organizations, were established at [the] national and international level in the 1960s and 1970s, spurred on by the decolonization era and a more general growth in non-governmental organizations. The issues that fuelled the movement ranged from broken treaties and loss of land to discrimination, marginalization, conflict and gross violations of human rights, including massacres. (SWIP 2009, 2)

While Indigenous action at the international level has occurred for centuries, the emergence of the Indigenous transnational movement in the 1970s is unique; insofar as it represents the inception of an Indigenous coalition of transnational actors. The inception of this society is typically traced to the UN Sub-Commission for Human Rights, which began work on a number of reports concerned with the impacts of discrimination on minority groups (Minde 2008, 53). ${ }^{144}$ Despite the problematic tendency to describe Indigenous peoples as minority populations, this work led to Indigenous issues being treated for the first time in special chapters of a UN study - the Study on Racial Discrimination in the Political, Economic, Social and

\footnotetext{
${ }^{144}$ As Minde (2008) observes, "The assignment of Special Rapporteurs opened the possibility, within the system, to point to individual states, criticising them for violating human rights; the Secretariat being expected to be neutral was unable to criticise individual states." (53)
} 
Cultural Spheres (1969) - in which they were described as "[d]isadvantaged in relation to the rest of the population: in some countries they are the victims of $d e$ facto discrimination and continue to suffer from prejudice." (quoted in Minde 2008, 54) Written by Hernán Santa Cruz (1969), the study also concluded with the recommendation that a new report be conducted that concerned itself solely with Indigenous peoples, and move beyond the issue of discrimination to include a focus on individual and equal rights (Minde 2008, 54).

With greater levels of international attention being paid to Indigenous issues, a space had begun to open within the UN for Indigenous peoples to engage transnationally on common issues. Moreover, Western public opinion was becoming more aware of Indigenous issues as alarming reports from South America began to highlight the negative impacts of gold mining, logging and the introduction of modern agricultural practices in Indigenous communities there (Minde 2008,54). In light of this, Minde (2008) observes that the Indigenous transnational movement evolved from a push and pull effect that brought together disparate groups of Indigenous peoples and their organizations;

It might seem odd that these often local and socially deprived [Indigenous] organizations were immediately engaged in international cooperation. This was the result of an historic "push-and-pull" effect: their territories all over the world became attractive for big development projects threatening their basis of existence. Indigenous peoples were therefore forced into action. At the same time they had discovered that the UN could offer them an attractive platform. (Minde 2008, 58)

However, the impetus for Indigenous transnationalism did not emanate solely from the international, but was also fostered in 'domestic' contexts'. Within Canada, for instance, the late 1960s and 1970s were marked by Government efforts to further 
integrate Indigenous peoples into Canadian society, in such a way that sought to "expunge all special rights, including the Indian Act, the reserves and the treaties and to transfer all welfare matters affecting the Indian population to the provinces." (Minde 20008, 59) Posed by this threat, Indigenous peoples residing in Canada responded with 'spontaneous militancy' and established a new federative structure called the National Indian Brotherhood in 1969, under the leadership of George Manuel (59).

With a view to creating a new political vision for the world's Indigenous peoples, Manuel "used his biography to publish a manifesto in the book "The Fourth World' [1974]." Articulating this vision, Manuel (1974) argued that,

The "Fourth world" means the coexistence of mankind based on mutual respect for each other's Culture, Social, Economic \& Political Institutions. It means that Indigenous peoples of the World, gain control of the Cultural, Social, Economic and Political Institutions. Within our own Indigenous Communities. Guaranteed by legal and constitutional safe guards to protect our Environment and our Indigenous lands. ${ }^{145}$ (quoted in Minde 2008, 59)

Furthermore, Manuel (1974) argued that Indigenous peoples were different from other minorities in that they had lost control of their traditional lands, and on this basis argued that Indigenous peoples needed to be compensated for this. Articulating a basis for global solidarism between Indigenous peoples, Manuel (1974) claimed that Indigenous peoples the world over required self-determination; specifically, "decision-making autonomy." (quoted in Minde 2008, 60) And, on this

\footnotetext{
145 This quote comes from a portion of text dedicated to the Sami, Aslak Nils Sara (Minde 2008, 59). This is significant because it alludes to the significance of the Sami in motivating the transnational movement, as it was the Sami that also inspired Augusto Willemsen Diaz's work on Indigenous issues when he worked on UN minority reports. Diaz "was fascinated by Sami reindeer herders' way of adapting to their circumstances since they 'brought with them in their nomadic migration two things: the school and the courts."' (Minde 2008, 53) Diaz's work in turn inspired the work of Hernán Santa Cruz, discussed above.
} 
basis, he helped found the World Council of Indigenous Peoples (WCIP) in 1975, at a meeting in Port Alberni that gathered around 260 people from 19 countries (Minde 2008, 60). As Minde (2008) suggests, the General Assemblies of the WCIP were thus established to build transnational Indigenous relations. And, the structure of the WCIP was intentionally created to give members a voice. "The intention was that the board should mirror that this was a global organisation."146 (Minde 2008, 60)

As a consequence of these and similar events, ${ }^{147}$ Indigenous transnationalism has evolved into a global movement that successfully lobbied for greater levels of participation within the UN through a dialogue with the members of international society. ${ }^{148}$ And, through this dialogue, several milestones have been achieved: 1) two UN International Decades of the World's Indigenous People; 2) the creation of the Permanent Forum on Indigenous Issues (PFII); and 3) the adoption of the Declaration (2007). In light of this, the SWIP (2009) notes that,

There has been a vigorous and dynamic interface between Indigenous peoples [...] and the United Nations [...] which [...] has produced at least three results: a) a new awareness of Indigenous peoples' concerns and human

\footnotetext{
146 For another account of the Indigenous transnational movement's evolution, see Rhiannon Morgan, Transforming law and institutions: Indigenous peoples, the United Nations and human rights (2011)

147 Minde (2008) observes that other similar events occurred that helped bring together Indigenous peoples at the global level. For instance, the International Indian Treaty Council (IITC) "attained UN consultative status in 1977 and in the same year they had their own representative in Geneva working with international issues." And, also in 1977 the IITC played a key role in preparing a conference titled "Conference on Discrimination against Indigenous Peoples of the Americas", and would later be known as 'Indigenous peoples' first meeting with the UN." Of 250 participants, 82 represented Indigenous organizations, and the conference adopted a declaration "claiming that Indigenous peoples should be recognized as "nations" and as such should be accepted as independent legal subject under international law." (62) Moreover, "[t]he conference agreed on a plan of action where Augusto Willemsen Diaz' idea of a UN working group for Indigenous issues was raised, once more, and they demanded that such a working group should be established." (Minde 2008, 63)

148 A key forum for the dialogue between international society and the Indigenous transnational movement has been the Indigenous Peoples Caucus. As Les Malezer (2010) explains, "The Indigenous Peoples' Caucus has been an important part of the interaction between the United Nations and Indigenous Peoples. It has become an important mechanism for UN officials who seek feedback on matters of protocol. It can also function as a steering mechanism to guide UN chairpersons and experts." (31)
} 
rights; b) recognition of Indigenous peoples' invaluable contribution to humanity's cultural diversity and heritage [...]; and c) an awareness of the need to address the issues of Indigenous peoples through policies, legislation and budgets. (1)

Speaking to the significance of the Indigenous transnational movement to contemporary IR, Franke Wilmer (1993) also observes that "Indigenous activism challenges the normative basis of international politics by asserting that the rights of sovereignty essential in order for a people to control their own political and economic development do not belong exclusively to nation-states emulating the European model." (2) For these reasons, Indigenous transnationalism has subsequently garnered considerable attention, both for the outcomes it has achieved and for the processes leading to them.

However, Indigenous successes through the UN have not been achieved without considerable resistance from states. This was particularly apparent in the context of processes leading to the Declaration (2007), which despite being passed by the UN General Assembly in 2007, was voted against by four powerful settler states: Australia, Canada, New Zealand and the United States. ${ }^{149}$ This resistance

${ }^{149}$ Since 2007, Australia, Canada, New Zealand and the United States have endorsed the Declaration (2007). Nuances in the reasoning for voting against the Declaration (2007) varied from state-tostate; however, certain commonalities were observable. Canada and New Zealand, for instance both argued - in general terms - that the Declaration (2007) was incompatible with their constitutional frameworks, while Australia and the United States both noted that the Declaration (2007) was ambiguous and too open to interpretation. Significantly, the Australian delegates made clear reference to concerns with the concept of self-determination in the text. "Australia's representative said his Government had long expressed its dissatisfaction with the references to self-determination in the text. Self-determination applied to situations of decolonization and the break-up of States into smaller states with clearly defined population groups. It also applied where a particular group with a defined territory was disenfranchised and was denied political or civil rights. Australia supported and encouraged the full engagement of Indigenous peoples in the democratic decision-making process, but did not support a concept that could be construed as encouraging action that would impair, even in part, the territorial and political integrity of a State with a system of democratic representative Government." (UN 2007a, online) 
typically played out during the drafting stages of the Declaration (2007) in the context of debates around self-determination; on the one hand, states voiced their opposition to this right by citing its potential to lead to a right of secession. On the other hand, Indigenous peoples cited self-determination as a central precondition for the protection of their collective rights, and for higher levels of independence over their lands, economics, culture and social affairs. In fact, self-determination appears in the Declaration (2007) explicitly under Articles 3 and 4. According to Article 3, "Indigenous peoples have the right to self-determination. By virtue of that right they freely determine their political status and freely pursue their economic, social and cultural development." And, according to Article 4 of the Declaration (2007), "Indigenous people, in exercising their right to self-determination, have the right to autonomy or self-government in matters relating to their internal and local affairs, as well as ways and means for financing their autonomous functions."

The inclusion of a specific right to Indigenous self-determination suggests that the Indigenous transnational movement was successful in challenging at least one of the problematic assumptions made by states in their relations with Indigenous peoples during decolonization. Specifically, it represents a move away from a minority rights framework to address Indigenous issues, by recognizing Indigenous peoples as peoples, and not simply populations. As Minde (2008) observes, "[t]he experience of the Indigenous movement was that the framework for general human rights and for special minority rights were unable to deal with issues connected to territories and collective rights." (76) And, "[b]ecause of this, it became important for the movement to create a distance from the ongoing work in 
the UN concerning minorities." (Minde 2008, 76) Significantly, and perhaps

ironically, one of the key stepping stones in this process came from within the UN

itself, when the UN Sub-Commission on Prevention of Discrimination and Protection

of Minorities, published the Cobo report (1986), which was itself heavily influenced

by the WCIP and 1977 Conference. ${ }^{150}$ While the Cobo report continued to perceive

an Indigenous right to self-determination primarily from a minimalist perspective,

the report proved pivotal in recasting Indigenous-state relations by noting an

Indigenous right to self-determination and implying their existence as peoples. ${ }^{151}$

According to paragraphs 579 and 580 of the report (1986),

Self-determination, in its many forms, must be recognized as the basic precondition for the enjoyment by the Indigenous peoples of their fundamental rights, and the determination of their own future. It must also be recognized that the right to self-determination exists at various levels and includes economic, social, cultural and political factors. In essence, it [selfdetermination] constitutes the exercise of free choice by Indigenous peoples, who must, to a large extent, create the specific content of this principle, in both its internal and external expression, which do not necessarily include the right to secede from the State in which they live and to set themselves up as sovereign entities. The right may in fact be expressed in various forms of autonomy within the State, including the individual and collective right to be different and to be considered different.

\footnotetext{
${ }^{150}$ As Minde (2008) observes, "statements and action plans from the WCIP's General Assembly in Sweden and the International NGO conference in Geneva in 1977 made a significant impact on the activity of Indigenous peoples in the UN in the years to come. The declarations from these conferences were used as important frames of reference for the Martínex Cobo study and laid the foundation for subsequent recommendations in the report." (64)

151 As Minde (2008) observes, the decision to frame Indigenous issues as distinct from minority issues was highly controversial and met resistance. Prior to the Cobo report, Chilean diplomat Hernán Santa Cruz, for instance, insisted on referring to Indigenous peoples as populations, whose issues could be best addressed through policies of assimilation and suggested that a report on Indigenous peoples could be included within one on minorities. However, the work of Willemsen Augusto Diaz and Carlos García Bauer "managed to prevent the new report on Indigenous peoples from being included as part of the study on the protection of minorities." (Minde 2008, 54) Doing so, they opened the necessary space for the subsequent Cobo Report. Most importantly, the implication of this "was that minorities and Indigenous peoples were be dealt with separately in the future." (Minde 2008, 55)
} 
Building on this type of momentum, "the organized and intensive work undertaken at the United Nations by Indigenous representatives led to the most substantive development for Indigenous rights when the Sub-Commission, authorized by ECOSOC, established the [Working Group on Indigenous peoples (WGIP)] to monitor developments relevant to Indigenous peoples."152 (Davis 2007, 56) Specifically, the WGIP was mandated: 1) to review "developments pertaining to the promotion and protection of the human rights and fundamental freedoms of Indigenous populations;" (ECOSOC 1982/34) and 2) "to give special attention to the evolution of standards concerning the rights of such populations." (ECOSO 1982/34) And, while Henderson (2008) rightfully observes that the WGIP was located at the lowest level of human rights bodies in the UN, the body proved central to processes leading to the Declaration (2007) as it established a forum within which Indigenous and state representatives could engage in constructive dialogue. ${ }^{153}$ In fact, Minde (2008) observes that despite being located at the lowest level of the UN, this position had three advantages for the Indigenous transnational movement. First, the WGIP enabled Indigenous peoples to create a space for themselves within the UN by avoiding the superpower rivalry of the Cold War that so often stymied progress in it. Second, the leadership of the WGIP was composed of independent experts that were relatively free from the influence of state interests - the WGIP was

\footnotetext{
152 Citing the importance of the WGIP, Lâm notes that "[...] it must be remembered, out of the WGIP has come, directly or indirectly, not only the Draft Declaration, but also the ideas for the 1993 Year of the World's Indigenous People, the 1995-2004 Decade of the World's Indigenous Peoples, a Permanent Forum for Indigenous Peoples, the UN Voluntary Fund for Indigenous Peoples, the UN Indigenous Fellowship Programme, and assorted WGIP studies on issues of prime concern to Indigenous peoples (treaties, land, heritage, health, education, and biodiversity)." (Lâm 2000, 76)

153 Henderson (2008), continues by noting that "[i]ts recommendations ha[d] to be considered and accepted by the Commission on Human Rights and the Economic and Social Council (ECOSOC) before reaching the General Assembly." (41)
} 
originally led by Asbjørn Eide, who was then superseded by his successor Erica Irene Daes (Minde 2008, 71; see also Lâm 2000, 76-77). Third, the WGIP allowed any Indigenous group or delegate to attend and address its meetings, with a voluntary UN fund established to support the travel costs of these groups/delegates.

By avoiding superpower rivalries and engaging in an open dialogue that was mediated by independent experts, Indigenous peoples and their representatives were thus better situated to voice their concerns at the international level than they had been in the past. According to Lâm (2000),

[...] Indigenous peoples spoke in their own voice, and employed their own discursive style, including the use of distinctive dress, language, and ceremony. They were, by and large, granted time on a formally equal basis with states and NGOs in consultative status with the United Nations. (80-81)

This was because "no one detained the power to make decisions on the Draft Declaration except its five experts." (Lâm 2000, 81) Yet, despite being better situated, Indigenous representatives were faced with some considerable barriers, and despite Lâm's (2000) bullish account of the WGIP, it is important to remember that states wielded a significantly greater degree of power over the WGIP than did their Indigenous counterparts. In fact, it is noteworthy that on matters pertaining to self-determination, the leadership of the WGIP moved slowly out of fear that the WGIP would be closed down by concerned UN member states. As Minde (2008) observes, "in 1983 [Eide] urged moderation [when it came to demands for selfdetermination] for two reasons: (1) Fear of the states closing down the WGIP and (2) that international organs had great difficulty defining 'peoples' in connection with self-determination." (78) 
In light of the controversy surrounding the concept of self-determination, it is also significant to note that despite an official decision made by the WGIP to begin working on a Draft Declaration on the Rights of Indigenous peoples (Draft Declaration) in 1985, it was not until 1991 that the WGIP introduced "language on the highly charged issue of self-determination." (Lâm 2000, 77) And, as pointed out by many Indigenous delegates, this language proved exceptionally weak; as Lâm (2000) explains,

[t]he initial language recognized that an Indigenous people could freely determine its relationship with a state in a spirit of coexistence with other citizens, and also pursue its social, economic, cultural and spiritual development in freedom and dignity." But, [t]he clause notably omitted any reference to the choice of political status [...]. (78)

It was on this basis that forceful advocacy on the part of the Indigenous transnational movement began to broaden the conceptualization of selfdetermination. In fact, Lâm (2000) suggests that this was observable in the position of Chairman Daes, who had originally maintained that Indigenous peoples were only entitled to a limited right to self-determination, but who changed her position in 1993 when faced with the persistent advocacy of Indigenous representatives. Speaking in the context of the early post-Cold War era, Daes stated,

In the case of former Eastern Europe, peoples that were joined together in States more than fifty years ago have re-emerged as separate states with the full recognition and protection of the United Nations. There are examples of Indigenous peoples that were only absorbed by States, in all but the most theoretical terms, within the past fifty years or less [...] It would be strange, and arguably racist, for the United Nations to recognize the break-up of a historical union of European peoples, but condemn the break-up of a union elsewhere in the world simply because Indigenous peoples were involved. (quoted in Lâm 2000, 79) 
With the support of Chairman Daes behind a broader conceptualization of an Indigenous right to self-determination, the WGIP introduced a draft of the Draft Declaration in the 1994 Report of the Sub-commission on Prevention of Discrimination and Protection of Minorities at its 46th session. Then, with this submitted, the "Commission on Human Rights ('CHR') established an open-ended inter-sessional working group elaborating a draft declaration on the rights of Indigenous people [...] in 1995." (Davis 2007, 56) However, this move threatened to undermine headway garnered on the concept of self-determination. While the intention of the working group was to include the participation of Indigenous peoples from its inception, the CHR - and later the Human Rights Council that replaced it in 2006 - remained an entirely state-based forum, and "unlike independent experts, [states] are highly interested parties, with little critical distance from the Draft Declaration." (Lâm 2000, 81) Megan Davis (2007) thus notes that despite the initial decision by the working group to incorporate the views of Indigenous peoples, participation was hampered from the outset. ${ }^{154}$ At the first session, for instance, Indigenous participation with the text was limited, while the second session ended in a walk-out by Indigenous representatives citing issues with the proposed work agenda and leading to "the Indigenous caucus call[ing] for the immediate adoption of the text 'without change, amendment or deletion' and

\footnotetext{
${ }^{154}$ Lâm (2000) reads this differently, arguing that "[...] the culture of participation - including knowledge, values, customs and alliances - that coalesced in the WGIP inevitably penetrates the WG on Draft Declaration. The earlier support of a number of states in the WGIP also remains, as does the strong solidarity of Indigenous peoples and the institution of the Indian Caucus, which meets a week ahead of the WG on the Draft Declaration to stake out positions [...] Finally, values and customs, once validated, die hard, even in international law making. And this may be the enduring legacy of the WGIP: that it validated the voices of Indigenous peoples, as well as their right to self-determination, which ultimately may be one and the same thing. (82)"
} 
express[ing] concerns about amendments to the text." (Davis 2007, 56; see also Deer 2010) And, by the third session, Davis (2007) observes that this position had subsequently become entrenched, resulting in an impasse that lasted from 19982004, with just two of the least controversial articles of the text being adopted. ${ }^{155}$

“It wasn't until the Working Group met in 2004 that significant advances were made in breaking the impasse between states and Indigenous peoples, as the abolition of the Indigenous Caucus' 'no change' position resulted in Indigenous participation in amendments to the text." (Davis 2007, 57; see also Deer 2010) It was at this stage that the concept of self-determination was revisited. On the one hand, Indigenous peoples and their representatives "argued that the international legal right of self-determination applied to them and indeed constituted the cornerstone upon which the (then) Draft Declaration was predicated." (Davis 2007, 57) On the other hand, state representatives remained focused on retaining a strict minimalist perspective, citing the term's association with territorial integrity, noninterference and a related right to secession (Davis 2007, 57). ${ }^{156}$ The outcome of these competing positions resulted in something of a compromise; through the inclusion of an Indigenous right to self-determination, Stefania Errico (2007a), observes that the Declaration (2007) implicitly accepts the view that Indigenous peoples are recognized as peoples by international law - from which the right to

\footnotetext{
155 Davis (2007) explains that earlier, "In 2002 Working Groups convened in February and December [...]. These meetings reflected the growing frustration at the inertia of the Working Group. The major controversy for Indigenous participants during this period was that the drafting was conducted by states, in private sessions, during the two weeks allocated by the UN for meeting time to work in 'informal consultations'." (57)

${ }^{156}$ Yet, this was not necessarily the objective of Indigenous peoples, who cited the 'safeguard clause' of the 1970 Declaration on the Principles of International Law Concerning Friendly Relation and Cooperation Among States, which was eventually included on the final Declaration in Article 46.
} 
self-determination follows. Consequently, it implies that Indigenous peoples have a right to exist and be different, recognizing that as a peoples - not a population - they have a right to be free from forced assimilation and/or destruction of their culture (747). Yet, at the same time, the Declaration (2007) retains a preoccupation with the territorial implications of extending rights of self-determination to Indigenous peoples, and is thus marked by minimalism and an internal/external dichotomy.

This is evidenced by language within the Declaration (2007) that expressly limits the capacity of Indigenous peoples to exercise external self-determination under only the most extreme of conditions; specifically, when they find themselves under conditions of colonial or alien domination or are the subjects of a racist regime. 157 This is in large part due to the influence of states, which in addition to deleting one preambular paragraph, included two more to better safeguard against the exercise of an Indigenous right to external self-determination - the final Declaration (2007) omitted the following statement found in the Draft Declaration; "recognizing that Indigenous peoples have the right freely to determine their relationships with States in a spirit of coexistence, mutual benefit and full respect.' And, where the added text is concerned, Errico (2007b) explains, that "[...] two preambular paragraphs have been introduced, recalling respectively the principles of the Charter of the United Nations and the Vienna Declaration and the Programme of Action, which should be read in conjunction with the sentences added at the end of Article 46, para 1." (758) This specifically reads,

157 This stems from the 1970 Declaration on the Principles of International Law Concerning Friendly Relations and Cooperation Among States. 
Nothing in this Declaration may be interpreted as implying for any State, people, group or person any right to engage in any activity or to perform any act contrary to the Charter of the United Nations or construed as authorizing or encouraging any action which would dismember or impair, totally or in part, the territorial integrity or political unity of sovereign and independent States. (UN 2007)

In other words, while the Declaration (2007) has helped to broaden and deepen levels of Indigenous self-determination within the state -advancing the maximalist approach - it remains marked by minimalism and Westphalian anxieties about the erosion of state sovereignty.

\section{Conclusion}

IR has traditionally associated the end of the Cold War and the onset of decolonization with a period of disorder in international politics. For Bull and Watson (1984), the moment marked an upheaval in the traditional norms and values of what had been primarily a Western society of states (see literature review). Similarly, scholars such as Gerrit Gong (1984) have contended that the onset of decolonization resulted in the erosion of the Standard, which came under critical scrutiny as Europeans lost some of their cultural self-confidence in the face of: 1) the horrors of the Second World War; and 2) calls for independence in European colonies. However, as Gong (1984) aptly notes, the erosion of the Standard did not result in the end of standards with which to judge membership in international society. Rather, he suggests that two contenders emerged to replace the Standard; a standard of human rights and a standard of modernity. A similar, but slightly different argument has been put forward by Bowden (2004), who claims that the Standard gave way to a new standard that premised itself on both human 
rights and modernity - thus where Gong (1984) saw human rights and modernity as two potential competitors, Bowden (2004) conceptualizes them as conjoined allies. Problematically however, IR scholars have conceptualized this shift in an uncritical fashion, arguing that it represented a move toward greater levels of inclusion in international relations. As Paul Keal (2003) puts it,

From the perspective of the late twentieth century the idea that international law recognized only claims of members of international society against each other is troubling. Fortunately it belongs to a phase of international law that has long been left behind. (207)

As suggested by this chapter, however, the Standard did not so much erode in the mid-20 $20^{\text {th }}$ century, so much as it transformed; this was observed in the way that it informed international society's discourse with the Indigenous members of world society on the issue of self-determination. Indeed, this dialogue sought to limit the exercise of self-determination to territorial entities, and not peoples. Speaking to this issue, this chapter has alluded to the fact that the transition from the classical Standard to a standard based on human rights and modernity did little to alter the contours of international relations, but actually helped to facilitate the expansion of international society through decolonization - by providing new states a basis upon which to limit sub-state calls for self-determination by the Indigenous members of world society. Through the Blue Water thesis, for instance, members of international society sought to restrict decolonization to territorial entities, rather than extend it to peoples. Bypassing Indigenous peoples and other sub-state peoples, decolonization did little to change relations between international society and the Indigenous members of world society for most of the $20^{\text {th }}$ century, as Indigenous peoples continued to be excluded from full participation within the 
society of states. In fact, the human rights framework that evolved in the postWorld War II era actually sought to subsume Indigenous peoples further within the states that they were ensconced in, by conceptualizing them as minority populations. ILO Convention 107 is symbolic of this approach, depicting Indigenous and other sub-state peoples as minority populations lacking in development, and positing rights to help integrate them into the fabric of the state. In other words, the transition to a standard premised on modernity and human rights did little to change the core feature of civilization; it remained a device for structuring relations between self and other, while justifying processes to subsume the other into the self.

This is not to suggest that the Indigenous members of world society were passive recipient of 'civilization.' For instance, the Indigenous transnational movement that coalesced in the 1970s provided for a more unified and forceful voice in dialogue with international society. And, whereas the preceding centuries of international Indigenous activism were characterized by only limited success, the inception of the Indigenous transnational movement in the 1970s translated into significant momentum for processes leading to the Declaration (2007) - as well as other UN activities. By working through the confines of the WGIP, Indigenous peoples and their representatives engaged with international society in an effort to challenge prevailing norms that governed Indigenous-state relations and to advocate for greater levels of Indigenous self-determination within the state. For this reason, the Declaration (2007) is thus conventionally - and justifiably - viewed as a hard fought step towards moving Indigenous-state relations in the direction of a maximalist approach to Indigenous self-determination. As is discussed in the 
following chapter however, such perspectives need to be tempered by a more critical reflection on the scope of the right to self-determination tendered by the document. Whereas some Indigenous scholars and jurists herald the Declaration (2007) as an important advance in Indigenous-state relations, others conceptualize it as an extension of colonial international relations - i.e. as an instrument aimed at dulling Indigenous activism by granting Indigenous peoples a limited right to selfdetermination (Corntassel 2007). In the next chapter, I explore this tension through an analysis of the exercise of the right to self-determination through an examination of its relationship to Indigenous knowledge - a concept that some Indigenous scholars like Jeff Corntassel (2007) contend is central to the long-term survival of Indigenous peoples. ${ }^{158}$

\footnotetext{
158 The significance of Indigenous knowledge is symbolized by the fact that the Declaration (2007) speaks explicitly to it through Article 31 . With the aim of augmenting the capacity of Indigenous peoples in exercising self-determination over their traditional knowledge, Article 31 states, "Indigenous peoples have the right to maintain, control, protect and develop their cultural heritage, traditional knowledge and traditional cultural expressions, as well as the manifestations of their sciences, technologies and cultures, including human and genetic resources, seeds, medicines, knowledge of the properties of fauna and flora, oral traditions, literatures, designs, sports and traditional games and visual and performing arts. They also have the right to maintain, control, protect and develop their intellectual property over such cultural heritage, traditional knowledge, and traditional cultural expressions." (UN 2007)
} 


\section{Chapter seven}

Civilization and Indigenous knowledge 
[...] few people have questioned how a European term and idea [...] came to be so embedded and important to cultures that had their own systems of government since the time before the term sovereignty was invented in Europe. Fewer still have questioned the implications of adopting the European notion of power and governance and using it to structure the postcolonial systems that are being negotiated and implemented within Indigenous communities today.

- Taiaiake Alfred 2005, 25

For some, the United Nations (UN) Declaration on the Rights of Indigenous Peoples (the Declaration, 2007) represents a significant step forward in relations between international society and the Indigenous members of world society. According to Phil Fontaine (2010), "[i]n the 1970s, Indigenous peoples from all over the world [...] travelled to Geneva, demanding representation at the international level. Thirty years later, we see Indigenous people speaking in the United Nations General Assembly." (9) Fontaine (2010) continues, "[t]he Declaration is fundamentally about building meaningful relationships with Indigenous peoples across the globe, and with nation-states and with Indigenous Rights supporters. [...] But it is also an expression of the global partnerships and solidarity of Indigenous Peoples." (9) In a similar vein, James Youngblood Henderson (2008) - an Indigenous lawyer and activist engaged in the process leading to the Declaration - regards it as a seminal accomplishment for contemporary Indigenous-state relations. According to Henderson (2008), the rights framework even served as the impetus for the formation of the Indigenous transnational movement, "[a]s the principles of peace and human rights were declared by the General Assembly, the vision was rekindled among Indigenous peoples. They created the diplomacy network and began to develop a new vision of a just global order based on human rights." (30) Indeed, it 
was through the human rights framework that Indigenous peoples successfully negotiated a right to self-determination. ${ }^{159}$

It is through the right to self-determination that some Indigenous peoples perceive a legal basis with which to redefine their relationship with states. As Kenneth Deer (2010) - former co-chair of the Indigenous Peoples' Caucus observes, "[f]rom the start of our international work, Indigenous peoples sought recognition of our right to self-determination. This right has been key from the beginning. [...] All our rights either flow from or are linked to our right of selfdetermination." (27) It is this assumption that subsequently underpins the Declaration's aim of establishing a new relationship between Indigenous peoples and the members of international society. In fact, Les Malezer (2010) notes that during the final stages of reviewing the draft Declaration, Denmark suggested that the document conclude with a motivating message to stress the importance of states in implementing the Declaration's standards, so as to move the members of international society towards a more equitable relationship with Indigenous peoples (44). Furthermore, despite wording used under Article 46 to limit the extent of an Indigenous right to self-determination - by asserting the territorial integrity of states - the Declaration does emphasize the concept of a 'partnership'

\footnotetext{
${ }^{159}$ In the same vein as Fontaine (2010) and Henderson (2008), Gilbert (2007) notes, "As [Patrick] Thornberry [2002] highlights, 'international law is conceived as a kind of club and members must accept the rules.' Indigenous peoples are latecomers to this 'exclusive club'. Until recently, the 'exclusive club' was only open to States, and in many ways the Indigenous peoples' movement has challenged such assumptions by claiming their right to access the international stage. The emphasis from the UN on partnership and mutual respect between States and Indigenous peoples offers an important new forum for discussion, and the UN Declaration would certainly become an important factor for increasing such dialogue. Overall, the adoption of the UN Declaration will indicate an important departure from a bloody past where international law played an important role in the destruction of Indigenous cultures, and from this perspective the Declaration is a promising step toward a future based on partnership and mutual respect." (230)
} 
between states and Indigenous peoples, premised on the human rights standards of the Declaration and on the condition of 'mutual respect.' According to the final paragraph of the Declaration's (2007) preamble, the General Assembly "solemnly proclaims the following United Nations Declaration on the Rights of Indigenous Peoples as a standard of achievement to be pursued in a spirit of partnership and mutual respect [between states and Indigenous peoples]."

Whereas scholars like Malezer (2010), Deer (2010) and Henderson (2008) remain optimistic about the future impact of the Declaration, critics note a number of weaknesses with it. For example, the Declaration is not a legally binding document; rather, its aim is to serve as a standard setting document that state parties enter into voluntarily. Thus, while it aspires to reshape Indigenous-state relations, this objective hinges on the extent to which state signatories choose to implement its standards at the domestic level. In addition, scholars point out problems with the content of Declaration standards (Corntassel 2007 \& 2008). While Jeff Corntassel (2007) recognizes the Declaration as an important standard setting instrument, he also notes that the process leading to it was marked by cooptation. Focussing on the first International Decade of the World's Indigenous People (1995-2004), Corntassel (2007) argues that states successfully dulled Indigenous diplomacy by extending fringe benefits to Indigenous representatives and offering the 'illusion of inclusion,' by 'blunting' and 'channeling' the endeavours of the Indigenous transnational movement. Borrowing these terms from Michael Lacy (1985), Corntassel (2007) explains that "[b]lunting simply means that an Indigenous political agenda is shifted and altered to fit the dominant norms of 
existing, institutional structures." (140) By contrast, "[c]hanneling effects occur when members of Indigenous groups, having accepted representation via global forums, confine their activities solely within these official structures and cease other forms of political mobilization outside of the UN system." (Corntassel 2007, 29)

Reflecting on the events of the past two decades, Corntassel (2008) subsequently argues that the rights-based framework - a key feature of the standard of modernity and human rights - limits the capacity of Indigenous peoples to exercise self-determination; "the rights discourse can take Indigenous peoples only so far." (107; see also Corntassel \& Bryce 2012) This is on four counts; first, Corntassel (2008) notes that the rights framework compartmentalizes Indigenous powers of self-determination "by separating questions of homelands and natural resources from those of political/legal recognition of a limited Indigenous autonomy within the existing framework of the host state(s)."160 (107) Second, he argues that the rights framework can lead to a denial of Indigenous identities and has the potential to categorize Indigenous peoples as sub-state populations without a significantly strong claim to self-determination. Corntassel (2008), for instance, observes that an Indigenous right to self-determination led Botswana to: 1) staunchly oppose ratification of the Declaration; and 2) to refer to its Indigenous

\footnotetext{
160 Jeff Corntassel gives the example of the 1999 Nisga'a Final Agreement. Through it, the provincial government of British Columbia, Canada, paid the Nisga'a tribal council \$190 million in a negotiated settlement that saw the Nisga'a surrender their tax exemption status under the Indian Act. (Corntassel 2008, 106) According to Corntassel (2008) this arrangement is indicative of the fact that "states tend to narrowly frame self-determination by focusing on state political/legal recognition of Indigenous peoples as self-governing entities while diverting energies away from more substantive discussions regarding the reclamation of Indigenous territories, livelihoods, natural resources, and the regeneration of community languages and culturally based practices." (107) Indeed, the agreement "provided a political/legal basis for limited autonomy but neglected to address interrelated issues of regenerating sustainable livelihoods, food security, and renewal of community relationships with the natural world." (Corntassel 2008, 107)
} 
peoples as 'races,' 'communities,' or 'tribes;' such a right "raised issues with serious economic, political, and constitutional ramifications, which in Botswana's view, could only contribute to ethnic conflicts within nations of which Africa had more than a fair share."161 (quoted in Corntassel 2008, 107) Third, Corntassel (2008) notes "that the framing of rights as political/legal entitlements has deemphasized the cultural responsibilities and relationship that Indigenous peoples have with their families and the natural world [...]." (Corntassel 2008, 107) And finally, he (2008) argues that "the rights discourse has limited the applicability of decolonization and restoration frameworks for Indigenous peoples by establishing ad hoc restrictions." (108) In light of these problems, Corntassel (2008) proposes an alternative concept to promote the future of Indigenous peoples: sustainable selfdetermination.

According to Corntassel (2008), sustainable self-determination is rooted in the transmission of Indigenous knowledge and culture from one generation to the next, as he suggests that it is only through the transmission of Indigenous knowledge that Indigenous peoples will be able to sustain their societies and political identities over the long-term. ${ }^{162}$ In his words, sustainable selfdetermination "is premised on the notion that evolving Indigenous livelihoods, food security, community governance, relationships to homelands and the natural world, and ceremonial life can be practiced today locally and regionally, thus enabling the

\footnotetext{
${ }^{161}$ In chapter six, it was also observed that the terminology of the rights discourse was used in a way that justified the assimilation of Indigenous 'populations' into the fabric of the state.

162 According to Corntassel (2008), the concept of sustainable self-determination builds on Anaya's conceptualization of self-determination (see chapter six), by adding the concept of sustainability, rather than fixating on the remedial solutions Anaya proposes to resolve historical breaches of selfdetermination: the creation of a new governance mechanism within a state that facilitates higher levels of autonomy. (118)
} 
transmission of these traditions and practices to future generations." (Corntassel $2008,119)$ Corntassel $(2008)$ continues, "[o]perating at multiple levels, sustainable self-determination seeks to regenerate the implementation of Indigenous natural laws on Indigenous homelands and expand the scope of an Indigenous selfdetermination process." (119) For Corntassel (2008), sustainable selfdetermination thus has four key features:

1. Sustainable self-determination refutes colonial and state-based forms of political/recognition as the main pathways to self-determination;

2. Sustainable self-determination adopts a broader view of self-determination by rejecting the compartmentalization of political and legal definitions, preferring instead those that take account of social, economic, cultural and political factors of shared governance and relational accountability;

3. Sustainable self-determination operates at the community and regional level, rather than simply at the global level (a level dominated by states);

4. Sustainable self-determination is premised on the assumption that Indigenous peoples will significantly influence the global political economy by rebuilding and strengthening their own local and regional economies. (119)

In light of this, Corntassel (2008) argues that the rights-based definition of self-determination is unable to promote the long-term viability of Indigenous peoples. Not only has the content of a right to self-determination been dulled by the members of international society, its Eurocentric origins fail to respond to Indigenous societies. What is required, is a responsibility-based process that, 
[...] entails sparking a spiritual revolution rather than seeking state-based solutions that are disconnected from Indigenous community relationships and the natural world. The pursuit of self-determination should be repositioned away from a narrowly constructed, state-driven rights discourse toward a responsibility-based movement centered on a sustainable self-determination process. (Corntassel 2008, 124)

Building on the work of Corntassel (2008), this chapter critically examines the rights-based framework fashioned by international society, paying close attention to its relationship with the concept of civilization, and how this relationship has in turn structured relations with Indigenous peoples on the matter of Indigenous knowledge. Selection of Indigenous knowledge is based on two factors. First, Indigenous knowledge is the very concept upon which Corntassel (2008) premises his definition of sustainable self-determination; ${ }^{163}$ second, the concept has received increasing levels of attention by international society over the past two decades and is recognized by the Declaration under Articles 11, 24, and 31. This chapter subsequently proceeds in three sections:

1. The first section defines Indigenous knowledge by distinguishing the concept from traditional and Western knowledge. Following this, it highlights the role Indigenous knowledge plays in the global economy and the manner in

\footnotetext{
163 Michael Blakeney (2006) highlights the connection between Indigenous knowledge and the right to self-determination in the context of intellectual property; arguing that, "[t]he growing selfrealisation of Indigenous peoples that the international recognition of their intellectual property rights in their cultural expressions would depend upon their own efforts, has resulted in the development of international solidarity through international conferences of Indigenous peoples. These conferences have promulgated intellectual property declarations, formulating norms for the protection of traditional knowledge. A significant initiative during the UN International Year for the World's Indigenous Peoples was the First International Conference on the Cultural and Intellectual Property Rights of Indigenous Peoples which was convened by the Nine Tribes of Mataatua in the Bay of Plenty Region of Aotearoa/New Zealand in June 1993. The resultant Mataatua Declaration on the Cultural and Intellectual Property Rights of Indigenous Peoples insisted that the protection of the rights of Indigenous peoples in their traditional knowledge was an aspect of the right of Indigenous people to self-determination." (114)
} 
which states have sought to govern it through the multilateral forums of international society.

2. The second section critically details the relationship between the governance of Indigenous knowledge and the intellectual property system by highlighting its relationship to the concept of civilization from a global political economy perspective.

3. The third section highlights the relationship between the intellectual property system and the standard of modernity and human rights in an effort to demonstrate how the extension of the rights-based framework of international society subsumes the Indigenous members of world society within a framework that impedes them from exercising self-determination at the domestic and international level.

\section{Indigenous knowledge and the global economy}

Despite its growing usage within international forums, the meaning of Indigenous knowledge remains ambiguous. This is in part due to the fact that Indigenous knowledge is often used interchangeably with the term traditional knowledge. "Different persons define [Indigenous and traditional knowledge] differently depending on their intellectual persuasion and professional interest. And many often use the concept of traditional knowledge interchangeably with that of Indigenous knowledge." (Mugabe 1998, online) For this reason, John Mugabe (1998) defines Indigenous knowledge by distinguishing it from traditional knowledge; citing the United Nations Environment Program (UNEP), Mugabe (1998) argues that traditional knowledge refers to knowledge "[...] which is held by 
members of a distinct culture and/or sometimes acquired 'by means of inquiry peculiar to that culture, and concerning the culture itself or the local environment in which it exists."' (online) By contrast, Indigenous knowledge refers to knowledge "held and used by a people who identify themselves as Indigenous of a place based on a 'combination of cultural distinctiveness and prior territorial occupancy relative to a more recently-arrived population with its own distinct and subsequently dominant culture." (Mugabe 1998, online) With this distinction in mind, some scholars go further, suggesting that the meaning of Indigenous knowledge emanates from its juxtaposition against Western knowledge systems. Identifying four elements of a knowledge system - 1) approach; 2) communication; 3) teaching methods, 4) explanation - Tonina Simeone (2004) argues that Indigenous knowledge is:

1. Holistic in its approach whereas western knowledge is compartmental;

2. Oral in its communication whereas Western knowledge is written;

3. Conveyed through observation whereas Western knowledge is theory-based;

4. Spiritual/value-based whereas Western knowledge strives for objectivity. ${ }^{164}$ Chidi Oguamanam (2006), however, observes that clear distinctions between Indigenous and Western knowledge risk essentializing the meaning of both, since these distinctions overlook evolutionary similarities. For instance, some of what is today deemed Western knowledge evolved from folklore and other customary practices that are more commonly associated with traditional knowledge.

\footnotetext{
164 Simeone (2004) uses the term traditional knowledge rather than Indigenous knowledge; however it can be inferred that she is speaking specifically about Indigenous knowledge as her brief focuses on Indigenous peoples and their traditional knowledge.
} 
Moreover, Oguamanam (2006) argues that juxtaposing Indigenous knowledge against Western knowledge may actually result in the former's marginalization. "Evaluating Indigenous or traditional knowledge in comparison to Western science tends to presuppose an 'overarching comparator' in the form of 'universal reason' or 'science,' which is always ontologically privileged." (Oguamanam 2006, 14) Because of its historical association with reason, it is Western knowledge that becomes inscribed with reason, resulting in a self-other dichotomy that represents Western knowledge as scientific/rational and traditional knowledge as folkloric/unscientific. ${ }^{165}$ Nevertheless, Oguamanam (2006) admits that despite the inherent risks in such juxtapositions it would be equally problematic to gloss over differences between Indigenous/traditional and Western knowledge. Thus, he (2006) proposes that basic differences between the two can be maintained, so long as they are contextualized. Drawing on the work of anthropologists, he observes that "we inhabit a world of 'trans-cultural discourse' where a baseline of universal reason prevails in all traditions. Such a baseline 'is driven by shared human economic needs and cognitive processes [... however] they are activated and expressed in different cultural contexts." ${ }^{166}$ (Oguamanam 2006, 15)

\footnotetext{
165 Michael Blakeney (1999) reminds us that until recently, the term folklore had been used to refer to traditional knowledge. In the 1980s the World Intellectual Property Organization (WIPO) and the United Nations Educational, Scientific and Cultural Organization (UNESCO) even convened a group of experts on the Protection of Expressions of Folklore by Intellectual Property. At the 1985 meeting of the Group of Experts however, "representatives of the Spanish-speaking countries [...] took the position that "folklore" was an archaism, with the negative connotation of being associated with the creations of lower or superseded civilizations." (Blakeney 1999, 2)

166 WIPO notes that, "[n]o single definition would fully do justice to the diverse forms of knowledge that are held by traditional communities; and no form of legal protection system can replace the complex social and legal systems that sustain [traditional knowledge] within the original communities." (WIPO, 4)
} 
With this mind, it is noteworthy that Indigenous knowledge has drawn considerable interest from the members of international society, as well as transnational corporations, over the past three decades. Indeed, the "value of traditional knowledge is now appreciated outside its epistemic and geographic confines." (Oguamanam 2006, 5) As early as the 1980s, for instance, "scientific breakthroughs in agriculture, pharmacology, biomedicine and genetic and conservation sciences [were] linked either directly to Indigenous or traditional knowledge or indirectly to insights therefrom." (Oguamanam 2006, 5) According to one study, it was estimated that when traditional knowledge was used, "the possibility of developing at least one marketable pharmaceutical from a thousand plants samples [rose] from 22 to 78 percent, or three and a half times." (Oguamanam 2006, 15) And, when using traditional knowledge, "the efficacy of screening for plants for medicinal properties increased more than 400 per cent." (Oguamanam 2006, 15) In light of these benefits, the ascent of Indigenous knowledge has in large part been attributed to its scientific and economic benefits. As Francesco Mauro and Preston Hardison (2000) observe,

Scientists are often skeptical of the value of [Indigenous knowledge] unless it has been recast in scientific terms, and may lump [Indigenous knowledge] with superstition, irrationalism, and tribalism. Scientists' arguments for preserving [Indigenous knowledge] tend to emphasize intellectual and economic benefits to non-native societies by providing leads to drug discovery and raw materials for biotechnology and agricultural innovation. (quoted in Deng 2008, 188)

In this way, the value of Indigenous knowledge has been cast in terms of its contribution to the world economy, as the scientific benefits of Indigenous knowledge have generated billions of dollars for multinational corporations and 
their host states. In fact, one estimate found that the plant-based medicinal knowledge of Indigenous peoples residing in tropical rainforests exceeded US $\$ 43$ billion for the pharmaceutical sector alone. (Ogumanam 2006, 15) Despite the financial benefits generated by Indigenous knowledge at the international level, however, Indigenous peoples have been largely excluded from sharing in these rewards. ${ }^{167}$ For example,

Total trade in herbal remedies and botanicals in 1995 yielded over US\$ 56 billion and the only payments to the communities were for the manual labor involved. According to Posey [1991], less than $0.001 \%$ of profits from drugs developed from natural products and traditional knowledge accrue to traditional people who provided technical leads for the research. (Mugabe 1998, online)

For these reasons, Indigenous peoples have voiced growing concern over the (mis)appropriation and usage of their traditional knowledge in the world economy, 168 leading Charles Kamau Maina (2011) to suggest that the ascent of Indigenous knowledge is indicative of a tension between two competing perspectives. "On the one hand, there has been an increased international recognition of Indigenous peoples' activities as creative, innovative, and important contributions to science, research and development, and general human progress." (Maina 2011, 144) But, “[o]n the other hand, increased instances of biopiracy have

\footnotetext{
167 This lack of incentive is compounded by the fact that by emphasizing the scientific and financial benefits of Indigenous knowledge, the transnational corporations and states that appropriate Indigenous knowledge remove it from the cultural and social context from which it stems. In other words, this emphasis on science and finance overlooks the social and cultural value Indigenous knowledge holds for the Indigenous communities that share it.

168 For example, Michael Blakeney (1999) identifies five major concerns voiced by Australian Aborigenes with respect to the usage of their traditional knowledge by corporate actors: 1) unauthorized copying of Indigenous works; 2) infringement of copyright of individual Indigenous artists; 3) appropriation of Indigenous themes and images; 4) culturally inappropriate use of Indigenous images and themes; and 5) expropriation of Indigenous knowledge without compensation.
} 
created an urgent need to protect and control the use of traditional knowledge and practices." (Maina 2011, 144)

In terms of those contributing to this debate, Maina (2011) identifies three principal actors: 1) sovereign states; 2) Indigenous peoples; and 3) industry representatives. ${ }^{169}$ Operating through the multilateral forums of international society however, states have significantly limited the participation of Indigenous peoples in these forums; such as: 1) the World Intellectual Property Organization (WIPO); 2) the Convention on Biological Diversity (CBD); and 3) the World Trade Organization (WTO) - see table VI.1. While each of these forums has played an important role in shaping the debate on Indigenous knowledge, none are Indigenous-specific;

[...] these forums are member driven, and as observers, Indigenous peoples cannot vote on the decisions that are made in these forums; even when these decisions have implications on Indigenous cultures and practices. These forums also either advance assumptions that emanate from their mandates, try to fit the issues into these mandates, or politicize these issues in order to either garner opposition or exclude them from the agenda. (Maina 2011, 157)

In this way, the structures of state-based, multilateral forums suggest that the members of international society retain a high degree of control over the traditional knowledge debate, this despite the fact that Article 31(1) of the Declaration -

\footnotetext{
169 Maina (2011) further defines these actors in the following way; "[i]ndigenous stakeholders include both specific communities and local, national, and international organizations that represent Indigenous communities in the international forums. Member states stakeholders include countries that are either members of organizations such as the WTO or signatories to an international instrument that deals with traditional knowledge issues. Member states stakeholders are either individual countries or regional blocks such as the African Union or the European Community (EC) [...]. Industry stakeholders include organizations that have some direct or indirect commercial interests in traditional knowledge and are involved in the debate at the international level." (Maina $2011,154)$
} 
endorsed by the members of international society - expresses an Indigenous right

to exercise control over their traditional knowledge. According to Article 31(1),

Indigenous peoples have the right to maintain, control, protect and develop their cultural heritage, traditional knowledge and traditional cultural expressions [...] They also have the right to maintain, control, protect and develop their intellectual property over such cultural heritage, traditional knowledge, and traditional cultural expressions.

Taking all this into account, tension in the rights-based framework of international society - around Indigenous knowledge - resonates with a political-economy perspective. ${ }^{170}$ Quoting Vincent Mosca (1996), this is also the conclusion reached by Maina (2011), who suggests that the governance of Indigenous knowledge must be conceptualized through a political economy lens; a lens that pays special attention to "the social relations, particularly the power relations, that mutually constitute the production, distribution, and consumption of resources." (147)

170 In the context of Indigenous knowledge, a political-economy lens draws attention to two important dimensions of the Indigenous knowledge debate; first, Frieden and Lake (2000) note that the, "[...] first dimension of interest concerns the degree to which the causes of international political and economic trends are to be found at the domestic or international level. All observers agree that in a complex world, both global and national forces are important." This view speaks to previous chapters of this thesis, which focused on how an international discourse centered on the concept of civilization has been used to overpower Indigenous voices in a way that subsumed them within the state. At the same time however, the debate on Indigenous knowledge also highlights the role of other domestic actors, in the form of trans-national corporations - in managing to influence the actions of international society. This point speaks to the second dimension; specifically, focussing attention on international interdependencies that draw attention to the interaction between states and social forces (Frieden \& Lake 2000, 5). Indeed, "[t]he second dimension [...] has to do with the relative importance of politicians and political institutions, on the one hand, and private social actors, on the other." (Frieden \& Lake 2000) They continue, "[i]n studying the politics of the world economy, questions continually arise about the relative importance of independent government action and institutions versus a variety of societal pressures on the policy-making process." (Frieden \& Lake 2000, 7) In the language of Barry Buzan (2004), this might be conceptualized in terms of a discourse between international (state) and world (non-state) society. 


\section{Table VI.1: Overview of key multilateral forums addressing the issue of traditional knowledge, as identified by Maina (2011)}

WIPO: WIPO conducted fact-finding missions in 1998 and 1999 to "identify intellectual property protection needs and expectations of traditional knowledge holders." (Maina 2011, 150) Since, WIPO has established the Intergovernmental Committee on Intellectual Property and Genetic Resources, Traditional Knowledge and Folklore (IGC) in 2000, which produced two sets of draft provisions pertaining to the legal and policy options for traditional knowledge protection. (Maina 2011, 151)

CBD: The CBD initially set out a plan of action for: 1) conserving biological diversity; 2) ensuring the long-term sustainable use of it; and 3) the fair/equitable benefit sharing of genetic resources. (CBD online) In 1994, Conference of the Parties (COP) - the CBD's governing body - "established the Working Group on the Implementation of CBD's Article 8(j) and Related Provisions of the Convention." (Maina 2011, 152) This Article specifically addresses equitable sharing of traditional knowledge.

WTO: “The WTO's involvement in traditional knowledge arose mainly because its 'Members' obligations concerning non-discrimination in international trade interact with the protection of [traditional knowledge].'” Moreover, "The Council for TRIPS is involved in traditional knowledge protection issues following instructions by the Doha Declaration to examine, inter alia, the protection of traditional knowledge and folklore. In November 2001, the Doha Declaration recognized the need for synchronizing provisions in international agreements, a need that prompted the review of TRIPS Article 27 on patentable and unpatentable inventions. Article 27.3(b) allows signatory governments to exclude some kinds of inventions from patenting." (Maina 2011, 153)

Conceptualizing traditional knowledge from the perspective of politicaleconomy, Maina (2011) subsequently argues that limited levels of Indigenous participation are related to two forms of power - covert and structural. As Maina (2011) explains, “[c]overt power allows an actor to set priorities for policymaking by [...] excluding some items from consideration." (148) By focusing analysis on the role of covert power in these multilateral forums, it is revealed "that stakeholders wield varying levels of power in the debate and decision-making processes." (Maina 
2011, 157-158) Where structural power is concerned, Maina (2011) observes that institutional barriers limit the full participation of Indigenous peoples within the multilateral forums of international society. As a consequence of these two forms of power, it follows that it is the members of international society that are setting the tone and terms of the Indigenous knowledge debate, and not the Indigenous members of world society themselves. "Most countries have neither fully engaged Indigenous peoples who live within their boundaries nor solicited their views on the issues under debate. This has resulted in the omission of Indigenous views from these countries' submissions to the international forums." (Maina 2011, 157-158) As such, Indigenous peoples' views on their traditional knowledge are being silenced by the multilateral forums of international society in a way that helps sustain state-based approaches to the governance of Indigenous knowledge. In the next section, I detail this further by connecting the intellectual property system to the colonial discourse on civilization.

\section{Civilization and the governance of Indigenous knowledge}

Working through multilateral forums, states have promoted the intellectual property system as a mechanism for the governance of Indigenous knowledge - a system originally designed to resolve tensions between profit and the public good. As Kenneth Shadlen, Andrew Schrank and Marcus Kurtz (2005) explain, "[i]f a government fails to enforce copyrights and patents, the processes of artistic creation and invention may take on the character of public goods and, subsequently, be subject to traditional collective action problems." (49) Thus, "[intellectual property rights] are designed to solve the collective action problem by offering inventors and 
authors temporary monopolies or, in the language of public choice theory, "selective incentives" to pursue their crafts." (Shadlen, Schrank \& Kurtz 2005, 49) In pursuit of this goal, the intellectual property system seeks to "give statutory expression to the moral and economic rights of creators in their creations and to the rights of the public in accessing those creations." (WIPO 2008, online) In addition, it aims "to promote creativity, and the dissemination and application of its results, and to encourage fair trade, which would contribute to economic and social development." (WIPO 2008, online) As such, the intellectual property system has, since the 1980s, been garnering momentum because of its perception "as a motor for technological innovation and industrial change." (Mugabe 1998, online)

\section{Table VI.2: Three key forms of intellectual property}

Patent: "A patent is a document, issued, upon application, by a government office (or a regional office acting for several countries), which describes an invention and creates a legal situation in which the patented invention can normally only be exploited (manufactured, used, sold, imported) with the authorization of the owner of the patent. "Invention" means a solution to a specific problem in the field of technology. An invention may relate to a product or a process. The protection conferred by the patent is limited in time (generally 20 years)."

Copyright: "Copyright deals with the rights of intellectual creators in their creation. [...] Copyright law, however, protects only the form of expression of ideas, not the ideas themselves. The creativity protected by copyright law is creativity in the choice and arrangement of words, musical notes, colors, shapes and so on. Copyright law protects the owner of rights in artistic works against those who "copy", that is to say those who take and use the form in which the original work was expressed by the author."

Trademark: "A trademark is any sign that individualizes the goods of a given enterprise and distinguishes them from the goods of its competitors."

The intellectual property system has been perceived as a framework with which to afford Indigenous peoples protections against the misappropriation of 
their traditional knowledge, while allowing for corporate actors to acquire this knowledge through compensation. In terms of its actual capacity to afford Indigenous peoples protection of their traditional knowledge however, the intellectual property system has been met with skepticism. For example, the Suva Statement on Indigenous Peoples Knowledge and Intellectual Property Rights (1995) claims that "imperialism is perpetuated through [the western] intellectual property rights systems."171 In fact, the Suva Statement (1995) juxtaposes intellectual property against a right to self-determination, when it states that "Indigenous peoples are willing to share our knowledge with humanity provided we determine when, where and how it is used: at present the international system does not recognise or respect our past, present and potential contribution." This view is in part attributable to the historic evolution of the intellectual property system at the international level - as defined by the Agreement on Trade Related Aspects of Intellectual Property Rights (TRIPS). At its most basic level, TRIPS seeks to promote innovation in domestic markets by committing states to minimum intellectual property standards; such as ensuring that the term of a copyright is at least 50 years and that a patent is enforceable for up to 20 years. As Olufunmilayo Arewa (2006) observes, however, TRIPS is widely perceived as a state-based agreement that safeguards corporate interests, and limits the capacity of developing states from pursuing their knowledge-based interests. In the context of developing countries, for instance, TRIPS has been accused of preventing low-income countries from

\footnotetext{
171 The Suva Statement is the final statement from the United Nations Development Program consultation on Indigenous peoples' knowledge and intellectual property; the statement "was prepared by the participants at the Regional Consultation on Indigenous Peoples' Knowledge and Intellectual Property Rights held in April 1995 in Suva, Fiji." (UNDP 1995, online)
} 
producing and purchasing generic copies of essential medicines; specifically, it is claimed that these medicines are in violation of TRIPS standards. While TRIPS was modified during the Doha round of negotiations to better enable states to access these life-saving drugs, the procurement of them in practice has for the most part been a slow-moving, if at times stagnating process.

Speaking to the issue of imperialism, Arewa (2006) suggests that many of the negative implications that TRIPS holds for developing states are rooted in the colonial past. She argues that the negotiation of TRIPS evidences hierarchies of culture that originated with the discourse on civilization, contrasting the civilized self against the uncivilized other. Arewa (2006) explains,

Hierarchies of culture reflect nineteenth century evolutionary assumptions about the relative status of different cultures. As a result of such hierarchies, a relative ranking of cultures became predominant in the nineteenth century. These evolutionary rankings assumed that all societies moved through an identical progression from "savagery" to "barbarism" to "civilization," and that European countries represented "civilization," or the apex of these rankings. (159-160)

As a result of this ranking system, Europeans were able to pursue their imperial ambitions, leading to the establishment of European colonies and the sub-division of non-European sovereignty. As a legacy of colonialism, non-Western countries were left in a vulnerable position when Europeans withdrew from these former colonies; while decolonization enabled the creation of new non-European states, it did little to rectify international imbalances of power. As a result, this left many decolonized states in a position of inferiority when it came time to negotiate international agreements with Western powers. For Arewa (2006), it was thus a consequence of 
European imperialism and the discourse on civilization that non-Western states were forced to accept the terms of TRIPS.

The work of May and Sell (2006) not only highlights imbalances of power in the negotiation of TRIPS, but also brings to light the role of corporate actors in the governance of Indigenous/traditional knowledge. ${ }^{172}$ Prior to reflecting on the work of May and Sell (2006), however, it is well to remember that despite the relatively limited room for corporate actors to forge a socially 'thick' society, they are important actors that have forged a socially 'thin' type of world society. ${ }^{173}$ In fact, Barry Buzan (2004) observes that corporate actors do - when their interests converge - act cooperatively in ways that mimic the behaviour of international society itself. "It is perfectly possible to imagine firms, and indeed clubs, mafias and other types of association agreeing pluralist type rules of recognition and conventions of communication amongst others of a similar type, and working out practical measures of coexistence." (Buzan 2004, 125) In this respect, Buzan (2004) notes that the members of corporate transnational society have influenced one of the primary institutions of international relations, international law. In fact, corporate actors have played a role in the constitution of international law, and are recognized as its subjects. As Buzan (2004) explains, "transnational corporations

\footnotetext{
172 As non-state actors with a common identity, corporations are being conceptualized here as members of world society. In Buzan's (2004) terms, we might think of them as forming a corporate transnational society - a second order society - composed of competing transnational corporations, who despite competing in the marketplace, build basic norms and values on their shared identity as corporations. For example, in the lead-up to TRIPS, this took the form of the Intellectual Property Committee (IPC), a group of US corporations that collectively lobbied the US Trade Representative to have their interest promoted and protected (see below).

173 According to Buzan (2004), "Clubs, firms, lobbies, associations and such are all more intensely organised locally than globally. But in the transnational realm of society, it is possible to achieve large, even global scale in an extremely thin way. Some firms and INGOs do this [...]." (2010) Buzan (2004) continues, arguing that in terms of classification, "the bulk of what one would find would be located in 'competing TNAs' (e.g. firms) [....]." (210-211)
} 
(TNCs) are so heavily bound up in international legal rights and duties, and can make and be held to legal claims to such an extent, that they must have standing as effective subjects of international law." (Buzan 2004, 120)

As it pertains to May and Sell (2006), this conceptualization of corporate actors suggests that the intellectual property system has been informed by the intersocietal relations between corporate transnational society and international society. Specifically, May and Sell's (2006) critical analysis of the processes leading to TRIPS reveals that the final agreement was originally conceived as a mechanism with which to benefit Western states and a socially thin society of corporate actors within the United States (US). As May and Sell (2006) explain,

The expanding possibilities for technical appropriation of knowledge or information, alongside widespread pirated reproduction and distribution of knowledge-based products, prompted rich countries' governments to act on behalf of their national corporate interests. (153)

In fact, May and Sell (2006) note that one of the key actors in the push for TRIPS was the Intellectual Property Committee (IPC), a group of US corporations which lobbied the United States Trade Representative (USTR) to push for an international agreement capable of protecting US corporate interests (154). With the aim of facilitating these protections, the US, in conjunction with powerful members of international society pushed for a text that committed signatories to enact strict intellectual property laws designed to benefit transnational corporations. And, in ways reminiscent of English imperialism (i.e. divide and conquer tactics), the US government set about threatening sanctions against some developing countries that opposed the agreement, while negotiating lucrative trade agreements with other developing states that they sought to 'win over.' 
In this way, Western states, alongside a socially 'thin' society of corporate actors, have used their power to promote a distinctly Western framework for governing Indigenous/traditional knowledge. ${ }^{174}$ As Arewa (2006) observes, the discourse on civilization that pervades this framework - as expressed by TRIPS has even played a role in defining the meaning of intellectual property itself. As she (2006) explains, TRIPS is a direct descendant of nascent conceptions of intellectual property that began to emerge in the $19^{\text {th }}$ century that were based "on existing national intellectual property systems and bilateral arrangements between certain countries. These existing systems protected knowledge that was thought to exist within the "civilized" countries." (161) Furthermore, it was a consequence of this discourse that until very recently, traditional knowledge was excluded from intellectual property protection.

[Nascent conceptions of intellectual property] also reflected more general societal beliefs in Europe and the United States about the devolution of certain forms of knowledge such as folklore. This devolutionary ethos formed the flip side of dominant evolutionary ideas by assuming that folklore would disappear with the evolution of societies from "savagery" to "barbarism" to "civilization." At least partially as a result of the evolutionary assumptions about the development of cultural systems and the existing dynamics of global power relationships, emerging global intellectual property frameworks largely did not protect folklore or most other forms of local knowledge. (Arewa 2006, 161)

By failing to meet the standards of European civilization, Indigenous knowledge has thus been excluded from intellectual property protection until quite recently. Instead, their knowledge has been traditionally conceptualized as part of the public realm, and freely appropriable. (163) For this reason, the Foundation for

174 In fact, many developing countries had in the 1960s and 1970s sought to dilute intellectual property laws, in an effort to narrow the technology gap between themselves and developed countries. 
Biotechnology Awareness and Education (FBAE; 2008) notes that, “[...] many of the claims sought by Indigenous peoples [in the field of intellectual property law] are not claims to something in the public domain, but rather claims for protection from corporate intellectual property." (online) The FBAE (2008) explains this in the context of Indigenous music, as Indigenous music is not usually protected by copyright. But, “[a] modern recording containing Indigenous music [...] may be copyrighted if it contains even minimal new elements [...]. So a commercial interest may, in effect, be able to hold copyrights in the products of an Indigenous group." (FBAE 2008, online) Recourse for such a violation can subsequently be undertaken at two levels, the domestic and the international. Where the domestic is concerned, research shows that Indigenous peoples are at a particular disadvantage; specifically, because they typically lack the resources necessary to be successful in litigation against more powerful corporate entities. Where the international level is concerned, Indigenous peoples are largely prohibited from finding legal recourse to address the misappropriation of their knowledge. Significantly, this too is a legacy of the colonial discourse of civilization; by virtue of having their claim to sovereignty withheld over the course of centuries, Indigenous peoples are now denied equal footing in the key settlement forums of international society. As the FBAE (2008) explains,

As long as Indigenous peoples are recognized as sovereign nations with a Western style legal system, they are able to bring their case to the coercive processes of the World Trade Organization (WTO) dispute resolution mechanism. Efforts to use international treaties to provide protection of Indigenous peoples as sovereign nations, however has been met with resistance. This is to prevent any formal recognition and rights to Indigenous peoples. (online) 
In other words, by virtue of not meeting the criteria of statehood, Indigenous peoples are impeded from voicing their complaints in the multilateral forums of international society.

\section{Governing knowledge through a standard of modernity/human rights}

As Gerrit Gong (1984), Brett Bowden (2002) and Jack Donnelly (1998) contend, the

mid- to late-20th century witnessed the disintegration of the Standard. This however did not so much herald the end of the Standard, so much as it marked its evolution (see chapter six). Drawing on human rights and the concept of modernity, the society of states used this 'new' standard of civilization to distinguish self from other. This played out through decolonization as colonial empires rationalized a process that granted independence to territorial entities on the one hand, while granting sub-state peoples a variety of human rights on the other. As it relates to Indigenous knowledge, it can be argued that the contemporary human rights framework perpetuates this standard in the field of traditional knowledge by articulating a legal basis for extending the intellectual property system. Indeed, both Simeone (2004) and Mugabe (1998) remind us that despite not being traditionally conceptualized as a rights-based instrument, intellectual property is an implicit component of the human rights framework that grew out of the post-World War II period. For example, the Universal Declaration of Human Rights (UDHR) implies an individual right to the protections afforded by intellectual property, under Article 7. According to it, "[a]ll are equal before the law and are entitled without any discrimination to equal protection of the law." As Mugabe (1998) 
explains, by virtue of being an internationally recognized form of legal protection, intellectual property is thus an implicit component of Article 7.175

Similarly, the International Covenant on Social Economic and Cultural Rights (ICSECR) articulates a soft legal basis for the protection of Indigenous knowledge, via intellectual property. Citing Posey (1994), Mugabe (1998) observes that Article 1 of the ICSECR "establishes the right of self-determination, including the right to dispose of natural wealth and resources. This implies the right to protect and conserve resources, including intellectual property." (online) Connecting a right of self-determination to intellectual property in this way, the ICESCR foreshadowed more explicit references to intellectual property within contemporary human rights documents. Mugabe (1998) highlights two reasons for this; first, he observes that the appropriation of Indigenous knowledge by multinational corporations without compensation is "seen as contravening fundamental moral, ethical and legal norms that protect people from any form of economic, ecological, political and social abuse." (online) Second, there is a general perception that Indigenous knowledge can be conceptualized as property and that international law should not discriminate in protecting different forms of property. For these reasons, intellectual property has become viewed as a legal mechanism with which to promote/protect Indigenous rights; especially those pertaining to their knowledge and culture.

\footnotetext{
${ }^{175}$ Article 27(2) of the UDHR also states that "[e]veryone has the right to the protection of the moral and material interests resulting from any scientific, literary or artistic production of which he is the author." For Mugabe (1998), this statement can also be conceptualized as a soft legal basis for regarding and protecting Indigenous and traditional knowledge through rights. (online)
} 
As critics note, however, the extent to which intellectual property can actually strengthen an Indigenous right to self-determination is questionable. Generally, there are two reasons for this; first, scholars note that logistical barriers, rooted in power dynamics, inhibit Indigenous peoples from fully accessing the protections afforded by intellectual property. Second, scholars point to cultural incompatibilities between the Western intellectual property system and Indigenous conceptualizations of knowledge. Where the former is concerned, Darrell Posey and Graham Dutfield (1996) argue that intellectual property,

[...] cannot adequately protect the knowledge and resources of Indigenous peoples, nor are they a panacea for the lack of self-determination of Indigenous peoples and the inequalities of wealth and power between local communities on one hand and governments and corporations on the other. Furthermore, not only do [intellectual property rights] have to be acquired by a process that can be difficult, time-consuming, and expensive, but they also have to be defended. Acquiring and defending [intellectual property rights] protection requires access to information, good legal advice, and financial resources, all of which may be beyond the reach of many Indigenous peoples. (93)

Similarly, the Assembly of First Nations (AFN; 2011) contends that the resources/qualifications necessary to protect Indigenous knowledge through intellectual property rights against powerful corporate actors are significant, and are usually not available to individual Indigenous peoples. ${ }^{176}$ "The qualifications necessary for an [intellectual property right] generally prevent Indigenous Peoples from owning their knowledge, yet they allow for third parties to claim, patent and

\footnotetext{
176 To this end, some scholars point out that the intellectual property system is also limited in its capacity to respond to the collective interests of Indigenous peoples, societies and/or communities. Specifically, it is pointed out that because intellectual property rights are designed primarily for use as individual rights, it is difficult for peoples to exercise them collectively. "Existing laws and mechanisms, such as intellectual property rights, are unable to protect Indigenous and traditional knowledge and are inadequate when it comes to collaboratively developed innovations (such as varieties resulting from participatory plant breeding (PPB), because, it is argued, they protect individual as opposed to collective rights." (IDRC 2012,3)
} 
benefit from [Aboriginal traditional knowledge (ATK)]." Consequently, “[...] this may mean that sharing ATK results in legally protected acts similar to theft and biopiracy in spirit." (AFN 2011, 3)

In fact, Posey and Dutfield (1996) suggest that the imposition of an IP system not only highlights logistical constraints - rooted in power differentials between Indigenous peoples, members of international society, and corporate transnational society - but also risks inflaming tensions between Indigenous communities. According to them, this is an implication of an inherently competitive system, which restricts ownership of knowledge to a particular individual or group. Indeed, "[...] Indigenous communities [...] that have occupied similar environments may possess the same, or similar, technical knowledge regarding a specific resource and its use. Therefore, payments to one community could engender conflict between Indigenous groups and result in protracted legal battles." (Posey \& Dutfield 1996, 109) As a result, "[t]his potential conflict between groups calls into question the wisdom of using [intellectual property] mechanisms in attempting to award retroactive payments for Indigenous knowledge." (Posey \& Dutfield 1996, 109) The conflict engendered by the intellectual property system further speaks to the cultural issues associated with the application of it to the field of Indigenous knowledge. For instance, Tony Simpson (1997) observes that the very extension of the intellectual property system to certain Indigenous peoples may appear offensive or abhorrent. As Simpson (1997) contends, "it may be said that the term 'Indigenous cultural and intellectual property' is an oxymoron." (18) Indeed, it "is a term which implies that the cultural heritage of Indigenous peoples can be protected by a reductionist 
Western legal philosophy that separates culture from knowledge and deals with them in different ways." (Simpson 1997, 18)

Cultural tensions were also observed by Chairman Daes of the Working Group on Indigenous Peoples, who highlighted problems in the way intellectual property is grafted onto Indigenous knowledge. For Daes, Indigenous knowledge is part of Indigenous heritage, which in itself cannot be conceptualized as a commodity or form of property; instead, it is "but one of the manifestations of an ancient and continuing relationship between peoples and their territory." (quoted in Bengwayan 2003, 6) As Michael Bengwayan (2003) explains of Daes' position, it was "more appropriate and simpler to refer to the collective cultural heritage of each Indigenous people rather than to make distinctions between Indigenous peoples,' 'cultural property' and 'intellectual property.'" (6) Further still, statements from the Indigenous transnational movement highlight a profound skepticism of the intellectual property system. Like the Suva Statement (see above), the Tambunan Statement on the Protection and Conservation of Indigenous Knowledge (1995) indicates that "[f]or the Indigenous peoples of Asia, the intellectual property rights system is not only a very new concept but it is also very western [...]."177

Indigenous peoples are not benefiting from the intellectual property rights system. Indigenous knowledge and [cultural] resources are being eroded, exploited and/or appropriated by outsiders in the likes of transnational corporations, institutions, researchers, and scientists who are after profits and benefits gained.

While not all Indigenous peoples perceive the intellectual property system as necessarily incompatible with their own cultural traditions, the views put forth by

177 The Tambunan Declaration is the final statement of the UNDP Consultation on the Protection and Conservation of Indigenous Knowledge. (Posey 1996) 
the Tambunan and Suva statements provoke serious questions about the viability of using the intellectual property system - articulated through the human rights framework - to address Indigenous knowledge issues. As logistical constraints premised in power differentials - and cultural inconsistencies show, the incorporation of Indigenous peoples into the intellectual property system carries inherent risks. As it relates to the concept of civilization, recent moves to make an explicit association between an Indigenous right to self-determination and intellectual property can subsequently be viewed as placing Indigenous peoples in a double-bind. On the one hand, Indigenous peoples may 'choose' to be included in the intellectual property system, and be afforded the system's limited legal protections - recalling that it is a system that: 1) imposes logistical constraints on Indigenous peoples, individuals and communities from fully participating in the intellectual property system; and 2) overlooks Indigenous cultural perspectives on traditional knowledge. On the other hand, they may 'choose' not to engage in the intellectual property system and be left vulnerable to the misappropriation of their cultural histories, traditions and knowledge by major corporate entities.

From this perspective, it may appear that international society - in particular a core group of predominantly Western members - has conspired with the corporate members of world society to impede the realization of Indigenous selfdetermination - i. e. by promoting a system of intellectual property that places Indigenous peoples in a double-bind. However, the promotion of the intellectual property system is likely more indicative of the influence of colonial legacies embedded within the social structures and institutions of international relations. 
Indeed, Western states and corporate actors have found themselves committed - at least implicitly - to the discourse on civilization in the context of the Indigenous/traditional knowledge debate for two inter-related reasons. First, Western states have historically been the primary drivers of the European discourse on civilization, and it is well to remember that corporate entities have historically aligned themselves with the norms, values and interests of their host states. ${ }^{178}$ Second, by virtue of promoting this discourse, both these sets of actors have constructed international institutions on the very foundation of civilization. By being committed to institutions founded on the concept of civilization, the Western members of international society - and to a lesser extent the corporate members of world society - have committed themselves to the civilizational assumptions of the rights-based framework that governs Indigenous/traditional knowledge. ${ }^{179}$

\footnotetext{
${ }^{178}$ From a historical perspective, it could be argued that corporations should be conceptualized as constituent members of international society. Although not states themselves, corporations have historically been perceived as advancing the commercial interests of states. It might also be recalled that for Hedley Bull (1977), trade was the most characteristic activity of international society. However, trade within international society itself - during much of the colonial period - occurred through colonial trading companies that were themselves connected to the state.

${ }^{179}$ In addition to these insights, an interesting parallel can also be drawn here between the rightsbased framework that governs Indigenous/traditional knowledge in the world economy, and Vitoria's jurisprudence. Just as Vitoria 'graciously' incorporated the Amerindians within the Law of Nations, so too has the human rights framework sought to incorporate Indigenous peoples into the intellectual property system. And, just as Vitoria's move to incorporate Indigenous peoples into the Law of Nations implied that the Amerindians needed to adopt Spanish customs in order to access the law, so too does the intellectual property system imply that Indigenous peoples must 'buy-into' a Western legal framework in order to receive its protections. Conversely, both Vitoria's jurisprudence and the intellectual property system imply that failure to adhere to Eurocentric assumptions about the Self results in the Other forfeiting international law's protections. Viewed in this light, the choice that the intellectual property system presents Indigenous peoples is one that echoes the self-other dynamics of the discourse on civilization; specifically, the intellectual property system serves as a trapping device that at once extends its legal benefits to others, only to limit the capacity of these others from exercising self-determination over their traditional knowledge.
} 


\section{Conclusion}

For some scholars, the human rights framework that was codified in the post-World War II era has represented an important transition in the relationship between international society and the Indigenous members of world society; specifically, it has been viewed as a framework with which to articulate a soft legal basis for Indigenous self-determination. However, Corntassel's (2008) critical analysis of contemporary Indigenous-state relations suggests that there are fundamental tensions implicit in using a Western legal framework to attend to relations between international society and the Indigenous members of world society. Focussing on the political economy of Indigenous knowledge, this chapter has sought to evaluate critically the capacity of the rights-based framework to promote and protect Indigenous self-determination through an historical analysis of the intellectual property system and its role as a tool for governing Indigenous knowledge. Through this analysis, three findings have been tendered: 1) the governance of Indigenous knowledge has occurred principally through the intellectual property system, a system predicated on the colonial discourse on civilization; 2) the concept of civilization is embedded within the social structures and institutions that govern Indigenous/traditional knowledge; and 3) members of international society especially Western states - as well as a socially 'thin' society of corporate actors have continued to promote these assumptions as a consequence of being embedded within the discourse of civilization themselves. As a consequence of these interrelated findings, the governance of Indigenous/traditional knowledge finds itself replicating many of the same assumptions Francisco de Vitoria used to define 
relations between the Spanish and Amerindians in the $16^{\text {th }}$ century. Thus, despite efforts to move away from the language of civilization and towards the language of modernity and human rights, the legacies of colonialism continue to play an important role in defining Indigenous-state relations today.

As these arguments speak to the more general relationship between international and world society, they are suggestive of nuances in the way that international and world society are conceptualized - both as independent categories of analysis and in their relationship to one another. Where the former is concerned, the findings of this chapter suggest that a shared identity does not necessarily equate to shared solidarity between the members of a society. In the case of international society, for instance, states - despite sharing collective norms and values around the primary institutions of international relations - diverge on matters of strategic interest. In the negotiation of the TRIPS agreement, for instance, a clear division in opinion was observed between the Western and nonWestern members of international society. While this is well-documented, a longterm view of relations within international society on matters pertaining to the intellectual property system suggests that these cleavages are rooted in the colonial past. Indeed, Arewa's (2006) critical analysis of the intellectual property system suggests that the concept of civilization lingers not only in the multilateral forums in which it has been articulated, but is embedded in the power-relations between the members of international society.

Arewa's (2006) insight on this matter also speaks to the issue of relations between international and world society; indeed, the colonial origins of the 
intellectual property system point to the fact that relations between international and world society are fluid. While it is true that colonial legacies provoked tension within international society in the lead-up to TRIPS, it is also noteworthy that these legacies may have contributed to the fermentation of relations between the Western members of international society and the corporate members of world society. As suggested above, these actors have both been implicated in the discourse on civilization and have used it to define their governance of traditional knowledge. As Arewa (2006) observes, the contemporary discourse on intellectual property is premised on late-19th century assumptions about the validity of uncivilized peoples' knowledge, and the view that it would disappear as these peoples gradually became more civilized. These implicit assumptions about civilization advanced by the corporate members of world society thus resonate with the cultural hierarchies embedded in international society. In this way, the discourse on civilization established implicit assumptions through which the Western members of international society and the corporate members of world society could collectively promote the intellectual property agenda.

In light of the colonial origins of the intellectual property system, it is perhaps unsurprising that it offers Indigenous peoples only limited legal protections in practice. This is so on at least two counts. On the one hand, the logistics of exercising intellectual property rights are prohibitive at both the international and domestic level. Internationally, the state-based, multilateral forums of international society inhibit Indigenous participation for a number of reasons: 1) the exercise of covert and structural power by states; and 2) the denial of Indigenous 
sovereignty/failure of Indigenous peoples to match the criteria of statehood. Domestically, legal systems that are used to uphold intellectual property rights rely on the assumption that litigants have the resources necessary to pursue recourse; yet, the discrepancy between Indigenous peoples and corporate actors in terms of these resources is often significant - the latter typically exercising considerably more power in the sense of disposing the necessary material and professional resources to make legal processes work in their favour. Second, the articulation and application of the intellectual property system has been critiqued for being culturally inconsistent with Indigenous values and beliefs. As a consequence, the fact that Indigenous peoples must use this system to negotiate the right to exercise self-determination over their traditional knowledge has been decried as appearing 'offensive' or 'abhorrent' (Simpson 1997). Given the relationship between intellectual property and the colonial discourse on civilization, and the impacts of the legal system on Indigenous peoples, this chapter has suggested that a recurring narrative can be identified within the relations between international society and the Indigenous members of world society. Indeed, while the language of civilization is no longer explicit, the legacies of this discourse have permeated the contemporary standard of modernity and human rights in a way that continues to subsume Indigenous peoples within a Western-legal framework that paradoxically excludes others from equal participation within international law, even when it includes them. 


\section{Chapter eight Conclusion}


In The Transformation of Political Community, [Andrew Linklater] argues that, because Europe has historically been comparatively more open to learn from other cultures, it has developed a higher level of morality and universality in its particular forms of political organization which enables it now to transcend the state as an incomplete form of universalization. [...] The West might not have been on its best behaviour all the time, but it certainly did occupy the highest level of moral and political development. Four hundred years of colonial and imperial history are presented here as the breeding ground of the most universal and highest form of morality available to the modern world-interspersed with a few misdemeanors which are deplorable but do not affect the value of this overall development.

- Beate Jahn 1998, 639

This thesis has sought to address the following research questions: What role have state-Indigenous relations had in constructing the colonial legacies of the discourse on civilization? And, what are the implications of this for understanding the relationship between international and world society in International Relations theory? To answer the question, the thesis proceeded by conducting an historical analysis of the evolution of contemporary international law, tracing its history back to the onset of colonialism in the $16^{\text {th }}$ century. It was at this critical juncture in world history that Francisco de Vitoria established an argument that justified Spanish colonialism by subsuming Amerindians into his Law of Nations. For Vitoria, Spain could undertake its colonial expansion only when the Amerindians were found in breach of the Law of Nations. Because the Amerindians were in constant breach of the Law of Nations - on account of their 'failure' to conform to the norms, values and customs of the Spanish - a basis was established for their conquest. In this way, Vitoria's jurisprudence set in motion a system of international law that would predicate its core assumptions on a self-other dichotomy distinguishing between a civilized society of states and an uncivilized collection of peoples; moreover, it would 
facilitate the expansion of European empires and the evolution of a once regional society of European empires into an international society of states. ${ }^{180}$

Embedded within international society are thus the legacies of the European discourse on civilization. Though the meaning of civilization is historically contingent - dependent on those that employ it - Prasenjit Duara (2004) explains that it has almost always served as a tool to identify and order value in the world.

The identification of value [...] sometimes implies the identification of a community of value, and civilization can also become the means of marking the Self from the Other. [...] However, what distinguishes the civilizational idea from nationalism is its appeal to a higher, transcendent source of value and authority, capable of encompassing the Other. (Duara 2004, 1)

It was in this way that European empires employed the concept of civilization, using it to not only justify expansion but to legitimate it on normative grounds. From the standpoint of empire, peoples could be ranked in a hierarchy according to their level of civilization. Because the meaning of civilization was always premised on European norms and values, a basis was established to justify imperial expansion as a mechanism to spread the benefits of civilization to uncivilized peoples. Over time, this would be undertaken through processes that subsumed the other into the self such as France's Mission Civilizatrice, the United States' Manifest Destiny, and the United Kingdom's White Man's Burden.

By the late-19th century, the discourse on civilization had become so pervasive that key features of European socio-political organization were finding expression in a legal principle, the Standard of Civilization (the Standard). According to the Standard, a country could only be considered civilized if it had

180 Vitoria's jurisprudence did not appear in a vacuum; his legal writings were premised upon the work of earlier European theologians, such as Pope Innocent IV (see chapter four). 
achieved five key criteria associated with Westphalian statehood: 1) the capacity to guarantee basic rights to its citizens and to foreigners; 2) to exist as an organized political bureaucracy; 3) to adhere to international law; 4) to maintain adequate and permanent diplomatic channels with other states; and 5) to conform to the norms and practices of international society (Gong 1984). Moreover, it was based upon this criterion that positive law scholars of the period justified the exercise of European extraterritorial influence. For instance, the Mandates system of the League of Nations articulated a legal framework through which Western states could exert influence over the former colonies of Germany and the Ottoman Empire. This system assumed that Western powers had achieved a greater degree of civilization than the mandates as a consequence of the former's statehood. In fact, the C mandates - primarily composed of what would today be considered Indigenous peoples - were categorized as having the lowest level of civilization on account of their non-state/tribal structures and geographical 'remoteness' from civilization.

It was not until the mid-20th century that the Standard finally began to erode as the European discourse on civilization came under considerable scrutiny from within Europe and from abroad. Within Europe, people began questioning the primacy of European civilization, having just witnessed the atrocities of the Second World War and fearing the prospect of nuclear conflict with the Soviet Union. Beyond Europe, peoples living in its former colonies began challenging the right of European powers to exert extraterritorial influence over them. Combined, these voices eroded Europe's cultural self-confidence, resulting in the formal processes of 
decolonization and a transition away from the Standard towards a new standard of modernity and human rights. Despite this transition however, relatively little changed in relations between international society and the Indigenous members of world society. In fact, some scholars point out that decolonization bypassed Indigenous peoples altogether, as states sought to retain a minimalist definition of self-determination. Rather, states extended to sub-state peoples a variety of human rights which sought to protect them from domestic discrimination and abuses of state power. In doing so, human rights reified sub-state peoples as domestic populations and subsumed them further within states.

Confronted by this, the Indigenous members of world society began to challenge the norms and values of international society through a transnational movement beginning in the mid- $20^{\text {th }}$ century. Working through the human rights framework, this movement successfully negotiated the Declaration on the Rights of Indigenous Peoples (the Declaration, 2007). Yet, while the Indigenous transnational movement successfully negotiated an Indigenous right to self-determination, this right has remained limited in scope and difficult to exercise in practice. Within the world economy, for instance, intellectual property rights - premised within the human rights framework - perpetuate colonial assumptions about traditional knowledge. Indeed, this system subsumes Indigenous peoples within a Western framework of international law that has historically privileged Western actors. In light of these problems, the human rights framework that governs Indigenous-state relations has come under critique from a number of scholars who suggest that Western frameworks of international law cannot adequately promote an Indigenous 
right to self-determination. Jeff Corntassel (2008), for instance, contends that Indigenous peoples must strive towards 'sustainable self-determination,' premised on a responsibility-based doctrine that empowers Indigenous communities at the ground level (see chapter seven).

Reflecting on this historical analysis of Indigenous-state relations, this chapter concludes the thesis by summarizing its implications for International Relations (IR) theory. This is achieved through the following three sections:

- The first section details the benefits of an inter-societal approach to the study of international relations; specifically, an approach that examines the relationship between international and world society. While this approach has been the purported basis of the English School, I argue that the vast majority of English School research has focused primarily on intra-societal relations within international society. Applied in this thesis, an inter-societal approach has thus been used to advance the English School in three respects: 1) supplementing its focus on intra-societal relations within international society by focusing on inter-societal relations between the society of states and world society; 2) establishing a space for collaboration between the English School and postcolonial theory; and 3) advancing the process of decolonizing English School theory by critically detailing its commitments to state-centric and Eurocentric assumptions.

- The second section examines the implications of an inter-societal approach to IR, in three categories: power, anarchy/order, and sovereignty. First, it emphasizes the significance of conceptualizing power in discursive/social 
terms - through which a space is opened to critically re-think foundational narratives about the expansion of international society. Second, it supports the argument of Keene (2002), that the concept of order has historically been deployed to facilitate intra-European order while facilitating disorder in the non-European world. Third, it argues that conventional accounts of sovereignty have enabled a strict distinction between the domestic and international level.

- The third section concludes the thesis by considering the way forward for theorizations of/approaches to understanding relations between international society and the Indigenous members of world society in the study of international relations. In particular, it suggests that recent efforts though valuable - remain a work in progress. This is achieved through a brief analysis of the relationship between the Declaration (2007) and the Idle No More movement in Canada.

\section{Towards an inter-societal approach}

The expansion of international society has been marked by the discourse on civilization, a discourse that enacts a Self-Other binary distinguishing between 'civilized' and 'uncivilized' peoples. As Keene (2002) puts it, the $18^{\text {th }}$ and $19^{\text {th }}$ centuries were marked by 'the project of bringing the benefits of 'civilization' to uncultivated wilderness and 'backward' peoples."181 (Keene 2002, 147) Yet, in analyzing this discourse, most English School scholars assume that the end of World

\footnotetext{
${ }^{181}$ According to Keene (2002) this involved the promotion of economic and technological progress, as well as the establishment of good government. (147)
} 
War II and the onset of decolonization marked a critical juncture, characterized by a decline in Europe's self-confidence and the erosion of the civilized-uncivilized binary (Gong 1984; Keal 2003; Keene 2002). In place of the Standard, scholars argue that a new standard of modernity and human rights evolved, which enabled a more tolerant international society that did away with the discriminatory distinction between self and other, leading to a single global order. Explaining this in the context of the United Nations (UN), Keene (2002) writes that,

The construction of the UN system represented an attempt to bring the two major purposes of modern international order together in a single political and legal framework that would be founded on the principle of reciprocal respect for the territorial sovereignty of all peoples, but would nevertheless continue to work to promote the goals of economic and technological progress, good government and individuals' rights that would bring about a more civilized world [italics in the original]. (147-148)

As Keene (2002) rightly observes however, "[w]hat replaced the old doctrine [...] was not a rejection of civilization as such, so much as the idea that it had to be pursued within the context of a more tolerant global order." (147) Moreover, by taking a long-term view of the discourse on civilization and its relationship to the contemporary standard of modernity and human rights, Keene (2002) points out that such an analysis "raises some awkward questions about the civilizing mission to which international order is currently dedicated [...]." (149) Indeed, "defenders [of the human rights tradition] should still face up to the long and not always attractive history of these features of order in modern world politics, and perhaps moderate some of their enthusiasm accordingly." (149) Despite moderating his enthusiasm for the human rights regime, Keene's (2002) statement - that the midtwentieth century marked the extension of "reciprocal respect for the territorial 
sovereignty of all peoples" - remains problematic. This is in large part due to the fact that Keene (2002) fixes his analysis almost exclusively on the evolution and expansion of international society itself, rather than examining its broader implications for the relationship between it and world society. While Keene (2002) incorporates non-European history, his focus on state history ultimately leads to an analysis that reiterates well established narratives about how a once regional society of European empires became a single, cosmopolitan order of states.

Keene (2002) is not alone in making these types of claims; working within the English School, Paul Keal (2003) notes that "[f]rom the perspective of the late twentieth century the idea that international law recognised only claims of members of international society against each other is troubling. Fortunately it belongs to a phase of international law that has long been left behind." (107) Despite analysing the relationship between international society and Indigenous peoples, Keal (2003) suggests that contemporary international relations is an increasingly hospitable space within which state and non-state actors are forging a single global order - premised on the norms and values of international law. Similar to Keene (2002), Keal's (2003) conclusion is the result of a narrow focus on the internal workings of international society, one that focuses on the evolution of international law within international society itself. Rather than focus on the role of Indigenous transnationalism in shaping the Indigenous rights debate, Keal (2003) depicts the origins of these rights as emanating principally from, and being generously extended by, international society. Accordingly, the main thrust of Keal's (2003) 
argument is to explain how international society can serve as a moral agent in international relations.

The distinctive contribution of this book lies, I [Keal] hope, in what it has suggested about the potential for international society to act as a standard setter and moral agent. I [Keal] have wanted to suggest in particular that international society can help redress the legacy of its historic expansion by acting as a standard bearer. ${ }^{182}$ (Keal 2003, 223)

In doing so however, Keal (2003) not only ignores the colonial legacies of civilization, but inadvertently diminishes the agency of Indigenous transnationalism in shaping international law. ${ }^{183}$

To varying degrees, both Keene (2002) and Keal (2003) allude to the emergence of a single global order premised on the norms and values associated with a standard of modernity and human rights. And, while this thesis is largely sympathetic towards the arguments advanced by both these scholars - in particular, their efforts to broaden our understanding of international society's evolution and expansion through the incorporation of non-European histories - it concludes that they do not go far enough. Specifically, it contends that they are not sufficiently attuned to the disjuncture between their de facto cosmopolitanism and the competing voices of non-state peoples that remain marginalized from participation within international society. Moreover, it suggests that this problem is the result of an implicit commitment to the state-centrism of the orthodox English School, an approach that places a special emphasis on analyzing the intra-societal relations and

182 Keal (2003) alludes to the content of this standard, when he argues that "[t]he moral basis of international society ought to be an obligation to promote and safeguard world order. For international society to promote world order, the states that constitute it would have to be willing to encourage right conduct by states towards peoples within their borders." (215) For Indigenous peoples, Keal (2003) suggests that this imply extending them "the right to self-determination, both within constitutional law and international or emerging global law." (217)

${ }^{183}$ A similar critique is levied by Karena Shaw (see literature review). 
internal dynamics of international society itself. By replicating this approach, 'critical' members of the English School, like Keene (2002) and Keal (2003), adopt a type of analytical tunnel vision that leads them to similar conclusions as those reached by the School's founding members. Amongst these conclusions is the view that international society can serve as the vessel with which to bring order to anarchy, and thereby establish some degree of cosmopolitan justice for humankind.184 Indeed, it is worth recalling that for Hedley Bull (1977), the order established by international society laid the foundation to advance the interests of all humankind.

Adopting an implicit commitment to the state-centric assumptions of the orthodox English School, critical English School scholars become limited in what they can say about international relations. In particular, a focus on international society limits the ability of these scholars to comment on the nuanced relationship between international and world society. 185 This thesis has thus sought to move the

\footnotetext{
184 Beate Jahn (1998) makes a similar argument about Critical Theory. As Jahn (1998) explains, Critical Theorists have principally concerned themselves with opening a space for all peoples to participate within the international system. Oriented within the Western tradition of political thought, these scholars have problematically elevated Western norms and values above others; and, in this way have tendered conclusions that are themselves steeped in Western values. In fact, Jahn (1998) notes that Critical Theory assumes that "reason and morality are not equally developed among the people and peoples of the world [...]." (640) Indeed, [...] not any kind of family, civil society, state, or system of states will do, but only those which conform to the European conception of the family, the European conception of civil society, to the European conception of the state based on objective law and an explicitly established constitution, and, finally to a state system which is made up of these types of political formations. (Jahn 1998, 640) Jahn (1998) argues that this results in a paternalistic relationship between "those societies that are committed to the Western form of family, civil society, and state, and those who are not (yet) committed to the values." Reminiscent of the European discourse on civilization, "[t]his relationship [...] has to be conducted along the lines of a teacher-novice relationship in which the teacher is fully competent with respect to the rules of the game while the novice has to be guided through alternating practices [...] by the teacher." (Jahn 1998, 640)

185185 We might also recall here that according to Bull, the purpose of international society in establishing order was to realize benefits for all of humankind. In this sense, international society is the vessel for a more peaceful global order.
} 
English School forward by adopting an approach - premised on the work of Barry

Buzan (2004) - that takes seriously the concept of world society, and moves away from a narrow focus on intra-societal relations within international society towards a broader focus on the inter-societal relations between the society of states and the members of world society. ${ }^{186}$ Adopting an inter-societal framework contributes to the English School in at least three ways. First it helps conceptualize international relations as more than just intra-societal relations occurring within international society. Specifically, it confronts the English School's tendency to depict international relations according to what RBJ Walker refers to as an Inside/Outside dichotomy - a dichotomy that depicts international relations as either: 1) a cosmopolitan society of rights holding members; or 2) an anarchic environment conditioned by the imperative of security. ${ }^{187}$ Critical English School scholars like Keal (2003) and Keene (2002) seem to gravitate towards the former when they describe the transition of a once conflict-ridden system of European empires to a global order of states and individual rights holders. From an inter-societal perspective, this account is problematized through a nuanced account of relations between state and non-state societies. In the specific context of Indigenous-state

\footnotetext{
186 As noted in chapter three, the term inter-societal, is used to refer in this thesis to the relations between the society of states and the Indigenous transnational movement, beginning in the mid- $20^{\text {th }}$ century. Indeed, prior to this period, relations between the two are better conceptualized as relations between the nascent members of international society and the Indigenous peoples they entered into diplomatic relations with. However, also as noted in chapter three, these historical foundations are important as they help contextualize the discursive foundation for the evolution of both international society and the Indigenous transnational movement.

${ }^{187}$ In another vein, Jones argues that the conclusions reached by IR are narrowed by its limited view of history. Indeed, "[w]hile a lot of writing in IR seems strangely more interested in the discipline itself than the world around us, even the substantive concerns that are recognized as defining IR's field of enquiry have remained stubbornly narrow. The themes and preoccupations of IR largely reflect the history of the West (in idealized form) and the interests of the powerful. For example, the theorization of the interstate system has been central to the self-determination of the discipline." (3)
} 
relations during the decolonization period, for instance, international relations were characterized by the emergence of an increasingly 'cosmopolitan' society of states that denied non-state peoples equal participation within it. In other words, it was a space that was at once characterized by: 1) greater inclusiveness within the intrasocietal relations of international society; and 2) persistent marginalization within the inter-societal relations between the society of states and the Indigenous members of world society.

Second, an inter-societal approach opens a space for partnering the English School with the insights of postcolonialism. As Siba Grovogui observes, the discipline of IR has been characterized by a "Westphalian common-sense" that assumes the state to be the primary feature of international relations (quoted in Jones 2006, 3). This state-centric account inevitably leads to a Eurocentric account of political history that traces the evolution of international relations to the Peace of Westphalia (1648), and the 'inception' of the inter-state system. In turn, this has led to a very specific reading of disciplinary origins that overlooks non-European and non-state histories. For example, Brawen Gruffyd Jones (2006) observes that in keeping with the Westphalian narrative, mainstream IR has been forced to depict the emergence of postcolonial states in the decolonization period as part of 'the expansion of international society.' Because of its attention to the expansion of international society, the English School can thus appear at odds with postcolonialism - which draws critical attention to the state- and Eurocentric assumptions that the former makes about political history. With this in mind, an inter-societal approach that borrows from English School analytics helps build a 
space for collaboration between both approaches by attending to the concept of world society, and its relationship to the concept of international society. Indeed, by attending to the political history of non-state peoples, an inter-societal approach allows for a critical history of colonial relations between state and non-state societies/peoples. In the specific context of this thesis, for instance, a focus on Indigenous-state relations has associated the origins of contemporary Indigenousstate relations with a European discourse on civilization that continues to inform them. In other words, an inter-societal approach opens a space for postcolonial research to fill important gaps in disciplinary - and English School - accounts of the 'origins' of international relations. ${ }^{188}$

Third, by partnering postcolonialism with the English School a foundation is established to help advance the process of 'decolonizing' IR theory. As Jones (2006) argues, "[t]he modern discipline of IR and its twentieth-century trajectory is presented to the newcomer in a huge number of textbooks and compilations. What is remarkably absent from IR's self-presentation [...] is awareness of its colonial and imperial roots and context." (2) Indeed, "[t]he routine reproduction of Eurocentric forms of social inquiry is parasitic on widespread ignorance of world history, including the histories of colonialism and imperialism and, even more so, the histories of non-European peoples." For Jones (2006), it is a matter of reflecting critically on IR's conventional histories, and paying closer attention to non-

\footnotetext{
188 It might be added, that this space is particularly novel, as it enables room for collaboration between what most consider a mainstream (English School) and critical (postcolonial) approach to the study of international relations. This is not to make any claims of a via media between all mainstream and critical approaches, but it does suggest that space for cross-fertilization and collaboration between such approaches is possible, which in turn will hopefully lead to a more comprehensive and balanced account of international relations.
} 
European history - including its relationship to European history - that scholarship can further the process of decolonizing IR. It is in this way that partnering postcolonialism with English School analytics can contribute to decolonizing IR theory. Indeed, by drawing attention to the concept of civilization in structuring relations between the society of states and the Indigenous members of world society, this thesis has sought to decolonize IR theory by brining to light the persistent legacies of the discourse on civilization in structuring these relations especially in the context of international law. In the next section I detail the implications of this for International Relations theory more generally; in particular, for three disciplinary themes: 1) power, 2) anarchy, 3) sovereignty.

\section{Disciplinary implications of an inter-societal approach}

In answering the research question the thesis has traced the historical evolution of inter-societal relations between Indigenous peoples and states. In doing so, it has sought to highlight the role of a self-other dichotomy, centred on the concept of civilization. While the concept of civilization has been employed as a structuring device by a number of peoples over the centuries - if not millennia - it was the European account of civilization that proved most influential. With this in mind, it is important to remember that the European account of civilization did not evolve in a vacuum, or simply through intra-European relations. Rather, as an inter-societal approach to IR contends, European accounts of civilization were co-constituted through colonial relations between European empires and non-European peoples. As it pertains to IR, this approach to international relations and the concept of 
civilization holds important implications for the way the discipline conceptualizes: 1) power; 2) anarchy; 3) and sovereignty.

\section{Power}

Analysis of the European discourse on civilization suggests that power is best conceptualized as a relationship between its social and material dimensions. This thesis has paid particular attention to its discursive dimensions, arguing that the discourse on civilization resulted in a juxtaposition between 'civilized' and 'uncivilized' peoples that enabled European imperialism. Of course, the exercise of this discourse would not have been possible without the considerable military might the expanding European powers used to assert themselves in the nonEuropean world (see Bull \& Watson 1984, Wolf 1982). Nevertheless, a focus on the discursive and social dimensions of power highlights the need to re-think narratives that de-contextualize the evolution and expansion of international society, which depict it as a linear process whereby superior European norms and values were projected into the non-European world. ${ }^{189}$ As Steve Smith (1996) explains, these accounts are themselves the product of hegemonic narratives that set the conceptual boundaries of the discipline. "Once established as common sense, theories become incredibly powerful since they delineate not simply what can be known but also what it is sensible to talk about or suggest. [...] Defining common sense is therefore the ultimate act of political power." (13) Instead, what is needed

\footnotetext{
189 It might be argued that these approaches naturalize the expansion, suggesting that it was only commonsensical that European norms and values ultimately prevailed because of their superiority.
} 
is a critical reflection on how discourses are used to inform 'common senses' and influence practice. As Adler (2005) explains of power,

[p] ower should enter a social theory of international politics [...] not only as material and institutional resources, but also as dominant normative understandings and discourses that help build subjectivity, institutionalise practices, and construct and transform social structures. (178)

In this thesis, this has been achieved by connecting contemporary international law to the colonial discourse on civilization and highlighting how this connection has embedded colonial legacies within the contemporary practice of international relations. In particular, it has suggested that the distinction between a civilized self and an uncivilized other permeates inter-societal relations between international society and the Indigenous members of world society. In practice, this has materialized in the form of (post)colonial processes that subsume the latter into the former - whether this is through territorial expansion or the extension of Western-based international law. Two implications stem from this analysis. At the theoretical level, it draws attention to the problematic assumptions that the discipline makes about the origins of international society. Indeed, Seth (2011) observes that the colonial legacies of civilization continue to permeate the way that IR interprets history. Traditional accounts of international society's expansion are those "of a period that includes the bloody conquest of the Americas, the transatlantic slave trade, the expropriation and sometimes genocide of Indigenous peoples, wars of conquest, land grabs, exploitation and oppression, [which] somehow manages to elide much of this history." (Seth 2010,171) In addition, Seth (2011) notes that traditional accounts of the expansion depict it as having "only one 
powerful actor, the white man, who eventually comes to see that the very principles of his club mandate inclusion rather than exclusion." (171)

At the practical level, this analysis suggests that the legacies of civilization inform international debates on Indigenous self-determination - especially in the context of rights-based frameworks. While these rights-based frameworks have been seized upon by the Indigenous transnational movement, their capacity to promote Indigenous self-determination at the ground level continues to be marked by important questions (see below). In the context of decolonization, it was observed that while human rights were extended to Indigenous peoples with the aim of protecting against discrimination, they were also articulated in a way that supported assimilation - as was the case with ILO Convention No 107. And, while the Indigenous transnational movement has successfully challenged this association by negotiating the Declaration (2007), the practicalities of using this framework remain a work-in-progress. Indeed, it was observed in chapter seven that colonial legacies permeate the international discourse on intellectual property and Indigenous knowledge. As a consequence of these legacies, hierarchies of power inhibit the practical realization of asserting self-determination over Indigenous knowledge. In light of all this, an inter-societal approach to international relations as applied in this thesis - helps shed light on the discursive dimensions of power; in particular, the way in which discourse influence practice. 
Anarchy

Increasingly, critical IR scholarship has detailed the Eurocentric assumptions of the discipline. Drawing on an inter-societal framework, this thesis has sought to advance these critiques by highlighting how traditional accounts of anarchy and order emanate from a historical distinction between 'civilized' and 'uncivilized' societies. This pivots on the assumption that societies are best conceptualized as moral communities. As Keal (2003) explains them, moral communities are composed by members who "[...] concede to each other rights and obligations with regard to being treated alike. [...] Implicit in this idea is that moral communities have boundaries that draw the line between who belongs and who does not." (Keal 2003, 29) This implies that "moral communities have rules; not only about the rights and duties members owe each other, but also rules determining rightful membership." (Keal 2003, 29) Moreover, it is assumed that members of moral communities need not extend these rights and obligations to non-members since there is no obligation "to treat non-members as they would treat fellow members." (Keal 2003, 29) Understood from this perspective, inter-societal relations can be conceptualized as occurring through a distinction between self and other, a distinction that enables the more powerful of the two to determine the character of international order.

For example, Edward Keene (2002) has observed that European empires deployed international law in a twofold way over the course of imperialism. On the one hand, European empires used international law to help create and sustain intraEuropean order; on the other hand, they used it as a tool with which to legitimate colonial expansion in the non-European world. Connected to the discourse on 
civilization, this included the articulation of legal frameworks like the Doctrine of Discovery that sought to limit intra-European conflict in the non-European world by setting legal parameters to the acquisition of land. Biased in favour of European empires, the terms of the Doctrine sub-divided Indigenous sovereignty by transferring Indigenous peoples' property rights to the 'discovering' colonial power. As a consequence of these property rights being acquired by the 'discovering' power, other colonial powers could no longer make a legal claim to the same land. In turn, this: 1) helped to reduce the prospect for intra-European conflict in the nonEuropean world; and 2) facilitated European colonial expansion by reducing the prospects for conflict. In other words, the nascent society of European empires devised a system of order designed to benefit intra-European relations to the detriment of inter-societal relations with non-European peoples.

An analysis of the relationship between international society and the Indigenous members of world society subsequently supports the view of scholars like Keene (2002), who argue that contemporary interpretations of order are derivative of European conceptualizations of civilization. Restricted to the members of international society, this discourse enabled the evolution of norms and values that promote order through a Westphalian system. As non-members, Indigenous peoples have been largely denied a voice in defining international order; indeed, Indigenous peoples have instead had to operate through this system despite not having a significant say in defining it. From an historical perspective, this resulted in processes that gradually subsumed Indigenous peoples within European empires. Today, the legacies of these processes continue to persist, despite the role of 
Indigenous transnationalism in working through the human rights regime to challenge the normative foundations of international law. As it speaks to the question of order and anarchy in international relations, an inter-societal approach highlights: 1) the role of colonial legacies in shaping international order between states and Indigenous peoples; and 2) how these legacies originated within a statebased society that defined the concept of order through a delineation between itself and those it considered other.

\section{Sovereignty}

As its name implies, IR has traditionally focussed on issues relevant to the international level; in particular state-to-state relations. An implication of this focus has been the articulation of disciplinary narratives that conceptualize sovereignty as territorially-based. Problematically, this territorial focus has marginalized the domestic level as a site of global politics, despite the fact that the meaning of sovereignty has never been fixed. Scholars like Taiaiake Alfred (2005) and Marshall Beier (2007) observe that the meaning of sovereignty is socially constituted and dependent on intersubjective spaces that reify its meaning. According to Alfred (2005), "[t]he reification of sovereignty in politics today is the result of the triumph of a particular set of ideas over others - no more natural to the world than any other man-made object." (46) Similarly, Beier (2005) observes that sovereignty resides, “[...] in the intersubjective spaces inhabited by norms, it can be confirmed or called into being in a given instance simply through the precedent established in any kind of formal recognition." (Beier 2007, 128) Speaking to the points raised by Alfred 
(2005) and Beier (2007), Joanne Barker (2005) subsequently observes that contrary to the territorial association IR makes with sovereignty, Indigenous peoples have traditionally conceptualized it as emanating from peoples - suggesting a need to reconceptualise and incorporate altogether different concepts of political authority into the study of IR (see chapter three).

Indeed, if sovereignty emanates from people, then IR's focus on the international level can be called into question, as conceptualizing sovereignty in this way suggests that sub-state peoples - just as states - can exercise a similar right. Recently, this has taken the form of a discourse on an Indigenous right to selfdetermination; and as Beier (2007) suggests, this debate bears considerably on the very foundations of international society. As he explains in the context of the term 'Indigenous peoples',

The aggregate signifier, "peoples," of course, bespeaks cohesive political communities with, therefore, a basis to sustain claims of group rights. It is this implication and the precedent it might set which hegemonic Euroderived institutions and practices of global governance cannot abide [...] At issue here is the viability of prevailing notions of sovereignty and of what sorts of communities can be counted as meaningfully sovereign. (127-128)

Working through an inter-societal framework, this thesis has supported this perspective, arguing that the concept of sovereignty has helped maintain a distinction between the international and domestic level. It suggests that the colonial legacies of civilization are at the root of discourses that seek to limit the concept of sovereignty to states; specifically, by limiting the participation of nonstate peoples - e.x. the Indigenous members of world society - to the domestic level. Scholarship has begun to re-think critically the domestic-international distinction however, with scholars of globalization noting the rise of non-state actors. For these 
scholars, IR must move towards an approach that emphasizes global/world politics as opposed to international politics. ${ }^{190}$ While such a move may help broaden IR's research agenda, it fails to theorize adequately the domestic as a site of the international because it assumes that domestic actors become important only when they operate at the transnational level. Consequently, such an approach has little problem incorporating Indigenous transnationalism into the analysis, but has difficulty justifying sub-state relations between a government and an Indigenous people. 191 As suggested by an inter-societal analysis, what is required is a more radical approach that rethinks the domestic-international dichotomy altogether. Such a move is supported by an historical analysis of relations between international society and the Indigenous members of world society, which highlights the sovereign claims of sub-state peoples. Speaking to the historical absence of these peoples from disciplinary IR, Beier (2004) puts this perspective thusly,

[...] lest the objection be raised that the politics of the Indigenous nations of the Americas have been specific to their places within the states in which they are spatially embedded and have not extended into the international realm, it is well to remember that the enactment of treaties has been a widely used instrument in relations between the First Nations and the colonial powers. (83)

\footnotetext{
190 According to Steve Smith, Patricia Owens and John Baylis (2012), their use of the term "[world politics] is meant to signal the fact that [their] interest is in the politics and political patterns of the world and not only those between nation-states." (2)

191 This is problematic as many Indigenous peoples conceptualize their relations with the state as occurring on a 'nation-to-nation' basis - to exclude such relations is to exclude a form of international relations occurring at the sub-state level.
} 


\section{Conclusion}

In his analysis of the relationship between international society and Indigenous peoples, Paul Keal (2003) argues that international society can play a critical role in addressing the legacies of colonialism. For Keal (2003), this means that "states and international society alike" must recognize Indigenous peoples as "peoples' with the right to self-determination, both within constitutional law and international or emerging global law." (217) Writing before the passage of the Declaration (2007), Keal (2003) argues that passage of it would go a considerable way towards moving international law in that direction. There is also merit to Keal's (2003) argument, insofar as the Declaration (2007) articulates a soft legal basis for redefining relations between international society and the Indigenous members of world society. As Victoria Tauli-Corpuz, Chair of the UN Permanent Forum on Indigenous Issues, indicated on the day the text was adopted, "[t]his day will forever be etched in our memories as a significant gain in our peoples' long struggle for our rights as distinct peoples and cultures." (UN 2007, online) Echoing Corpuz, Les Malezer, Chairperson of the Global Indigenous Caucus, noted that the adoption of the Declaration (2007) addressed the fact that already existing human rights law had long been denied to Indigenous peoples; as he observes, the Declaration (2007) is "based on rights that had been approved by the United Nations system but which had somehow, over the years, been denied to Indigenous peoples." (UN 2007, online) It is a "framework for States to protect and promote the rights of Indigenous people without exclusion or discrimination." (UN 2007, online) 
Though politically significant, and a testament to the advocacy of the Indigenous transnational movement, the Declaration (2007) is not without its flaws. In particular, important questions can be raised against the actual capacity of the Declaration (2007) to serve in practice, as the basis for a transformation in relations between states and the Indigenous members of world society. For instance, it is worth recalling that negotiation of the Declaration (2007) was marked by significant state reservations that led Australia, Canada, New Zealand and the United States to vote against the document, in large part because of the language of selfdetermination and its potentially corrosive effects on state sovereignty. ${ }^{192}$

Australia's representative said his Government had long expressed its dissatisfaction with the references to self-determination in the text. Selfdetermination applied to situations of decolonization and the break-up of States into smaller states with clearly defined population groups. It also applied where a particular group with a defined territory was disenfranchised and was denied political or civil rights. (UN 2007, online)

In effect, the argument levied against the Declaration (2007) by the Australian representative was that the participation of Indigenous peoples within a democratic state eliminated the need to further extend such peoples a right to selfdetermination. ${ }^{193}$ Reminiscent of colonial assumptions about the integration of uncivilized peoples into civilized states, the Australian representative at once cast Indigenous peoples as domestic populations while claiming that they could be best

\footnotetext{
192 The UN explains that "Countries voting against the Declaration said they could not support it because of concerns over provisions on self-determination, land and resources rights and, among others, language giving Indigenous peoples a right of veto over national legislation and State management of resources." (UN 2007, online)

193 As explained by the Australian representative, "Australia supported and encouraged the full engagement of Indigenous peoples in the democratic decision-making process, but did not support a concept that could be construed as encouraging action that would impair, even in part, the territorial and political integrity of a State with a system of democratic representative Government." (UN 2007, online)
} 
served by the modern state. And, while it is true that Australia - along with Canada, ${ }^{194}$ New Zealand and the United States - has since endorsed the Declaration (2007), its position at the General Assembly vote speaks to fundamental cleavages between states and the Indigenous members of world society. This is the case at both a theoretical and practical level. At the theoretical level, the position of Australia highlights the fact that Indigenous-state relations continue to be marked by the colonial legacies of civilization. At a more practical level, this has resulted in three inter-related and tangible outcomes:

1. Processes of colonialism that have subsumed Indigenous peoples within states and western forms of international law;

2. The denial of Indigenous sovereignty - an account of sovereignty that perceives it as emanating from people and not territory;

3. The denial of Indigenous peoples as equal participants in the multilateral forums of international society, its debates and discourses.

From a contemporary standpoint, these points speak to the issue of implementing the Declaration (2007) in practice - at the domestic and international levels. At the international level it was observed that the articulation of human rights remain predicated on colonial assumptions about civilization, which affect the capacity of Indigenous peoples to assert self-determination over their traditional

\footnotetext{
194 Speaking to questions of self-determination and the potentially corrosive effect on state sovereignty, Canada explained its decision to vote against the Declaration (2007) at the Human Rights Council - in part - accordingly, "the concept of free, prior and informed consent is used in many contexts within the Draft Declaration. It could be interpreted as giving a veto to Indigenous peoples over many administrative matters, legislation, development proposals and national defence activities which concern the broader population and may affect Indigenous peoples. Also, in relation to self-government provisions, the text does not provide effective guidance about how Indigenous governments might work with other levels of government, including laws of overriding national importance and matters of financing." (Government of Canada 2010, online)
} 
knowledge. While the Indigenous transnational movement has made headway in voicing its concerns internationally, it remains to be seen whether the concerns of Indigenous voices will be translated into everyday relations with states. At the domestic level, these concerns are being voiced in a number of postcolonial states. In Canada, for instance, the Idle No More movement has recently provoked important questions about the colonial legacies of Canada's relationship with the Indigenous peoples ensconced within its borders. Drawing on the rights-based language of the Declaration (2007) - and of international society -195 this movement has at its roots sought to renegotiate Aboriginal relations with Canada's state government. As expressed by the movement, this renegotiation is concerned with the question of sovereignty and the 'right' of Indigenous peoples to assert it, despite being ensconced within the state. As the 'tag-line' of the movement makes clear, members of the movement are "unified and standing together for Indigenous sovereignty."196 (INM 2013, online)

In this way, the Idle No More movement provokes even more questions about the future direction of relations between international society and the Indigenous members of world society. On the one hand, it is clear that the rights-based language of the Declaration (2007) has become a tool with which to garner support for higher degrees of Indigenous self-determination. In this respect, it is noteworthy

\footnotetext{
195 The movement has referred to itself as the 'Indigenous rights movement.' (INM 2013, online)

196 The summer of 2013 has itself been referred to by the movement as 'sovereignty summer.' And, according to the manifesto of the Idle No More movement, "We contend that: The Treaties are nation to nation agreements between The Crown and First Nations who are sovereign nations. The Treaties are agreements that cannot be altered or broken by one side of the two Nations. The spirit and intent of the Treaty agreements meant that First Nations peoples would share the land, but retain their inherent rights to lands and resources. Instead, First Nations have experienced a history of colonization which has resulted in outstanding land claims, lack of resources and unequal funding for services such as education and housing." (INM 2013, online)
} 
that most Indigenous peoples do not seek territorial sovereignty, but have instead sought a greater degree of accommodation within the state, by advocating for stronger rights that will enable them to exercise greater levels of self-determination and assert their status as 'nations within.' On the other hand, the fact that these struggles persist, suggests that the rights-based framework of the Declaration (2007) is still a long way from being realized. While the coming decades will help clarify the extent to which the Declaration (2007) has helped catalyze change in the relationship between international society and the Indigenous members of world society, there still seems to be considerable work to be done. As an inter-societal approach to these issues suggests, much of the potential success for mobilizing change will fundamentally hinge on the capacity of Indigenous peoples and states to challenge the colonial legacies of civilization; in particular, to find a way for territorial and people-based definitions of sovereignty to coexist. ${ }^{197}$ This is no easy task, as the very foundations of international relations have themselves been shown to be predicated on the historical marginalization of the latter. As states and the Indigenous members of world society continue to redefine their relationship with one another, it will be wise to heed the words of former Grand Chief of the Assembly of First Nations, Phil Fontaine, who reminds us that "[t]he adoption of the Declaration by the United Nations was not an endpoint; it is [only] the beginning." (IBA 2011, 5) The next step, it would appear, will be realizing these rights in

\footnotetext{
${ }^{197}$ A suggested by this thesis, this seems to be largely taking place in the context of debate around the concept of self-determination and the extent to which this concept can be exercised by Indigenous peoples residing within states.
} 
practice through the decolonization of international law, through a comprehensive engagement with the colonial legacies of civilization. 


\section{Bibliography}

. (1993). The Mataatua declaration on cultural and intellectual property rights of indigenous peoples. Commission on Human Rights Sub-Commission of Prevention of Discrimination and protection of Minorities Working Group on Indigenous Populations, 19-30 July 1993. Retrieved from:

http://www.wipo.int/export/sites/www/tk/en/databases/creative heritag e/docs/mataatua.pdf

- (1992). Indigenous peoples earth charter. Conference of Churches in Aotearoa New Zealand. Retrieved from:

http://www.trc.org.nz/content/indigenous-peoples-earth-charter

. (1885). The general act of the Berlin Conference on West Africa. Retrieved from:

http://africanhistory.about.com/od/eracolonialism/l/n BerlinAct1885.htm

Adler, E. (2005). Barry Buzan's use of constructivism to reconstruct the English School: 'Not all the way down.' Millennium: Journal of International Studies, $34,171-182$.

Albert, M., Brock, L., Wolf, K.D. (Eds.) (2000) Civilizing world politics: Society and community beyond the state. Lanham: Rowman and Littlefield Publishers, Inc.

Alexandrowicz, C.H. (1973). The European-African confrontation: A study in treaty making. Leiden: A.W. Sijthoff International Publishing Company.

Alexandrowicz, C.H. (1971). The juridical expression of the Sacred Trust of Civilization. The American Journal of International Law, 65, 149-159.

Alfred, T. (2005). Sovereignty. In Barker, J. (Eds.) Locations of contestation and possibility in indigenous struggles for self-determination (pp. 33-50). Lincoln: University of Nebraska Press.

Alfred, T. (1999). Peace, power, righteousness: An indigenous manifesto. Oxford: Oxford University Press.

Amnesty International. (2013). The United nations Declaration on the Rights of Indigenous Peoples. Retrieved from:

http://www.amnesty.ca/our-work/issues/indigenous-peoples/the-unitednations-declaration-on-the-rights-of-indigenous-people

Anaya, S.J. (Eds.) (2003). International law and indigenous peoples. Aldershot: Ashgate Publishing Company. 
Anaya, S.J. (1996a). Indigenous peoples in international law. New York: Oxford University Press.

Anaya, S.J. (1996b). Indigenous peoples in international law (2nd ed). New York: Oxford University Press.

Anaya, S.J. (1993). A contemporary definition of the international norm of selfdetermination. Transnational Law and Contemporary Problem, 3, 131-164.

Anaya, S.J. (1990). The capacity of international law to advance ethnic or nationality rights claims. Iowa Law Review, 75.

Anghie, A. (2006). Decolonizing the concept of "good governance." In Jones, B.G. (Eds.) Decolonizing international relations (109-130). Lanham: Rowman \& Littlefield Publishers.

Anghie, A. (2004). Imperialism, sovereignty and the making of international law. Cambridge: Cambridge University Press.

Anghie, A. (1999). Finding the peripheries: Sovereignty and colonialism in nineteenth-century international law. Harvard International Law Journal, 40, $1-80$.

Anghie, A. (1996). Francisco de Vitoria and the colonial origins of international law. Social \& Legal Studies, 5, 321-336.

Arewa, O.B. (2006). TRIPS and traditional knowledge: Local communities, local knowledge, and global intellectual property frameworks. Marquette Intellectual Property Law Review, 10, 156-180.

Aristotle. (1996). The politics and the constitution of Athens. Cambridge: Cambridge University Press.

Arneil, B. (1996). John Locke and America: The defence of English colonialism. Oxford: Oxford University Press.

Assembly of First Nations. (2011). Discussion paper: Aboriginal traditional knowledge and intellectual property rights. Ottawa: Assembly of First Nations.

Barcham, M. (2000). (De) Constructing the politics of indigeneity. In Ivison, D., Patton, P., Sanders, W. (Eds.) Political theory and the rights of indigenous peoples (137-151). Cambridge: Cambridge University Press.

Barker, J. (2005). For whom sovereignty matters. In Barker, J. (Eds.) Sovereignty matters: Locations of contestation and possibility in indigenous struggles for self-determination (pp. 1-31). Lincoln: University of Nebraska Press. 
Battiste, M. (2010). Indigenous knowledge and indigenous peoples' education. Introduction. In Subramanian, S.M. \& Pisupati, B. (Eds.) Traditional knowledge in policy and practice: Approaches to development and human wellbeing (pp. 31-51). Tokyo: United Nations University Press.

Baylis, J. \& Smith, S. (Eds.). (2001). The globalization of world politics: An introduction to international relations. Oxford: Oxford University Press.

Bederman, D.J. (2001). Grotius and his followers on treaty construction. Journal of the History of International Law, 3, 18-37.

Bedford, D., \& Workman, T. (1997). The Great Law of Peace: Alternative internation(al) practices and the Iroquoian Confederacy. Alternatives, 22, 87-111.

Beier, J.M. (Eds.) (2009). Indigenous Diplomacies. New York: Palgrave MacMillan.

Beier, J.M. (2007). Inter-national affairs: Indigeneity, globality and the Canadian state. Canadian Foreign Policy Journal, 13, 121-131.

Beier, J.M. (2005). International relations in uncommon places: Indigeneity, cosmology, and the limits of international theory. New York: Palgrave MacMillan.

Beier, J.M. (2004). Beyond hegemonic state(men)ts of nature: Indigenous knowledge and non-state possibilities in international relations. In Chowdhry, G. \& Nair, S. (Eds.) Power, postcolonialism and international relations: Reading race, gender and class (82-114). London \& New York: Routledge.

Bellamy, A.J. (2005a). Introduction: International society and the English School. In Bellamy, A.J. (Eds.) International society and its critics (pp. 1-26). Oxford: Oxford University Press.

Bellamy, A.J. (2005b). Conclusion: Whither international society. In Bellamy, A.J. (Eds.) International society and its critics (pp. 1-26). Oxford: Oxford University Press.

Bengwayan, M.A. (2003). Intellectual and cultural property rights of Indigenous peoples and tribal peoples in Asia. London: Minority Rights Group International.

Bergeron, KM. (2012) Global activism and changing identities: Interconnecting the global and the local - The Grand Coucil of the Crees and the Saami Council. In Blaser, M., et al. (Eds.) Indigenous peoples and autonomy: Insights for a global age. Vancouver: UBC Press.

Bhaba, H.K. (1994). The location of culture. Oxon: Routledge. 
Blakeney, M. (2006) Hans Christian Andersen and the protection of traditional cultural expressions. In Porsdam, H. (Eds) Copyright and other fairy tales: Hans Christian Andersen and the commodification of creativity (108-128). Northampton: Edward Elsgar Publishing, Inc.

Blaser, M., et al. (2010). Reconfiguring the web of life: Indigenous peoples, relationality, and globalization. In Blaser, M., et al. (Eds.) Indigenous peoples and autonomy: Insights for a global age. Vancouver: UBC Press.

Boutros-Gali, B. (1992). An agenda for peace. Retrieved from: http://www.un-documents.net/a47-277.htm

Bowden, B. (2009). The empire of civilization: The evolution of an imperial idea. Chicago: University of Chicago Press.

Bowden, B. (2005). The colonial origins of international law: European expansion and the classical Standard of Civilization. Journal of the History of International Law, 7, 1-23.

Bowden, B. (2004a) In the name of progress and peace: The 'Standard of Civilization' and the universalizing project. Alternatives: Global, Local, Political, 29, 43-68.

Bowden, B. (2004b). The idea of civilization: Its origins and socio-political character. Critical Review of International Social and Political Philosophy, 7, 25-50.

Bowden, B. (2002). Globalisation and the shifting 'Standard of Civilization' in international society. Jubilee Conference of the Australasian Political Studies Association. Canberra: Australian National University

Boyle, J. (1992). Natural law and international ethics. In Nardin, T. \& Mapel, D.R. (Eds.) Traditions of international ethics (112-135). Cambridge: Cambridge University Press.

Bratt, D., \& Kukucha, C.J. (Eds.) (2011). Readings in Canadian Foreign Policy: Classic debates and new ideas. Oxford: Oxford University Press.

Brodie, J. \& Rein, S. (Eds.) (1999). Critical concepts: An introduction to politics (4th ed.). Toronto: Pearson Prentice Hall.

Brown, S. (1992). International relations in a changing global system: Towards a theory of the world polity. Boulder: Westview.

Bruyneel, K. (2007). The third space of sovereignty: The postcolonial politics of USIndigenous relations. Minneapolis: University of Minnesota Press.

Bull, H. (1990). The importance of Grotius in the study of International Relations. In Bull, H., Kingsbury, B., Roberts, A. (Eds.) Hugo Grotius and International Relations (pp. 65-93). Oxford: Clarendon Press. 
Bull, H. (1977). The anarchical society: A study of order in world politics (3rd ed.) New York: Columbia University Press.

Bull, H. (1966). International theory: The case for a classical approach. World Politics, 18, 361-377.

Bull, H. \& Watson, A. (Eds.) (1984). The expansion of international society. Oxford: Clarendon Press

Burchill, S. (1996) Liberalism. In Burchill, S., et al (Eds.) Theories of International Relations (3rd Ed) (55-83). Houndmills: Palgrave Macmillan.

Butler, J. (201). Performative agency. Journal of cultural economy, 3, 147-161.

Buzan, B. (2005). Not hanging separately: Responses to Dunne and Adler. Millennium: Journal of International Studies, 34, 183-194.

Buzan, B. (2004). From international to world society?: English School theory and the social structure of globalization. Cambridge: Cambridge University Press.

Buzan, B. (2001). The English School: An underexploited resource in IR. Review of International Studies, 27, 471-488.

Byrd, J.A. \& Heyer, K.C. (2008). Introduction: International discourses of Indigenous rights and responsibilities. Alternatives, 33, 1-5.

Campbell, D. (1992). Writing security: United States foreign policy and the politics of identity. Minneapolis: University of Minnesota Press.

Carmen, A. (2010). The right to free, prior and informed consent: A framework for harmonious relations and new processes for redress. In Hartley, J., Joffe, P., \& Presten, J. (Eds). Realizing the UN Declaration on the Rights of Indigenous Peoples: Triumph, hope, action (120-134). Saskatoon: First Nations Summit Society.

Carr, E.H. (1939). The Twenty Years' Crisis. New York: Palgrave Publishers, Ltd.

Castellino, J. (2005). Conceptual difficulties and the right to indigenous selfdetermination. In Ghanea, N. \& Xanthaki, A. (Eds.) Minorities, peoples and self-determination: Essays in honour of Patrick Thornberry (pp. 55-74). Leiden: Martinus Nijhoff Publishers.

Chapman, A.R. (1998). A human rights perspective on intellectual property, scientific progress, and access to the benefits of science. Proceeding from WIPO, '98: Panel discussion on intellectual property and human rights. Geneva: World Intellectual Property Organization. 
Chowdhry, G. \& Nair, S. (2004). Introduction: Power in a postcolonial world: Race, gender and class in international relations. In Chowdhry, G. \& Nair, S. (Eds.) Power, postcolonialism and international relations: Reading race, gender and class (1-32). London \& New York: Routledge.

Clavin, P. Defining transnationalism. Contemporary European History, 14, 421-439.

Coates, K.S. (2004). A global history of Indigenous Peoples: Struggle and survival. Houndmills: Palgrave MacMillan.

Coleman, W.D. (Eds.) (2011). Property, Territory, Globalization: Struggles over autonomy. Vancouver: UBC Press.

Connolly, W.E., (2000) The liberal image of the nation. In Ivison, D., Patton, P., Sanders, W. (Eds.) Political theory and the rights of indigenous peoples (183198). Cambridge: Cambridge University Press.

Coombe, R. (2005). Cultural rights and intellectual property debates. Human Rights Dialogue, 2, 34-36.

Corntassel, J. (2012). Re-envisioning resurgence: Indigenous pathways to decolonization and sustainable self-determination. Decolonization: Indigeneity, Education \& Society, 1, 86-101.

Corntassel, J. (2008). Toward sustainable self-determination: Rethinking the contemporary indigenous-rights discourse. Alternatives, 33, 105-132.

Corntassel, J. (2007). Partnership in action? Indigenous political mobilization and co-optation during the first UN indigenous decade (1995-2004). Human Rights Quarterly, 29: 137-166.

Corntassel and Bryce. (2012). Practicing sustainable self-determination: Indigenous approaches to cultural restoration and revitalization. The Brown Journal of World Affairs, XVIII, 151-162.

Tauli-Corpuz, V. (2003). Biodiversity, traditional knowledge and rights of Indigenous peoples. Penang: Third World Network.

Cox, R. (1981). Social forces, states and world orders: Beyond international relations theory. Millennium: Journal of International Studies, 10, 126-155.

Crawford, N. (1994). A security regime among democracies: Cooperation among the Iroquois nations. International Organization, 48, 345-385.

Cristescu, A. (1981). The right to self-determination: Historical and current development on the basis of United Nations instrument. New York: United Nations.

Curry, S. (2004). Indigenous sovereignty and the democratic project. Aldershot: Ashgate Publishing Company. 
Curry, B. \& Makin, K. (2013, January 10) Number of recognized aboriginal people should double, court rules. The Global and Mail. Retrieved from: http://www.theglobeandmail.com/news/national/number-of-recognizedaboriginal-people-should-double-court-rules/article7029340/

Cutler, C.A. (1991). The 'Groatian tradition' in international relations. Review of International Studies, 1991, 41-65.

Davis, M. (2008). Indigenous struggles in standard setting: The United Nations Declaration on the Rights of Indigenous Peoples. Sydney: Indigenous Law Centre

Davis, M. (2007). The United Nations Declaration on the Rights of Indigenous Peoples. Sydney: Indigenous Law Centre

Deer, K. (2010). Reflections on the development, adoption, and implementation of the UN Declaration on the Rights of Indigenous Peoples. In Hartley, J., Joffe, P., \& Presten, J. (Eds). Realizing the UN Declaration on the Rights of Indigenous Peoples: Triumph, hope, action (18-28). Saskatoon: First Nations Summit Society.

Deloria Jr., V. (1999). Self-determination and the concept of sovereignty. In Wunder, J.R. (Eds). Native American sovereignty (107-114). New York: Taylor \& Francis.

Deloria Jr., V \& Lytle, C. (1984). The Nations Within: The past and future of American Indian sovereignty. New York: Pantheon Books.

Deng, F.M. (2008). Identity, diversity, and constitutionalism in Africa. Washington: United States Institute of Peace.

Deskaheh (Chief General Levi). (1923). The red man's appeal for justice. Retrieved from: http://law.lib.buffalo.edu/collections/berman/pdfs/Redmanappeal.pdf

Donnely, J. (1998). Human Rights: A new Standard of Civilization? International Affairs, 74, 1-23.

Doyle, M. (1997). Ways of war and peace. New York: W.W. Norton \& Company.

Drahos, P. (1998). The universality of intellectual property rights. Proceeding from WIPO, '98: Panel discussion on intellectual property and human rights. Geneva: World Intellectual Property Organization.

Duara, P. (2004). The discourse of civilization and decolonization. Journal of World History, 15, 1-5. 
Dunne, T. (2010). The English School. In Dunne, T., Kurki, M., \& Smith, S. (Eds). International relations theories: Discipline and diversity (127-147). New York: Oxford University Press.

Dunne, T. (2005a). System, state and society: How does it all hang together? Millennium: Journal of International Studies, 34, 157-170.

Dunne, T. (2005b). The new agenda. In Bellamy, A.J. (Eds.) International society and its critics (pp. 65-79). Oxford: Oxford University Press.

Dunne, T. (1997) Colonial encounters in international relations: Reading Wight, writing Australia. Australian International Affairs, 51, 309-323.

Dunne, T. (1995). The social construction of international society. The European Journal of International Relations, 1, 367-389.

Dunne, T. \& Schmidt, B. (2011). Realism. In Baylis, J., Smith, S. \& Owens, P. (Eds.). The globalization of world politics: An introduction to international relations ( $^{\text {th }}$ Ed). Oxford: Oxford University Press.

Dutfield, G. (2000). The public and private domains: Intellectual property rights in traditional knowledge. Science Communication, 21: 274-295.

Economic and Social Council. (1982). Resolution 1982/34: Study of the problem of discrimination against indigenous populations. Retrieved from: http://ap.ohchr.org/documents/alldocs.aspx?doc id=8660

Eisenberg, A. \& Spinner-Halev, J. (Eds.). Minorities within minorities: Equality, rights and diversity. Cambridge: Cambridge University Press.

Engle, K. (2010). The elusive promise of indigenous development: Rights, culture, strategy. Durham \& London: Duke University Press.

Epp, R. (1998). The English School on the frontiers of international society: a hermeneutic recollection. British International Studies Association, 24, 47-64.

Errico, S. (2007a). The UN declaration on the Rights of Indigenous Peoples is adopted: An overview. Human Rights Law Review, 7: 741-755

Errico, S. (2007b). The UN declaration on the Rights of Indigenous Peoples is adopted: An overview. Human Rights Law Review, 7: 756-759

Fanon, F. (1963). The wretched of the earth. New York: Grove Press.

Fidler, D.P. (Spring 2001). The return of the Standard of Civilization. Chicago Journal of International Law, 2, 137-157.

Finnemore, M. (1996). Norms, culture, and world politics: Insights from sociology's institutionalism. International Organization, 50, 325-347. 
Fitzpatrick, P. (2001). Terminal legality: Imperialism and the (de)composition of law. In Kirkby, D. \& Coleborne, C. (Eds.) Law, history, colonialism: The reach of empire (pp. 9-25). Manchester \& New York: Manchester University Press.

Fontaine, P. (2010). A living instrument. In Hartley, J., Joffe, P., \& Preston, J. (Eds.). Realizing the UN Declaration on the rights of indigenous peoples: Triumph, hope, and action (8-11). Saskatoon: Purich Publishing Limited.

Ford, L. (2010). Settler sovereignty: Jurisdiction and indigenous peoples in America and Australia, 1788-1836. Cambridge: Harvard University Press.

Forsyth, M. (1992). The tradition of international law. In Nardin, T. \& Mapel, D.R. (Eds.) Traditions of international ethics (pp. 23-41). Cambridge: Cambridge University Press.

Foundation for Biotechnology Awareness and Education. (2008). Intellectual property and Indigenous peoples: Current legal standing. Retrieved from: http://www.fbae.org/2009/FBAE/website/biotechnology-andipr intellectual-property.html

Frieden, J.A. \& Lake, D.A. (2000). International political economy: Perspectives on global power and wealth. London: Bedford/St. Martin's.

Friedman, J. (2008). Indigeneity: Anthropological notes on a historical variable. In Minde, H. (Eds.) Indigenous peoples: Self-determination, knowledge, indigeneity (pp. 29-48). Delft: Eburon Academic Publishers.

Gilbert, J. (2007). Indigenous rights in the making: The United Nations Declaration on the Rights of Indigenous Peoples. International Journal on Minority and Group Rights, 14: 207-230.

Gigoux, C. \& Samson, S. (2011). Globalization and Indigenous peoples: New old patterns. In Turner, B.S. (Eds.) The Routledge international handbook of globalization studies (287-311). New York: Routledge.

Glauser, B. (2011). Being indigenous: The concept of indigenity, a conversation with two ayoreo leaders. In Venkateshwar, S. \& Hughes, E. (Eds.) The politics of indigeneity: Dialogues and reflections on indigenous activism (pp. 21-44). London: Zed Books.

Gong, G. (1984). The Standard of Civilization in international society. Oxford: Clarendon Press.

Government of Canada. (2010). Canada's position: United Nations draft Declaration on the Rights of Indigenous Peoples. Retrieved from: http://www.aadnc-aandc.gc.ca/eng/1100100014078/1100100014079

Government of Canada. (1923). Statement Respecting the Six Nations Appeal to the League of Nations. League of Nations doc. no. 11/34286/28075. Geneva. 
Graham, L. \& Mcjohn, S. (2005). Indigenous peoples and intellectual property.Washington University Journal of Law and Policy, 19, 313-337.

Gross L. (1948). The Peace of Westphalia, 1648-1948. American Journal of International Law, 42, 20-41.

Grovugui, S.N. (2004). Postcolonial criticism: International reality and modes of inquiry. In Chowdhry, G. \& Nair, S. (Eds.) Power, postcolonialism and international relations: Reading race, gender and class (pp. 33-55). London \& New York: Routledge.

Grovogui, S.N. (2002). Regimes of sovereignty: International morality and the African condition. European Journal of International Relations, 8, 315-38.

Grovugui, S.N. (2001) Come to Africa: A hermeneutics of race in international theory. Alternatives, 26, 425-448.

Guenther, M. (2006). The concept of indigeneity. Social Anthropology, 14, 17-32.

Hall, S. (1996). When was the post-colonial: Thinking at the limit. In Chambers, I. \& Curti, L. (Eds). The post-colonial question: Common skies divided horizons (242-260). London \& New York: Routledge.

Halliday, F. \& Rosenberg, J. (1998). Interview with Ken Waltz. Review of International Studies, 24, 371-386.

Halliday, F. (1994). Rethinking international relations. Vancouver: University Press.

Halperin, S. (2006). International Relations theory and the hegemony of western conceptions of modernity. In Jones, B.G. (Eds.) Decolonizing international relations (pp. 43-63). Lanham: Rowman \& Littlefield Publishers.

Harris, C. (2004). How did colonialism dispossess? Comments from an edge of empire. Annals of the Association of American Geographers, 94, 1165-182.

Hauptman, L.M. (2008). Seven generations of Iroquois leadership: The Six Nations since 1800. Syracuse: Syracuse University Press.

Henderson, J. (2008). Indigenous Diplomacy and the rights of peoples: Achieving UN recognition. Saskatoon: Purich Publishing Ltd.

Hobbes, T. (1651). Leviathan. New York: Penguin Classic.

Hobson, J.M. (2012). The Eurocentric conception of world politics: Western international theory, 1760-2010. Cambridge: Cambridge University,

Holder, C. (2008). Culture as an activity and Human Right: An important advance for indigenous peoples and international law. Alternatives, 33, 7-28. 
Holder, C. (2005). Self-determination as a basic human right: The Draft UN Declaration on the Rights of Indigenous Peoples. In Eisenberg, A. \& SpinnerHalev, J. (Eds.). Minorities within minorities: Equality, rights and diversity (pp. 294-315). Cambridge: Cambridge University Press.

Holsti, K.J. (2009). Theorising the causes of order: Hedley Bull's The Anarchical Society. In In Navari, C. (Eds.) Theorising international society: English School methods (125-147). New York: Palgrave MacMillan.

Huntington, S.P. (1993). The clash of civilizations? Foreign Affairs, 72, 22-49.

Idle No More. (2013a). Idle No More. Retrieved from:

http://www.idlenomore.ca/

Idle No More. (2013b). Sovereignty summer. Retrieved from:

http://www.idlenomore.ca/tags/ sovsummer

Indigenous Bar Association. (2011). Understanding and implementing the UN Declaration on the rights of Indigenous peoples. Winnipeg: Indigenous Bar Association.

International Labor Organization. (1957). Indigenous and Tribal Populations Convention, C107. Retrieved from:

http://www.ilo.org/dyn/normlex/en/f?p=1000:12100:0::NO::P12100 ILO C ODE:C107

International Labor Organization. (1989). Convention No. 169. Retrieved from: http://www.ilo.org/indigenous/Conventions/no169/lang--en/index.htm

Ivison, D. (2002). Postcolonial liberalism. Cambridge: Cambridge University Press.

Ivison, D., Patton, P.. \& Sanders W. (2000). Introduction. In Ivison, D., Patton, P., Sanders, W. (Eds.) Political theory and the rights of indigenous peoples (1-21). Cambridge: Cambridge University Press.

Jackson, R. (2009). International Relations as a craft discipline. In Navari, C. (Eds.) Theorising international society: English School methods (21-38). New York: Palgrave MacMillan.

Jahn, B. (2005a) Barbarian thoughts: Imperialism in the philosophy of John Stuart Mill. Review of International studies, 31, 599-618.

Jahn, B. (2005b). Kant, Mill, and illiberal legacies in international affairs. International Organization, 59, 177-207.

Jahn, B. (1998). Critical theory as the latest edition of liberal idealism. Millennium: Journal of International Studies, 27, 613-641. 
Joffe, P. (2010). Canada's opposition to the UN Declaration: Legitimate concerns or ideological bias? In Hartley, J., Joffe, P., \& Presten, J. (Eds). Realizing the UN Declaration on the Rights of Indigenous Peoples: Triumph, hope, action (7094). Saskatoon: First Nations Summit Society.

Johnson, J.J. (2008). Indigeneity's challenges to the white settler-state: Creating a thirdspace for dynamic citizenship. Alternatives, 33, 29-52.

Jones, B.G. (2006). Introduction: International Relations, Eurocentrism, and imperialism. In Jones, B.G. (Eds.) Decolonizing international relations (1-19). Lanham: Rowman \& Littlefield Publishers.

Jones, R. (1981). The English School: A case for closure. Review of International Studies, 7, 1-13.

Jung, D. (2001). The political sociology of world society. European Journal of International Relations, 7, 443-474.

Kades, E. (2001). History and interpretation of the great case of Johnson v. M'Intosh. William and Mary Law School Faculty Publications, Paper 50. Retrieved from: http://scholarship.law.wm.edu/cgi/viewcontent.cgi?article=1050\&context=f acpubs

Kayaoglu, T. (2010). Westphalian Eurocentrism in International Relations theory. International Studies Review, 12, 193-217.

Kayaoglu, T. (2007). The extension of Westphalian sovereignty: State building and the abolition of extraterritoriality. International Studies Quarterly, 51, 649675.

Keal, P. (2003). European conquest and the rights of indigenous peoples: The moral backwardness of international society. Cambridge: Cambridge University Press.

Keck, M.E. \& Sikkink, K. (1999). Transnational advocacy networks in international and regional politics. International Social Science Journal, 51, 89-101.

Keene, E. (2009). International society as an ideal type. In Navari, C. (Eds.) Theorising international society: English School methods (104-124). New York: Palgrave MacMillan.

Keene, E. (2005). International political thought: An historical introduction. Cambridge: Polity Press.

Keene, E. (2002). Beyond the anarchical society: Grotius, colonialism and order in world politics. Cambridge: Cambridge University Press.

Keohane, R.O. Review. American Political Science Review, 86, 1112-1113. 
Keohane, R.O. (Eds.). (1986). Neorealism and its critics. New York: Columbia University Press

Keohane, R.O. \& Nye, J.S. (1981). Transnational relations and world politics. Cambridge: Harvard University Press.

Kingsbury, B. (1999). The applicability of the international legal concept 'Indigenous peoples' in Asia. In Bauer, J.R. \& Bell, D.A. (Eds) The east Asian challenge for human rights (336-377). Cambridge: Cambridge University Press.

Kingsbury, B. (1998). "Indigenous Peoples" in international law: A constructivist approach to the Asian controversy. The American Journal of International Law, 92, 414-457.

Kingsbury, K. \& Roberts, A. (1990). Introduction: Grotian thought in International Relations. In Bull, H., Kingsbury, B., Roberts, A. (Eds.) Hugo Grotius and International Relations (pp. 1-64). Oxford: Clarendon Press.

Koivurova, T. (2010). Sovereign states and self-determining peoples: Carving out a place for transnational indigenous peoples in a world of sovereign states. International Community Law Review, 12, 191-212.

Krasner, S.D. (1999). Sovereignty: Organized hypocrisy. Princeton: Princeton University Press.

Krasner, S.D. (1983). Structural causes and regime consequences: Regimes as intervening variables. In Krasner, S.D. (Eds.) International Regimes (1-22). Ithaca: Cornell University Press.

Kymlicka, W. (2000). American multiculturalism and the 'nations within.' In Ivison, D., Patton, P., Sanders, W. (Eds.) Political theory and the rights of indigenous peoples (216-236). Cambridge: Cambridge University Press.

Kymlicka, W. (1999). Theorizing Indigenous rights. The University of Toronto Law Journal, 49, 281-293.

Lâm, M.C. (2000). At the edge of the state: Indigenous peoples and self-determination. Ardsley: Transnational Publishers, Inc.

Larson, E.K., Johnson, Z., \& Murphy, M. (2008). Emerging indigenous governance: Ainu rights at the intersection of global norms and domestic institutions. Alternatives, 33, 53-82.

League of Nations. (1924). The covenant of the League of Nations. Retrieved from: http://avalon.law.yale.edu/20th century/leagcov.asp

Lenzerini, F. (Eds.) (2008). Reparations for indigenous peoples: International \& comparative perspectives. Oxford: Oxford University Press. 
von Lewinski, S. (1998). Intellectual property, nationality, and non-discrimination. Proceeding from WIPO, '98: Panel discussion on intellectual property and human rights. Geneva: World Intellectual Property Organization.

Lewkowicz, N. (2007). The Spanish School as a forerunner to the English School of international relations. Historia, 6, 85-96.

Lindley, M.F. (1926) The acquisition and government of backward territory in international law: Being a treatise on the law and practice relating to colonial expansion. London: Longmans, Green and Co.

Linklater, A. (2005). The English School. In Burchill, S., et al (Eds.) Theories of International Relations ( ${ }^{\text {rd }}$ Ed) (55-83). Houndmills: Palgrave Macmillan.

Lightfoot, S.R. (2008). Indigenous rights in international politics: The case of "overcompliant" liberal states. Alternatives, 33, 83-104.

Little, R. (2009). History, theory and methodological pluralism in the English School. In Navari, C. (Eds.) Theorising international society: English School methods (78-103). New York: Palgrave MacMillan.

Little, R. (2005). The English School and world history. In Bellamy, A.J. (Eds.) International society and its critics (pp. 1-26). Oxford: Oxford University Press.

Little, R. (2000). The English School's contribution to the study of International Relations. European Journal of International Relations, 6, 395-422.

Little, R (1996). The growing relevance of pluralism? In Smith, S., Booth, K. \& Zalewski, M. (Eds) International theory: Positivism and beyond (66-86). Cambridge: Cambridge University Press.

Maaka, R. (2000). Engaging with indigeneity: Tino Rangatiratanga in Aoteroa. In Ivison, D., Patton, P., Sanders, W. (Eds.) Political theory and the rights of indigenous peoples (89-109). Cambridge: Cambridge University Press.

Macklem, P. (Fall 2008). Indigenous recognition in international law: Theoretical observations. Michigan Journal of International Law, 30, 177-210.

Maina, C.K. (2011). Power relations in the traditional knowledge debate: A critical analysis of forums. International Journal of Cultural Property, 18, 143-178.

Malezer, L. (2010). Dreamtime discovery: New reality and hope. In Hartley, J., Joffe, P., \& Presten, J. (Eds). Realizing the UN Declaration on the Rights of Indigenous Peoples: Triumph, hope, action (29-46). Saskatoon: First Nations Summit Society. 
Mann, M. (1996). Authoritarian and liberal militarism: A contribution from comparative and historical sociology. In Smith, S., Booth, K. \& Zalewski, M. (Eds) International theory: Positivism and beyond (221-239). Cambridge: Cambridge University Press.

Manuel, G. (1974). The fourth world: An Indian reality. Cambridge: Collier-Macmillan Canada.

Makinda, S. (1998). The United Nations and state sovereignty: Mechanism for managing international security. Australian Journal of Political Science, 33, 101-115.

Marks, R.B. (2002). The origins of the modern world: A global and ecological narrative. Lanham: Rowman and Littlefield Publishers, Inc.

Marshall, J. (1832). Worcester v. Georgia. 31 U.S. (6 Peters) 515. Retrieved from: http://supreme.justia.com/cases/federal/us/31/515/case.html

Marshall, J. (1831). Cherokee Nation v. Georgia. 30 U.S. (5 Peters) 1. Retrieved from: http://supreme.justia.com/cases/federal/us/30/1/case.html

Marshall, J. (1823). Johnson and Graham's Lessee v. McIntosh. 21 U.S. 8 Wheat. 543. Retrieved from: http://supreme.justia.com/cases/federal/us/21/543/case.html

Matz, N. (2005). Civilization and the mandate system under the League of Nations as origin of trusteeship. Max Planck Yearbook of United Nations Law, 9, 47-95.

Mauro, F. \& Hardison, P. (2000). Traditional knowledge of Indigenous and local communities: International debate and inititatives. Ecological Applications, $10,1263-1269$.

May, C. \& Sell, S.K. (2006). Intellectual property rights: A critical history. Boulder: Lynne Rienner Publishers.

Mayall, J. (2009). The limits of progress: Normative reasoning in the English School. In Navari, C. (Eds.) Theorising international society: English School methods (209-226). New York: Palgrave MacMillan.

Mayall, J. (2000). World politics: Progress and its limits. Cambridge: Polity Press.

Mayall, J. (1990). Nationalism and international society. Cambridge: Polity Press.

Mazower, M. (2006). An international civilization? Empire, internationalism and the crisis of the mid-twentieth century. International Affairs, 82, 553-566.

Merlan, F. (2009). Indigeneity: Global and local. Current Anthropology, 50, 303-333.

Métis National Council. (2013) Citizenship. Retrieved from:

http://www.metisnation.ca/index.php/who-are-the-metis/citizenship 
Meyer, J.W., Boli, J., Thomas, G.M., Ramirez, F.O. (July 1997). World society and the nation-state. American Journal of Sociology, 103, 144-181.

Mgbeoji, I. (2010). Making space for grandma: The emancipation of traditional knowledge and the dominance of western-style intellectual property rights regime. In Subramanian, S.M. \& Pisupati, B. (Eds.) Traditional knowledge in policy and practice: Approaches to development and human well-being (pp. 147-171). Tokyo: United Nations University Press.

Miller, R.J. (2006). Native America, discovered and conquered: Thomas Jefferson, Lewis \& Clark, and manifest destiny. Westport, CT: Praeger Publishers.

Miller, R.J., et al. (Eds.). (2010). Discovering Indigenous Lands: The Doctrine of Discovery in the English colonies. New York, NY: Oxford University Press.

Minde, H. (2008). The destination and the journey: Indigenous peoples and the United Nations from the 1960s through 1985. In Minde, H. (Eds.) Indigenous peoples: Self-determination, knowledge, indigeneity (pp. 49-86). Delft: Eburon Academic Publishers.

Minde, H., et al. (2008). Introduction. In Minde, H. (Eds.) Indigenous peoples: Selfdetermination, knowledge, indigeneity (pp. 1-26). Delft: Eburon Academic Publishers.

Minority Rights Group International. (2003). Report: Intellectual property rights of indigenous and tribal peoples in Asia. London: Bengwayan, M.A.

Moore, M. (2005). Internal minorities and indigenous self-determination. In Eisenberg, A. \& Spinner-Halev, J. (Eds.). Minorities within minorities: Equality, rights and diversity (pp. 271-293). Cambridge: Cambridge University Press.

Moore-Gilbert, B. (1997). Postcolonial theory: Contexts, practices, politics. London \& New York: Verso.

Morgan, R. (2011). Transforming law and institutions: Indigenous peoples, the United Nations and human rights. Farnham: Ashgate Publishing Ltd.

Morgenthau, H.J. (1948). Politics among nations: The struggle for power and peace ( $6^{\text {th }}$ ed). New York: McGraw Hill.

Mosco, V. (1996). The political economy of communication: Rethinking and renewal. Corwin: Pine Forge Press.

Mozaffari, M. (2001). The transformationalist perspective and the rise of a global standard of civilization. International Relations of the Asia Pacific, 1, 247-264.

Mugabe, J. (1998). Intellectual property and traditional knowledge. Proceeding from WIPO, '98: Panel discussion on intellectual property and human rights (online). Geneva: World Intellectual Property Organization. 
Narayan, U. (1995). Colonialism and its others: Considerations on rights and care discourses. Hypatia, 10, 133-140.

Navari, C. (2009). Introduction: Methods and methodology in the English School. In Navari, C. (Eds.) Theorising international society: English School methods (pp. 1-20). New York: Palgrave MacMillan.

Niezen, R. (2003). The origins of indigenism: Human rights and the politics of identity. Berkely: University of California Press.

Niezen, R. (2000) Recognizing indigenism: Canada unity and the international movement of indigenous peoples. Comparative Studies in Society and History, $42,119-148$.

Norgren, J. (2004) The Cherokee cases: Two landmark federal decisions in the fight for sovereignty. Norman: University of Oklahoma Press.

Office of the High Commission on Human Rights. The ILO and Indigenous and tribal peoples. Retrieved from:

http://www.ohchr.org/Documents/Publications/GuideIPleaflet8en.pdf

Oguamanam, C. (2006). International law and indigenous knowledge: Intellectual property, plant biodiversity, and traditional medicine. Toronto: University of Toronto Press.

Onondaga Nation. (2007). The two row wampum belt. Retrieved from: http://www.onondaganation.org/culture/wpm_tworow.html

Oppenheim, L. (1905) International law: A treatise, volume 1. London \& New York: Longmans, Green and co.

Osco, MF. (2010). Ayllu: Decolonial critical thinking and (an)other autonomy. In Blaser, M., et al. (Eds.) Indigenous peoples and autonomy: Insights for a global age. Vancouver: UBC Press.

Osiander, A. (2001). Sovereignty, International Relations, and the Westphalian myth. International Organization, 55, 251-287.

Osterhammel, J. (1997). Colonialism: A theoretical overview. Princeton: Markus Wiener Publishers.

Pagden, A. (1993). European encounters with the New World: From Renaissance to Romanticism. New Haven \& London: Yale University.

Pearson, D.J. (Spring 2004). Medical diplomacy and the American Indian: Thomas Jefferson, the Lewis and Clark Expedition, and the subsequent effects on American Indian Health and public policy. Wicazo Sa Review, 19, 105-130. 
Pearson, D.J. (Fall 2003). Lewis Cass and the politics of disease: The Indian Vaccination Act of 1832. Wicazo Sa Review, 18, 9-35.

Pihama, L. (2005). Asserting indigenous theories of change. In Barker, J. (Eds) Sovereignty Matters: Locations of contestation and possibility in indigenous struggles for self-determination. Lincoln: University of Nebraska Press.

Pollock, S. (2006). The language of the Gods in the world of men: Sanskrit, culture, and power in premodern India. Berkeley: University of California Press.

Pomerance, J. (1982). Self-determination in law and practice. Boston: Martinus Nijhoff Publishers.

Portes, A. (1999). Conclusion: Towards a new world order - the origins and effects of transnational activities. Ethnic and Racal Studies, 22, 463-77.

Posey, D. (1994). International agreements for protecting indigenous knowledge. In Sanchez, V. \& Juma, C. (Eds.) Biodiplomacy: Gentic resources and international relations. Nairobi: African Centre for Technology Studies.

Posey, D. \& Dutfield, G. (1996). Beyond Intellectual Property: Towards traditional resource rights for Indigenous peoples and local communities. Ottawa: International Development Research Centre.

Preston, J. (2010). Realizing the human rights of Indigenous peoples: Partnerships with non-Indigenous NGOs. In Hartley, J., Joffe, P., \& Presten, J. (Eds). Realizing the UN Declaration on the Rights of Indigenous Peoples: Triumph, hope, action (95-110). Saskatoon: First Nations Summit Society.

Reus-Smit, C. (2012). International Relations, Irrelevant? Don't Blame Theory. Millennium: Journal of International Studies, 40, 525-540.

Reus-Smit, C. (2009). Constructivism and the English School. In Navari, C. (Eds.) Theorising international society: English School methods (pp. 58-77). New York: Palgrave MacMillan.

Reus-Smit, C. (2005). The constructivist challenge after September 11. In Bellamy, A.J. (Eds.) International society and its critics (pp. 81-94). Oxford: Oxford University Press.

Reus-Smit, C. (2001). Human rights and the social construction of sovereignty. Review of International Studies, 27, 519-538.

Risse-Kappen, T. (1995). Brining transnational relations back in: Non-state actors, domestic structures and international institutions. Cambridge: Cambridge University Press. 
Roberson, B.A. (2009). Law, power and the expansion of international society. In Navari, C. (Eds.) Theorising international society: English School methods (pp. 189-208). New York: Palgrave MacMillan.

Roberson, B.A. (Eds.) (1998). International society and the development of International Relations theory. London \& Washington: Pinter.

Roy, A. (2001). Sovereignty and decolonization: Realizing Indigenous selfdetermination at the United Nations and in Canada. (Master's Dissertation). Retrieved from: http://web.uvic.ca/igov/research/pdfs/audrey roy thesisfinal.pdf

Ruiz, M. \& Vernooy, R. (2011). Introduction: Widening the horizon. In Ruiz, M. \& Vernooy, R. (Eds). The custodians of biodiversity: Sharing access to and benefits of genetic resources (3-9). Ottawa: International Development Research Centre.

Russett, B. \& Oneal, J. (2000). Triangulating peace: Democracy, interdependence, and international organizations. New York: W.W. Norton \& Company.

Said, E. (1978). Orientalism. New York: Random House.

Salazar, S. (1998). Intellectual property and the right to health. Proceeding from WIPO, '98: Panel discussion on intellectual property and human rights. Geneva: World Intellectual Property Organization.

Saurin, J. (2006). International Relations as the imperial illusion; or, the need to decolonize IR. In Jones, B.G. (Eds.) Decolonizing international relations (2342). Lanham: Rowman \& Littlefield Publishers.

Scheinin, M. (2005). What are indigenous peoples? In Ghanea, N. \& Xanthaki, A. (Eds.) Minorities, peoples and self-determination: Essays in honour of Patrick Thornberry (pp. 3-13). Leiden: Martinus Nijhoff Publishers.

Schmidt, B. (1998). The political discourse of anarchy: A disciplinary history of International Relations. Albany: State University of New York Press.

Schmidt, S. (2011). To order the minds of scholars: The discourse of the Peace of Westphalia in International Relations literature. International Studies Quarterly, 55, 601-623.

Schroeder, D. (2010). Traditional knowledge, indigenous communities and ethical values. In Subramanian, S.M. \& Pisupati, B. (Eds.) Traditional knowledge in policy and practice: Approaches to development and human well-being (pp. 3151). Tokyo: United Nations University Press.

Schwarzenberger, G. (1990). The Grotius factor in international law and relations: A functional approach. In Bull, H., Kingsbury, B., Roberts, A. (Eds.) Hugo Grotius and International Relations (pp. 301-312). Oxford: Clarendon Press. 
Scott, C. \& Mulrennan, M. (2012) Reconfiguring mare nullius: Torres Strait Islanders, indigenous sea rights, and the divergence of domestic and international norms. In Blaser, M., et al. (Eds.) Indigenous peoples and autonomy: Insights for a global age. Vancouver: UBC Press.

Seth, S. (Eds). (2013). Postcolonial theory and international relations: A critical introduction. New York: Routledge.

Seth, S. (2011). Postcolonial theory and the critique of international relations. Millennium: Journal of International Studies, 40, 167-183.

Shadlen, K.C., Schrank, A. \& Kurtz, M.J. (2005). The political economy of intellectual property protection: The case of software. International Studies Quarterly, 49, 45-71.

Shani, G. (2008) Toward a post-Western IR: The Umma, Khalsa Panth, and critical International Relations theory. International Studies Review, 10, 722-734.

Shaw, K. (2008). Indigeneity and political theory: Sovereignty and the limits of the political. New York: Routledge.

Shaw, K. (2002). Indigeneity and the international. Millennium: Journal of International studies, 31, 55-81.

Shaw, M.N. (2005). Self-determination and the use of force. In Ghanea, N. \& Xanthaki, A. (Eds.) Minorities, peoples and self-determination: Essays in honour of Patrick Thornberry (pp. 35-54). Leiden: Martinus Nijhoff Publishers.

Simeone, T. (2004). Indigenous traditional knowledge and intellectual property rights. Retrieved from: http://www.parl.gc.ca/content/lop/researchpublications/prb0338-e.htm

Simpson, A. (2000). Paths toward a Mohawk nation: Narratives of citizenship and nationhood in Kahnawake. In Ivison, D., Patton, P., Sanders, W. (Eds.) Political theory and the rights of indigenous peoples (113-136). Cambridge: Cambridge University Press.

Simpson, L. (2006). The legacy of Deskaheh: Decolonising indigenous participation in sustainable development governance. In Green, J.F. \& Bradnee Chambers, W. (Eds.) The politics of participation in sustainable development governance (108-130). Tokyo: United Nations University Press.

Simpson, T. (1997). Indigenous heritage and self-determination: The cultural and intellectual property rights of Indigenous peoples. Denmark: IWGIA. 
Smallacombe, S. (2000) On display for its aesthetic beauty: How Western institutions fabricate knowledge about Aboriginal cultural heritage. In Ivison, D., Patton, P., Sanders, W. (Eds.) Political theory and the rights of indigenous peoples (152-162). Cambridge: Cambridge University Press.

Smith, S. (1996) Positivism and beyond. In Smith, S., Booth, K. \& Zalewski, M. (Eds) International theory: Positivism and beyond (11-44). Cambridge: Cambridge University Press.

Smith, S., Owens, P., \& Baylis, J. (2011). Introduction. In Baylis, J., Smith, S. \& Owens, P. (Eds). The Globalization of world politics: An introduction to international relations (0-13). Oxford: Oxford University Press.

Spiegel, S.L., et al. (Eds.) (2004). World politics in a new era (5th Ed.). Oxford: Oxford University Press.

Stavenhagen, R. (1996). Self-determination: Right or Demon? In Clark, D. \& Williamson, R. (Eds) Self-determination: International perspectives. London: Macmillan Press.

Stavenhagen, R. (1994). Indigenous rights: Some conceptual problems. In Assies, W.J. \& Hoekema, A.J. (Eds). Indigenous peoples' experience with selfgovernment: Proceedings of the seminar on arrangements for selfdetermination by Indigenous peoples within national states, 10 and 11 February, 1994, University of Amsterdam (9-30). Copenhagen: IWGIA and University of Amsterdam.

Steiner, C. (1998). Intellectual property and the right to culture. Proceeding from WIPO, '98: Panel discussion on intellectual property and human rights. Geneva: World Intellectual Property Organization.

Stirk P.M.R. (2012). The Westphalian model and sovereign equality. Review of International Studies, 38, 641-660.

Subramanian, S.M. \& Pisupati, B. (2010). Introduction. In Subramanian, S.M. \& Pisupati, B. (Eds.) Traditional knowledge in policy and practice: Approaches to development and human well-being (pp. 1-11). Tokyo: United Nations University Press.

Suganami, H. (2005). The English School and international theory. In Bellamy, A.J. (Eds.) International society and its critics (pp. 29-63). Oxford: Oxford University Press.

Sylvester, C. (2012). Postcolonialism. In Baylis, J., Smith, S., \& Owens, P. (Eds). The Globalization of World Politics: An introduction to international relations (5 th $^{\text {th }}$ Ed) (182-185). Oxford: Oxford University Press. 
Tabobondung, R. (2012) Indigenous perspectives on globalization: Selfdetermination through autonomous media creation. In Blaser, M., et al. (Eds.) Indigenous peoples and autonomy: Insights for a global age. Vancouver: UBC Press.

Taracena, C. (2010). Implementing the Declaration: A state representative perspective. In Hartley, J., Joffe, P., \& Presten, J. (Eds). Realizing the UN Declaration on the Rights of Indigenous Peoples: Triumph, hope, action (6069). Saskatoon: First Nations Summit Society.

Tauli-Corpuz, V. (2003). Biodiversity, traditional knowledge and rights of Indigenous peoples. Penang: Third World Network.

Teschke, B. (2003). The myth of 1648: Class, geopolitics, and the making of modern international relations. London: Verso.

Todorov, T. (1992). The conquest of America: The question of the other. New York: Harper Perennial.Tuck, R. (1999). The rights of war and peace: Political thought and the international order from Grotius to Kant. Oxford: Oxford University Press.

Tully, J. (2000). The struggles of indigenous peoples for and of freedom. In Ivison, D., Patton, P., Sanders, W. (Eds.) Political theory and the rights of indigenous peoples (36-59). Cambridge: Cambridge University Press.

Tully, J. (1993) An approach to political philosophy: Locke in contexts. Cambridge: Cambridge University Press.

United Nations. (2009). State of the world's indigenous peoples. Retrieved from: http://www.un.org/esa/socdev/unpfii/documents/SOWIP web.pdf

United Nations. (2007a). General Assembly adopts Declaration on the rights of indigenous peoples: 'Major step forward' towards human rights for all, says president. Retrieved from: http://www.un.org/News/Press/docs/2007/ga10612.doc.htm

United Nations. (2007b). United Nations Declaration on the Rights of Indigenous Peoples.: $\quad$ Retrieved from: http://www.un.org/esa/socdev/unpfii/documents/DRIPS en.pdf.

United Nations. (1960). United Nations General Assembly Resolution 1541 (XV): Principles which should guide members in determining whether or nor an obligation exists to transmit the information called for under article 73 of the Charter. Retrieved from:

http://daccess-ddsny.un.org/doc/RESOLUTION/GEN/NR0/153/15/IMG/NR015315.pdf?OpenE $\underline{\text { lement }}$ 
United Nations. (1960). United Nations General Assembly Resolution 1514 (XV): Declaration on the granting of independence to colonial countries and peoples. Retrieved from: http://daccess-ddsny.un.org/doc/RESOLUTION/GEN/NR0/152/88/IMG/NR015288.pdf?OpenE lement

United Nations. (1952). United Nations General Assembly Resolution 637 (VII): The right of peoples and nations to self-determination. Retrieved from: http://www.un.org/ga/search/view doc.asp?symbol=A/RES/637(VII)\&Lang =E\&Area=RESOLUTION

United Nations. (1945). Charter of the United Nations. Retrieved from: http://www.un.org/en/documents/charter/

United Commission on Human Rights. (1986). Study of the Problem of discrimination against Indigenous populations (Cobo Report). New York: United Nations.

United Nations Development Programme. (1995). Final statement from the UNDP consultation on Indigenous peoples' knowledge and intellectual property Rights, Suva. Retrieved from:

http://www.who.int/genomics/elsi/regulatory data/region/international/051/en/ index.html

Venkateshwar, S. (2011). Indigeneity and international indigenous rights organizations and forums. In Venkateshwar, S. \& Hughes, E. (Eds.) The politics of indigeneity: Dialogues and reflections on indigenous activism (pp. 191-245). London: Zed Books.

Venkateshwar, S. et al. (2011). Conclusion. Naming and claiming second-wave indigeneity: A dialogue and reflections. In Venkateshwar, S. \& Hughes, E. (Eds.) The politics of indigeneity: Dialogues and reflections on indigenous activism (pp. 246-255). London: Zed Books.

Vincent, R.J. (1986). Human rights and international relations. Cambridge: Cambridge University Press.

Vincent, R.J. (1992). The idea of rights in international ethics. In Nardin, T. \& Mapel, D.R. (Eds.) Traditions of international ethics (250-269). Cambridge: Cambridge University Press.

Waitere, H. \& Allen, E. (2011.) Beyond indigenous civilities: Indigenous matters. In Venkateshwar, S. \& Hughes, E. (Eds.) The politics of indigeneity: Dialogues and reflections on indigenous activism (pp. 45-74). London: Zed Books. 
Walt, S.M. (2002) The enduring relevance of the realist tradition. In Katznelson, I., \& Milner, H.V. (Eds). Political Science: The state of the discipline. New York: W.W. Norton.

Waltz, K.N. (1979). Theory of international politics. Long Grove: Waveland Press, Inc.

Watson, A. (1992). The evolution of international society: A comparative historical analysis. New York: Routledge.

Watson, A. (1984a). European international society and its expansion. In Bull, H. \& Watson, A. (Eds.). The expansion of international society (13-32). Oxford: Clarendon Press.

Watson, A. (1984b), New states in the Americas. In Bull, H. \& Watson, A. (Eds.). The expansion of international society (127-142). Oxford: Clarendon Press.

Weigård, J. (2008). Is there a special justification for indigenous rights? In Minde, H. (Eds.) Indigenous peoples: Self-determination, knowledge, indigeneity (pp. 177-192). Delft: Eburon Academic Publishers.

Wessendorf. K. (Eds.) (2009). The indigenous world 2009. Copenhagen: International Work Group for Indigenous Peoples.

Westlake, J. (1914). The collected papers of John Westlake on public international law. Cambridge: Cambridge University Press.

Wheaton, H. (1836) Elements of international law (6 $6^{\text {th }}$ edition). New York: Carey, Lea and Blanchard.

Wight, M. (1992) International theory: The three traditions. New York: Holmes.

Wight, M., Wight, G., Porter, B. (Eds). (1991). International theory: The three traditions. Leicester: Leicester University Press.

Wilkins, D.E. \& Kiiwetnepinesiik Stark, H. (Eds.) (2011). American Indian politics and the American political system (3rd Ed). Plymouth: Rowman \& Littlefield Publishers, Inc.

Wilmer, F. (1993). The Indigenous voice in world politics: Since time immemorial. Newbury Park: Sage.

Williams Jr., R.A. (1990). The American Indian in Western legal thought: The discourses of conquest. Oxford: Oxford University Press.

Wilson, P. (2009). The English School's approach to international law. In Navari, C. (Eds.) Theorising international society: English School methods (167-188). New York: Palgrave MacMillan.

Wilson, W. (1918). Fourteen Points. Retrieved from: http://avalon.law.yale.edu/20th century/wilson14.asp 
Wolf, E.R. (1982). Europe and the people without history. Berkley: University of California Press.

World Intellectual Property Organization. (2008). Understanding copyright and related rights. Retrieved from:

http://www.wipo.int/freepublications/en/intproperty/909/wipo pub 909.html

World Intellectual Property Organization. Intellectual Property and Traditional Knowledge: Booklet number 2. Retrieved from:

http://www.wipo.int/export/sites/www/freepublications/en/tk/920/wipo pub 920.pdf

World Trade Organization. (1994). Agreement on trade-related aspects of intellectual property rights. Retrieved from: http://www.wto.org/english/tratop e/trips e/t agm0 e.htm

Xanthaki, A. (2007). Indigenous rights and United Nations standard: Selfdetermination, culture and land. Cambridge: Cambridge University Press.

Xanthaki, A. (2005). The right to self-determination: Meaning and scope. In Ghanea, N. \& Xanthaki, A. (Eds.) Minorities, peoples and self-determination: Essays in honour of Patrick Thornberry (pp. 15-33). Leiden: Martinus Nijhoff Publishers. 